\title{
ANÁLISE QUANTITATIVA POR RESSONÂNCIA MAGNÉTICA DA EPILEPSIA PARCIAL SINTOMÁTICA DE DIFÍCIL CONTROLE COM IMAGEM QUALITATIVA NEGATIVA PARA LESÃO EPILEPTOGÊNICA
}

Tese apresentada ao Departamento de Neurociências e Ciências do Comportamento Faculdade de Medicina de Ribeirão Preto da Universidade de São Paulo para obtenção do título de doutor em Medicina.

Área de Concentração: Neurologia.

Orientador: Prof. Dr. Antônio Carlos dos Santos.

VERSÃO CORRIGIDA 


\section{AUTORIZO A REPRODUÇÃO E DIVULGAÇÃO TOTAL E PARCIAL DESTE TRABALHO, POR QUALQUER MEIO CONVENCIONAL OU ELETRÔNICO, PARA FINS DE ESTUDO E PESQUISA, DESDE QUE CITADA A FONTE.}

Abud, Lucas Gianstante

Análise quantitativa por ressonância magnética da epilepsia parcial sintomática de difícil controle com imagem qualitativa negativa para lesão epileptogênica / Lucas Giansante Abud. - Ribeirão Preto, São Paulo, 2017. Versão corrigida.

XIV, 60f.

Doutorado - Tese apresentada à Faculdade de Medicina de Ribeirão Preto da Universidade de São Paulo para obtenção do título de doutor em Medicina. Área de Concentração: Neurologia.

Título em inglês: Multimodal quantitative analysis of magnetic resonance in refractory symptomatic partial epilepsy with negative qualitative MR image for epileptogenic lesion

1. Epilepsia parcial refratária. 2. RM negativa. 3. RM não lesional. 4. Multimodal. 5. Pós-processamentos individualizados. 6. Análise quantitativa. 
FOLHA DE APROVAÇÃO

Lucas Giansante Abud

\section{Análise quantitativa por ressonância magnética da epilepsia parcial sintomática de difícil controle com imagem qualitativa negativa para lesão epileptogênica}

Tese apresentada à Faculdade de Medicina de Ribeirão Preto da Universidade de São Paulo para obtenção do título de doutor em Medicina.

Área de Concentração: Neurologia.

Aprovado em:

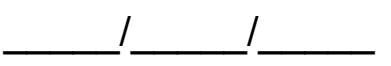

Banca Examinadora

Prof. Dr.

Instituição: Assinatura:

Prof. Dr.

Instituição: Assinatura:

Prof. Dr.

Instituição: Assinatura:

Prof. Dr. Instituição: Assinatura: 
À minha esposa Ticiana, companheira e grande amor da minha vida, que esteve ao meu lado desde o começo da realização deste trabalho, sempre apoiou meus projetos e me deu força nos momentos mais difíceis.

Aos meus amados filhos, Raphaela e Lucca, que no final da elaboração da tese sentiram um pouco a falta do pai, mas que um dia espero terem orgulho da realização deste projeto.

Aos meus queridos e amados pais, Fátima e Aloísio, sempre presentes na minha vida, incentivadores e apoiadores da continuidade acadêmica e da busca incessante pelo conhecimento desde o início da escolaridade até os dias de hoje. Aos meus irmãos Daniel e Thiago, companheiros, amigos e grandes incentivadores da continuidade acadêmica e da busca incessante pelo conhecimento. 


\section{AGRADECIMENTOS}

Ao Prof. Dr. Antônio Carlos dos Santos, meu orientador, pelos grandes ensinamentos, incentivo e estímulo na neurorradiologia.

Ao Prof. Dr. João Pereira Leite, pelos valiosos ensinamentos desde a época da iniciação cientifica durante minha graduação em Medicina.

Ao Prof. Dr. Carlos Ernesto Garrido Salmon, pela imensa colaboração e pelos ensinamentos sobre os pós-processamentos e técnicas quantitativas, além de uma indispensável orientação na elaboração da tese.

Ao Dr. Tonicarlo Rodrigues Velasco, pela imensa colaboração na indicação dos pacientes e ensinamentos em cirurgia da epilepsia.

Ao Dr. Américo Ceike Sakamoto, pelos ensinamentos em cirurgia da epilepsia.

À Sra. Ticiana Sales Vilar Abud, minha esposa, pelos conselhos, amizade, incentivo e apoio na elaboração deste trabalho.

Ao Dr. Aloísio Russo Abud, meu pai e colega de trabalho, e minha mãe Fátima Affonso Giansante Abud, pelo exemplo, conselho, amizade, incentivo e ajuda na elaboração deste trabalho.

Ao Prof. Dr. Daniel Giansante Abud e ao Dr. Thiago Giansante Abud, meus irmãos e colegas de trabalho, pelos conselhos, amizade, incentivo e ajuda na realização desta tese.

Ao Dr. Guilherme Seizem Nakiri pelo apoio e participação fundamental no artigo de qualificação da tese.

À Ma. Luciana Maria Mijoler da Cunha, pela colaboração na organização dos protocolos de ressonância magnética dos pacientes.

À Sra. Jaqueline Macários da Silva, pela imensa colaboração nos pósprocessamentos quantitativos das técnicas de ressonância, disposição e trabalho de meses na construção dos diversos grupos de pacientes e controles, sem a qual não teria conseguido alcançar os resultados almejados. Muito obrigado.

Ao Me. Rodrigo Antônio Pessini, pela grande colaboração nos pósprocessamentos quantitativos das técnicas de ressonância.

À Sra. Célia Aparecida Garcia do Carmo, pela receptividade e imensa colaboração na organização do agendamento dos pacientes, sem a qual a casuística ficaria comprometida. 
Às Sras. Silvana Lo Turco e Luciana Patrício, pela receptividade e colaboração na organização de toda a documentação necessária para o andamento adequado da pós-graduação.

Aos médicos e professores do centro de imagem e do centro de cirurgia da epilepsia, pelos ensinamentos fundamentais para a minha formação profissional.

A todos os funcionários do centro de ciências da imagem e física médica, do laboratório de processamento de imagens, informática radiológica e do centro de cirurgia da epilepsia. Muito obrigado por terem feito parte desta fase tão importante da minha vida.

Aos pacientes, pela valiosa colaboração. 


\section{RESUMO}

ABUD, L.G. Análise quantitativa por ressonância magnética da epilepsia parcial sintomática de difícil controle com imagem qualitativa negativa para lesão epileptogênica. (Doutorado direto) - Faculdade de Medicina de Ribeirão Preto, Universidade de São Paulo, São Paulo, 2017.

A RM convencional de rotina pode ser inconclusiva a cerca de um terço dos pacientes com epilepsia parcial (focal) refratária. Esses pacientes com RM negativa, quando indicados para cirurgia, representam um grande desafio, visto que a identificação de uma lesão estrutural epileptogênica por esse método pode ser considerada o melhor fator prognóstico para eliminação das crises no período pósoperatório. O objetivo foi avaliar o rendimento e a utilidade da RM quantitativa por meio de pós-processamentos individualizados nesse grupo de pacientes. Trata-se de um estudo prospectivo de uma coorte de 46 pacientes com epilepsia focal farmacorresistente com RM-3 Teslas não lesional e potenciais candidatos a cirurgia. Todos os pacientes foram submetidos a um novo protocolo de RM, incluindo 3D T1 e técnicas avançadas, e, posteriormente, avaliados por pós-processamentos individualizados de cinco medidas quantitativas extraídas dessas sequências. Essas medidas consistiram em espessura cortical (EC) e do sinal de junção entre as substâncias branca e cinzenta (JBC), ambas extraídas da sequência 3D T1, assim como da relaxometria T2 (RT2), taxa de transferência de magnetização (TTM) e difusibilidade média (DM). Os dados extraídos de todo o cérebro foram individualmente comparados com um grupo de controle saudáveis, utilizando-se das técnicas de análise baseada em superfície para a EC e de análises baseadas em voxel para as demais medidas. Utilizou-se do videoencefalograma de superfície e semiologia das crises para determinar a possível zona epileptogênica (ZE), sendo que 31 pacientes foram considerados como foco localizatório suspeito (FLS). As medidas quantitativas detectaram individualmente mudanças de sinal em alguma região do cérebro de $32,6 \%$ a $56,4 \%$ dos pacientes. No subgrupo classificado como FLS, os pós-processamentos detectaram individualmente alterações na região de origem eletroclínica das crises em 9,7\% (3/31) a 31,0\% (9/29) dos pacientes. Esse rendimento foi mais alto com a DM $(31,0 \%$ ou $9 / 29)$ e RT2 $(25,0 \%$ ou $7 / 28)$ e mais baixo com a EC e JBC $(9,7 \%$ ou $3 / 31)$. Alterações observadas fora da região 
presumida da ZE foram sempre superiores, variando de $25,8 \%$ (8/31) a $51,7 \%$ (15/29). Em cinco pacientes (5/46 ou 10,9\%) foi possível identificar alteração estrutural após a avaliação visual com direcionamento localizatório pelos pósprocessamentos. Embora a análise quantitativa da RM individualizada possa sugerir lesões ocultas no protocolo convencional, é preciso ter cautela devido à aparente baixa especificidade dos achados. Nesse grupo de pacientes, essas alterações devem refletir não só as alterações na região da ZE, mas também anormalidades microestruturais secundárias às crises ou, menos provavelmente, malformações cerebrais extensas não visíveis nos protocolos de rotina. Uma potencial utilidade prática desses métodos é auxiliar na colocação de eletrodos intracranianos em casos selecionados. Por outro lado, o estudo mostrou capacidade de detectar lesões potencialmente epileptogênicas que passaram despercebidas na inspeção visual convencional da RM após reavaliações dirigidas pelos pós-processamentos, notadamente pela medida da EC. Isso sugere que essas técnicas podem ser usadas como uma ferramenta de triagem para evitar que qualquer lesão visível seja ignorada ou a fim de guiar uma nova inspeção visual dirigida para uma região suspeita.

Palavras-chave: 1. Epilepsia parcial (focal) refratária. 2. RM negativa. 3. RM não lesional. 4. Multimodal. 5. Pós-processamentos individualizados. 6. Análise quantitativa. 


\section{ABSTRACT}

ABUD, L.G. Multimodal quantitative analysis of magnetic resonance in refractory symptomatic partial epilepsy with negative qualitative MR image for epileptogenic lesion. (Doutorado direto) - Faculdade de Medicina de Ribeirão Preto, Universidade de São Paulo, São Paulo, 2017.

Conventional MRI may be inconclusive in about one-third of patients with refractory partial epilepsy. These patients with negative MRI when indicated for surgery represent a great challenge since the identification of an epileptogenic structural lesion by this method can be considered the best prognostic factor for the elimination of the crises in the postoperative period. Our objective was to evaluate the yield and utility of quantitative MRI through individualized post-processing in this group of patients. The present thesis is a prospective study of a cohort of forty-six patients with drug-resistant partial epilepsy, with non-lesional 3-Teslas MRI and potential surgical candidates. All patients underwent a new MRI protocol, including 3D T1 and advanced techniques, and were subsequently evaluated through individualized post-processing of five quantitative measures extracted from these sequences. These measurements consisted of the cortical thickness (CT) and the signal between the white and gray matters junction (WGJ), both extracted from the 3D T1 sequence, as well as the T2 relaxometry (RT2), magnetization transfer rate (MTR) and mean diffusibility (MD). Data extracted from the whole brain were individually compared to a healthy control group using surface-based analysis (SBM) techniques for CT and voxel-based analyzes (VBA) for the other measures. Surface VEEG and seizure semiology were used to determine the possible epileptogenic zone (EZ). Consequently 31 patients were considered to have a suspect location for the Focus (SLF). Quantitative measurements individually detected abnormalities in some regions of the brain from $32.6 \%$ to $56.4 \%$ of patients. In the subgroup classified as FLS post-processing individually detected abnormalities inside the region of electroclinical origin of seizures in $9.7 \%(3 / 31)$ to $31.0 \%(9 / 29)$ of the patients. This yield was higher with MD (31.0\% or $9 / 29)$ and RT2 $(25.0 \%$ or $7 / 28)$ and lower with CT and WGJ (9.7\% or 3/31). Abnormalities observed outside the presumed EZ region were always higher, ranging from $25.8 \%(8 / 31)$ to $51.7 \%(15 / 29)$. In five patients $(5 / 46$ or $10.9 \%)$ it was possible to identify some structural abnormality after the MRI 
visual inspection with orientation of the location by post-processing. Although the MRI quantitative analysis through individualized post-processing may suggest hidden structural lesions in the conventional protocol, caution should be exercised because of the apparent low specificity of theses findings for the EZ. In this group of patients these abnormalities should reflect not only the alterations in the EZ region, but also the microstructural abnormalities secondary to the seizures or less likely extensive cerebral malformations not visible in the routine protocols. A practical potential utility of these methods is to assist in the placement of intracranial electrodes in selected cases. On the other hand, the study showed a certain capacity to detect potentially epileptogenic lesions that became unnoticed in the MRI conventional visual analysis after re-evaluations directed by post-processing, notably by CT measurement. This suggests that these methods should be used either as a screening tool to prevent any visible lesions from being ignored or to guide a new visual inspection directed to a suspect region.

Keywords: Partial refractory epilepsy. 2. Negative MRI. 3. Non-lesional MRI. 4. Multimodal. 5. Individualized post-processing. 6. Quantitative analysis. 


\section{LISTA DE FIGURAS}

FIGURA 1 Ressonância magnética típica de esclerose hipocampal .....................31

FIGURA 2 Ressonância magnética típica de heterotopia periventricular de substância cinzenta........................................................................ 32

FIGURA 3 Ressonância magnética típica de uma displasia cortical focal ..............32

FIGURA 4 Ressonância magnética evidenciando uma meningocele transesfenoidal da fossa pterigopalatina ............................................33

FIGURA 5 Ressonância magnética evidenciando um ganglioglioma ....................34

FIGURA 6 Ilustração de um registro de EEG pelo método de superfície ..............37

FIGURA 7 Ilustração dos tipos de movimentação das moléculas de água............42

FIGURA 8 Fenômeno de difusão através de três aquisições ortogonais em meio anisotrópico

FIGURA 9 Exemplo de ressonância magnética de uma displasia cortical focal tipo 2, utilizando a sequência de imagem por tensor de difusão 45

FIGURA 10 Ajuste exponencial da intensidade de sinal média versus o tempo de eco dos diferentes tecidos cerebrais.

FIGURA 11 Exemplo da utilidade do pulso de transferência de magnetização após contraste via endovenosa em uma criança com quadro de encefalite herpética 48

FIGURA 12 Exemplo da utilidade do pulso de transferência de magnetização em um paciente com epilepsia focal e duvidosa lesão cortical

FIGURA 13 Exemplo de lesão identificada apenas com a sequência 3D FLAIR ....53

FIGURA 14 Análise da relaxometria baseada em voxel em uma paciente com suspeita de epilepsia do lobo temporal esquerdo

FIGURA 15 Displasia cortical focal, espessura cortical e FreeSurfer 63

FIGURA 16 Fluxo de trabalho inicial da avaliação pelo FreeSurfer e com base em uma imagem 3D T1 
FIGURA 17 Fluxo de trabalho utilizando o software FreeSurfer e com base em uma imagem 3D T1

FIGURA 18 Exemplo de como uma região com espessura cortical considerada alterada aparece na visualização pelo QDEC do pacote FreeSurfer ...83

FIGURA 19 Exemplos de como o programa SPM12 pode apresentar as regiões alteradas

FIGURA 20 Fluxo de trabalho com os passos da morfometria baseada em voxel clássica (VBM), realizada pelo programa de mapeamento estatístico paramétrico (SPM) e com base em uma imagem 3D T1.

FIGURA 21 Fluxo de trabalho pelo programa de mapeamento estatístico paramétrico (SPM12) do chamado mapa de junção entre as substâncias branca e cinzenta. .88

FIGURA 22 Imagens que exemplificam o fluxo de trabalho da formação das imagens de junção entre as substâncias branca e cinzenta (JBC) ......89

FIGURA 23 Processo de validação do contraste negativo como a alteração a ser identificada nos mapas de junção entre as substâncias branca e cinzenta (JBC). 90

FIGURA 24 Processo de validação do contraste negativo como a alteração a ser identificada nos mapas da relaxometria T2 (RT2) .92

FIGURA 25 Fluxo de trabalho visando um alinhamento satisfatório dos mapas da relaxometria $\mathrm{T} 2(\mathrm{RT} 2)$ 93

FIGURA 26 Fluxo de trabalho visando um alinhamento satisfatório dos mapas de transferência de magnetização (TTM) . 94

FIGURA 27 Fluxo de trabalho visando um alinhamento satisfatório dos mapas de difusibilidade média (DM). 96

FIGURA 28 Pós-processamentos individualizados da medida da espessura cortical (EC) de dois pacientes, utilizando-se da ferramenta QDEC para visualização das alterações no cérebro-padrão inflado. 101 
FIGURA 29 Exemplo do paciente 22, operado e com diagnóstico de displasia cortical tipo la 103

FIGURA 30 Exemplos dos pós-processamentos dos mapas de relaxometria T2 (RT2) pelo programa de mapeamento estatístico paramétrico (SPM12) de dois pacientes 105

FIGURA 31 Exemplo do pós-processamento dos mapas da taxa de transferência de magnetização (TTM) pelo programa de mapeamento estatístico paramétrico (SPM12) do paciente 7 107

FIGURA 32 Exemplos dos pós-processamentos dos mapas de difusibilidade média (DM) pelo mapeamento estatístico paramétrico (SPM12) de dois pacientes. 110

FIGURA 33 Exemplo do paciente 7, considerado com foco localizatório suspeito pela origem eletroclínica das crises e que apresentou colocalização de achados concordantes com a possível zona epileptogênica localizada na região frontotemporal esquerda 112

FIGURA 34 Exemplo do paciente 24 que mudou para o estado de ressonância magnética positiva apenas após a avaliação visual com direcionamento localizatório guiada pelos pós-processamentos 114

FIGURA 35 Exemplo do paciente 14 que mudou para o estado de ressonância magnética positiva unicamente apenas após a avaliação visual com direcionamento localizatório guiada pelos pós-processamentos 115

FIGURA 36 Exemplo do paciente 19 que mudou para o estado de ressonância magnética positiva somente após a avaliação visual com direcionamento localizatório guiada pelos pós-processamentos 116

FIGURA 37 Detalhamento da caraterização do espessamento cortical do paciente 19 na ressonância magnética estrutural 117

FIGURA 38 Exemplo do paciente 20 que mudou para o estado de ressonância magnética positiva apenas após a avaliação visual com direcionamento localizatório guiada pelos pós-processamentos 118 
FIGURA 39 Exemplo do paciente 18 que mudou para o estado de ressonância magnética positiva apenas após associação de avaliação visual com direcionamento localizatório guiada pelo videoencefalograma e da sequência 3D FLAIR. 120

FIGURA 40 Exemplo do paciente 39 que mudou para o estado de ressonância magnética positiva apenas após associação de avaliação visual com direcionamento localizatório guiada pelo videoencefalograma e da sequência 3D FLAIR 121

FIGURA 41 Exemplo do paciente 32, cujos achados na ressonância magnética foram inicialmente considerados duvidosos, porém confirmados após a associação de avaliação visual com direcionamento localizatório guiada pelo videoencefalograma e da sequência 3D FLAIR 122 


\section{LISTA DE TABELAS}

TABELA 1 Classificação das crises (ILAE) 23

TABELA 2 Principais causas de epilepsia de acordo com a idade de início das crises 24

TABELA 3 Nova classificação das displasias corticais focais 25

TABELA 4 Resumo das principais sequências utilizadas nos protocolos de rotina e suas principais aplicações

TABELA 5 Resumo da avaliação sistematizada sugerida pelo trabalho de Bronen et al. (1997)

TABELA 6 Características gerais dos pacientes 72

TABELA 7 Taxa de pacientes com achados alterados identificados com cada técnica quantitativa seguindo critérios de concordância espacial com os achados da avaliação eletroclínica das crises. Na segunda e terceira linhas, a taxa considera somente os pacientes com foco localizatório suspeito. .98

TABELA 8 Resultados por paciente da localização dos achados no videoencefalograma, nas análises das medidas quantitativas de ressonância magnética e na reavaliação visual com direcionamento localizatório, considerando todos os dados em conjunto. 105 


\section{LISTA DE GRÁFICOS}

GRÁFICO 1 Taxa de falso-positivos versus o agrupamento de voxels na análise individual dos pós-processamentos dos controles saudáveis, referente aos mapas de junção entre as substâncias branca e cinzenta (JBC) e com valor-p não corrigido de 0,001 102

GRÁFICO 2 Taxa de falso-positivos versus o agrupamento de voxels na análise individual dos pós-processamentos dos controles saudáveis, referente aos mapas da relaxometria T2 (RT2) e com valor-p corrigido pelo de Family-wise error (FWE) de 0,05. 104

GRÁFICO 3 Taxa de falso-positivos versus o agrupamento de voxels na análise individual dos pós-processamentos dos controles saudáveis, referente aos mapas de transferência de magnetização (TTM) e com valor-p corrigido pelo de Family-wise error (FWE) de 0,05 106

GRÁFICO 4 Taxa de falso-positivos versus o agrupamento de voxels na análise individual dos pós-processamentos dos controles saudáveis, referente aos mapas de difusibilidade média (DM) e com valor-p corrigido pelo de Family-wise error (FWE) de 0,05 108 


\section{LISTA DE ABREVIATURAS E SÍMBOLOS}

3D

ADC

AF

AVDLEEG

AVDLPP

b

CBC

CCIFM

CIREP

DCF

DCF2

DCFs

DIR

DTI

DWI

EC

EEG

EFRTM

FDR

FLAIR

FLS

FNL

FOV

FWE

FWHM
Volumétrico(a)

Coeficiente Aparente de Difusão, do inglês apparent diffusion coefficient

Anisotropia Fracionada

Avaliação visual com direcionamento localizatório pelo EEG

Avaliação visual com direcionamento localizatório pelos pósprocessamentos

Fator de difusão

Contraste entre as substâncias branca e cinzenta

Centro de Ciências da Imagem e Física Médica

Centro de Cirurgia de Epilepsia

Displasia Cortical Focal

Displasia Cortical Focal do tipo II

Displasias Corticais Focais

Dupla inversão-recuperação

Imagem de Tensor de Difusão, do inglês diffusion tensor imaging

Imagem Ponderada em Difusão, do inglês diffusion weighted imaging

Espessura Cortical

Eletroencefalograma

Epilepsia Parcial (focal) Refratária ao Tratamento Medicamentoso

Taxa de Falsas Descobertas, do inglês false discovery rate

Fluid attenuated inversion-recovery

Foco Localizatório Suspeito

Foco não Localizatório

Campo de Visão, do inglês field of view

Probabilidade de uma ou mais falsas descobertas, do inglês family-wise error

Largura à Meia Altura, do inglês full width at half maximum 


\begin{tabular}{|c|c|}
\hline \multirow{3}{*}{$\begin{array}{l}\text { GMO } \\
\text { HCFMRP/USP }\end{array}$} & Gray-matter only \\
\hline & Hospital das Clínicas da Faculdade de Medicina de Ribeirão \\
\hline & Preto da Universidade de São Paulo \\
\hline ILAE & International league against epilepsy \\
\hline ITM & Imagem com Transferência de Magnetização \\
\hline JBC & Junção entre as substâncias branca e cinzenta \\
\hline LAPIR & $\begin{array}{l}\text { Laboratório de Processamento de Imagens e Informática } \\
\text { Radiológica }\end{array}$ \\
\hline LE & Lesional \\
\hline Mcom & Pulso com transferência de magnetização \\
\hline MDC & Malformação(ões) do Desenvolvimento Cortical \\
\hline MP-RAGE & $\begin{array}{l}\text { Gradiente eco, do inglês magnetization prepared rapid } \\
\text { acquisition gradient echo }\end{array}$ \\
\hline Msem & Pulso sem transferência de magnetização \\
\hline mm & Milímetro \\
\hline ms & Milissegundo \\
\hline NLE & Não Lesional \\
\hline PET & $\begin{array}{l}\text { Tomografia por Emissão de Pósitrons, do inglês positron } \\
\text { emission tomography }\end{array}$ \\
\hline RM & Ressonância Magnética \\
\hline RT2 & Relaxometria T2 \\
\hline SBM & $\begin{array}{l}\text { Morfometria Baseada em Superfície, do inglês surface- } \\
\text { based morphometry }\end{array}$ \\
\hline SEEG & Estereoletroencefalograma \\
\hline SPECT & $\begin{array}{l}\text { Tomografia por Emissão de Fóton Único, do inglês single } \\
\text { photon emission computed tomography }\end{array}$ \\
\hline SPM & $\begin{array}{l}\text { Mapeamento Estatístico Paramétrico, do inglês statistical } \\
\text { parametric mapping }\end{array}$ \\
\hline STIR & Short time inversion recovery \\
\hline swI & $\begin{array}{l}\text { Imagem Ponderada por Susceptibilidade, do inglês } \\
\text { susceptibility weighted imaging }\end{array}$ \\
\hline $\mathbf{T}$ & Tesla ou teslas \\
\hline TC & Tomografia Computadorizada \\
\hline TE & Tempo de Eco \\
\hline
\end{tabular}


TM

TR

TTM

VBA

VBM

VBR

VEEG

$\mathbf{Z}$

ZE
Transferência de Magnetização

Tempo de Repetição

Taxa de Transferência de Magnetização

Análise baseada em voxel, do inglês voxel based analysis

Morfometria baseada em voxel, do inglês voxel based morphometry

Medidas do voxel baseadas em relaxometria, do inglês voxel based relaxometry

Videoencefalograma

Desvio-padrão

Zona Epileptogênica 


\section{SUMÁRIO}

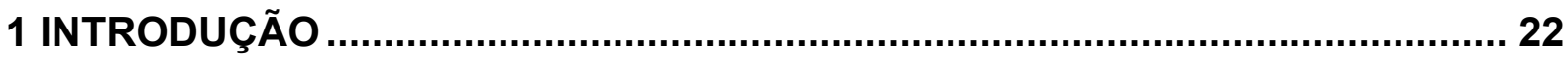

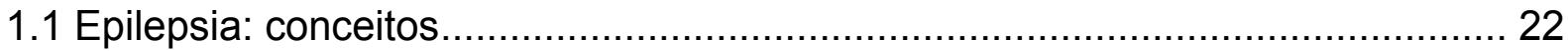

1.2 Ressonância magnética convencional e epilepsia.......................................... 26

1.3 Outros métodos localizatórios: eletroencefalograma e medicina nuclear ........... 36

1.4 Novas técnicas de ressonância magnética e epilepsia..................................... 40

1.4.1 Imagem de tensor de difusão: DTI ........................................................... 40

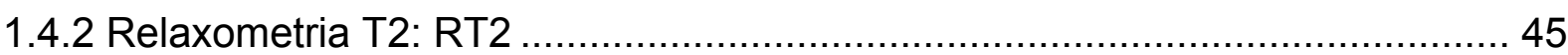

1.4.3 Imagem de transferência de magnetização: ITM ......................................... 47

1.4.4 Outras sequências mais recentes de imagem por RM ................................ 50

1.5 Técnicas de pós-processamentos das imagens por RM na epilepsia ................ 53

1.5.1 Análise das medidas baseadas em voxel: VBA .......................................... 54

1.5.1.1 Medidas do voxel baseadas em morfometria...........................................55

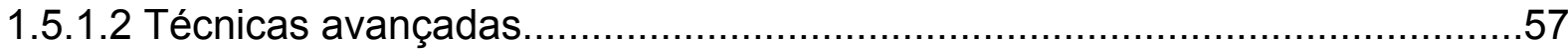

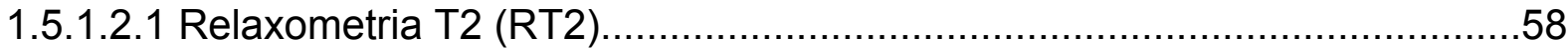

1.5.1.2.2 Taxa de transferência de magnetização (TTM)........................................59

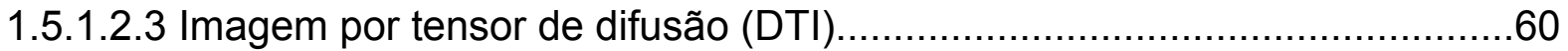

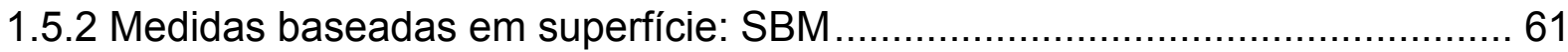

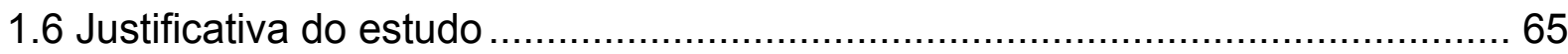

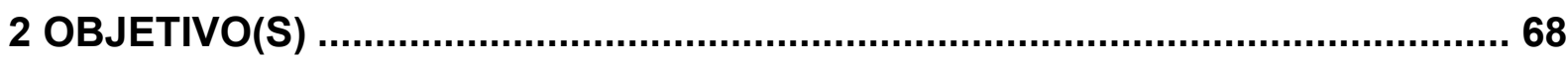

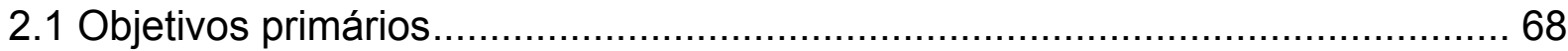

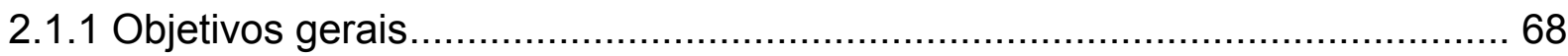

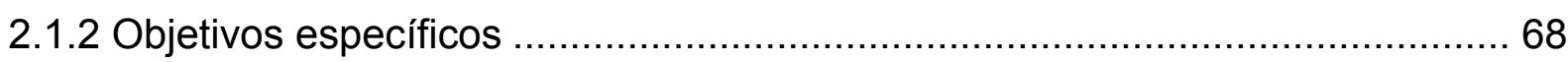

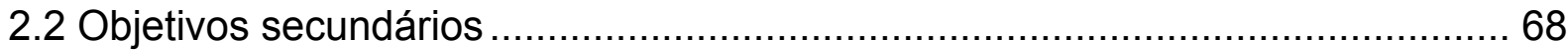

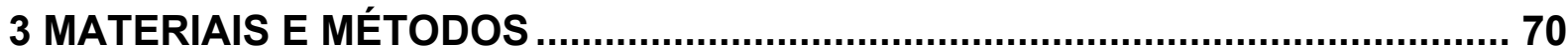

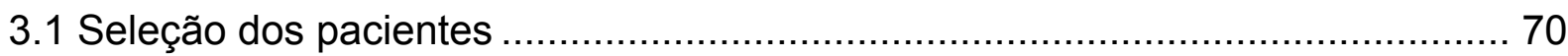

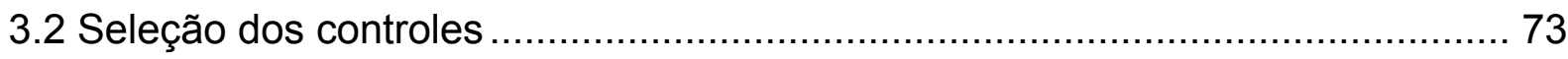

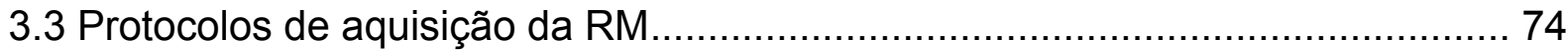

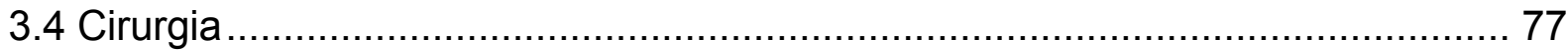

3.5 Localização das crises: semiologia e EEG ……….................................... 77 


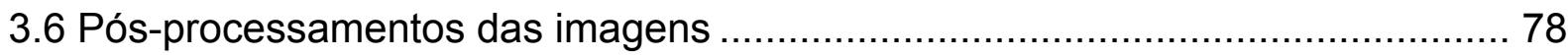

3.6.1 Análise baseada em superfície (SBM) e espessura cortical ......................... 79

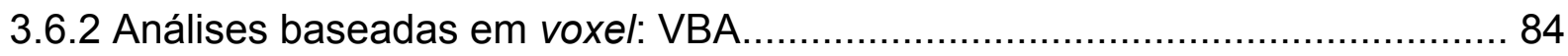

3.6.2.1 Análises baseadas em voxel dos mapas de junção entre as substâncias

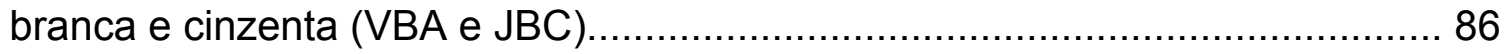

3.6.2.2 Análises baseadas em voxel dos mapas da relaxometria T2 (VBA e

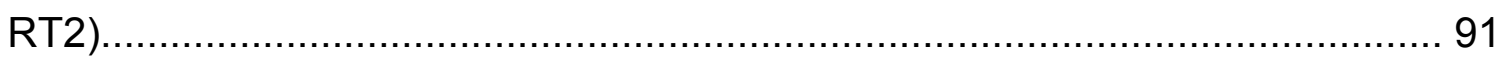

3.6.2.3 Análises baseadas em voxel dos mapas de taxa de transferência de

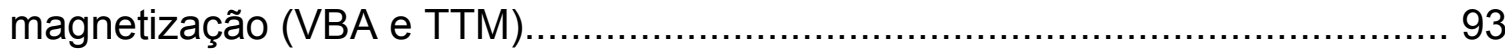

3.6.2.4 Análises baseadas em voxel dos mapas de difusibilidade média (VBA e DM)

3.7 Avaliação visual da RM com direcionamento localizatório pelos pós-

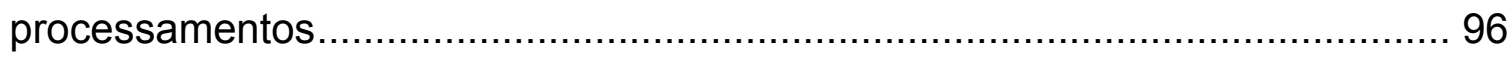

3.8 Avaliação de mudança do estado localizatório dos pacientes na RM no decorrer

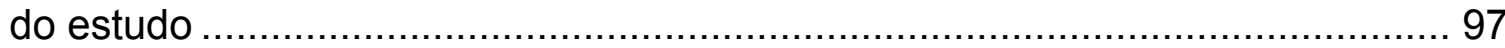

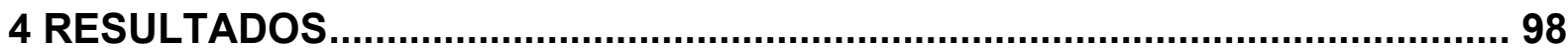

4.1 Avaliação da espessura cortical (SBM da EC)........................................... 100

4.2 Avaliação dos mapas de junção entre as substâncias branca e cinzenta (VBA da

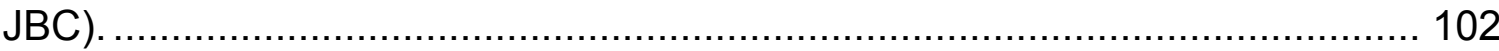

4.3 Avaliação dos mapas da relaxometria T2 (VBA da RT2) .............................. 104

4.4 Avaliação dos mapas de transferência de magnetização (VBA da TTM)......... 106

4.5 Avaliação dos mapas de difusibilidade média (VBA da DM). ......................... 108

4.6 Avaliação conjunta das análises quantitativas.............................................. 111

4.7 Avaliação visual da RM com direcionamento localizatório pelos pós-

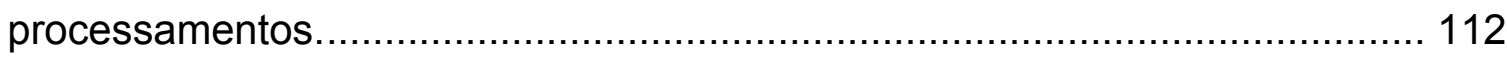

4.8 Avaliação de mudança do estado localizatório dos pacientes na RM no decorrer

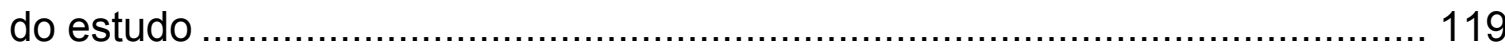

4.9 Avaliação geral de mudança do estado localizatório na RM qualitativa ........... 123

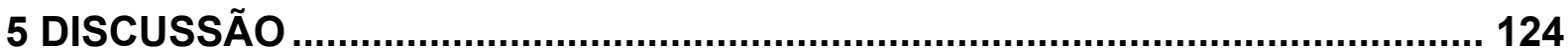

6 CONCLUSÃO

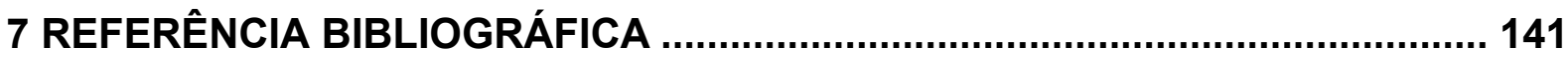




\section{INTRODUÇÃO}

\subsection{Epilepsia: conceitos}

A epilepsia é uma enfermidade conhecida desde a antiguidade, havendo relatos de manifestações clínicas semelhantes às crises epilépticas da época dos egípcios e sumérios, por volta de 3.500 a.C. Inicialmente essas manifestações eram relacionadas a fenômenos sobrenaturais e espirituais, mas por volta de 400 a.C. Hipócrates já começava a suspeitar de alterações orgânicas cerebrais como causa dessa doença, contestando, em seu livro Sobre a Doença Sagrada, a crença de que essas pessoas estariam possuídas.

Atualmente podemos definir epilepsia como um distúrbio neurológico crônico caracterizado por crises epilépticas recorrentes não provocadas por um insulto sistêmico ou neurológico agudo, considerada um problema de saúde pública que atinge mais de 50 milhões de pessoas em todo o mundo (BANERJEE; FILIPPI; HAUSER, 2009). Por sua vez, essas crises epilépticas são definidas como sinais e sintomas transitórios de atividade neuronal cerebral anormal, excessiva ou síncrona, geralmente causada por alterações bioquímicas e/ou estruturais que envolvem predominantemente o córtex cerebral (FISHER et al., 2005).

Os impactos socioeconômicos desta enfermidade elencados na literatura são consideráveis, pois geralmente está associada à depressão, ansiedade, estigmas e distúrbios psiquiátricos. Os pacientes sofrem as consequências diretas e indiretas das crises, tais como abandono escolar, perda do emprego, mudanças na produtividade, menor expectativa de vida, disfunções cognitivas, morte súbita e acidentes, ou seja, afetam a qualidade de vida tanto dos pacientes quanto dos familiares envolvidos (JONES et al., 2006; TAYLOR et al., 2011).

Existem diversas formas de classificação das epilepsias, sendo uma das mais amplamente consideradas a elaborada pela International League Against Epilepsy, ou ILAE, revista entre 2005-2009. Ela estabelece basicamente quatro grupos: focal, generalizada, indeterminada e síndromes especiais/outras epilepsias (Tabela 1). 
de consciência. Quando a consciência não é afetada elas são classificadas como crises focais perceptivas, caso contrário, crises focais disperceptivas, que podem ser primariamente disperceptivas ou evoluir a partir de crises focais perceptivas. Além disso, uma crise focal pode se espalhar por todo o cérebro, o que é chamado de focal evoluindo para tônico-clônica bilateral.

Muitas vezes, as epilepsias focais e generalizadas podem apresentar lesões histológicas ou anatômicas detectáveis de diversas etiologias, dentre as quais podemos citar, de maneira não exaustiva, a esclerose hipocampal, as malformações do desenvolvimento cortical (MDC), os tumores, as malformações vasculares e as sequelas/alterações cicatricais e glióticas (Tabela 2) (SPENCER, 1994; ENGEL, 2001). As epilepsias ainda podem ser classificadas como sintomáticas e subdivididas de acordo com a localização da lesão estrutural, temporal, frontal, occipital, límbica etc.

TABELA 2: Principais causas de epilepsia de acordo com a idade de início das crises.

\begin{tabular}{lccccc}
\hline \multicolumn{1}{c}{ Causa da epilepsia } & \multicolumn{5}{c}{ Idade do surgimento das crises (anos) } \\
\hline & $0-2$ & $3-30$ & $21-40$ & $41-60$ & $>60$ \\
1. Doença metabólica & $\mathrm{X}$ & & & & \\
2. Anóxia perinatal & $\mathrm{X}$ & & & & \\
3. Infeç̧ão & $\mathrm{X}$ & $\mathrm{X}$ & & & \\
4. Malformação do desenvolvimento & $\mathrm{X}$ & $\mathrm{X}$ & & & \\
5. Facomatoses & $\mathrm{X}$ & $\mathrm{X}$ & & & \\
6. Esclerose hipocampal & & $\mathrm{X}$ & & & \\
7. Epilepsia generalizada primária & & $\mathrm{X}$ & & & \\
8. Malformação vascular & & $\mathrm{X}$ & $\mathrm{X}$ & & \\
9. Trauma & & $\mathrm{X}$ & $\mathrm{X}$ & $\mathrm{X}$ & \\
10. Tumor & & $\mathrm{X}$ & $\mathrm{X}$ & $\mathrm{X}$ & $\mathrm{X}$ \\
11. Acidentes vasculares cerebrais & & & & $\mathrm{X}$ & $\mathrm{X}$ \\
\hline
\end{tabular}

Fonte adaptada de Bronen (1992) e disponível em

http://www.ajronline.org/doi/pdfplus/10.2214/ajr.159.6.1442376?src=recsys (Acesso em: 10/10/2017).

Já no grupo das MDC encontramos uma ampla gama de patologias que podem cursar com epilepsia focal refratária ao tratamento medicamentoso (EFRTM), além de outros distúrbios neurológicos, incluindo a displasia cortical focal (DCF), polimicrogiria, agiria e esquizencefalia (BARKOVICH et al., 2012). Porém, no 
contexto da epilepsia, não há como não destacar a DCF com sua classificação atualizada em três tipos e respectivos subtipos, conforme descrito na tabela 3 (BLUMCKE et al., 2011).

TABELA 3: Nova classificação das displasias corticais focais.

1. Tipo I

2. Tipo II

3. Tipo III a: DCF com laminação cortical radial anormal.

b: DCF com laminação cortical tangencial anormal.

c: DCF com laminação cortical radial e tangencial anormal.

a: DCF com neurônios dismórficos.

b: DCF com neurônios dismórficos e células em balão.

a: distorção arquitetural da camada cortical no lobo temporal com esclerose do hipocampo associadamente.

b: distorção arquitetural da camada cortical adjacente a um tumor glial ou glioneuronal.

c: distorção arquitetural da camada cortical adjacente a uma malformação vascular.

d: distorção arquitetural da camada cortical adjacente a outras lesões adquiridas na primeira infância, tais como trauma, evento isquêmico, encefalite.

DCF: Displasia cortical focal

Fonte adaptada e disponível em https://www.ncbi.nlm.nih.gov/pmc/articles/PMC3403799/ (Acesso em: 03/03/2017).

De acordo com dados da literatura, as epilepsias focais sintomáticas correspondem a cerca de $60 \%$ dos casos de epilepsia, e aproximadamente $20 \%$ desses pacientes, ou seja, $12 \%$ do total apresentam uma resposta clínica insatisfatória, mesmo recebendo farmacoterapia antiepiléptica adequada. Em casos selecionados, a intervenção neurocirúrgica pode ser necessária para eliminar ou reduzir as crises recorrentes (ROSENOW; LUDERS, 2001; ARROYO, 1993; ENGEL et al., 2003). 
No Brasil, a prevalência desse distúrbio neurológico é elevada, assim como em todo mundo. Segundo estudo brasileiro, a prevalência urbana de epilepsia foi de 18,6/ 1.000 habitantes em uma cidade média do estado de estado de São Paulo São José do Rio Preto (BORGES et al., 2004). Nesse mesmo trabalho, que utilizou uma amostra de 17293 indivíduos, a epilepsia ativa apresentou prevalência de 8,2/1.000. Outro estudo avaliou uma população total de 96.300 pessoas em três áreas de dois municípios do Sudeste do Brasil e encontrou as seguintes taxas: 9,2/1.000 e 5,4/1.000 de epilepsia acumulada e ativa, respectivamente (NORONHA et al., 2007).

Em números absolutos projetados para os dados atuais da população brasileira de um pouco mais de 200.000.000 de habitantes, segundo o Instituto Brasileiro de Geografia e Estatística (www.ibge.gov.br/), teríamos entre 1.080.000 e 1.640.000 indivíduos com epilepsia no Brasil, ou seja, se considerarmos ainda a taxa de $12 \%$ de epilepsia focal sintomática resistente ao tratamento farmacológico e os dados populacionais acima descritos, supõe-se que entre 130.000 - 190.000 brasileiros estariam em condições de serem avaliados quanto à possibilidade de tratamento cirúrgico, visando reduzir ou eliminar o número das crises. Resumindo, a avaliação pré-operatória desse grupo de pacientes visa caracterizar o tipo de epilepsia, identificar a área geradora de crise e avaliar se ela pode ser abordada cirurgicamente.

\subsection{Ressonância magnética convencional e epilepsia}

Sobretudo no contexto das epilepsias refratárias, a ressonância magnética (RM) surgiu como uma ferramenta indispensável para a localização pré-operatória da lesão epileptogênica devido a sua excelente resolução espacial dos tecidos do sistema nervoso central. Pode ser considerada, talvez, o melhor método para identificação desta lesão (SPERLING et al., 1986; BROOKS et al., 1990; BRONEN et al. 1997; TELLEZ-ZENTENO et al., 2010; ABUD et al., 2015).

As imagens de RM mais comumente utilizadas nos protocolos para avaliação desses pacientes, ditas convencionais, são baseadas nos tempos de relaxação longitudinal (T1) e transversal (T2) das substâncias que formam os tecidos. Dependendo dos parâmetros utilizados na sequência de aquisição, as 
imagens podem estar predominantemente ponderadas em T1 e T2, ou seja, dependendo da concentração e do tipo das moléculas que formam os tecidos, teremos os diferentes sinais que produzem as imagens. Além das clássicas sequências T1 e T2, outras ainda ditas convencionais foram surgindo, cada qual com a sua aplicabilidade, por exemplo: FLAIR (fluid attenuated inversion-recovery) e T2 gradiente eco (Tabela 4). O FLAIR é uma sequência ponderada em T2 em que é suprimido o sinal da água (líquor), já rotineiramente utilizada nos protocolos de epilepsia, notadamente para a detecção de lesões corticais displásicas e esclerose hipocampal. Com essas sequências busca-se detectar visualmente na prática diária das diversas lesões epileptogênicas, avaliando-se de maneira criteriosa e utilizandose de um protocolo mais ou menos fixo, o qual, na instituição, chamamos de protocolo rotina para epilepsia, que será apresentado na metodologia, e visa englobar todas as etiologias deste grupo de pacientes apresentadas na tabela 2.

TABELA 4: Resumo das principais sequências utilizadas nos protocolos de rotina e suas principais aplicações.

\begin{tabular}{ll}
\hline \multicolumn{1}{c}{ Sequência } & \multicolumn{1}{c}{ Aplicabilidade } \\
\hline Volumétrica T1 & $\begin{array}{l}\text { Anatomia e morfologia dos giros. Muito útil } \\
\text { na caracterização de malformações } \\
\text { corticais. }\end{array}$
\end{tabular}

Coronal FLAIR e T2

Avaliação dos hipocampos: atrofia e aumento de sinal, achados característicos da esclerose temporal mesial.

Córtex cerebral: borramento da transição Axiais FLAIR e T2 branco-cinzenta visto nas DCFs. Também é a melhor sequência para identificar áreas de gliose.

Detectar calcificações e hemorragias,

T2 Gradiente eco presentes em infecções, tumores e sequelas.

FLAIR: Fluid attenuated inversion-recovery. DCFs: Displasias corticais focais.

Em 2015 foi apresentada uma revisão pictórica das principais patologias relacionadas com a epilepsia focal, destacando os achados de imagem em exames de RM 3 Teslas $(T)$ e seguindo uma linha de classificação etiológica que nos parece 
bastante didática e abrangente, além de ser fundamental o seu conhecimento para nortear a avaliação do exame (ABUD et al., 2015). Foram abordados nessa revisão diversos pontos, como a realização de um protocolo específico para epilepsia, utilização de RM de alto campo, avaliação sistemática e padronizada das imagens, além de indicados os próximos passos da pesquisa por meio da abordagem de pósprocessamento com técnicas avançadas.

Nesse ponto, a sensibilidade da RM no campo do diagnóstico de um provável substrato anatômico com utilização de um protocolo-padrão ou dito convencional tem sido relatada como variando de $13 \%$ a $86 \%$, dependendo do tipo de população estudada (KING et al., 1998; BERG et al., 2000; SCOTT et al., 1999). Ou seja, uma lesão epileptogênica, mesmo que presente, pode ser invisível na RM com utilização das sequências convencionais, principalmente quando se trata de uma DCF, e isto tem impactos significativos nos resultados cirúrgicos (eliminação ou redução das crises), já que a identificação da alteração estrutural na RM é de fundamental importância no sucesso pós-operatório dos pacientes submetidos a cirurgia, havendo, portanto, correlação positiva entre ambas as variáveis (TELLEZZENTENO et al., 2010). Além disso, os pacientes sem lesões visíveis na RM também são menos indicados para a cirurgia e, consequentemente, perdem a possibilidade do benefício desse tratamento em casos potencialmente necessários.

Essa grande meta-análise publicada por Tellez-Zenteno et al. (2010) abrangeu estudos cirúrgicos em epilepsia temporal e extratemporal e forneceu dados importantes sobre esse tema. Quarenta artigos preencheram os critérios de elegibilidade e, juntos, descreveram os resultados em 697 pacientes com epilepsia não lesional (NLE) e 2860 doentes com epilepsia lesional (LE). A prevalência geral de epilepsia NLE (RM e histopatológico) nesses estudos foi de $26 \%$, porém chegou a $45 \%$ no grupo das extratemporais. A prevalência variou bastante pelo método utilizado para definir a epilepsia NLE. Ele foi significativamente mais elevado nos casos definidos por ressonância magnética (44\%) do que pela histopatologia (16\%). Nos estudos que foram utilizados a RM para definir a presença de lesão, a proporção de pacientes livres de crises após a cirurgia foi de $46 \%$ na epilepsia NLE e $70 \%$ na epilepsia LE, com resultados muito próximos quando o critério foi a histopatologia (39\% versus 67\%), porém tendendo a um melhor prognóstico póscirúrgico quando a lesão era visível na RM. Aplicando a RM como critério de epilepsia LE e NLE e agrupando esses pacientes em epilepsia temporal e 
neocortical, a taxa geral de pacientes livres de crises foi de $51 \%$ versus $75 \%$ e $35 \%$ versus $60 \%$, respectivamente. Embora esse trabalho não deva ser considerado como uma contraindicação à cirurgia na epilepsia NLE, reforça a importância da identificação das lesões nas avaliações pré-operatórias, em especial na RM, já que os resultados são clinicamente e estatisticamente significativos em vários subgrupos, além de bastante homogêneos entre os estudos. Pode-se concluir que a RM positiva para a lesão epileptogênica ainda é o fator prognóstico mais forte para a eliminação das crises epilépticas no pós-operatório.

Em virtude da extrema importância de identificar possíveis substratos epileptogênicos nos exames de RM nesse grupo de desordens, Bronen et al. (1997) já haviam sugerido e orientado uma abordagem sistemática na avaliação das imagens destes pacientes. Essa sistematização visa primeiramente padronizar uma forma de inspeção visual no intuito de que todas as possíveis localizações de acometimento e patologias sejam avaliadas cuidadosamente pelo neurorradiologista, para que lesões, ainda que muito sutis, possam ser detectadas (Tabela 5). 
TABELA 5: Resumo da avaliação sistematizada sugerida por BRONEN et al. (1997).

\begin{tabular}{|c|c|}
\hline Avaliar & O que identificar \\
\hline 1. Hipocampo & $\begin{array}{l}\text { Aumento do sinal T2 (FLAIR) e atrofia } \\
\text { Cuidado com a bilateralidade. }\end{array}$ \\
\hline
\end{tabular}

2. Regiões periventriculares

Focos nodulares de heterotopia da substância cinzenta. Cuidado com pequenos nódulos.

Espessamento cortical (polimicrogiria, paquigiria, agiria e DCF). Atenção especial às discretas anormalidades, como os borramentos da transição branco-cinzenta.

4. Regiões periféricas

Lesões atróficas sequelares e encefaloceles.

Lesões tumorais com grande efeito de

5. Anormalidades evidentes

massa, grandes áreas de
encefalomalacia e malformações
vasculares.

FLAIR: Fluid attenuated inversion-recovery. DCF: Displasia cortical focal.

Adaptação de fonte disponível em http://www.ajronline.org/doi/pdf/10.2214/ajr.169.1.9207533 (Acesso em: 26/02/2017). 
Seguindo uma estratégia associando a prevalência e o conhecimento, a primeira estrutura a ser inspecionada é o hipocampo (Figura 1), avaliando-se principalmente o sinal e a morfologia, além de conferir atenção especial ao acometimento bilateral e à associação com outras patologias (dual pathology). Após os hipocampos, passa-se para uma averiguação cuidadosa das regiões periventriculares na busca de heterotopias de substância cinzenta que, quando discretas, necessitam de atenção redobrada para detectá-las (Figura 2). $\mathrm{Na}$ sequência, faz-se a avaliação do córtex cerebral, visando o diagnóstico das malformações corticais, com atenção especial a achados de espessamento cortical, alteração da morfologia dos giros e sulcos, borramento da transição entre as substâncias branca e cinzenta, atrofias corticais e ao mais típico das displasias corticais focais (DCFs): a faixa de alteração de sinal entre uma eventual lesão cortical e a cavidade ventricular (Figura 3 ).

FIGURA 1: Ressonância magnética típica de esclerose hipocampal. A) Imagem coronal T2 e B) Imagem coronal FLAIR evidenciando atrofia e alto sinal T2 do hipocampo direito. FLAIR: Fluid attenuated inversion-recovery. Short time inversion recovery Gray-matter only.
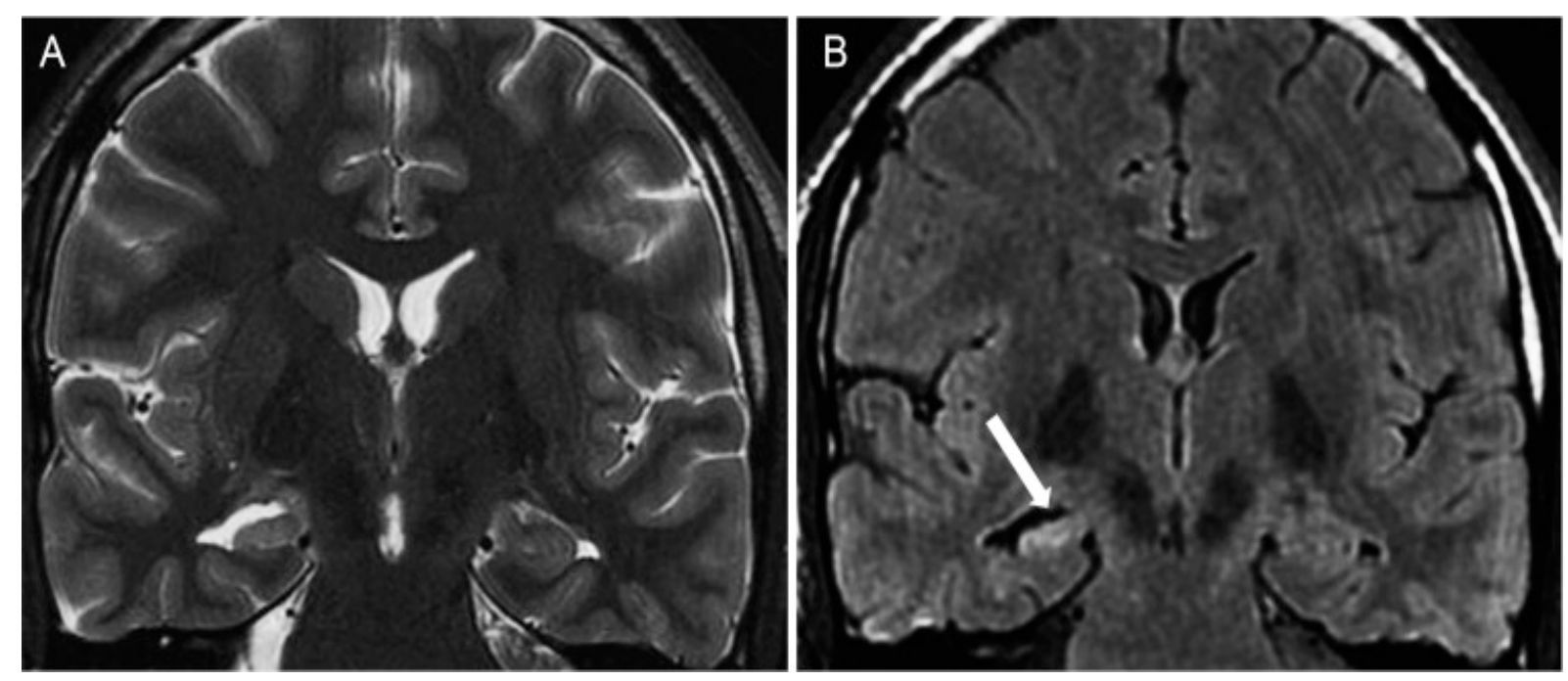

Lucas Abud et al. Clinics (Sao Paulo). 2015 Sep; 70(9): 654-661.

Fonte disponível em https://www.ncbi.nlm.nih.gov/pmc/articles/PMC4557590/ (Acesso em: 20/02/2017). 
FIGURA 2: Ressonância magnética típica de heterotopia periventricular de substância cinzenta. A) Coronal T2 e B) Coronal T1 demostrando nódulos com o mesmo sinal da substância cinzenta adjacentes aos ventrículos laterais.
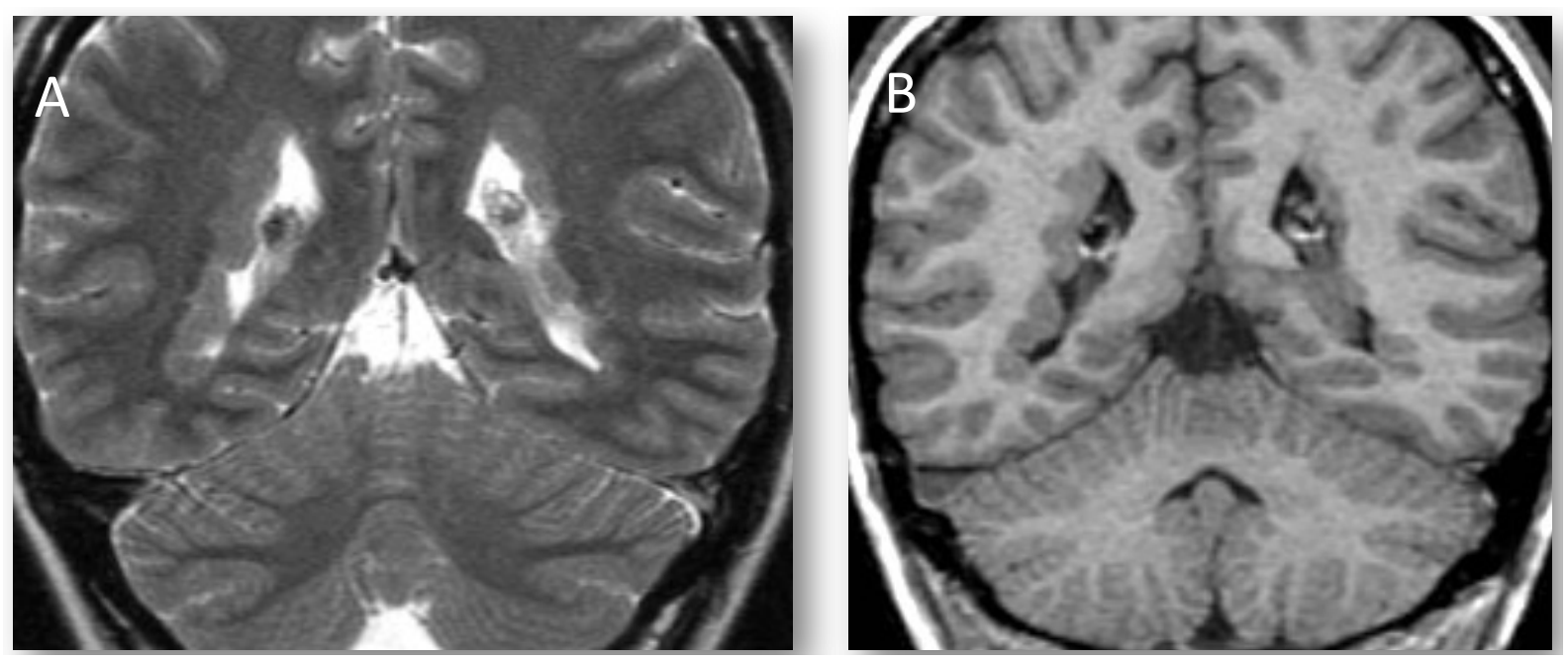

Fonte: arquivo pessoal (Acesso em: 20/02/2017).

FIGURA 3: Ressonância magnética típica de uma displasia cortical focal. A) Axial T2, demonstrando hiperintensidade focal e espessamento do córtex frontal esquerdo, com perda de diferenciação entre as substâncias cinzenta-branca (seta branca). B) Axial FLAIR, mostrando uma banda de alto sinal anormal que se estende do córtex ao ventrículo lateral (setas brancas). FLAIR: Fluid attenuated inversionrecovery.
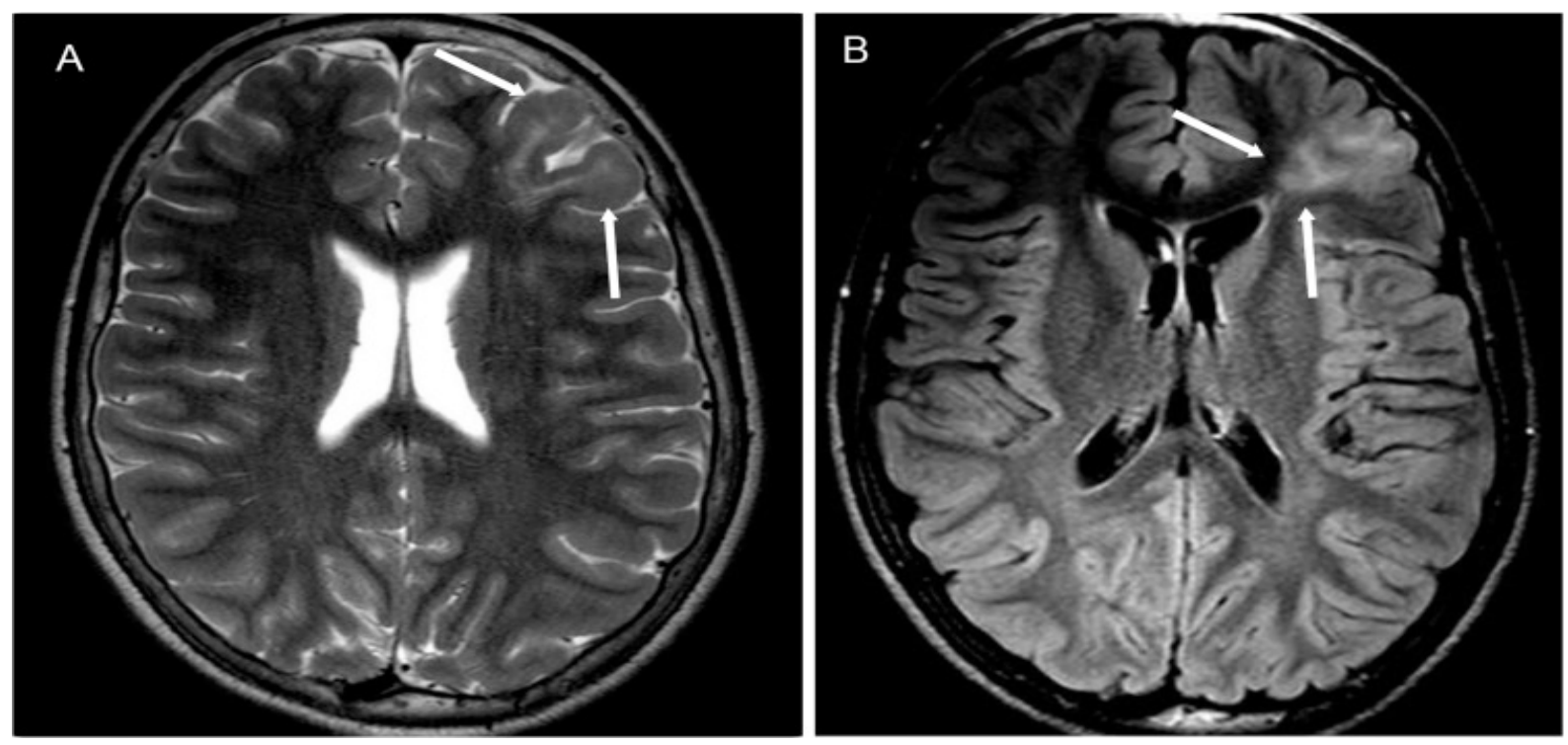

Lucas Abud et al. Clinics (Sao Paulo). 2015 Sep; 70(9): 654-661.

Fonte disponível em https://www.ncbi.nlm.nih.gov/pmc/articles/PMC4557590/ (Acesso em: 20/02/2017). 
Bronen et al. (1997) ainda elencaram as anormalidades que cursam com alterações atróficas (sequelas, facomatoses/Sturge-Webere, etc) e outras patologias periféricas, como as encefaloceles temporais (Figura 4). Também ressaltaram o que chamaram de anormalidades evidentes, como os tumores e as malformações vasculares (figura 5). Por fim, sugeriram que esta avaliação, denominada de abordagem sistemática (systematic approach), possa aumentar a sensibilidade na detecção de lesões epileptogênicas, notadamente sutis. Entretanto, não foi realizado um estudo comparando a sensibilidade da utilização dessa estratégia contra um grupo-controle que não a utiliza, sob o argumento de que na instituição onde o trabalho foi realizado todos seguiam o mesmo protocolo de avaliação.

FIGURA 4: Ressonância magnética evidenciando meningocele transesfenoidal da fossa pterigopalatina. A) imagem coronal T2 e B) imagem axial T1 evidenciam uma coleção em continuidade com o espaço subaracnóideo, com a mesma intensidade do líquido cefalorraquidiano em todas as sequências, que se projeta na fossa pterigopalatina direita.

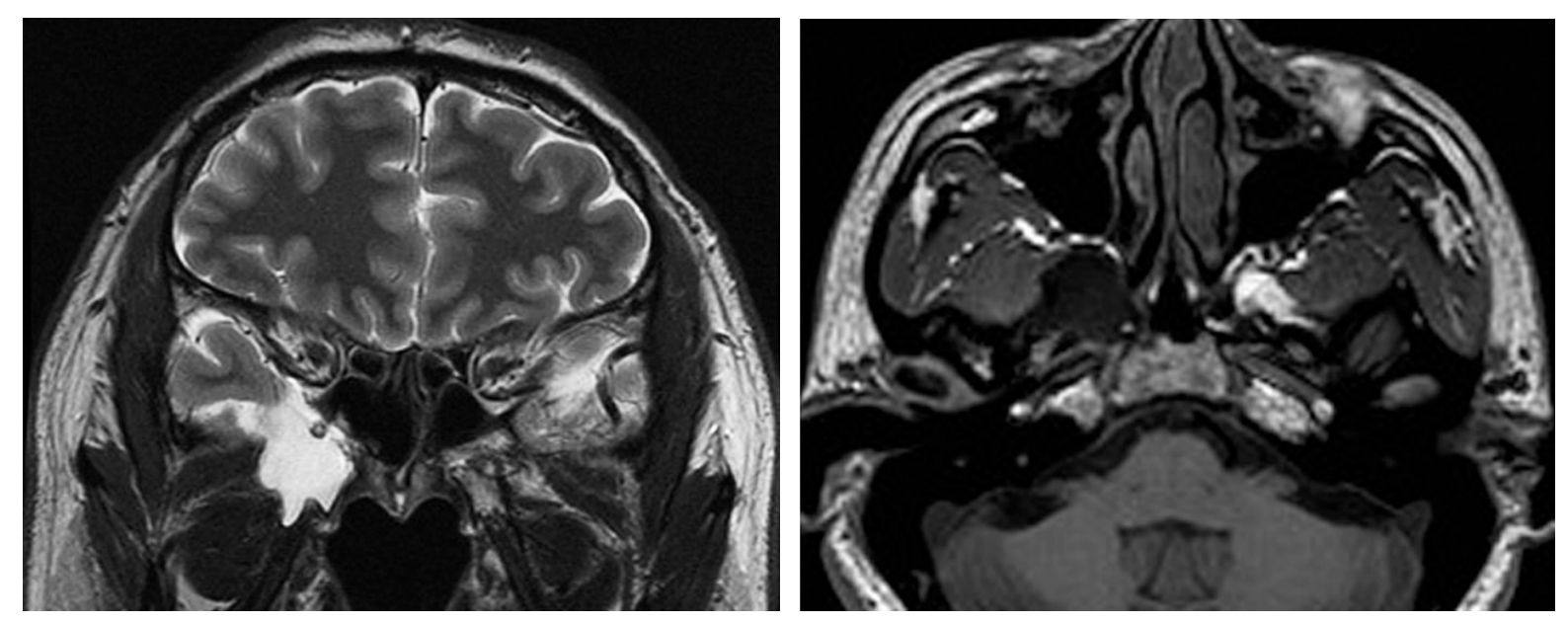

Fonte: arquivo pessoal (Acesso em: 20/02/2017). 
FIGURA 5: Ressonância magnética evidenciando um ganglioglioma. A) Imagem coronal ponderada em T2 e B) Imagem coronal ponderada em T1 após a administração endovenosa de contraste a base de gadolínio mostram uma lesão sólido-cística no lobo temporal mesial esquerdo com realce intenso (setas brancas).
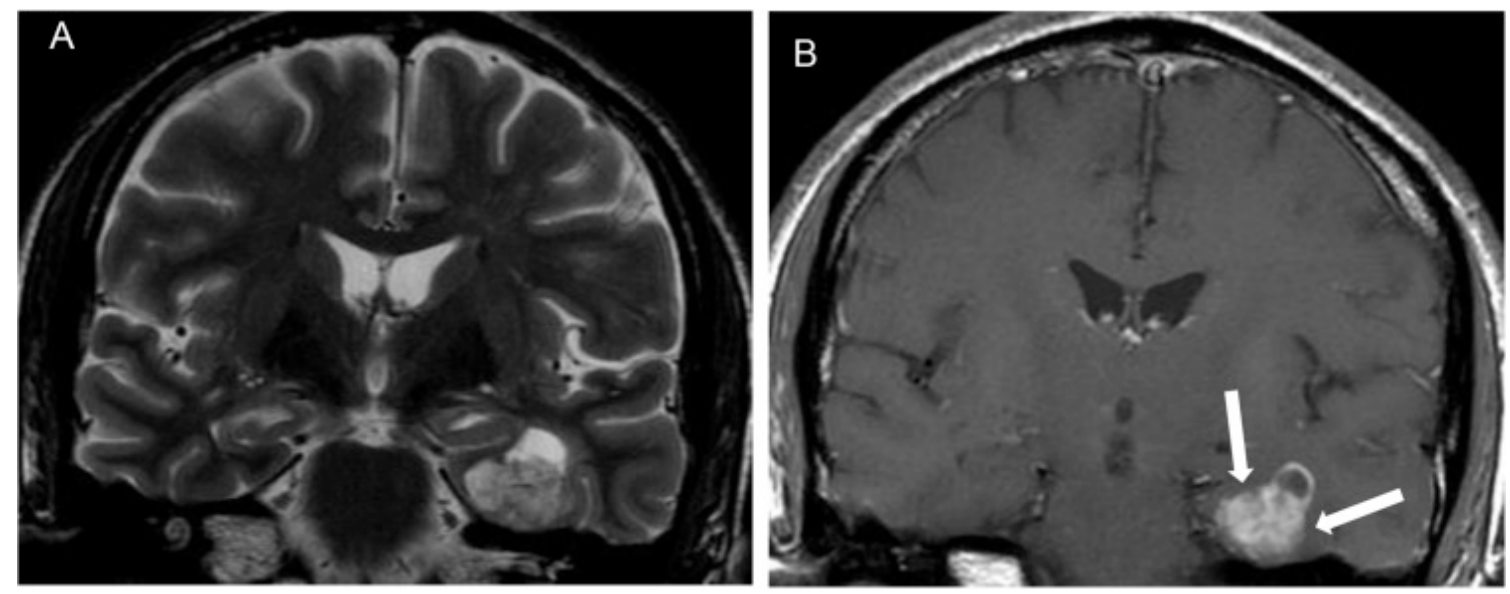

Abud LG et al. Clinics (Sao Paulo). 2015 Sep; 70(9): 654-661.

Copyright $\odot 2015$ Clinics

Fonte disponível em https://www.ncbi.nlm.nih.gov/pmc/articles/PMC4557590/ (Acesso em: 20/02/2017).

Outras duas questões importantíssimas que devem ser consideradas na avaliação do exame de RM destes pacientes é: a utilização de protocolo específico para epilepsia e a experiência do especialista em imagem que irá analisar as imagens. Protocolos de maior sensibilidade e especificidade são amplamente disseminados pelos centros de pesquisa em epilepsia e incluem cortes com espessura mais fina, de alta resolução e com orientação perpendicular ao eixo longitudinal do hipocampo (COMMISSION ON NEUROIMAGING OF THE INTERNATIONAL LEAGUE AGAINST EPILEPSY, 1998).

Em um grande estudo, Von Oertzen et al. (2002) compararam a sensibilidade e especificidade de lesões epileptogênicas validadas por resultados histopatológicos após a cirurgia entre três grupos e avaliaram 123 pacientes consecutivos da seguinte forma: (1) Relatório de RM padrão realizado por radiologista fora de um grande centro, dito como não especialista; (2) Relatório de avaliação de RM padrão realizado por um neurorradiologista especialista de um grande centro de epilepsia, dito como especialista; e (3) relatório de RM, utilizando 
um protocolo dedicado para epilepsia realizado por neurorradiologista especialista. O termo RM padrão foi utilizado para os exames que não possuíam as sequências mais finas nem as perpendiculares aos hipocampos.

Nesse estudo, a sensibilidade para lesões focais dos relatórios de RM padrão dos não especialistas foi de $39 \%$, enquanto a dos especialistas para o mesmo exame chegou a 50\%. Já com um protocolo de RM dedicado de epilepsia e avaliado por um neurorradiologista especialista, a sensibilidade foi de $91 \%$. Além disso, os diagnósticos neuropatológicos foram sugeridos corretamente em $22 \%$ dos relatórios pelos não especialistas, enquanto os especialistas os previram corretamente, utilizando-se de uma RM dedicada, em $89 \%$ dos relatórios.

Além de um protocolo dedicado e avaliação realizada por um neurorradiologista especialista, há embasamento na literatura que a RM de alto campo de 3-T tem potencial para melhorar esta sensibilidade devido a uma maior relação sinal-ruído quando comparada com a de 1,5-T, o que pode ser traduzido em maior resolução de imagem, possivelmente permitindo a detecção de lesões epileptogênicas sutis (KNAKE et al., 2005; PHAL et al., 2008; MELLERIO et al., 2014; ZIJLMANS et al., 2009).

Mellerio et al. (2014) mostraram que a RM 3-T melhora a taxa de detecção e caracterização da displasia cortical focal do tipo 2 (DCF2). Nesse estudo, dois revisores independentes avaliaram 25 pacientes com diagnóstico histológico de DCF2 estudados em RM de 1,5 e 3,0 T, e comparou-se a identificação dos cinco critérios típicos de DCF2 (espessamento cortical, borrando, alterações de sinal corticais, alterações de sinal subcorticais e sinal do "transmantle"). Sessenta e oito por cento (17/25) das lesões foram detectadas na RM 3-T, duas das quais passaram despercebidas na de 1.5-T. O sinal do transmantle foi significativamente melhor identificado na RM de 3-T. Phal et al. (2008) já haviam encontrado resultados semelhantes na avaliação de lesões estruturais e também demonstraram desempenho estatisticamente significativo melhor da RM 3-T em relação a de 1,5-T em qualidade de imagem, deteç̧ão de lesões estruturais e caracterização das lesões. Nesse trabalho, em um total de 74 casos, as alterações foram mais frequentemente detectadas na de 3-T (65/74 x 55/74), assim como mais bem caracterizadas segundo parâmetros previamente estabelecidos (63/74 x 51/74).

Diante de todas essas evidências supõe-se que um exame de RM de 3-T é aconselhável quando os pacientes com epilepsia refratária têm uma RM de 1.5-T 
considerada negativa ou inespecífica para localização de lesões epileptogênicas ou se a RM de 3-T puder ser usada rotineiramente na investigação de substratos epileptogênicos diante da suspeita de uma DCF em pacientes candidatos à cirurgia.

É aconselhável, para esse grupo de pacientes com EFRTM, que uma avaliação visual sistematizada de todas as imagens seja realizada por um neurorradiologista com vasta experiência e amplo conhecimento em imaginologia das epilepsias, utilizando-se de um protocolo dedicado às principais patologias do grupo. Para tanto, deve-se fazer um exame de ressonância magnética em aparelho de alto campo, preferencialmente 3-T.

\subsection{Outros métodos localizatórios: eletroencefalograma e medicina nuclear}

Como nem todas as alterações encontradas nos exames de RM são responsáveis pelo início das crises, há necessidade de verificação com outros métodos. Além da RM estrutural, os outros que fazem parte do arsenal não ou minimamente invasivo são, principalmente, a monitorização por videoencefalograma (VEEG) de superfície, a tomografia por emissão de fóton único (SPECT, do inglês single photon emission computed tomography) ictal/interictal e a tomografia por emissão de pósitrons (PET, do inglês positron emission tomography) interictal (DUNCAN, 1997). Esses métodos permitem, por meio de estudos das atividades elétricas e funcionais, sugerir a localização da zona de início ictal - região de gatilho que inicia o processo de geração de crises, cuja remoção poderá permitir controlálas (ROSENOW; LUDERS, 2001).

Para avaliação do EEG de superfície, os eletrodos colocados no couro cabeludo permitem um estudo do registro gráfico das correntes elétricas e têm como objetivo principal, neste grupo de pacientes, determinar a localização da área geradora da atividade irritativa no córtex cerebral, a chamada zona epileptogênica (ZE) (Figura 6). Na rotina, há basicamente dois tipos de gravações de EEG não invasivo (de superfície ou do couro cabeludo): o EEG "interictal", ou seja, registro das atividades paroxísticas epileptiformes entre as crises epilépticas, e as gravações de longo prazo (de forma ambulatorial ou telemétrica), que procuram capturar eventos ictais habituais, e também interictais, visando um diagnóstico mais preciso e 
muito útil nas avaliações pré-cirúrgicas (TSIPTSIOS; HOWARD; KOUTROUMANIDIS, 2010).

A monitorização por VEEG de superfície consiste na gravação simultânea prolongada do registro eletroencefalográfico e do paciente por uma câmera de vídeo (YOGARAJAH et al., 2009). Um tempo de registro mais prolongado já é comprovadamente vantajoso para documentar de maneira mais bem detalhada as características semiológicas das crises epilépticas, localizar com segurança o início e a propagação das descargas e classificar corretamente os diferentes tipos de crises epilépticas. Nas epilepsias focais, as alterações mais importantes do EEG para a localização de crises são aquelas que ocorrem nos primeiros 30 segundos após o início da crise epiléptica.

FIGURA 6: Ilustração de um registro de EEG pelo método de superfície. De acordo com as alterações da atividade cerebral que podem ser detectadas nesse registro, os resultados podem ser úteis para diagnóstico e localização das crises nos pacientes com epilepsia.

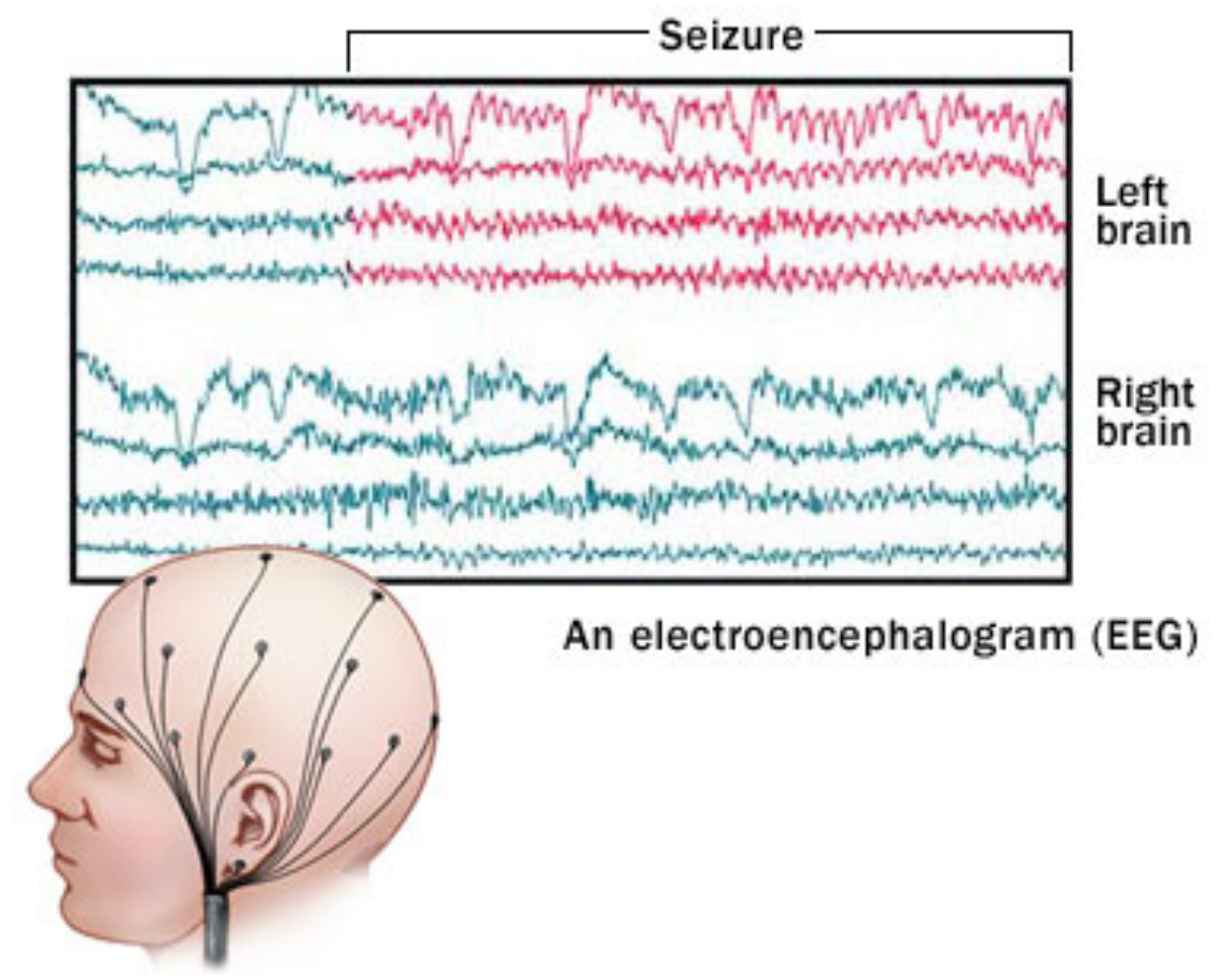

\section{(9) Mayo Foundation for Medical Education and Research. All rights resenved.}

Fonte: Disponível em http://www.mayoclinic.org/tests-procedures/eeg/multimedia/eeg-brainactivity/img-20005915 (Acesso em: 26/02/2017). 
Entretanto, O EEG de superfície tem algumas limitações já discutidas em diversos estudos (SMITH, 2005). A atividade elétrica registrada por eletrodos colocados no couro cabeludo reflete, sobretudo, a soma de potenciais excitatórios e inibitórios de neurônios localizados nas camadas mais superficiais do cérebro. Também são necessários alguns centímetros quadrados do córtex para que sejam ativados de forma sincrônica, a fim de gerar um potencial suficiente para que mudanças possam ser registradas nos eletrodos colocados no couro cabeludo. Há ainda a questão de amostragem espacial do couro cabeludo, uma vez que algumas regiões do cérebro, particularmente as áreas basais e mesiais dos hemisférios, não são cobertas totalmente pela colocação-padrão dos eletrodos de superfície. Por fim, pode haver problema de uma localização enganosa quanto à zona da atividade elétrica devido, sobretudo, à propagação da atividade elétrica ao longo das vias fisiológicas. Com isso, a chance de falsa lateralização e localização pelos achados do EEG do couro cabeludo pode variar de 6 a 18\% (LEE et al., 2000).

A medicina nuclear também tem seu papel na investigação das ZE, e é considerada um método de neuroimagem funcional representado pelo SPECT e PET. A aplicação desses métodos baseia-se no pressuposto de que o aumento da atividade neuronal durante as crises está associado a um aumento do metabolismo e fluxo sanguíneo cerebral regional (SASAKI et al., 2000). As imagens podem ser obtidas para avaliar o estado funcional num momento específico a escolher. Ou seja, a realização de exames rápidos após as crises (ictais) visa representar o exato momento da crise, enquanto os exames entre os períodos de crise (interictais) representam o momento fora da crise.

O SPECT detecta alterações do fluxo sanguíneo cerebral regional por meio da administração endovenosa de substância radioativa (radiofármaco ou radiotraçador) ao paciente, seguida do mapeamento tridimensional da distribuição dessa substância no cérebro. O PET, por sua vez, detecta alterações do metabolismo da glicose pela administração endovenosa de um material radioativo que se acumula na área do corpo a ser examinada. Atualmente, a maioria dos aparelhos de PET são sincronizados com tomografia computadorizada (TC), o que permite combinar as imagens metabólicas com as anatômicas, resultando na sigla PET-TC. Apesar da qualidade da imagem ser melhor no PET-TC, na prática, o SPECT é o método de medicina nuclear mais amplamente disponível e utilizado nos pacientes com EFRTM. 
Isso acontece porque, além da desvantagem financeira do PET-TC, ainda há menor disponibilidade dos isótopos emissores de pósitrons por terem uma meia-vida muito curta. O SPECT ictal é classicamente realizado imediatamente após o início da crise clínica ou do EEG durante as monitorizações prolongadas; já o SPECT interictal deve ser feito quando os pacientes estão livres de crises epilépticas há pelo menos 24 horas.

Porém, mesmo com todo o arsenal não invasivo apresentado visando detectar a ZE em um número expressivo dos pacientes com EFRTM (aproximadamente $25 \%$ ou mais), esses exames não localizam de forma satisfatória a zona de início das crises. Além disso, mesmo diante de alguma localização suspeita, há a necessidade de uma confirmação mais precisa antes de levá-los a uma cirurgia de lesionectomia. Dessa forma, devem ser realizadas investigações invasivas para um adequado planejamento cirúrgico (SPENCER; GUIMARAES; SHEWMON, 1998).

Os dois principais tipos de investigação eletroencefalográfica invasiva mais comumente realizados são a colocação de placas subdurais com eletrodos dispostos em tiras ou a distribuição de eletrodos intracerebrais implantados via estereotáxica para gravação do EEG, chamado de estereoeletroencefalograma (SEEG).

Atualmente, podemos dizer que o SEEG é considerado o método padrãoouro para localização da ZE, porém, por se tratar de um método invasivo e com riscos inerentes ao procedimento, mesmo que muito baixos, deve ser reservado aos pacientes em que os métodos não invasivos falharam na localização das regiões de início das crises (COSSU et al., 2005). A morbidade relacionada ao implante de eletrodos varia de pequenas e transitórias intercorrências até déficits permanentes graves, geralmente relacionados a uma hemorragia intracerebral. Para a epilepsia do lobo temporal, a colocação de eletrodos nos forames ovais tem se mostrado confiável quando o intuito principal é determinar a lateralização (VELASCO et al. 2006). 


\subsection{Novas técnicas de ressonância magnética e epilepsia}

Adicionalmente, novas técnicas de imagem por RM foram surgindo nos últimos anos e são aplicadas a esse grupo de pacientes com o intuito de melhorar a detecção dos substratos epileptogênicos. Essas novas modalidades incluem imagem de tensor de difusão (DTI), imagem de transferência de magnetização (ITM), relaxometria T2 (RT2), espectroscopia de prótons, imagem ponderada por susceptibilidade (SWI) e imagens com dupla inversão-recuperação (DIR), além de novas possiblidades de sequenciamento volumétrico (COLOMBO et al., WIDDESS, DIEHL; NAJM, 2006; RUGG-GUNN et al., 2006; MADAN; GRANT, 2009; LEITE et al., 2007; SAINI et al., 2010).

Devido à grande extensão do assunto e suas diversas aplicabilidades, focaremos em detalhar as sequências utilizadas no nosso estudo.

\subsubsection{Imagem de tensor de difusão: DTI}

A aquisição de imagens de difusão por ressonância magnética (DWI) é uma técnica relativamente recente de geração de imagens que se utiliza da mensuração das tendências do movimento aleatório das moléculas de água em um dado meio (SUNDGREN et al., 2004; JELLISON et al., 2004). Essas imagens podem ser adquiridas com a utilização de sequências habitualmente utilizadas na aquisição de imagens de RM estrutural, adicionando-se dois pulsos de gradiente opostos que introduzam variações de fase em spins que estejam se difundindo (movimentando), um dertermina defasagem e o outro refasagem da magnetização. Para moléculas estacionárias (que não se difundem), as fases induzidas por esses pulsos de gradiente irão se cancelar completamente e não haverá qualquer atenuação do sinal de difusão. No caso de um deslocamento coerente no sentido do gradiente aplicado, devido ao movimento em massa, não haverá diferença líquida de fase proporcional ao deslocamento. Em outras palavras, quando aplicados dois gradientes aos campos magnéticos separados por um intervalo de tempo, ambos com a mesma intensidade e direção, porém com sentidos opostos, haverá uma anulação da excitação produzida pelo primeiro. Apesar disso, essa anulação não acontece com os prótons que se difundiram ao longo da direção do gradiente, e o sinal contido nas 
imagens obtidas dessa forma contém justamente a informação a respeito dos prótons que se moveram ao longo do gradiente.

Além disso, na DWI, esses gradientes de difusão são aplicados em uma sequência ecoplanar com tempo de relaxação muito alto, produzindo imagens fortemente ponderadas em T2. Assim, uma área de alto sinal na imagem ponderada em difusão pode decorrer de uma restrição na movimentação das moléculas de água, do aumento do T2 ou de ambos. Uma alternativa para esse problema é utilizar o mapa do coeficiente aparente de difusão (ADC), ou seja, utiliza-se um cálculo matemático com as informações obtidas da DWI adquiridas com diferentes gradientes de difusão e cria-se um mapa "pixel a pixel" com essas medidas.

Importante termos o conceito de que as moléculas de água podem difundir livremente no meio que ocupam (movimento browniano) ou apresentarem restrição total ou movimentação preferencialmente em uma direção, ou seja, em um meio homogêneo o movimento de difusão acontece igualmente em qualquer direção, o que é denominado de movimento isotrópico. Consequentemente, em meios com a substância branca cerebral, por exemplo, observa-se que esse movimento das moléculas ocorre preferencialmente e mais rapidamente no sentido das fibras e mais lentamente nas demais direções, o que é denominado de difusão anisotrópica. Esses dois tipos extremos de movimento da água estão ilustrados na figura 7 . 
FIGURA 7: Ilustração dos tipos de movimentação das moléculas de água. A) Imagem ilustrativa de uma difusão anisotrópica, ocorrendo preferencialmente ao logo do feixe da substância branca. B) Imagem ilustrativa de uma difusão isotrópica, aleatória.

(a)

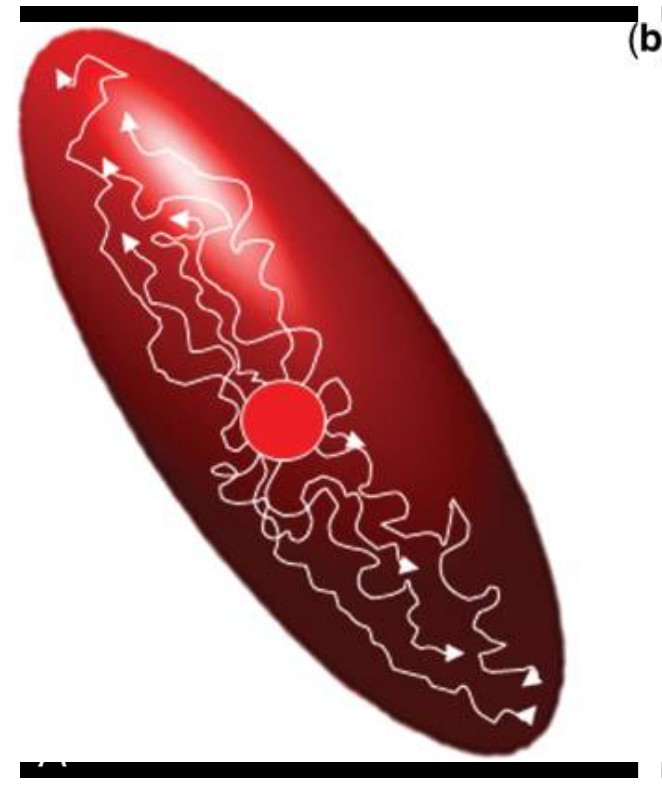

T.A.G.M. Huisman. Cancer Imaging. 2010; 10(1A): S163-S171

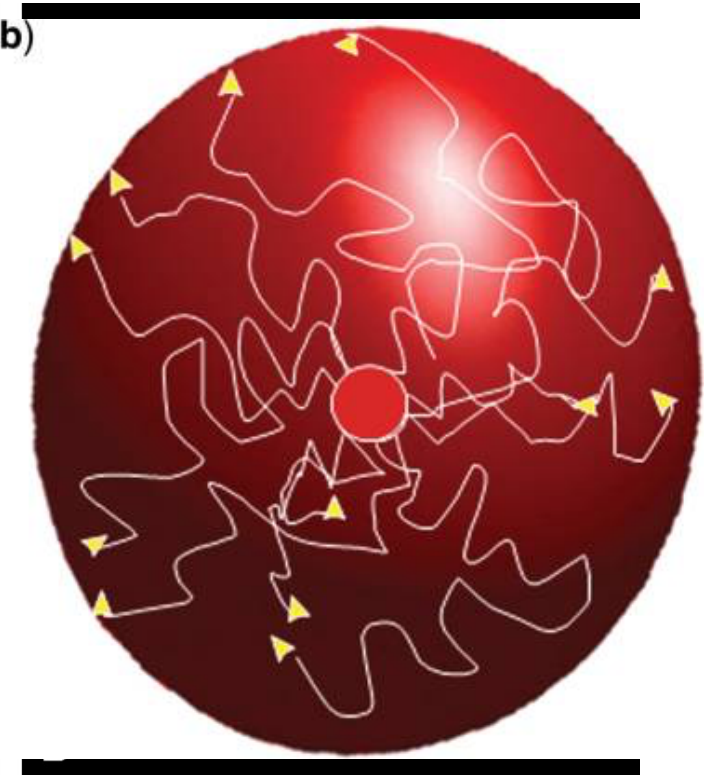

(2)

C) 2010 International Cancer Imaging Society 20/02/2017).

Fonte disponível em https://www.ncbi.nlm.nih.gov/pmc/articles/PMC2967146/ (Acesso em:

Em tecidos onde a difusibilidade aparente é isotrópica basta utilizar um parâmetro escalar simples para a medida do ADC. Essa medida recebe o nome de aparente, pois, no voxel, a movimentação medida não é apenas relacionada ao gradiente de concentração, havendo influência da movimentação decorrente do gradiente térmico, do gradiente de pressão e das interações iônicas, não sendo, portanto, uma medida absoluta. O cálculo do ADC de um determinando voxel é dado por:

$$
A D C=(1 / b) \times \ln \left(S I_{0} / S I\right)(1)
$$

Onde $\mathrm{SI}_{0}$ é a intensidade da imagem na ausência de aplicação de gradientes de difusão, SI é a intensidade da imagem mediante a aplicação de gradientes de difusão e b é o fator de sensibilização à difusão em unidades de s/mm. 
No entanto, nos meios em que a difusão é anisotrópica, como no encéfalo, o coeficiente de difusão escalar simples não é mais suficiente para descrever o fenômeno de difusão. Nesses casos, são necessárias ao menos três direções, dispostas nas três dimensões espaciais, geralmente ortogonais. Posteriormente, essas imagens podem ser combinadas por um pós-processamento, formando uma imagem chamada isotrópica, resultante da enésima do produto das imagens anisotrópicas. Isto é, caso tenham sido realizadas três aquisições ortogonais, a imagem final será a raiz cúbica do produto das três imagens adquiridas (Figura 8). Se esses valores forem correlacionados à direção da aquisição das imagens, temos o tensor de difusão, que descreve a mobilidade molecular ao longo de todas as direções, além da correlação entre as direções, que relaciona o valor do ADC com a avaliação da anisotropia.

FIGURA 8: Fenômeno de difusão utilizando três aquisições ortogonais em meio anisotrópico. Superior: diagramas das distribuições de deslocamento da difusão em um tensor de difusão - as elipsoides indicam os deslocamentos de difusão. A difusão é altamente anisotrópica em tecidos como a substância branca. A direção que representa a maior difusibilidade é paralela aos feixes das fibras. Inferior: por meio de um procedimento conhecido como diagonalização de matrizes é possível definir o principal vetor próprio (autovetor associado com o maior dos três valores próprios), que representa a orientação da difusibilidade máxima, o que, por sua vez, reflete a orientação de feixes das fibras.
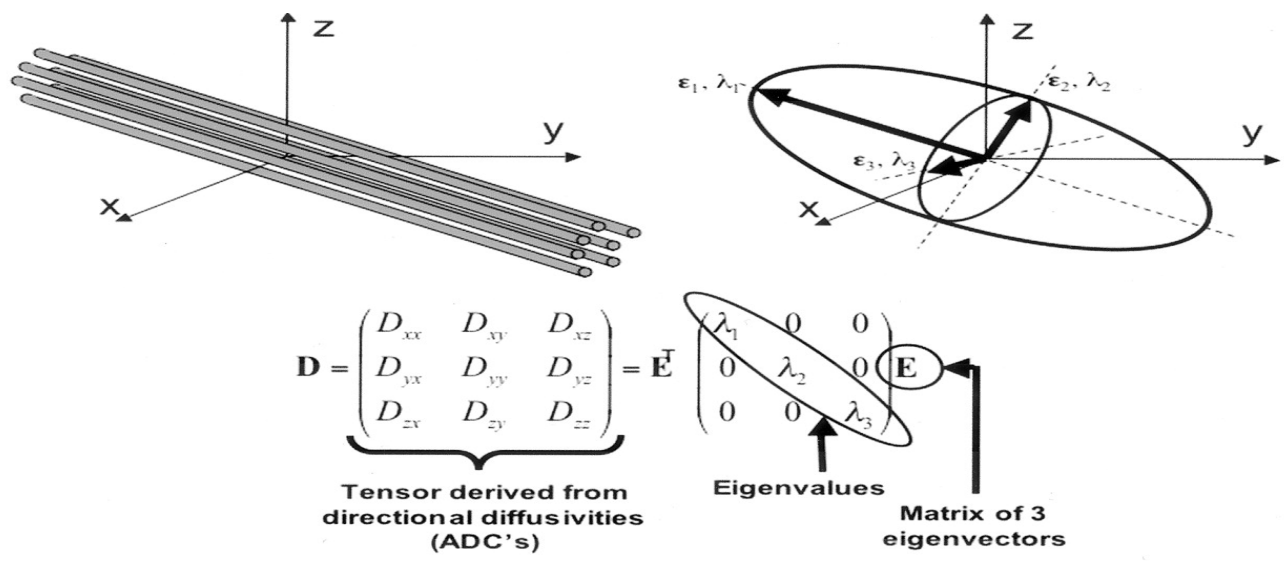

Brian J. Jellison et al. AJNR Am J Neuroradiol
2004;25:356-369

Fonte disponível em http://www.ajnr.org/content/25/3/356.short (Acesso em: 20/02/2017). 
São necessárias imagens de difusão no mínimo em seis direções não colineares, além de uma imagem sem gradiente de difusão $(b=0)$, para começar a obter sequências de DTI. A partir da DTI, pode-se derivar algumas medidas que trazem informações sobre a microestrutura tecidual - a difusibilidade média, a difusibilidade paralela, a difusibilidade perpendicular e a anisotropia fracionada (LITTLE; HOLLOWAY, 2007).

Cada uma das medidas derivadas dessa técnica pode ser quantificada. A anisotropia fracionada (AF) é uma medida de difusão anisotrópica da água que traduz a orientação do eixo das estruturas dos feixes de fibras ao longo do qual as moléculas de água se movem de forma preferencial. Ela varia de 0 a 1 , sendo uma AF de 0 relacionada a um meio totalmente isotrópico e uma AF de 1 a um outro totalmente anisotrópico. A DM é a média dos valores da diagonal principal do tensor de difusão, que inclui a difusibilidade perpendicular, intensidade de difusão do tensor perpendicular ao eixo da fibra, e a difusibilidade paralela, intensidade de difusão do tensor paralelo ao eixo da fibra. Assim, a DM pode ser considerada uma medida equivalente ao ADC e, portanto, será utilizada dessa forma neste trabalho. Consequentemente, a DTI pode ser usada para avaliar, indiretamente, a integridade neuronal e axonal com base nesses parâmetros (GRAHAM et al., 2004).

Trabalhos também têm demonstrado alterações desses parâmetros extraídos do DTI nas regiões das malformações corticais (Figura 9), consistentes com os resultados de RM convencional e, dessa forma, encorajam a utilização dessa sequência como ferramenta útil na detecção de pequenas lesões corticais epileptogênicas sutis, sem alterações subcorticais evidentes (LEE et al., 2004; LIM et al., 2005). As anormalidades desses parâmetros encontradas nas malformações corticais e proximidades, notadamente nas DCFs, decorrem, principalmente, de aumento da difusividade perpendicular, aumento do coeficiente aparente de difusão ou difusividade média e redução da anisotropia fracionada (KINI; GEE; LITT, 2016). 
FIGURA 9: Exemplo de ressonância magnética de uma displasia cortical focal tipo 2, utilizando a sequência de imagem por tensor de difusão. A) Imagem axial ponderada em T2, demonstrando um espessamento focal do córtex parietal direito (setas brancas). B) Corregistro de imagem axial T1 com o mapa de anisotropia fracionada, demonstrando perda de organização das fibras na região da displasia (setas brancas) em comparação com a região contralateral.
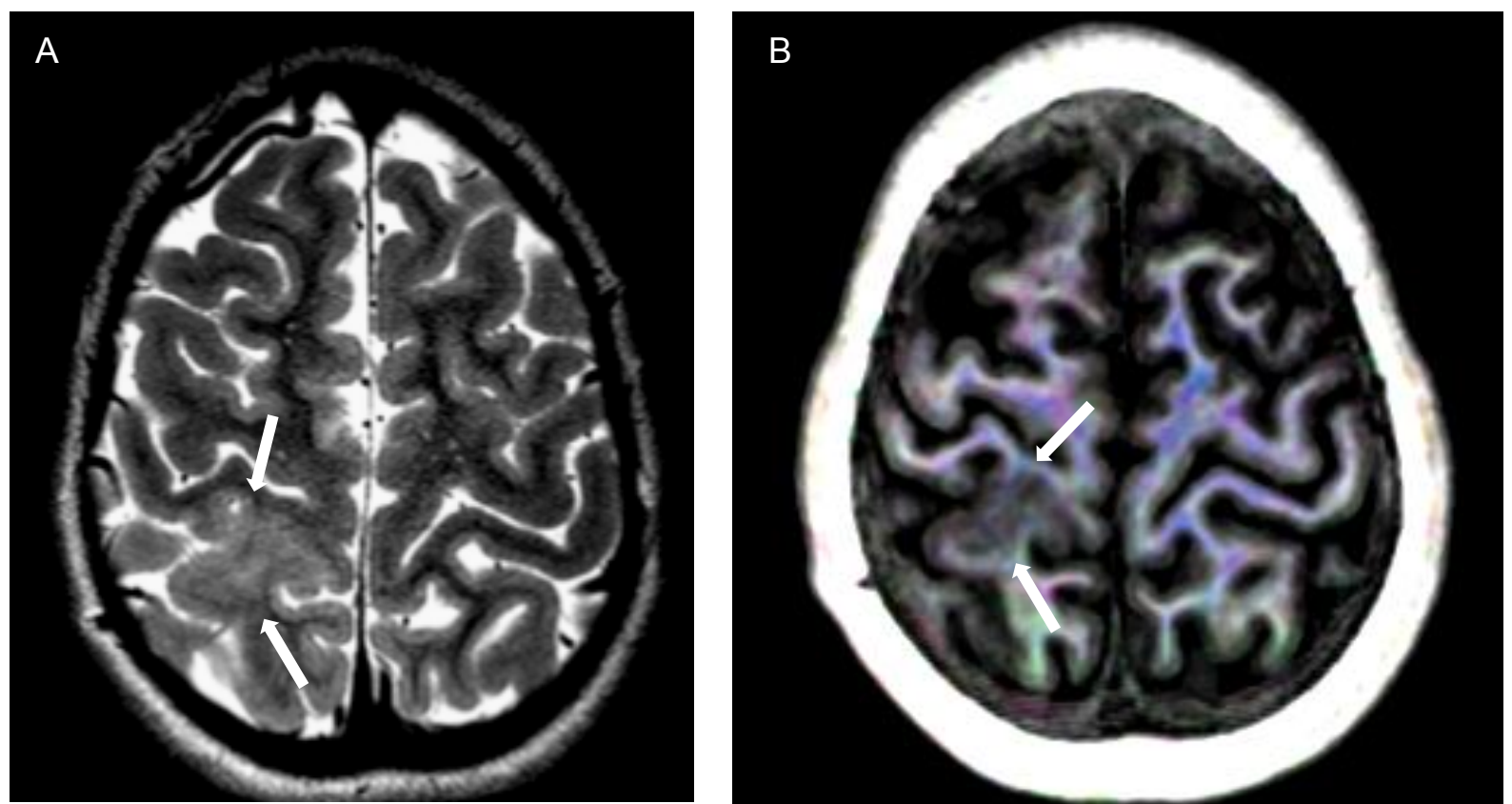

Fonte: arquivo pessoal de trabalho apresentado no RSNA - Radiological Society of North America 2011 (Congresso). Refractory partial epilepsy: a pictorial review of magnetic resonance imaging features at 3 TESLA. (Acesso em: 01/03/2017).

\subsubsection{Relaxometria T2: RT2}

A RT2 é uma técnica que possibilita quantificar as alterações na intensidade de sinal nas sequências ponderadas em T2 por meio de várias medidas consecutivas do sinal em diferentes tempos de eco (TE), da obtenção de uma curva de decaimento e de um gráfico exponencial (Figura 10). O potencial teórico da utilização desta técnica encontra-se no fato de que muitos dos tecidos patológicos cerebrais são acompanhados de um aumento na intensidade de sinal nas sequências ponderadas em T2, visto que esses tecidos são mais hidratados que os normais e, portanto, geram curvas de decaimento mais prolongadas. Dessa forma, é um método capaz de determinar medidas mais objetivas, independentemente do brilho identificado nas inspeções visuais (JACK, 1996). 
FIGURA 10: Ajuste exponencial da intensidade de sinal média versus o tempo de eco dos diferentes tecidos cerebrais.

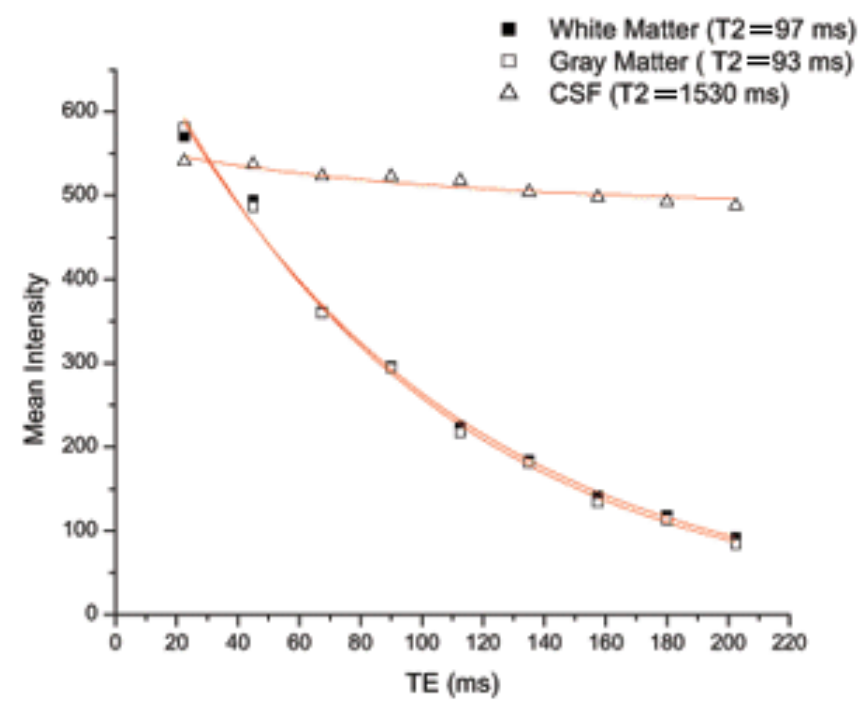

Carneiro AAO et al. Braz. J. Phys.

vol.36 no.1a São Paulo Mar. 2006

Copyright $\odot 2006$ Braz. J. Phys

Fonte disponível em http://www.scielo.br/scielo.php?script=sci_arttext\&pid=S010397332006000100005 (Acesso em: 20/02/2017).

O valor da RT2 na avaliação de pacientes com epilepsia já foi, diversas vezes, demonstrado em estudos anteriores nos casos de epilepsia do lobo temporal mesial (COAN et al., 2014; SATO et al., 2016; CHEN et al., 2016). Esse aumento do tempo de relaxação 2 pode, inclusive, ser caracterizado em indivíduos com epilepsia do lobo temporal mesial e RM normal, o que ajuda na lateralização e localização da ZE nesses pacientes. Apesar da literatura ser bem mais escassa ao abordar as epilepsias focais extratemporais mesiais, parece claro que as lesões corticais potencialmente responsáveis pelas ZEs cursariam com aumento de parâmetro na RT2 devido à desorganização estrutural e ao aumento da hidratação. Além disso, já foi demonstrado que pacientes com epilepsia focal apresentam alterações na RT2 não apenas nas regiões de anormalidade estrutural identificáveis na RM, mas também em regiões a elas distantes. Entretanto, essas anormalidades não podem simplesmente ser atribuídas como secundárias aos efeitos das crises epilépticas, 
permanecendo assim um tanto quanto inespecíficas e de etiologia indeterminada (BRIELLMANN et al., 2004).

\subsubsection{Imagem de transferência de magnetização: ITM}

O fenômeno de transferência de magnetização (TM) baseia-se na interação entre os prótons de água livre e os prótons ligados às macromoléculas, por exemplo, a mielina (HENKELMAN; STANISZ; GRAHAM, 2001). As imagens de RM convencional têm como fonte principal de contraste o comportamento magnético dos prótons de água livre ("população de prótons livres"). Não obstante, apesar de sua desprezível contribuição para a formação das imagens convencionais por seu curto tempo de relaxação transversal, os prótons ligados às macromoléculas ("população de prótons ligados") exercem influência sobre os prótons livres, modificando suas características magnéticas. Dessa forma, se aplicado um pulso de transferência de magnetização (pulso de radiofrequência dito fora de ressonância, em especial da água livre) que afete diretamente aos prótons ligados, esses trocam parte de sua magnetização com os prótons livres. Assim, apesar dos prótons ligados à macromolécula serem invisíveis nas imagens de RM, ao aplicar esse pulso de radiofrequência, há uma transferência de energia para as moléculas de água livre vizinhas, que são identificadas nas imagens, saturando-as parcialmente e reduzindo assim o sinal detectado. Nessa técnica quantitativa são adquiridas duas imagens, uma com um pulso de transferência de magnetização aplicado precedente à imagem (Mcom) e outra sem esse pulso (Msem). Consequentemente, se subtrairmos as duas imagens teremos uma estimativa da fração de prótons ligados em uma determinada amostra. Faz-se a diferença percentual entre ambas as imagens por um cálculo matemático, pixel a pixel, sendo representada pela seguinte fórmula e chamada de taxa de transferência de magnetização (TTM):

$$
\mathrm{TTM}=(\text { Mcom }- \text { Msem }) / \text { Mcom * } 100
$$

Dessa forma, pode-se elaborar um mapa das diferentes regiões de interesse do encéfalo em que os valores de cada pixel representam a porcentagem de perda de sinal provocada por este fenômeno de transferência de magnetização. Como no 
encéfalo as principais macromoléculas são proteínas e esfingolípides encontradas nas membranas dos axônios e da mielina. Quando há uma desorganização do tecido encefálico, como na morte/perda neuronal e desmielinização, o valor da TTM tende a diminuir proporcionalmente.

Essa técnica já é bastante utilizada na prática clínica diária de modo qualitativo para melhorar o contraste em exames de angiorressonância e em imagens após a administração endovenosa do contraste paramagnético com intuito de facilitar a visualização do realce em lesões cerebrais (Figura 11).

FIGURA 11: Exemplo da utilidade do pulso de transferência de magnetização após contraste via endovenosa em uma criança com quadro de encefalite herpética. Notase que o realce pelo gadolínio é mais bem visualizado na imagem com pulso de transferência de magnetização $(B)$ do que na imagem sem o pulso (A).
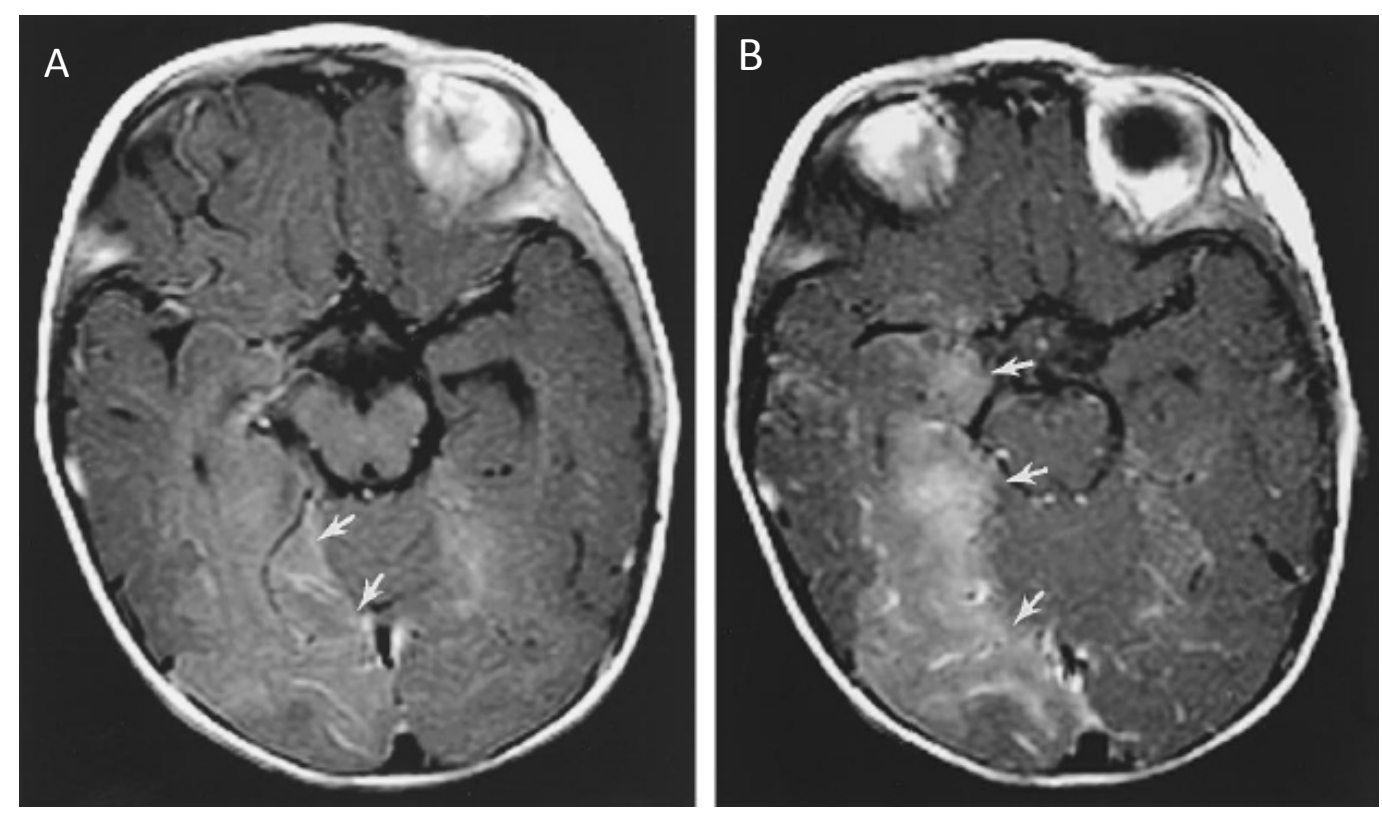

() 2017 AD Elster, ELSTER LLC

All rights reserved.

Fonte disponível em http://mriquestions.com/mt-imagingcontrast.html (Acesso em: 20/02/2017).

Outra grande aplicação desta técnica, agora de forma quantitativa, é no estudo de doenças que acometem a substância branca encefálica, tendo sido amplamente utilizada na esclerose múltipla por ser uma doença desmielinizante que acomete progressivamente este tecido cerebral. Em pacientes com esta doença, estudos já demonstraram diferenças significativas de TTM mesmo na substância 
branca dita com "aparência normal" quando comparada com indivíduos saudáveis, o que indica um envolvimento mais difuso do que parece existir nas imagens convencionais (VAN BUCHEM et al., 1998).

Estudos mais recentes têm sugerido que este método também pode ser útil na deteç̧ão de DCF sútil e de difícil caracterização nas técnicas convencionais (VEZINA, 2011). Isto ocorre porque essas lesões corticais estão acompanhadas frequentemente de um desarranjo da substância branca marginal (mielina), o que determina uma queda na TTM nesta região em comparação com uma substância branca saudável, podendo facilitar a visualização de uma alteração estrutural, inclusive de forma qualitativa (Figura 12).

FIGURA 12: Exemplo da utilidade do pulso de transferência de magnetização em um paciente com epilepsia focal e duvidosa lesão cortical. A) Imagem axial ponderada em T2, evidenciando um discreto e até mesmo duvidoso espessamento cortical focal (seta), possivelmente relacionado a uma displasia cortical focal. B) Imagem axial de transferência de magnetização no mesmo nível de corte da sequência anterior, evidenciando claramente uma banda curvilínea de sinal aumentado anormal (seta) e confirmando o achado como patológico.
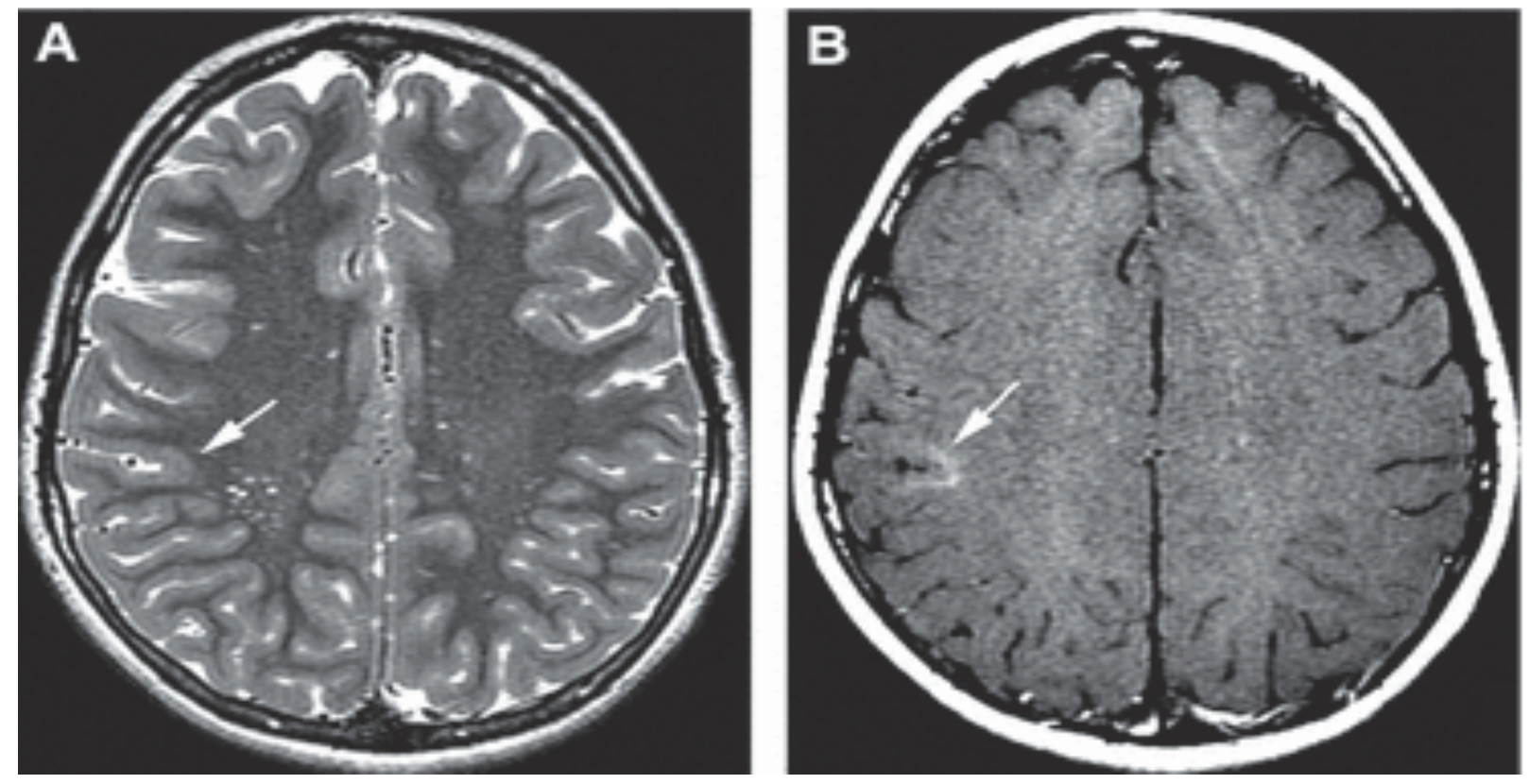

Louis-Gilbert Vézina. Epilepsia. 2011 Jul; 7(52): 25-27

Copyright (๑) 2011 Epilepsia

Fonte disponível em http://onlinelibrary.wiley.com/doi/10.1111/j.1528-1167.2011.03147.x/full (Acesso em: 01/03/2017). 


\subsubsection{Outras sequências mais recentes de imagem por RM}

Além das sequências descritas até agora, que são mais comumente passíveis de análises quantitativas, existem outras não rotineiramente utilizadas que podem aumentar a detecção de lesões corticais nos exames de RM devido à capacidade de melhorar a diferenciação entre as substâncias branca e cinzenta. Entre elas, destacam-se: STIR (Short time inversion recovery), sequência volumétrica (3D) FLAIR e GMO (Gray-matter only ), que utiliza-se de dupla inversãorecuperação (DIR). As sequências de inversão-recuperação são utilizadas para suprimir o sinal de algum tecido específico com objetivo de facilitar a identificação de alterações patológicas que acometem as diversas estruturas do corpo humano, ou seja, no intuito de aumentar a sensibilidade na detecção de certos tipos de lesões em avaliações qualitativas e, por vezes, até mesmo quantitativas.

A sequência STIR, apesar de rotineiramente utilizada em alguns protocolos, geralmente apenas é realizada no plano coronal, quando o seu objetivo principal é detectar a maior causa de EFRTM, a esclerose temporal mesial (SCHMIDT; POHLMANN, 2011). Trata-se de uma sequência que elimina o sinal da gordura ao mesmo tempo em que há um aumento da intensidade de outras estruturas, proporcionalmente ao aumento do conteúdo da água. Portanto, é capaz de melhorar a diferenciação entre as substâncias branca e cinzenta, além de poder aumentar a deteç̧ão de patologias que envolvem tipicamente essas regiões, por exemplo a DCF. Dessa forma, sua utilização neste grupo de pacientes não precisa ficar restrita para a avaliação dos hipocampos e pode ser expandida para avaliar todo o encéfalo em dois ou mais planos ortogonais, sendo o coronal e o axial bastante difundidos.

A forma volumétrica do FLAIR com cortes muito finos (milimétricos), que permitem reconstruções nos diversos planos, ainda não é amplamente difundida, pois grande parte das máquinas de RM não a possui, o que a faz ser uma considerada técnica avançada. Embora a utilização desta sequência em um ou dois planos, geralmente os axiais anatômicos e coronal perpendicular aos hipocampos, detecte grande parte dessas alterações epileptogênicas, lesões menores podem passar despercebidas enquanto lesões maiores podem ser mal delineadas (SAINI et al., 2010). 
O trabalho publicado em 2010 sugere que o FLAIR 3D pode auxiliar na investigação diante de uma alta suspeita para DCF, especialmente quando ocultas em protocolos convencionais de RM, podendo também ser usada para definir mais precisamente a extensão de uma lesão já previamente identificada (Figura 13). As características de imagem da DCF analisadas neste trabalho foram: EC, intensidade de sinal cortical, anormalidade de sinal da substância branca e anormalidade de sinal da JBC. Ao avaliar nove pacientes com epilepsia focal, verificou-se ser possível melhorar a avaliação anatômica com essa técnica em todos os indivíduos. Acrescese que, em três dos pacientes nos quais o protocolo rotina para epilepsia de RM foi normal, o FLAIR 3D ajudou na identificação das lesões. Ainda neste estudo, um destes três pacientes foi submetido a cirurgia, e a avaliação histopatológica revelou DCF. 
FIGURA 13: Exemplo de lesão identificada apenas com a sequência 3D FLAIR. Sequências axial FLAIR não volumétrico $(A)$, coronal T2 não volumétrico $(B)$ e reconstrução coronal T1 3D (C) sem evidências de lesão estrutural. Entretanto, com a realização da sequência FLAIR 3D reconstruída nos planos axial (D), sagital (E) e coronal $(F)$, foi possível evidenciar, de forma clara, um espessamento focal, assim como hipersinal da substância branca adjacente, achados esses quase patognomônicos de uma displasia cortical focal (setas brancas) e provavelmente relacionada à zona epileptogênica do paciente em questão. FLAIR: Fluid attenuated inversion-recovery.

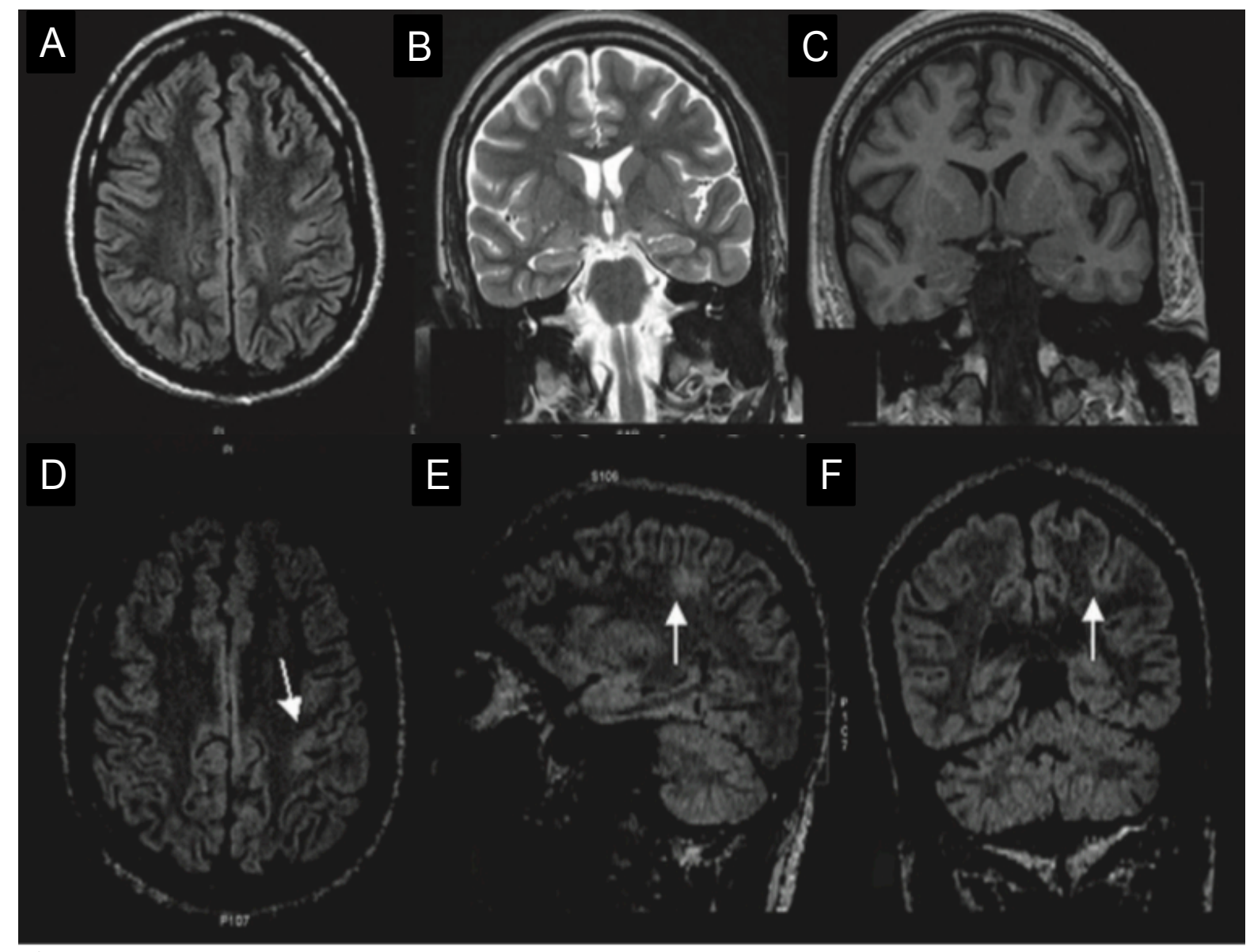

Saini J. Acta radiol.

2010 Mar;51(2):218-25

Copyright @ 2010 , @ SAGE Publications

Fonte disponível em http://journals.sagepub.com/doi/pdf/10.3109/02841850903433805 (Acesso em: 06/03/2017).

A sequência GM0 utiliza dois pulsos de inversão-recuperação que suprimem os sinais da água com longos tempos de relaxação (líquor) e da substância branca, aumentando ainda mais a diferenciação entre as substâncias branca e cinzenta. 
Dessa forma, esta técnica tem potencial para aumentar a sensibilidade da detecção de patologias corticais e justacorticais. Estudo recente utilizando esta sequência de dupla inversão-recuperação demonstrou que a sua forma volumétrica foi superior ao FLAIR para a detecção de metástases localizadas na substância cinzenta (66.7\% vs. 48.1\%) (CHEN et al., 2012).

Em pacientes com esclerose múltipla, achados semelhantes no que se refere ao aumento da sensibilidade já haviam sido descritos (GEURTS et al., 2005). Este estudo mostrou aumento na detecção de lesões intracorticais e no número total de lesões, além de uma melhora na diferenciação entre as lesões justacorticais e da substância branca propriamente dita em comparação às sequências denominadas de convencionais. Na avaliação dos pacientes com epilepsia, a utilização da sequência GM0 também parece ser vantajosa. Outro estudo publicado em 2006 avaliou quatro pacientes com esclerose tuberosa e concluiu haver uma melhor visualização de todas as lesões corticais pelo aumento do brilho, além do fato de três lesões corticais de dois pacientes terem sido visualizadas apenas nesta sequência especificamente (COTTON; RAMBAUD; HEMIER, 2006).

\subsection{Técnicas de pós-processamentos das imagens por RM na epilepsia}

Com os parâmetros extraídos das técnicas avançadas anteriormente apresentadas, além das medidas da espessura cortical (EC) e da avaliação da transição branco-cinzenta classicamente utilizando-se da sequência volumétrica adquirida em T1, podemos, por meio das novas ferramentas de pósprocessamentos, realizar avaliações quantitativas e comparar regiões corticais entre indivíduos após os cérebros serem colocados em um espaço comum (grupo versus grupos e notadamente indivíduo versus grupo). Também podemos potencialmente evidenciar lesões sutis não detectáveis habitualmente na inspeção visual no protocolo rotina para epilepsia (MARTIN; BENDER; FOCKE, 2015).

Os pós-processamentos de sequências de ressonância magnética para diagnósticos individualizados utilizam-se basicamente de dois modelos: as medidas baseadas em voxel e as medidas do córtex cerebral baseadas na superfície. 


\subsubsection{Análise das medidas baseadas em voxel: VBA}

Uma maneira interessante de fazer estas comparações regionais é, por meio da elaboração de mapas paramétricos com inferências estatísticas específicas de um determinado voxel, saber em quais regiões do cérebro seriam esperadas eventuais respostas ou alterações. Voxel é o menor ponto tridimensional de uma imagem. Essa análise baseada em voxel (VBA) pode ter como fonte as diversas técnicas apresentadas, isto é, medidas do voxel baseadas em morfometria (Voxelbased morphometry - VBM), medidas do voxel baseadas em relaxometria (VBR) e assim por diante (MARTIN; BENDER; FOCKE, 2015; ASHBURNER; FRISTON, 2000).

Inicialmente os estudos envolvendo técnicas quantitativas eram somente realizados pela segmentação manual por meio de desenhos em regiões de interesse, o que limitava bastante o estudo quando o objetivo maior exploratório era justamente identificar alterações estruturais não visíveis e não apenas aprofundar a avaliação de patologias já previamente identificadas. Atualmente, estas avaliações são frequentemente realizadas pelo mapeamento estatístico paramétrico (SPM), um pacote de software disponível gratuitamente para $\circ$ MATLAB (http://www.nitrc.org/projects/spm/) que permite uma avaliação mais automatizada e padronizada. Isto possibilita realizar processamentos que forneçam características de um determinado parâmetro, além de obter novas informações a respeito da estrutura cerebral. Como já dito anteriormente, tais avaliações são conhecidas genericamente como medidas baseadas em voxel. Karl Friston começou o projeto do SPM por volta de 1991 e, após, muitas mudanças foram feitas entre cada lançamento de atualização. Principalmente, novos componentes e recursos foram sendo introduzidos, e os bugs corrigidos, sempre com o objetivo de tornar a vida mais fácil para os usuários (ASHBURNER, 2012).

Para essas análises estatísticas entre indivíduos diferentes, os exames de RM precisam ser combinados espacialmente. As diferentes regiões são expandidas e/ou contraídas para se ajustarem a um espaço-padrão ou modelo. Esse espaço pode ser criado por uma média de um grande número de exames, e todo esse processo é conhecido como "normalização espacial". Diferentes algoritmos podem ser usados para executar este registro, mas eles normalmente incluem uma transformação não linear. Não se trata de um processo acrítico, dado que uma 
"normalização espacial" 'perfeita' nivelaria todas as diferenças estruturais entre cérebros individuais. Para ajustar isto, pode ser aplicado um passo posterior, denominado modulação, no qual a quantidade de substância encefálica é corrigida de acordo com o grau de contração ou expansão durante a "normalização espacial", de modo que a quantidade total de matéria permanece a mesma que na imagem original. Outro passo importante é a segmentação em diferentes compartimentos teciduais (geralmente substância cinzenta, substância branca e líquido cefalorraquidiano), de modo que a cada voxel é atribuída uma probabilidade de pertencer a uma determinada classe ou compartimento tecidual. Como um terceiro passo, as imagens precisam ser "suavizadas", um método adicional para diminuir a variação entre diferentes cérebros e aumentar a relação sinal-ruído. A etapa de "suavização" é, além disso, necessária para permitir que os dados melhor se adaptem ao modelo de campos aleatórios gaussianos, que é uma suposição básica para a maioria das análises estatísticas voxel a voxel. Após esses passos iniciais de pós-processamento mencionados em alguns textos, bem como o préprocessamento, faz-se a análise estatística.

A análise estatística é geralmente baseada em uma abordagem univariada (um único teste aplicado repetidamente a todos os voxels) desses mapas de probabilidade. Como esta análise de voxel por voxel compreende cerca de 1.400 .000 voxels (em resolução de $1 \mathrm{~mm}$ ) e o mesmo número de testes, é necessário corrigir o problema de testes múltiplos ou múltiplas comparações, de modo a reduzir resultados falso-positivos. Para isso, são adotados critérios mais restritivos para a definição da significância estatística como os índices FDR (false discovery rate) e FWE (Family-wise error).

\subsubsection{Medidas do voxel baseadas em morfometria}

A técnica VBM utiliza sequências estruturais volumétricas tipicamente ponderadas em T1 para identificar diferenças anatômicas entre grupos e tem sido aplicada a diferentes doenças, inclusive neurodegenerativas e psiquiátricas, distúrbios do movimento, esclerose múltipla e, finalmente, epilepsia, o que favorece a compreensão de como o cérebro muda nestes distúrbios e como essas mudanças cerebrais se relacionam com aspectos clínicos característicos (WHITWELL, 2009). 
As análises morfométricas realizadas no SPM/MATLAB no contexto dos pacientes com epilepsia buscam ampliar os recursos de identificação de lesões, notadamente a DCF e outras MDC, pela caracterização automatizada das substâncias cinzenta e branca, assim como pela transição entre as mesmas (HUPPERTZ et al., 2005).

Huppertz et al. (2005), utilizando-se do software de mapeamento estatístico paramétrico SPM99 e da sequência de RM 3D T1, avaliaram a junção entre as substâncias branca e cinzenta do cérebro (JBC) em 25 pacientes operados por epilepsia crônica e com DCF comprovada histologicamente. Neste estudo, compararam a JBC baseada em voxel de um paciente versus uma base de dados composta por indivíduos saudáveis. Apesar de não caracterizarem o borramento da JBC em todos os 25 pacientes (21/25), os autores concluíram que o pósprocessamento melhora a visualização da DCF e pode fornecer uma valiosa ferramenta diagnóstica adicional na avaliação pré-cirúrgica de pacientes com epilepsia. Esta conclusão embasou-se principalmente pela inclusão de quatro casos com lesões não reconhecidas ou reconhecidas incompletamente nos exames de RM com protocolo "convencional".

Outro estudo mais recente comparou a técnica VBM utilizando o programa SPM5 com a análise visual convencional de um neurorradiologista experiente (WAGNER et al., 2011). Foram avaliados 91 pacientes com DCF2 (Ila, $\mathrm{n}=17$, Ilb, $\mathrm{n}=74$ ) comprovadas histologicamente, e os avaliadores tiveram as mesmas informações clínicas (eletroencefalografia e semiologia), mas ficaram cegos em relação aos resultados de cada um. Para a análise VBM, criaram-se mapas denominados 'imagem de extensão' e 'imagem de junção' através da distribuição da substância cinzenta e branca analisada numa base de voxel e comparada com uma base de dados normal que consistia de 150 controles (70 mulheres, 80 homens, idade média na realização da RM de 30,9 anos, com intervalo de 15-77 anos). Os exames de RM foram adquiridos em cinco aparelhos distintos. Comparou-se o mapa de cada indivíduo com o mapa gerado pelos indivíduos do grupo-controle com base no desvio-padrão. A taxa de detecção de DCF utilizando o VBM foi superior à análise visual convencional no subgrupo lla (82\% versus $65 \%)$, e não houve diferença no subgrupo Ilb (92\% versus 91\%). No entanto, a combinação de análise visual convencional e análise morfométrica forneceu informações complementares e detectou 89 dos 91 das DCFs (98\%). Além disso, essa combinação foi 
significativamente superior à análise visual convencional isolada em ambos os subgrupos $(94 \%$ versus $65 \%, \mathrm{P}=0,031$ para o subgrupo $1 \mathrm{la}, 99 \%$ versus $91 \%, \mathrm{P}=$ 0,016 para o subgrupo Ilb). Concluiu-se, então, que a aplicação adicional da análise morfométrica de RM aumenta a sensibilidade diagnóstica para a DCF2 em comparação com a análise visual convencional isolada, que suporta a aplicação da análise VBM em todos os pacientes RM-negativos após a análise visual convencional no centro de realização do estudo.

O VBM também já se mostrou satisfatório na identificação de DCF no polo temporal em pacientes com esclerose temporal mesial, comparando um paciente versus um grupo-controle no trabalho de Pail et al. (2012). Os autores avaliaram neste estudo 18 pacientes submetidos à ressecção temporal anteromesial. A esclerose do hipocampo foi confirmada no exame histopatológico pós-operatório em todos os pacientes, e uma MDC foi revelada em 11 deles. Os resultados do VBM estavam em congruência com a presença/ausência de DCF em 13 pacientes (72,2\%). O VBM se mostrou falso-negativo em um paciente e falso-positivo em outros quatro. Na maioria dos casos positivos o VBM revelou aumento de substância cinzenta no local. A inspeção visual da RM sugeriu sinais de MDC no polo temporal em 11 casos (quatro falso-negativos e quatro falso-positivos). Essa abordagem visual detectou corretamente presença/ausência de MCD temporopolar em 10 pacientes $(55,6 \%)$. Ou seja, enquanto esta correspondência foi significativa ( $p=$ 0,047 ) na congruência entre presença/ausência de lesão no polo temporal e avaliação do VBM ela não foi significativa para a análise visual e prova histológica.

Alguns trabalhos recentes utilizaram outras sequências volumétricas estruturais, como T2 e FLAIR, e até mesmo descreveram uma maior sensibilidade para diferenças sutis de intensidade de sinal das DCFs em comparação com as sequências volumétricas ponderadas em T1 (HOUSE et al., 2013; RINEY et al., 2012).

\subsubsection{Técnicas avançadas}

Como já mencionado, as comparações regionais por meio da elaboração de mapas paramétricos, com inferências estatísticas específicas de um determinado voxel, podem ter como base as diversas técnicas avançadas. 


\subsection{Relaxometria T2 (RT2)}

A técnica chamada VBR baseia-se na comparação estatística ao nível do voxel dos dados quantitativos retirados dos mapas de RT2 que podem ser utilizados para identificar regiões com variação significativa no tempo de relaxação T2 (Figura 14) (PELL et al., 20014; KOSIOR et al. 2012; RUGG-GUNN et al., 2012).

FIGURA 14: Análise da relaxometria baseada em voxel em uma paciente com suspeita de epilepsia do lobo temporal esquerdo. A) Coronal FLAIR mostrando um alargamento da amígdala esquerda questionável. B) O mapa da relaxometria analisada voxel a voxel com limiar de $\alpha=0,01$ sobreposta no cérebro normalizado espacialmente ( $3^{\circ}$ eco normalizado) mostra uma anormalidade no lobo temporal esquerdo, incluindo a amígdala, e ajuda a confirmar o foco presumido da crise epiléptica. FLAIR: Fluid attenuated inversion-recovery.
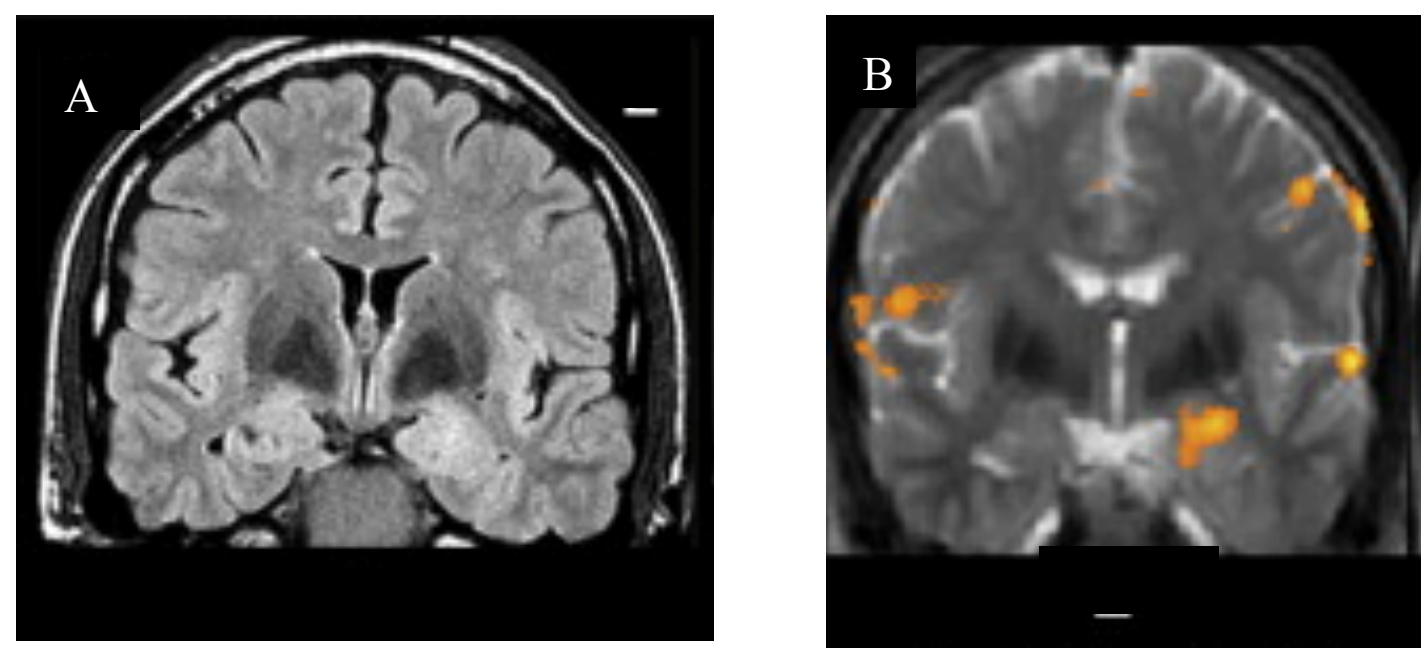

Kosior R et al. Epilepsy Res. 2012 Mar;99(1-2):46-54.

(อ2012 Epilepsy Res

Fonte disponível em http://www.epires-journal.com/article/S0920-1211(11)00322-6/abstract (Acesso em: 20/02/2017).

Rugg-Gunn et al. (2005) estudaram três grupos de pacientes com epilepsia com base no mapeamento de RT2 e o SPM na análise VBR de um indivíduo versus um grupo de controle. Foram 14 pacientes com crises epilépticas focais e lesões adquiridas visíveis na RM, 20 pacientes com malformações corticais visíveis na RM e 45 com RM convencional sem evidências de lesões. Esta análise estatística voxel- 
a-voxel identificou regiões de sinal T2 aumentado em todos os 14 pacientes com lesões cerebrais adquiridas e em 18 dos 20 pacientes com MDC (90\%). Já no grupo dos pacientes com RM negativa, observou-se aumento do sinal T2 em 23 dos 45 pacientes, sendo que, em 20 destes, as áreas de aumento do sinal T2 coincidiram com as anormalidades do EEG e semiologia das crises epilépticas. Ou seja, houve um incremento de rendimento na detecção de 20/45 (51\%) utilizando a técnica VBR através do SPM na análise individualizada de um paciente versus um grupo-controle de indivíduos normais. Além disso, essa técnica foi relativamente sensível naqueles com lesões visíveis na RM.

Outro trabalho mais recente de Kosior et al. (2012) também procurou avaliar o desempenho unicamente desta técnica (VBR), utilizando-se de uma RM de 3T como ferramenta de diagnóstico para pacientes com epilepsia, cujo foco de origem das crises era incerto. Neste estudo foram avaliados 59 pacientes: 32 com foco suspeito pela avaliação semiológica e EGG e 45 controles saudáveis. Dividiu-se, primeiramente, cada hemisfério cerebral em 13 regiões predefinidas e determinou-se o escore VBR com base na presença de anormalidades em qualquer uma dessas regiões. Todos os pacientes apresentaram anormalidades significativas nas medidas do VBR em comparação com o grupo-controle e $70 \%$ tiveram alterações nas medidas do VBR no foco suspeito, observando-se também outras regiões adicionais alteradas a serem elucidadas. Por fim, a técnica de VBR ainda previu corretamente os focos de origem das crises em $50 \%$ dos pacientes, os quais foram confirmados com base no histórico de acompanhamento e nas investigações clínicas.

\subsection{Taxa de transferência de magnetização (TTM).}

Outro estudo de Rugg-Gunn et al. (2003) buscou testar a hipótese de que a imagem por transferência de magnetização analisada voxel a voxel pudesse identificar regiões com taxa de transferência de magnetização anormal em pacientes com epilepsia focal. Este trabalho avaliou tanto pacientes que apresentavam alterações estruturais nos exames de RM quanto aqueles com exames de RM normais, comparando-os a um grupo-controle de 30 indivíduos. Foram identificadas reduções significativas de TTM em todos os 10 pacientes com lesões cerebrais adquiridas não progressivas e em 13 dos 15 com malformações corticais, sempre correspondendo com as anormalidades identificadas na inspeção visual de RM 
convencional. Além disso, o trabalho mostrou redução significativa do TTM em 15 dos 42 pacientes com epilepsia focal dita criptogênica, ou seja, sem alteração estrutural visível. Em todos eles, as áreas de redução da TTM apresentaram concordância com a anormalidade epileptiforme vista no EEG e/ou em semiologia clínica. Entretanto, apareceram outras regiões com TTM anormal na avaliação voxel a voxel, que eram normais nos exames de imagem convencional e não demonstraram correspondência com os achados do EEG.

Estudo mais recente de Salmenpera et al. (2007) também abordou a técnica VBA, utilizando-se, por exemplo, da TTM, além de outros métodos quantitativos. Assim como o trabalho apresentado anteriormente, este também fez uma avalição individualizada pelo mapeamento estatístico paramétrico, comparando um indivíduo versus um grupo-controle de 26 voluntários (13 homens, idade média de 33 anos e faixa 20-56 anos). Foram incluídos pacientes com epilepsia focal refratária, que eram potenciais candidatos cirúrgicos e apresentaram RM negativa para alterações estruturais. As anormalidades encontras na TTM pela VBA foram totalmente concordantes em pacientes com foco único no VEEG do couro cabeludo em apenas 5\% (4/77). Embora a taxa de concordância tenha sido baixa, os autores sugeriram cautela com os dados, pois nos pacientes positivos essa avaliação pode auxiliar na investigação dos focos epileptogênica e até mesmo guiar a colocação de eletrodos intracranianos.

\subsection{Imagem por tensor de difusão (DTI)}

Thivard et al. (2005) também estudaram pacientes com crises focais refratárias ao tratamento medicamentoso e que poderiam se beneficiar de cirurgia. Neste estudo, o objetivo foi saber se a sequência DTI poderia ser uma alternativa não invasiva para localizar a ZE ou, pelo menos, indicar a colocação de eletrodos intracerebrais para o SEEG quando o prosseguimento para uma investigação mais invasiva fosse necessário. Foram avaliados 16 pacientes, apenas dois com alterações potencialmente epileptogênicas na RM. Utilizou-se do método VBA e do software SPM99 com os parâmetros retirados da sequência DTI realizada em todo o cérebro para avaliar objetivamente as propriedades de difusão. Para isso, foram calculados mapas individuais do ADC ou DM e AF, e comparados com um banco de dados de voluntários saudáveis. O grupo-controle deste estudo incluiu 40 voluntários 
saudáveis (15 mulheres, 25 homens, idade média: 33,4 anos \pm 9,8 e faixa etária de 18 a 59 anos) sem história de distúrbios neurológicos e com RM padrão normal. Todos foram investigados com SEEG. A zona epileptogênica suspeita foi temporal em 10 pacientes, frontal em dois e occipital em quatro. Treze dos 16 pacientes (13/16) apresentaram anormalidades de difusão, sendo que o ADC (DM) alterado apresentou melhor correlação com os dados do SEEG, enquanto os achados anormais de AF foram geralmente encontrados em localizações mais distantes das regiões suspeitas de serem a ZE. Em 11 pacientes (11/16) identificou-se alguma região de aumento significativo do $A D C$ e, em 7 (7/16) deles, esta região foi a mesma explorada com eletrodos intracranianos. Os autores concluíram que os resultados sugerem que esta avaliação, em especial o ADC (DM), pode ser útil e fornecer dados espaciais sobre a localização e extensão da rede epileptogênica, notadamente nas epilepsias extratemporais.

Chen et al (2008) também buscaram verificar se o DTI poderia ajudar na localização da ZE em pacientes com epilepsia crônica e RM negativa. Neste estudo foram avaliados 15 pacientes por meio da aplicação da técnica VBA, utilizando-se dos parâmetros retirados da sequência de DTI: DM e AF. Foram elaborados mapas e realizada uma comparação individual de cada paciente versus um grupo-controle de 40 voluntários saudáveis, usando valor- $\mathrm{p}<0,05$ corrigido. $O$ grupo de controle foi formado por 40 voluntários saudáveis ( 20 homens e 20 mulheres, idade média 30,5 anos $\pm 9,7$ anos e faixa etária de 16 a 52 anos). Verificaram-se regiões de aumento da DM em 13 pacientes (13/15), sendo que em sete deles (7/15) houve concordância com a origem eletroclínica das crises. Fez-se o estudo em aparelho de RM de 3T. Regiões com AF significativamente reduzida foram observadas em cinco pacientes (5/15), sendo que em dois deles (2/15) houve concordância com a localização eletroclínica das crises. Quer dizer, os resultados desse estudo também indicaram que a sequência DTI, juntamente com a técnica VBA, pode fornecer informações suplementares sobre as áreas epileptogênicas em pacientes com RM negativa e EFRTM e, portanto, ser útil na avaliação pré-cirúrgica.

\subsubsection{Medidas baseadas em superfície: SBM}

Outra forma de avaliação das regiões cerebrais é o grupo de técnicas que reconstroem e analisam a superfície cortical do cérebro, respeitando a geometria 
dos giros corticais (Surface-based morphometry - SBM). Essas técnicas têm o potencial de melhorar a detecção em relação à técnica VBM de lesões espacialmente restritas e escondidas nos giros cerebrais. Também podem ser realizadas de maneira automatizada, o que proporciona uma avaliação mais objetiva e reprodutível.

Um software bastante difundido e utilizado no estudo para o processamento da SBM é o FreeSurfer (Athinoula A. Martinos Center for Biomedical Imaging at Massachusetts General Hospital, Massachusetts, USA). As versões mais atuais deste programa permitem um procedimento totalmente automático para segmentação das substâncias cinzenta e branca, além de outras funcionalidades, como a segmentação cortical, volumetria subcortical e criação de registros interindivíduos. Uma das principais vantagens deste software é a existência de dezenas de artigos que evidenciam resultados robustos em termos das medições. Há, inclusive, um trabalho publicado recentemente que mostra uma correlação satisfatória entre a medida da EC neste processamento, utilizando-se de uma sequência estrutural 3D T1 com a EC obtida na medida histológica (CARDINALE et al., 2014). Este artigo evidenciou, mais especificamente, uma boa concordância entre essas medidas em 27 amostras de regiões cerebrais ressecadas de pacientes com epilepsia, o que reforça a precisão do método.

Esta técnica SBM, baseada em algoritmos computacionais, permite avaliar a espessura e o volume da camada cortical que, devido às suas circunvoluções, podem representar uma dificuldade na inspeção visual (FISCHL; DALE, 2000). Ou seja, esses métodos de segmentação e de medidas da EC têm potencial de melhorar a detecção das malformações corticais, em particular das DCFs, que representam uma parcela significativa das causas de epilepsia focal, notadamente das neocorticais, e, portanto, poderão ser utilizados na prática durante as avaliações pré-operatórias desses pacientes. Além disso, o software FreeSurfer possibilita uma forma de visualização das regiões do córtex alteradas (espessamento ou afilamento) chamada QDEC, que se trata de um algoritmo de apresentação, utilizando-se de um protótipo de um cérebro inflado, onde tais regiões aparecem coloridas de acordo com o nível de significância e tipo de alteração (espessamento ou afilamento). Essa forma de apresentação facilita a identificação de tais alterações na inspeção visual (Figura 15). 
FIGURA 15: Displasia cortical focal, espessura cortical e FreeSurfer. A) Uma imagem axial ponderada em T2 demonstrando um espessamento focal do córtex parietal direito (setas brancas). B) Análise automatizada da espessura cortical gerada pelo FreeSurfer, usando uma imagem volumétrica T1. Essas medidas mostram claramente uma área focal de espessamento cortical significativo na região parietal superior direita que corresponde à lesão observada na sequência ponderada em T2.
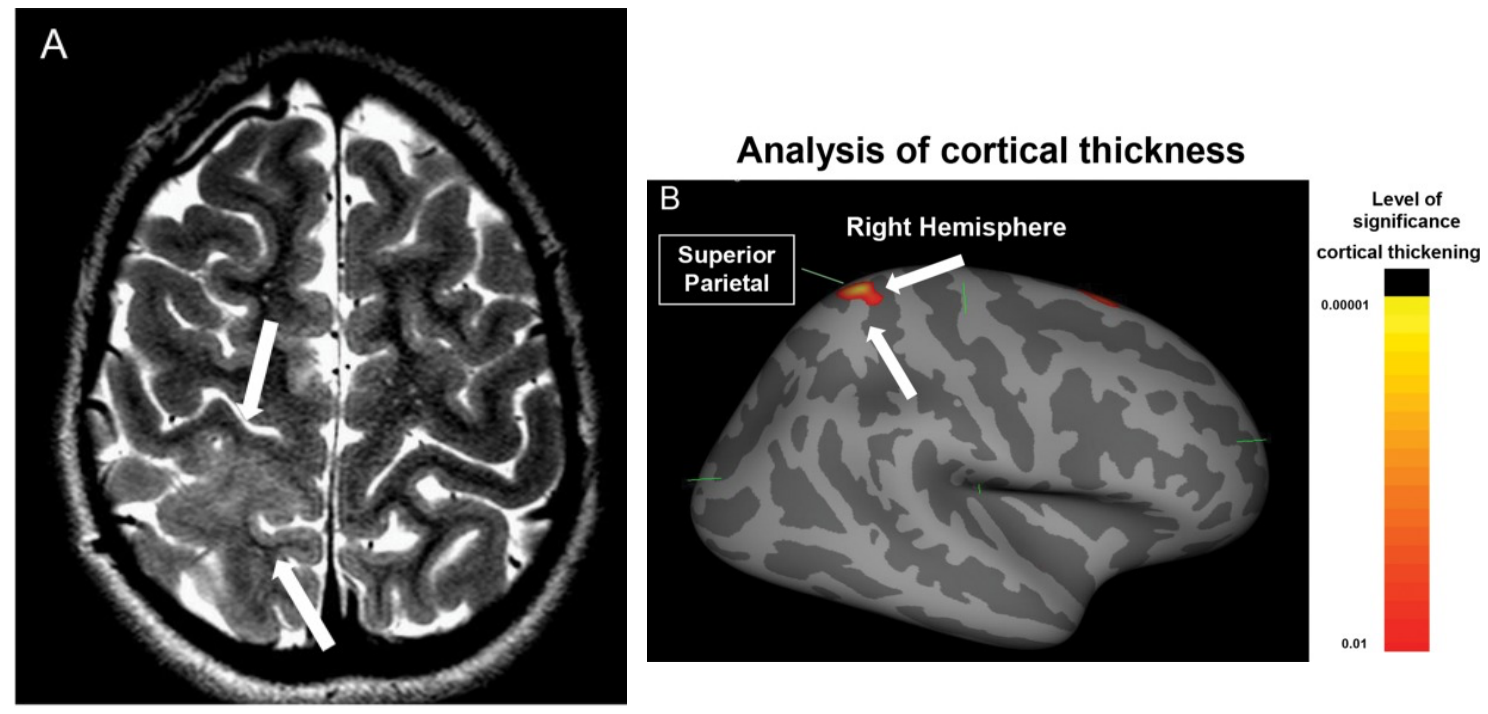

Lucas Abud et al. Clinics (Sao Paulo). 2015 Sep; 70(9): 654-661.

(C) 2015 Clinics

Fonte disponível em https://www.ncbi.nlm.nih.gov/pmc/articles/PMC4557590/ (Acesso em: 20/02/2017).

Além da EC relatada anteriormente, esse software consegue calcular ainda outros quatro parâmetros potencialmente utilizáveis na avaliação das epilepsias: i: EC; ii: contraste substância branca/cinzenta; iii: profundidade do sulco; iv: curvatura e v: distorção Jacobiana. i: EC: é a distância mais curta entre a superfície de substância branca à superfície pial. ii: Contraste entre as substâncias branca e cinzenta ( $C B C)$ : é o cálculo do contraste intensidade T1 não normalizada calculada 0,5 milímetros acima e abaixo da interface branco/cinzenta com interpolação trilinear das imagens. Os valores de CBC vão de -1 a 0 e, quando próximos de zero, indicam um grau mais elevado de borramento desta transição. iii: profundidade do sulco: é o cálculo da profundidade/altura de cada ponto acima da superfície normal. Os valores de profundidade vão de -2 a 2 , sendo que os mais baixos indicam sulco profundo 
enquanto os mais elevados apontam sulco raso. iv: Curvatura: medida como 1/R, em que $r$ é o raio de um círculo inscrito e curvatura média representa a média de duas curvaturas principais com uma unidade de $1 / \mathrm{mm}$. A média de curvatura quantifica a nitidez de dobragem cortical. v: Distorção jacobiana: trata-se de uma medida de deformação cerebral global que ocorre no processo de registo, em que as características dos giros e sulcos de cada sujeito são alinhadas por deformação de todo o cérebro para uma superfície esférica média ("cérebro normal"). Durante esse processo, cada vértice é submetido a uma transformação não linear esférica.

Em contrapartida, uma das principais desvantagens do uso desta técnica é o elevado tempo para concluir a análise de um indivíduo. Em uma arquitetura de múltiplos núcleos (AMD ${ }^{\mathrm{TM}}$ Phenon ${ }^{\mathrm{TM}} 9600 \times 4$ ), cada análise consome 20-33 horas/ indivíduo/núcleo de processador. Entretanto, essa desvantagem é relativa, pois as novas versões são, em geral, mais rápidas e, além disso, há uma dependência da capacidade de processamento de cada computador onde o trabalho é realizado.

No campo da epilepsia, inúmeros estudos utilizam-se das técnicas de medida da EC, segmentação, volumetria hipocampal e volumetria das camadas corticais" (DESPOTOVIC et al., 2011; THESEN et al., 2011; AKHONDI-ASL et al., 2011; MARTINS et al., 2016). Embora esse tipo de abordagem tenha sido bem mais amplamente debatida nas epilepsias do lobo temporal, testando esse processo como ferramenta auxiliar no diagnóstico da esclerose hipocampal ou temporal mesial, também já existem evidências da potencialidade desse método na detecção de lesões epileptogênicas neocorticais.

Thesen et al. (2011), por exemplo, testaram a técnica SBM através de sequência 3D T1 obtida em uma ressonância magnética de 3T e compararam pacientes com lesões únicas conhecidas $\mathrm{e}$, de forma individualizada, os compararam com um grupo de controle normal. O grupo-controle consistia de 41 indivíduos saudáveis, com faixa etária 19 a 66 anos, idade média de 36,4 anos e formado por 23 mulheres. Esse trabalho utilizou o pacote de software FreeSurfer e estudou 11 pacientes com epilepsia focal e anormalidades estruturais corticais na RM. Com a combinação dos parâmetros de EC e CBC, foi possível identificar $92 \%$ de lesões corticais (sensibilidade), com alguns falso-positivos $(96 \%$ de especificidade). Além disso, o trabalho afirma que a sensibilidade e especificidade foram superiores na avaliação da $E C$ do que na $C B C$, tendo sido, respectivamente, $100 \%$ e $84 \%$ para a EC, $61 \%$ e $78 \%$ para CBC. Ambos os parâmetros (EC e CBC) 
foram bastante superiores aos demais (curvatura, distorção Jacobiana, etc.) na amostra utilizada. As alterações estruturais detectadas foram relacionadas com as zonas de início das crises, a histologia anormal e o resultado positivo em todos os pacientes encaminhados para cirurgia. Entretanto, segundo o trabalho, o método não conseguiu descrever adequadamente a extensão da lesão na maioria dos casos.

Ainda lançando mão do arsenal disponível no pacote, FreeSurfer, Blackmon et al. (2015) avaliaram, entre outras variáveis, o aumento do CBC nas DCFs (tipos I, II e III) em 20 pacientes com comprovação histológica. Comparativamente à análise visual da RM convencional, houve aumento do rendimento diagnóstico de $70 \%$. Entretanto, para testar se essa diferença de CBC foi mais pronunciada na região ressecada e avaliada histopatologicamente, localizou-se manualmente a zona de ressecção, orientando-se pela RM pós-operatória.

Utilizando uma outra técnica SBM (segmentação anatômica Laplaciana restrita usando um algoritmo de proximidade) Hong et al. (2014) avaliaram a capacidade de detecção da DCF2 em pacientes com epilepsia extratemporal inicialmente diagnosticados como RM negativa na inspeção de rotina. A avaliação também foi individualizada, ou seja, a comparação foi de cada paciente versus o grupo-controle de normais. O método foi testado em 19 pacientes (15 com DCF histologicamente confirmada). Avaliaram-se nesse estudo a EC, a profundidade do sulco e curvatura da superfície cortical e a especificidade em 24 controles saudáveis e 11 controles de doença com epilepsia do lobo temporal. De acordo com os critérios utilizados (usando controles saudáveis e controles doentes para criação de um algoritmo complexo de aprendizado), a sensibilidade chegou a $74 \%$ e a especificidade a $100 \%$, isto é, não foram detectadas lesões em controles saudáveis.

\section{6 Justificativa do estudo}

Durante o acompanhamento dos pacientes com epilepsias, sempre que a cirurgia se mostra o melhor caminho na tentativa de eliminar ou reduzir o número de crises, há a necessidade de caracterizar o local da ZE com a maior precisão possível. Porém, persiste o problema de que uma parcela substancial de pacientes com EFRTM não apresenta lesão estrutural identificável na RM convencional. Além 
disso, mesmo que uma lesão potencialmente epileptogênica seja identificada pela RM, é preciso confirmar que ela seja realmente a causa das descargas elétricas cerebrais. Para isso, o VEEG de superfície e a semiologia clínica das crises devem ser rotineiramente realizados. Esses pacientes também podem ser encaminhados a outros estudos localizatórios não invasivos de medicina nuclear (tomografia por emissão de pósitrons/tomografia computadorizada ou PET-CT), ou mesmo a métodos invasivos como a colocação de placas subdurais e, mais recentemente, inserção de eletrodos intracranianos (SEEG).

De qualquer forma, a literatura é bastante clara ao afirmar que um estudo de RM considerado negativo é um fator indiscutível de pior prognóstico caso haja necessidade de cirurgia. Neste contexto, novas sequências avançadas de RM e técnicas de pós-processamentos surgem com a promessa de tentar melhorar a detecção das lesões epileptogênicas por este método. Apesar do grande número de trabalhos publicados na área de neuroimagem, utilizando RM, assim como de técnicas avançadas e análises quantitativas em pacientes com EFRTM e exames de imagem inicialmente normais, a literatura é escassa de estudos que avaliem vários métodos quantitativos e sequências avançadas em um mesmo grupo de pacientes.

Diante do exposto, a presente pesquisa buscou preencher essa lacuna por meio da realização de uma análise quantitativa individualizada, visando testar os limites da RM na identificação da ZE nesse grupo de pacientes. Esta avaliação quantitativa individualizada significa que um paciente será comparado a um grupocontrole na busca por regiões significativamente diferentes sob um determinado parâmetro. Além disso, procuramos realizar sequências adicionais a serem usadas para novas avaliações visuais qualitativas. Esse segundo grupo de sequências foi pensado com o intuito de oferecer ao paciente a possiblidade de alguma vantagem mais imediata.

Desse modo, com a autorização do Departamento de Epilepsia do Hospital das Clínicas da Faculdade de Medicina de Ribeirão Preto da USP (HCFMRP/USP), oferecemos a realização de uma RM suplementar, a qual denominamos de protocolo avançado. Esse protocolo avançado será pormenorizado na metodologia, mas basicamente inclui sequências 3D T1, DTI, RT2 e ITM para serem usadas nos pósprocessamentos quantitativos individualizados, além das sequências a serem utilizadas em novas avaliações qualitativas, sendo elas axial T2 STIR e axial GMO DIR com cortes finos, além de eventualmente sequências 3D FLAIR e GM0. 
Então, de maneira sucinta, o trabalho foi elaborado levando-se em consideração principalmente duas importantes questões. A primeira delas é que a não identificação de lesão na RM, a chamada RM negativa ou NLE, pode ser considerada um dos fatores prognósticos mais fortes para um desfecho desfavorável na eliminação ou redução do número de crises após cirurgia. A segunda é a escassez de estudos que apliquem várias medidas quantitativas de maneira individualizada num mesmo grupo de pacientes com EFRTM e RM negativa e que permitissem comparações mais diretas. 


\section{OBJETIVO(S)}

\subsection{Objetivos primários}

\subsubsection{Objetivos gerais}

O objetivo deste trabalho foi avaliar, por meio de um estudo prospectivo, o rendimento e a utilidade da RM quantitativa através de pós-processamentos individualizados em uma coorte de pacientes com EFRTM neocortical, potenciais candidatos à cirurgia, de lesionectomia e em acompanhamento como RM negativa para lesões epileptogênicas ou com achados sutis/inespecíficos, utilizando-se de grande parte do arsenal das técnicas avançadas.

Esse trabalho vislumbrou a possibilidade de avaliar se esses métodos quantitativos poderiam ser úteis não só para uma indicação cirúrgica mais precoce, sem a necessidade de procedimentos invasivos, o que encurtaria o tempo de investigação pré-operatória e das comorbidades inerentes ao processo investigatório, mas também como forma de orientar a colocação de placas e eletrodos intracranianos para a avaliação do EEG.

\subsubsection{Objetivos específicos}

Avaliar a correspondência entre os achados dos pós-processamentos quantitativos de RM e aqueles da avaliação eletroclínica no que se refere à localização de suspeição da ZE.

Avaliar se esses pós-processamentos podem influenciar no aumento da detecção de lesões estruturais neocorticais potencialmente epileptogênicas visíveis pelo método de RM convencional, porém que inicialmente pudessem passar despercebidas nas avaliações visuais por serem sutis.

\subsection{Objetivos secundários}

Além do objetivo principal, decidimos avaliar como foi o seguimento destes pacientes ao longo do trabalho, notadamente se houve alguma alteração no seu 
status no que se refere à RM. Ou seja, se algum paciente passou a ser considerado como RM lesional (RM LE) e o que influenciou esta mudança.

Nos eventuais casos em que fosse detectada alguma possível lesão estrutural potencialmente epileptogênica anteriormente não identificada, investigamos se alguma sequência adicional de RM propiciou esta detecção e se houve influência de algum direcionamento localizatório não relacionado aos pósprocessamentos quantitativos do estudo. 


\section{MATERIAIS E MÉTODOS}

Trata-se de um estudo prospectivo de uma coorte de pacientes com EFRTM em acompanhamento como RM negativa para lesões epileptogênicas ou com achados sutis/inespecíficos e potenciais candidatos à cirurgia.

O trabalho ocorreu no HCFMRP/USP, localizado no Campus Universitário, bairro Monte Alegre, CEP: 14048-900, no município de Ribeirão Preto-SP.

\subsection{Seleção dos pacientes}

Todos os pacientes com indícios de EFRTM mais possivelmente neocorticais que estavam em acompanhamento no Centro de Cirurgia de Epilepsia (CIREP) do HCFMRP/USP, que já haviam sido submetidos à monitorização com VEEG de longa duração e apresentavam exame de RM 3T realizado no centro de imagem da instituição, inicialmente considerado negativo para lesões epileptogênicas, e que apresentaram grande parte do acompanhamento précirúrgico como tal, foram considerados candidatos potenciais para o estudo. Foram mantidos no trabalho aqueles inicialmente incluídos apenas após diversas revisões e discussões interdisciplinares, e que necessitassem de orientação por outros métodos localizatórios para que houvesse suspeição ou identificação de lesões corticais discretas potencialmente epileptogênicas. Foi mantida a inclusão desses pacientes, visto que este grupo também pode ser beneficiado pela implementação de um protocolo que auxilie na identificação dessas lesões de forma mais ágil, encurtando assim o tempo de avaliação pré-cirúrgica, inclusive com redução de custos e potenciais morbidades, na medida em que seriam realizados menos procedimentos e exames com esse intuito, muitos deles invasivos. Todos os pacientes também foram avaliados por meio de exame neurológico completo, exame neuropsicológico, avaliação social e avaliação psiquiátrica.

O CIREP do HCFMRP/USP é considerado um polo brasileiro neste tipo de avaliação e atende pacientes de todo o Brasil, quase em sua totalidade pelo Sistema Único de Saúde - SUS. Este fato, embora seja motivo de orgulho para a instituição, impossibilita ou dificulta a realização de novos exames ainda não comprovadamente essenciais aos pacientes devido aos elevados custos financeiros e, principalmente, 
as dificuldades de transporte desses pacientes, muitos deles oriundos de um contexto socioeconômico típico de uma país ainda em desenvolvimento. A forma encontrada para contornar essa situação com intuito de não onerar o sistema nem os familiares e, sobretudo, evitar aumento dos agravos de saúde e psicológicos inerentes a esse tipo de desordem, foi conciliar o dia do exame do paciente com o retorno já agendado pelo ambulatório do CIREP - HCFMRP/USP entre março de 2010 e junho de 2016. Além disso, houve o cuidado de não prejudicar a rotina do departamento no manejo desses pacientes e, assim, o nosso estudo foi desenhado para andar em paralelo com o que já é padronizado pela instituição. Para que isso acontecesse, o pesquisador responsável entrou em contato com os pacientes, com os quais, a todo momento, manteve essa comunicação direta. Sempre que possível e/ou necessário (motivos cognitivos que impossibilitassem uma adequada compreensão), conversávamos também com um familiar responsável pelo tratamento. Não foram incluídos menores de 18 anos ou pacientes que necessitassem de anestesia para a realização do exame.

Importante reiterar que todos os pacientes incluídos já haviam sido submetidos ao menos a um exame de RM de $3 \mathrm{~T}$ no serviço de radiodiagnóstico do HCFMRP/USP, utilizando-se de sequências habitualmente empregadas na investigação desse grupo de doenças (protocolo rotina para epilepsia) e apresentavam suspeição semiológica e/ou eletrofisiológica para crises focais.

Seguindo toda essa estrutura proposta, conseguimos que 46 pacientes fossem submetidos a um novo exame de RM com as sequências complementares (protocolo avançado). O trabalho foi aprovado pelo Comitê de Ética e Pesquisa do HCFMRP/USP em março de 2011 (anexo A). Todos os pacientes assinaram o termo de consentimento livre e esclarecido (anexo B).

As características gerais dos pacientes estão resumidas na tabela 6 . Neste grupo de 46 indivíduos, 22 eram homens e 24 mulheres. A faixa etária foi de 20 a 51 anos, com média de 34,6 anos e desvio-padrão de 8,0 anos. Já a duração média das crises foi de 23 anos com desvio-padrão de 7,3 anos. 
TABELA 6: Características gerais dos pacientes.

\begin{tabular}{|c|c|c|c|c|c|c|c|c|}
\hline Paciente & Sexo & $\begin{array}{l}\text { Idade } \\
\text { (RM) }\end{array}$ & HPD & $\begin{array}{l}\text { Idade de } \\
\text { início } \\
\text { das } \\
\text { crises }\end{array}$ & $\begin{array}{l}\text { Tempo de } \\
\text { crise }\end{array}$ & $\begin{array}{c}\text { RM } \\
\text { inicial }\end{array}$ & $\begin{array}{c}\text { VEEG } \\
\text { Semiologia }\end{array}$ & Operado \\
\hline 01 & $\mathrm{~F}$ & 38 anos & NDN & 20 anos & 12 anos & ESLEC & NLSR & Não \\
\hline 02 & $F$ & 36 anos & NDN & 7 anos & 29 anos & ESLEC & LTD POST & Não \\
\hline 03 & $\mathrm{~F}$ & 22 anos & NDN & $<1$ mês & 21 anos & ESLEC & NLSR & Não \\
\hline 04 & $M$ & 41 anos & TCE PC & 15 anos & 26 anos & ESLEC & RFTE & Não \\
\hline 05 & $M$ & 30 anos & NDN & 4 anos & 26 anos & ESLEC & RFTE & Não \\
\hline 06 & $M$ & 20 anos & NDN & 6 anos & 14 anos & ESLEC & RRD MED & Não \\
\hline 07 & $\mathrm{~F}$ & 22 anos & PCSF & $<1$ ano & 21 anos & ESLEC & RFTE & Não \\
\hline 08 & $\mathrm{~F}$ & 25 anos & NDN & $<1$ ano & 24 anos & ESLEC & RFTD & Não \\
\hline 09 & $\mathrm{~F}$ & 34 anos & NDN & 15 anos & 19 anos & ESLEC & NLSR & Não \\
\hline 10 & $M$ & 30 anos & NDN & 13 anos & 17 anos & ESLEC & LFD RR & Não \\
\hline 11 & $M$ & 28 anos & NDN & 6 anos & 22 anos & ESLEC & LFD MED DL & Não \\
\hline 12 & $\mathrm{~F}$ & 26 anos & NDN & $<1$ ano & 25 anos & ESLEC & RRD & Não \\
\hline 13 & $\mathrm{~F}$ & 25 anos & NDN & $<1$ ano & 24 anos & ESLEC & LPD & Não \\
\hline 14 & $M$ & 32 anos & NDN & 12 anos & 20 anos & ESLEC & LFD & Não \\
\hline 15 & $\mathrm{M}$ & 38 anos & NDN & 29 anos & 20 anos & ESLEC & LTE & Não \\
\hline 16 & $M$ & 31 anos & TCE PC & 9 anos & 22 anos & ESLEC & HCD SR & Não \\
\hline 17 & $\mathrm{~F}$ & 27 anos & NDN & 13 anos & 14 anos & ESLEC & NLSR & Não \\
\hline 18 & $\mathrm{M}$ & 34 anos & INT. NEO & 12 anos & 22 anos & ESLEC & LFE & DCF IIb \\
\hline 19 & $\mathrm{M}$ & 36 anos & NDN & 7 anos & 29 anos & ESLEC & NLSR & Não \\
\hline 20 & $\mathrm{~F}$ & 31 anos & ISNC & 15 anos & 14 anos & ESLEC & RTPOE & Não \\
\hline 21 & $M$ & 39 anos & NDN & 22 anos & 17 anos & ESLEC & NLSR & Não \\
\hline 22 & $M$ & 51 anos & NDN & 12 anos & 39 anos & ESLEC & LTE POST & DCF la \\
\hline 23 & $\mathrm{~F}$ & 36 anos & TCE PC & 19 anos & 17 anos & ESLEC & NLSR & Não \\
\hline 24 & $M$ & 46 anos & NDN & 12 anos & 34 anos & ESLEC & RTPOE & Não \\
\hline 25 & $M$ & 22 anos & S. West & 8 anos & 14 anos & ESLEC & LFE & Não \\
\hline 26 & $\mathrm{M}$ & 39 anos & NDN & 4 anos & 35 anos & ESLEC & NLSR & Não \\
\hline 27 & $\mathrm{~F}$ & 38 anos & PCF & 2 anos & 36 anos & ESLEC & RFTE & Não \\
\hline 28 & $\mathrm{~F}$ & 46 anos & NDN & 25 anos & 21 anos & ESLEC & NLSR & Não \\
\hline 29 & $\mathrm{~F}$ & 46 anos & PCF & 12 anos & 34 anos & ESLEC & RTO NL & Não \\
\hline 30 & $\mathrm{~F}$ & 33 anos & NDN & 25 anos & 8 anos & ESLEC & RRE & Não \\
\hline 31 & $M$ & 33 anos & NDN & 5 anos & 18 anos & ESLEC & NLSR & Não \\
\hline 32 & $M$ & 36 anos & TCE PC & 10 anos & 26 anos & ESLEC & LPE & DCF Ila \\
\hline 33 & $\mathrm{M}$ & 31 anos & PREM & 5 anos & 26 anos & ESLEC & RFTD & Não \\
\hline 34 & $M$ & 37 anos & NDN & 11 anos & 26 anos & ESLEC & NLSR & Não \\
\hline 35 & $\mathrm{~F}$ & 32 anos & NDN & 11 anos & 21 anos & ESLEC & NLSR & Não \\
\hline
\end{tabular}




\begin{tabular}{ccccccccc}
\hline Paciente & Sexo & $\begin{array}{c}\text { Idade } \\
\text { (RM) }\end{array}$ & HPD & $\begin{array}{c}\text { Idade de } \\
\text { início } \\
\text { das } \\
\text { crises }\end{array}$ & $\begin{array}{c}\text { Tempo de } \\
\text { crise }\end{array}$ & $\begin{array}{c}\text { RM } \\
\text { inicial }\end{array}$ & $\begin{array}{c}\text { VEEG } \\
\text { Semiologia }\end{array}$ & Operado \\
\hline 36 & F & 47 anos & NDN & 11 anos & 36 anos & ESLEC & NLSR & Não \\
37 & F & 24 anos & PREM & $<1$ ano & 23 anos & ESLEC & NLSR & Não \\
38 & M & 44 anos & NDN & 23 anos & 21 anos & ESLEC & LTE & Não \\
39 & F & 34 anos & NDN & 19 anos & 15 anos & ESLEC & RRE MED & DCF Ilb \\
40 & F & 25 anos & NDN & 13 anos & 12 anos & ESLEC & LTD & Não \\
41 & F & 49 anos & NDN & 7 anos & 32 anos & ESLEC & LFD & Não \\
42 & M & 34 anos & NDN & 5 anos & 29 anos & ESLEC & RFTD & Não \\
43 & M & 45 anos & NDN & 16 anos & 29 anos & ESLEC & LTE NC & Não \\
44 & F & 36 anos & NDN & 7 anos & 29 anos & ESLEC & NLSR & Não \\
45 & F & 45 anos & NDN & 16 anos & 29 anos & ESLEC & LTE NC & Não \\
46 & F & 29 anos & NDN & 2 anos & 27 anos & ESLEC & LOE & DCF Ila \\
\hline
\end{tabular}

RM: Ressonância magnética. HPD: História pregressa da doença. VEEG: Videoencefalograma. F: Feminino. M: Masculino. NDN: Nada digno de nota. TCE PC: Trauma craniencefálico com perda da consciência. PCSF: Parto cesáreo com sofrimento fetal. INT. NEO: Internação no período neonatal. ISNC: Infecção do sistema nervoso central. S. West: Síndrome de West. PCF: Parto cesáreo com fórceps. PREM: Prematuridade. $<1$ mês: Antes do primeiro mês de vida. $<1$ ano: Antes do primeiro ano de vida, porém depois do primeiro mês. ESLEC: Exame sem lesões epileptogênicas convincentes. NLSR: Não lateralizatório e sem regionalização. LTD POST: Lobo temporal direito posterior. RFTE: Região frontotemporal esquerda. RRD MED: Região rolândica direita medial. LPD: Lobo parietal direito. RFTD: Região frontotemporal direita. LFD RR: Lobo frontal direito na região rolândica. LFD MED DL: Lobo frontal direito medial e dorsolateral. RRD: Região rolândica direita. HCD SR: Hemisfério cerebral direito sem regionalização. LFE: Lobo frontal esquerdo. RTPOE: Região têmporo-occipital esquerda. LTE POST: Lobo temporal esquerdo posterior. RTO NL: Região têmporooccipital não lateralizatória. RRE: Região rolândica esquerda. LPE: Lobo parietal esquerdo. LTE: Lobo temporal esquerdo. LTE NC: Lobo temporal esquerdo neocortical. LOE: Lobo occipital esquerdo. DCF: Displasia cortical focal.

\subsection{Seleção dos controles}

O grupo-controle utilizado para a avaliação quantitativa será detalhado a seguir para cada técnica. Ele foi extraído do banco de dados do Laboratório de Processamento de Imagens e Informática Radiológica (LAPIR) do centro de imagem do HCFMRP/USP. Os voluntários saudáveis participantes não tinham história de distúrbios neurológicos, e o laudo da RM convencional foi considerado normal, essencialmente sem alterações sugestivas de microangiopatia, sinais de redução volumétrica cerebral ou alterações morfológicas. Aliás, os exames de RM dos controles foram cuidadosamente analisados pelo pesquisador para afastar erros de protocolos, que deveriam ser idênticos aos usados nos pacientes (ver seção 3.3), baixa qualidade das imagens e alterações cerebrais, mesmo que consideradas 
variações da normalidade, que pudessem atrapalhar a avaliação quantitativa multimodal.

Para as avaliações SBM da EC pelo pacote FreeSurfer e VBA de junção branco-cinzenta pelo pacote SPM, o grupo-controle incluiu 92 voluntários saudáveis (44 mulheres, 48 homens, idade média: 30,9 anos $\pm 9,8$ e faixa etária de 18 a 51 anos).

Para as avaliações VBA da RT2 pelo pacote SPM, o grupo-controle incluiu 53 voluntários saudáveis (27 mulheres, 26 homens, idade média: 30,2 anos \pm 9,1 e faixa etária de 19 a 51 anos.

Para as avaliações VBA da TTM (TR) pelo pacote SPM, o grupo-controle incluiu 48 voluntários saudáveis (18 mulheres, 30 homens, idade média: 32,9 anos \pm 9,9 e faixa etária de 19 a 51 anos).

Para as avaliações VBA da DM (DTI) pelo pacote SPM, o grupo-controle incluiu 45 voluntários saudáveis (17 mulheres, 28 homens, idade média: 31,2 anos \pm 10,0 e faixa etária de 19 a 50 anos.

\subsection{Protocolos de aquisição da RM}

Todos os exames de RM encefálica foram realizados no equipamento Philips Achieva Duo de 3,0-T (Philips Medical Systems, Best, the Netherlands), usando uma bobina de cabeça de oito canais de recepção e com disponibilidade de gradiente de campo magnético de até $80 \mathrm{mT} / \mathrm{m}$ (amplitude máxima de gradiente). As imagens foram avaliadas e armazenadas em formato DICOM no LAPIR do HCFMRP/USP para integrarem o banco de dados e serem utilizadas posteriormente nas fases de processamento.

Primeiramente será detalhado todo o protocolo realizado de rotina nos pacientes em investigação de epilepsia (protocolo rotina para epilepsia) e, em seguida, o protocolo complementar que instituímos para os pacientes incluídos na pesquisa (protocolo avançado). 
Protocolo rotina para epilepsia

- SAGITAL 3D T1 Gradiente eco (MP-RAGE): tempo de repetição (TR): 2500 ms; TE: 2,9 ms; tempo de inversão: 900 ms, echo time spacing: 6,3 ms, flip angle: $8^{\circ}$, FOV: $240 \times 240$ mm; matriz: $240 \times 240$, espessura de corte: $1,0 \mathrm{~mm}$, sem intervalo. Essa sequência foi realizada em todos os 46 pacientes da pesquisa.

- AXIAL T2: TR: 4200 ms, TE: 120 ms, flip angle: 90, field of view (FOV): 240 x 240 mm, matriz: $480 \times 340$ e 2,5 mm de espessura de corte, sem intervalo. Essa sequência foi realizada em todos os 46 pacientes da pesquisa.

- CORONAL FLAIR: TR: $11000 \mathrm{~ms}$, TE: $125 \mathrm{~ms}$, FOV: 180 x $180 \mathrm{~mm}$, matriz: $220 \times 174$ e $3 \mathrm{~mm}$ de espessura de corte, sem intervalo. Tempo de inversão e recuperação: 2800 ms. Essa sequência foi realizada em todos os 46 pacientes da pesquisa.

- AXIAL FLAIR: TR: 11000 ms, TE: 125 ms, FOV: 1240 x 180 mm, matriz: $268 \times 175$ e $3 \mathrm{~mm}$ de espessura de corte, sem intervalo. Tempo de inversão e recuperação: 2800 ms. Essa sequência foi realizada em todos os 46 pacientes da pesquisa.

- CORONAL T2 STIR: TR: shortest (aprox. $2830 \mathrm{~ms}$ ), TE: $30 \mathrm{~ms}$, FOV: 200 x 200 mm, matriz: 324 × 320 e 3 mm de espessura de corte, sem intervalo. Tempo de inversão e recuperação: 300 ms. Esta sequência foi realizada em todos 46 pacientes da pesquisa.

- AXIAL DWI: TR: shortest (aprox.: $3122 \mathrm{~ms}$ ), TE: shortest (aprox.: $69 \mathrm{~ms}$ ), flip angle: 90', FOV: 230 × $230 \mathrm{~mm}$, matriz: $192 \times 113$ e $4 \mathrm{~mm}$ de espessura de corte, com $1 \mathrm{~mm}$ de intervalo. Fator de difusão (b): 1000. Essa sequência foi realizada em todos 46 pacientes da pesquisa. 
Protocolo avançado:

- $\quad$ SAGITAL 3D T1 MP-RAGE: idem ao do protocolo rotina acima descrito.

- AXIAL SWI: TR: 14 ms, TE: 20 ms, flip angle: 15O, FOV: 268 x 243 mm, matriz: $240 \times 200$ e $1 \mathrm{~mm}$ de espessura de corte, sem intervalo. Essa sequência foi realizada em todos os 46 pacientes da pesquisa.

- AXIAL T2 STIR: TR: shortest (aprox. $6131 \mathrm{~ms}$ ), TE: $30 \mathrm{~ms}$, field of view (FOV): 200 x $168 \mathrm{~mm}$, matriz: $324 \times 273$ e 2,5 mm de espessura de corte, sem intervalo. Tempo de inversão e recuperação: 300 ms. Essa sequência foi realizada em todos os 46 pacientes da pesquisa.

- $\quad$ AXIAL GMO: TR: 11000 ms, TE: 25 ms, FOV 240 x 184 mm, matriz 240 $\times$ 171, espessura do corte: $3 \mathrm{~mm}$, sem intervalo. Tempo de inversão e recuperação: 3400 e 325 ms. Esta sequência foi realizada em 38 pacientes da pesquisa (38/46 ou $82,6 \%$ ) do total de 46 . Não realizada nos pacientes que foram submetidos a sua forma 3D, inicialmente não disponível para utilização.

- SAGITAL 3D GM0: TR: 5500 ms, TE: shortest (aprox. 256 ms), FOV 240 x $240 \mathrm{~mm}$, matriz $200 \times 200$, espessura do corte: $1,2 \mathrm{~mm}$, sem intervalo. Tempo de inversão e recuperação: 5500 e 450 ms. (sequência opcional). Essa sequência inicialmente não fazia parte do protocolo e desta forma foi realizada em oito pacientes da pesquisa ( $8 / 46$ ou $17,4 \%)$.

- SAGITAL 3D FLAIR: TR: 5000 ms, TE: shortest (aprox. 332 ms), FOV $240 \times 240 \mathrm{~mm}$, matriz $240 \times 240$, espessura do corte: $1,0 \mathrm{~mm}$, sem intervalo. Tempo de inversão e recuperação: 1600 ms. (sequência opcional). Essa sequência inicialmente não fazia parte do protocolo e desta forma foi realizada em 16 pacientes da pesquisa (16/46 ou 34,8\%).

- $\quad$ AXIAL 3D TM: utilizando uma sequência ponderada em DP (densidade de prótons). TR: 7,3 ms, TE: 3,6 ms, flip angle: $8^{\circ}$, FOV $240 \times 180 \mathrm{~mm}$, matriz 240 x 178, espessura do corte (reconstrução): 0,5 mm, sem intervalo. Nessa modalidade foram adquiridos dois conjuntos de imagens dinâmicos, sem e com pulso de saturação (TMcon e TMsem). Essa sequência foi realizada em todos os 46 pacientes da pesquisa. 
- AXIAL 3D DTI: TR: $8900 \mathrm{~ms}$, TE: $65 \mathrm{~ms}$, FOV: $256 \times 256 \mathrm{~mm}$, matriz: $128 \times 128$, espessura de corte: $2 \mathrm{~mm}$, sem intervalo, largura de banda: 1346 kHz, fator de EPI: 67, ângulo de inclinação: $90^{\circ}$, Number of Signals Averaged: 1, codificação de difusão em 32 direções diferentes e valores de $b$ iguais a zero e $1000 \mathrm{~s} / \mathrm{mm} 2$. Essa sequência foi realizada em todos os 46 pacientes da pesquisa.

- AXIAL RT2: TR: 3000 ms, TE: 20 a $100 \mathrm{~ms}$ (5 TE): flip angle 90', acquisition matrix $240 \times 180$, FOV $240 \times 180$, espessura do corte: $3 \mathrm{~mm}$, sem intervalo. Essa sequência foi realizada em todos os 46 pacientes da pesquisa.

\subsection{Cirurgia}

Cinco pacientes (indicados pelos números 18, 22, 32, 39 e 46) foram operados após presunção do local da origem das crises, utilizando-se de todo o conjunto de exames realizados durante a avaliação pré-operatória. Todos os resultados anátomo-histopatológicos foram de DCF, sendo dois casos de DCF Ilb (pacientes 18 e 39), dois de DCF lla (pacientes 32 e 46) e um caso de DCF la (paciente 22).

\subsection{Localização das crises: Semiologia e EEG}

Em todos os pacientes o exame de monitorização prolongada do VEEG de superfície foi realizado em equipamento digital (Vangard Systems, Cleveland, $\mathrm{OH}$, EUA), usando-se eletrodos de escalpo aplicados de acordo com o sistema internacional 10/20, com eletrodos intermediários adicionais do sistema 10/10 e eletrodo esfenoidal. As descargas ictais e interictais foram avaliadas pela análise visual. Essa monitorização pode se estender por até 3 a 5 dias, registra ininterruptamente $O$ EEG sob regime de supressão parcial ou total dos antiepilépticos e grava, em vídeo, a fenomenologia clínica das crises, o que permite sincronização entre semiologia e registro eletroencefalográfico. As crises foram assistidas pela enfermagem com análises estruturadas do nível de consciência do paciente, assim como de suas funções cognitivas e motoras. Dois pacientes foram 
submetidos a colocação de placas subdurais para realização de monitorização do EEG de maneira invasiva.

A localização do possível foco de origem das crises foi determinada com base na revisão das informações clínicas disponíveis (semiologia) e dos achados do VEEG de superfície. Os achados do EEG das placas subdurais colocadas nos pacientes 18 e 22 também foram considerados. Assim, os pacientes foram classificados como apresentando foco localizatório suspeito (FLS) ou como foco não localizatório (FNL). O termo FLS foi definido diante de lobo ou região específica (frontotemporal e têmporo-occipital, por exemplo) suspeita, além de preferencialmente uma lateralizarão mais bem definida. Ou seja, se o paciente apresentasse sintomas ou achados eletrofisiológicos de localização e lateralização claros, ou melhor, uma área suspeita localizada, era classificado como FLS, mesma designação conferida àqueles com regionalização mais específica, mesmo que não lateralizatória, por exemplo na região frontal anterior, região frontal mesial e região têmporo-occipital. Todos os demais pacientes foram considerados como FNL. Assim, 31 pacientes foram inicialmente considerados como FLS $(31 / 46$ ou $67,4 \%)$ e 15 como FNL (15/46 ou 32,6\%) pelos critérios eletroclínicos.

\subsection{Pós-processamentos das imagens}

Todos os dados obtidos ainda foram pós-processados pela equipe de informática do LAPIR com acompanhamento do pesquisador. Em relação à avaliação quantitativa, utilizou-se o banco de dados do LAPIR para composição dos indivíduos do grupo-controle. Os pacientes foram avaliados quanto à presença ou não de alteração considerada significativa pelos parâmetros escolhidos nos pósprocessamentos individualizados de cada medida quantitativa. Nos pacientes considerados como FLS, consideramos que houve uma concordância entre os métodos (VEEG / semiologia versus pós-processamentos) se a região e/ou o lobo dos achados da RM fossem os mesmos da origem eletroclínica das crises. A localização de todas essas alterações foi anotada com detalhe anatômico para posteriormente orientar uma inspeção visual direcionada. 


\subsubsection{Análise baseada em superfície (SBM) e espessura cortical}

Para a análise da EC utilizando a sequência volumétrica 3D T1 MP-RAGE escolhemos o software FreeSurfer (Athinoula A. Martinos Center for Biomedical Imaging at Massachusetts General Hospital, Massachusetts, USA). Em estações específicas de trabalho, foram realizadas segmentação, reconstrução e avaliação automática da substância cinzenta. A execução inicial de uma análise de imagem de um único indivíduo para cálculo da EC é composta de um fluxo de processamento das superfícies, em que é construído um modelo de superfície cortical baseado em topologia de folha que representa a superfície pia-máter, além de um modelo de superfície que representa a interface entre as substâncias branca e cinzenta (Figura 16) (DALE; FISCHL; SERENO, 1999).

FIGURA 16: Fluxo de trabalho inicial da avaliação pelo FreeSurfer e com base em uma imagem 3D T1. Após conversões das imagens e de pós-processamentos, há reconhecimento da superfície pial e da interface branco-cinzenta delineadas pelas linhas vermelha e rocha respectivamente. A distância entre essas linhas é a EC.

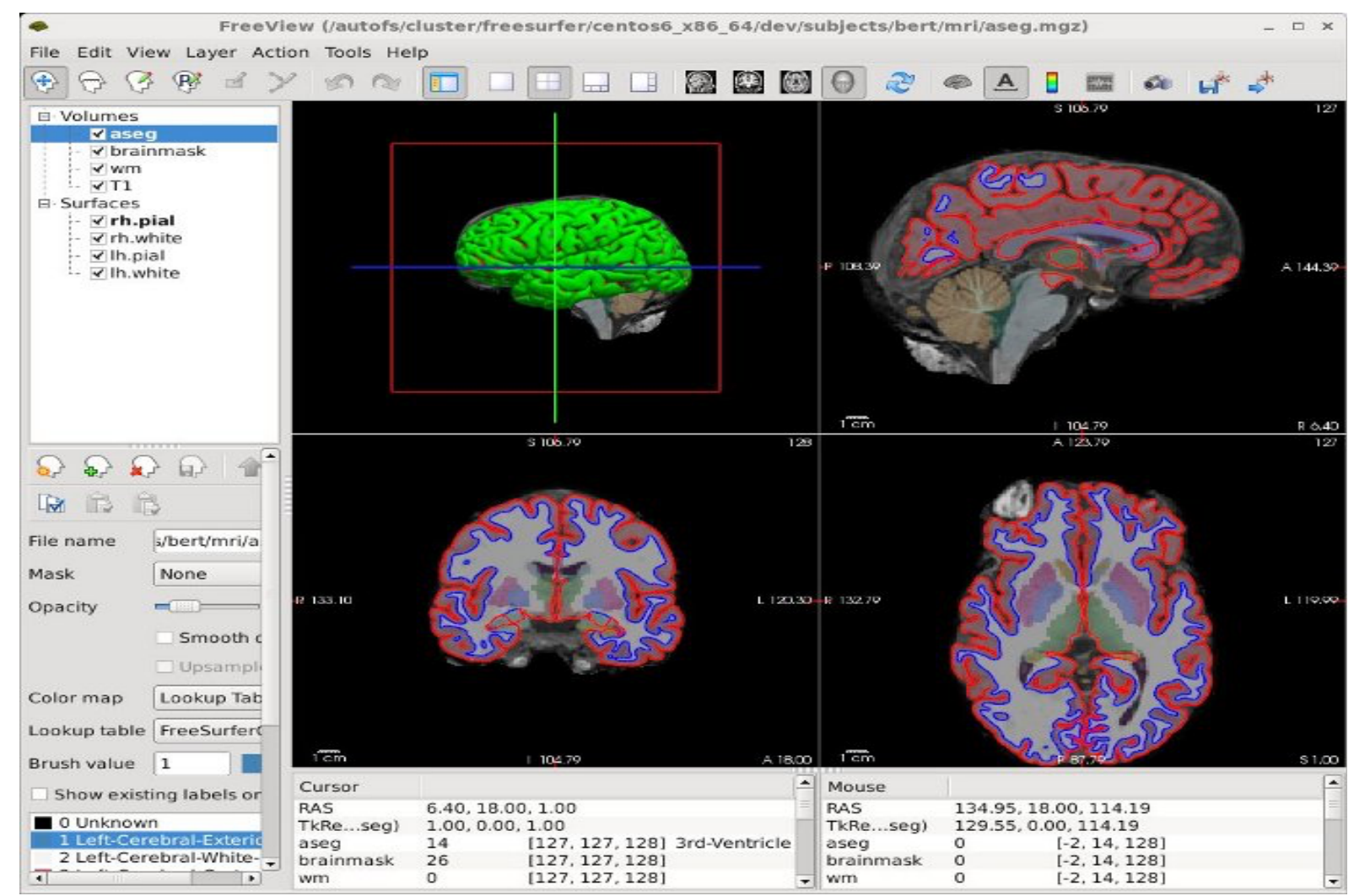

Fonte disponível em http://FreeSurfer.net/fswiki/DownloadAndlnstall (Acesso em: 07/03/2017). 
Para as análises realizadas, utilizam-se os níveis de intensidade dos voxe/s para identificar os limites entre a substância cinzenta-branca e a superfície pial, baseando-se também numa segmentação. Posteriormente, as superfícies piais e da transição branco-cinzenta do córtex são interligadas por polígonos, cujos pontos de reunião ou vértices podem ser caracterizados por coordenadas em três planos. Com isso, consegue-se processar as imagens de tal forma que desdobramentos e achatamentos das superfícies possam ser feitos. No alinhamento e parametrização dessas superfícies cria-se, em geral, uma esfera para estabelecer um sistema de coordenadas, o que é comparável entre sujeitos diferentes. Essas superfícies de cada um dos indivíduos são alinhadas com um atlas de superfície cortical esférico, e um registro é obtido com base neste atlas por meio de um algoritmo de deformação não linear. Ou seja, este registro baseia-se no alinhamento dos sulcos corticais e, em seguida, faz-se o ajuste de anatomia, ao contrário dos métodos tradicionais baseados em intensidades (FISCHL; SERENO; DALE, 1999). Assim, baseado no mesmo princípio já descrito anteriormente de normalização espacial, os parâmetros extraídos de um indivíduo podem ser comparados com um grupo de indivíduos após combinar o tamanho da esfera do sujeito com o do grupo de controle. $O$ atlas esférico criado simplifica a análise interindivíduos, já que o mapeamento ponto a ponto é obtido por uma coordenada esférica (FISCHL et al., 1999). Esse processo está representado na figura 17. 
FIGURA 17: Fluxo de trabalho utilizando o software FreeSurfer e com base em uma imagem 3D T1. Primeiramente, os limites entre a substância cinzenta-branca e a superfície pial são determinados com base numa segmentação cerebral. Em seguida, as superfícies são tesseladas por polígonos, cujos pontos de reunião ou vértices podem ser caracterizados por coordenadas. Para que haja a possibilidade de comparação entre sujeitos, as imagens do cérebro são deformadas em um espaço comum, geralmente uma esfera. Assim, os cérebros podem ser espacialmente normalizados para um dado modelo.

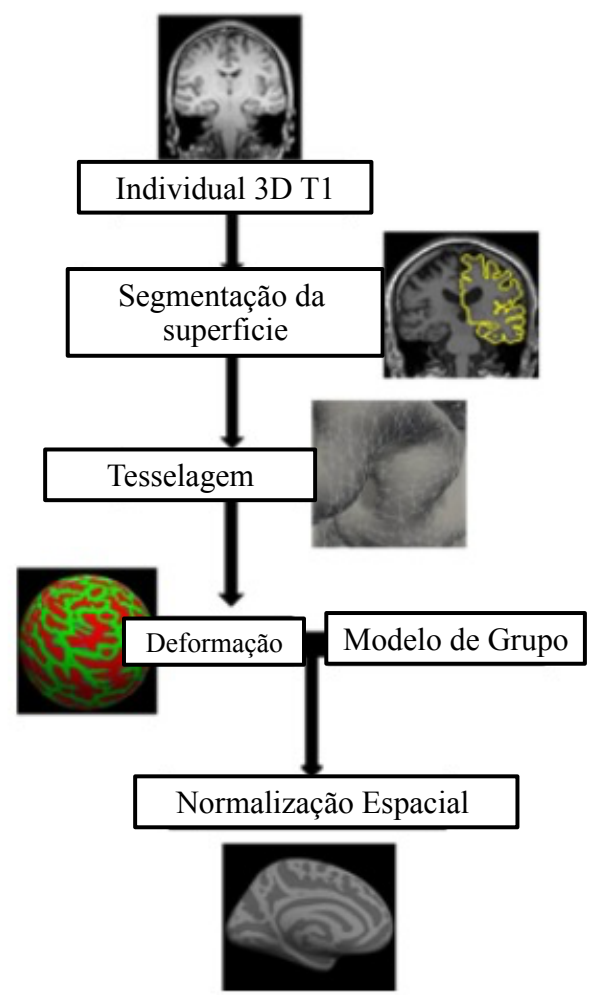

Martin P et al. Quant Imaging Med Surg. 2015 Apr;5(2):188-203.

@2015 Quantitative Imaging in Medicine and Surgery

Fonte disponível em https://www.ncbi.nlm.nih.gov/pmc/articles/PMC4379317/ (Acesso em: 20/02/2017).

Neste estudo, a avaliação de um paciente versus o grupo-controle foi realizada pela ferramenta QDEC contida no pacote do FreeSurfer. QDEC um acrônimo para Query (consultar), Design, Estimate (estimativa) e Contrast (contraste). Esse programa possibilita a visualização das áreas que apresentam diferenças (aumento ou diminuição) estatísticas definidas por um Z-valor limiar previamente definido ou pelo FDR, situação em que o Z-valor é calculado automaticamente pelo software para a devida correção pelas múltiplas comparações 
entre os diferentes vértices. Além desses parâmetros (FDR e Z-valor), outro que pode alterar a sensibilidade e especificidade dos resultados é o "smoothing" ou suavizamento. Esse último consiste em promediar o efeito das regiões adjacentes para a análise, em vez dela (ser ponto a ponto, ou seja, ao escolher um suavizamento de $10 \mathrm{~mm}$ estamos admitindo que as regiões a serem comparadas representam o efeito de vértices vizinhos situados a $10 \mathrm{~mm}$ de distância e assim por diante. Para facilitar a representação das regiões alteradas, elas aparecem coloridas e desenhadas na superfície de um cérebro-padrão inflado totalmente ou com circunvoluções representadas. É possível identificar em qual lobo ou giro foi encontrada uma determinada alteração, de forma visual pelo conhecimento anatômico ou, ainda, clicando em cima do achado onde, consequentemente, aparecerá o nome da região. Ao clicar na região demonstrada como alterada, o programa também mostra graficamente o valor da espessura da região para todas as imagens analisadas, diferenciando claramente a medida do sujeito em questão comparativamente a todos os indivíduos do grupo-controle (Figura 18). 
FIGURA 18: Exemplo de como uma região com espessura cortical considerada alterada aparece na visualização pelo QDEC do pacote FreeSurfer. Do lado direito temos o cérebro-padrão inflado, demonstrando uma região em azul em topografia do lóbulo paracentral (interior do círculo branco). Ao clicar em cima dessa região aparece uma tabela (localizada ao lado esquerdo), evidenciando as dispersões das medidas nessa região do indivíduo, analisado como uma pequena bola azul (seta preta), e de todos os indivíduos do grupo-controle como pequenos quadrados vermelhos. Ou seja, a medida da espessura cortical desse indivíduo está acima das medidas de todos os controles. Ainda é possível notar que o programa identifica a região caso haja necessidade de confirmação ou dúvida anatômica (interior do círculo preto).

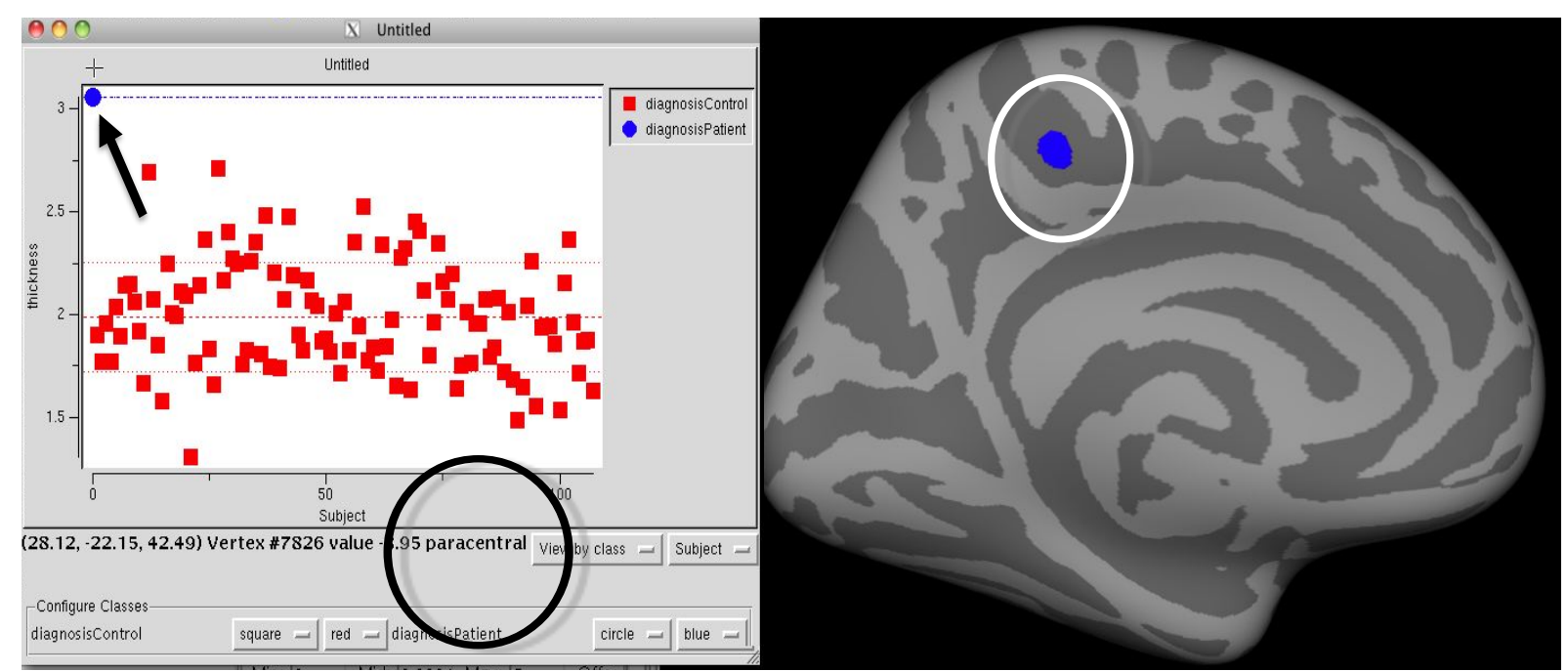

Fonte Arquivo pessoal (Acesso em: 20/02/2017).

Para a identificação das regiões estatisticamente diferentes, foi utilizado o trabalho de Thesen et al. (2011) como modelo para a escolha do "smoothing" e, com isso, trabalhamos com $10 \mathrm{~mm}$ para este parâmetro, bastante próximo dos $9 \mathrm{~mm}$ considerados como o de melhor performance nesse estudo. Para definição do limiar de significância no Z-valor, foi adotada uma taxa de FDR de 0,05 na tentativa de controlar de maneira mais eficaz os falso-positivos. Antes de iniciarmos a avaliação dos pacientes, 30 indivíduos normais do grupo-controle foram comparados de forma individualizada e com o restante do grupo de controle, para fins de observação da taxa de falso-positivos em um grupo sabidamente saudável.

Em síntese, para toda a avaliação da EC pelo método SBM empregamos o pacote FreeSurfer e avaliamos de maneira individualizada (um indivíduo versus o 
grupo de controle composto de pessoas saudáveis) por meio da ferramenta QDEC, utilizando um "smoothing" de 10 mm e um FDR de 0,05 para correção do limiar do Zvalor, tanto para a avaliação de um paciente versus o grupo-controle quanto para avaliação de um indivíduo do grupo-controle versus o restante do grupo-controle.

\subsubsection{Análises baseadas em voxel: VBA}

Após essa análise inicial da EC, utilizando o pacote FreeSurfer, todas as demais avaliações foram feitas com base na elaboração de mapas paramétricos com inferências estatísticas específicas de um determinado voxel, comparando da mesma forma um paciente versus um grupo de controle normal, ou seja, a técnica VBA com a utilização do programa SPM12. Para essas análises estatísticas entre indivíduos diferentes, os exames de RM precisam ser combinados espacialmente. As diferentes regiões são expandidas ou contraídas para se ajustarem a um espaçopadrão ou modelo. Este espaço-padrão pode ser criado por uma média de um grande número de exames, e todo o processo é conhecido como "normalização espacial".

Alterações significativas dos valores dos parâmetros escolhidos, os quais serão descritos posteriormente, foram detectadas por comparações múltiplas. Como esta análise de voxel a voxel pode compreender centenas de milhares de voxels, é necessário corrigir o problema de testes múltiplos a fim de reduzir resultados falsamente positivos de forma semelhante à avaliação da EC. Portanto, métodos como a utilização do FWE ou valor-p não corrigido (probabilidade de significância) podem ser utilizados pelo programa SPM. Além disso, o programa permite limitar o reconhecimento dessas alterações com base na definição do tamanho de um agrupamento contíguo de voxels alterados ou clusters. Dessa forma, regiões muito pequenas e bastante isoladas, provavelmente ruído, não são indicadas como alteradas. Para visualizar essas alterações o programa disponibiliza imagens que apresentam os locais das alterações de forma esquemática, utilizando, inclusive, os modelos dos cérebros normalizados, entre outras possibilidades (Figura 19). 
FIGURA 19: Exemplos de como o programa SPM12 pode apresentar as regiões alteradas. A) Apresentação esquemática mostrando o agrupamento de voxels (ponta de seta vermelha) na região frontal direita. No interior do círculo preto também é possível identificar os parâmetros utilizados no cérebro, no caso um valor-p $<0,05$ corrigido pelo FWE e um agrupamento de 40 voxels. B) Mesmo paciente e mesma região de $A$, mostrando focos amarelos e vermelhos sobrepostos a uma imagem 3DT1 de um cérebro-padrão do programa. C) Outro paciente em que a região alterada (focos vermelhos e amarelos) é mostrada sobreposta ao cérebro-padrão utilizado para o corregistro dos pacientes. D) Outro paciente em que as próprias imagens (mapa de ADC neste caso) são utilizadas como referência, sobrepostas às regiões alteradas (focos vermelhos e amarelos). SPM: Mapeamento estatístico paramétrico, do inglês statistical parametric mapping. FWE: Family-wise error.

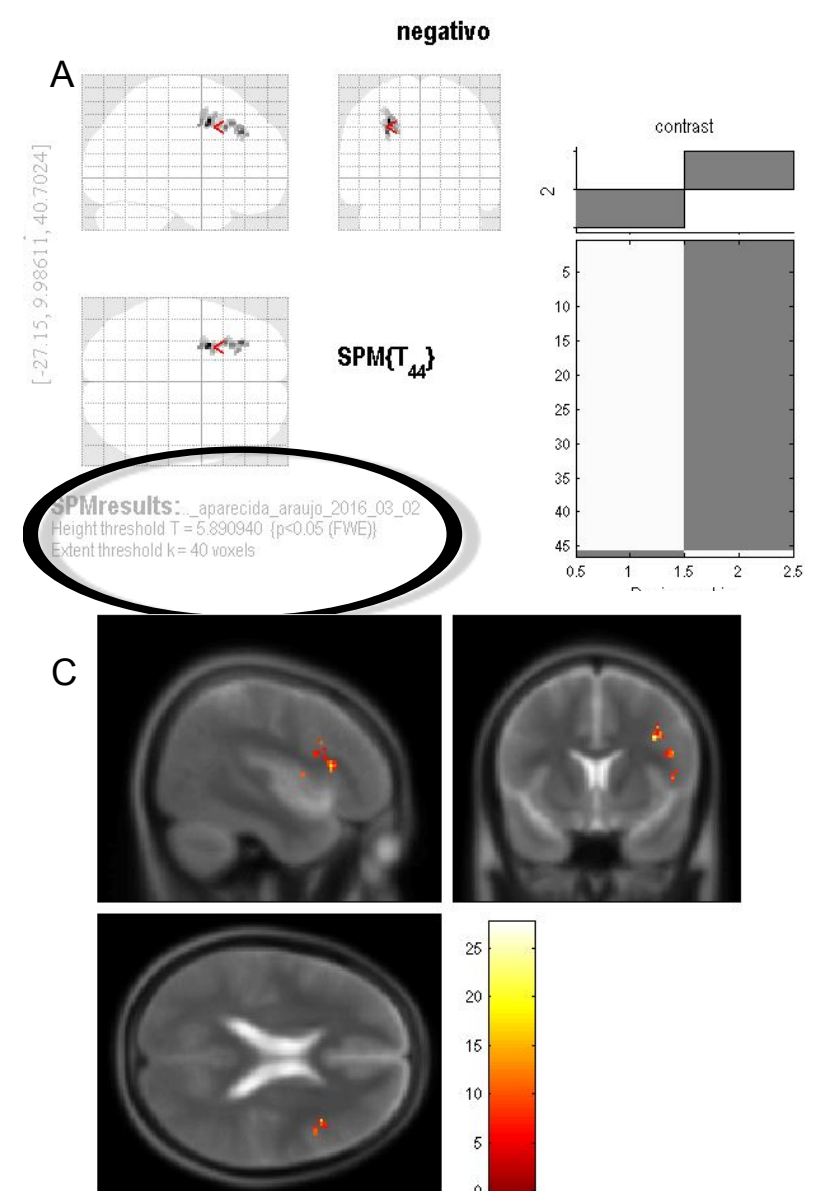

B
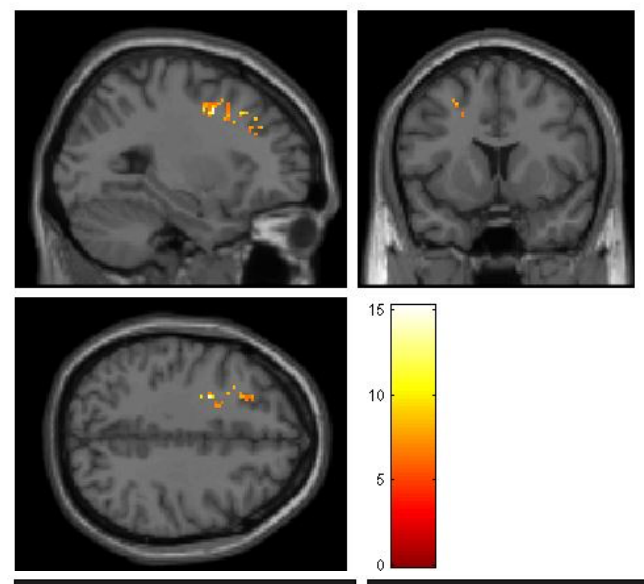

$\mathrm{D}$
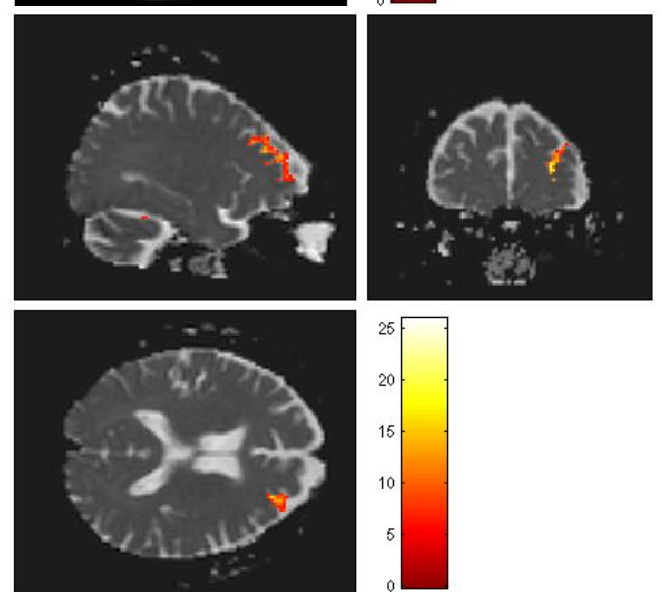

Fonte: Arquivo pessoal (Acesso em: 21/03/2017).

A investigação pode ser feita para cada uma das medidas quantitativas a fim de verificar se há aumento ou redução das mesmas de um indivíduo ou paciente em 
relação ao grupo de controles saudáveis. Ou seja, em cada análise individual há a necessidade de realizar dois testes. Por exemplo, o primeiro para saber se há alguma região naquele indivíduo com a medida considerada aumentada em relação ao grupo e, posteriormente, se existe alguma região com a medida considerada diminuída. O primeiro teste foi denominado como variável "contraste negativo", e o segundo variável "contraste positivo".

Antes de definir os parâmetros a serem usados nas avaliações dos pacientes, devem ser feitos testes, em 20 pessoas, para analisar as diferenças regionais de um indivíduo do grupo de controle saudáveis versus o restante desse grupo, para cada uma das medidas quantitativas retiradas das sequências de RM. Neste estudo, definimos como um valor aceitável de falso-positivos o que seria encontrado nesse tipo de avaliação da EC pela técnica SBM. Os valores-p deveriam ser escolhidos entre um não corrigido de 0,001 ou um resultante de um FWE igual ou menor a 0,05 (padronizados pelo programa). O valor do agrupamento de voxels seria o menor que possibilitasse atingir a taxa de falso-positivos já previamente determinada pela técnica SBM da EC, iniciando com 0 e aumentando de 5 em 5 . Em seguida, procedemos às avaliações, também de maneira individual, de cada um dos pacientes e do respectivo grupo de controles saudáveis. Em ambas as avaliações foram eliminados os achados que se localizassem fora do parênquima cerebral e distantes do córtex, ou seja, tudo o que foi encontrado nos ventrículos, nas cisternas, nos sulcos, no tronco encefálico e cerebelo, assim como na tábua óssea e fora do crânio.

\subsubsection{Análises baseadas em voxel dos mapas de junção entre as substâncias branca e cinzenta (VBA e JBC)}

Utilizando-se ainda da sequência volumétrica T1 MP-RAGE em estações específicas de trabalho e ferramentas implementadas no pacote SPM, criou-se mapas de junção branco-cinzenta, nos quais cada voxel apresenta essa informação. O conjunto de dados dessa sequência foi normalizado para o cérebro-padrão do Instituto Neurológico de Montreal, usando um tamanho de voxel de $1 \mathrm{~mm} \times 1 \mathrm{~mm} \times$ $1 \mathrm{~mm}$. Após a imagem normalizada, segmentamos em substância cinzenta, substância branca e líquido cefalorraquidiano (Figura 20). Embora o programa gere mapas probabilísticos (valores entre zero e um) destes compartimentos para a 
análise de JBC, estes mapas foram binarizados, escolhendo, como critério voxels, menos de $10 \%$ de contaminação dos outros compartimentos. Esses mapas binarizados foram sobrepostos às imagens originais, o que possibilitou obter a distribuição de intensidades de pixel de cada um dos compartimentos.

FIGURA 20: Fluxo de trabalho com os passos da morfometria baseada em voxel clássica (VBM), realizada pelo programa de mapeamento estatístico paramétrico (SPM) e com base em uma imagem 3D T1. A imagem individual ponderada em T1 é espacialmente normalizada, segmentada e suavizada. Fluxos de trabalho semelhantes podem ser aplicados a outras sequências. Com essa imagem resultante, é possível comparar com as imagens igualmente processadas de uma população, utilizando-se de algumas correções disponíveis.

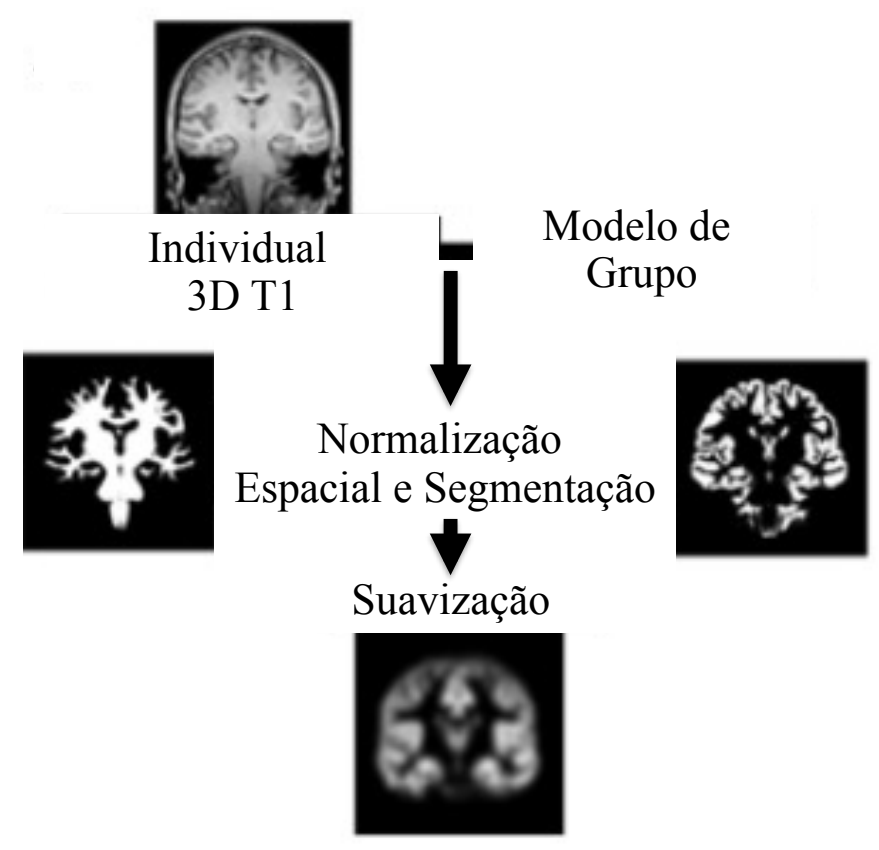

Martin P et al. Quant Imaging Med Surg. 2015 Apr;5(2):188-203.

@2015 Quantitative Imaging in Medicine and Surgery

Fonte disponível em https://www.ncbi.nlm.nih.gov/pmc/articles/PMC4379317/ (Acesso em: 20/02/2017).

Em uma segunda etapa, cria-se uma imagem binária de junção branco/cinzenta. Para a definição destes limiares da binarização, tomamos como base reportes prévios (HUPPERTZ et al.,2005). Foi utilizado como limite inferior à 
intensidade de pixel média na substância cinzenta do sujeito, mais um desviopadrão destes mesmos valores. Como limite superior, adotamos a intensidade de pixel média na substância branca do sujeito, mais um desvio-padrão das intensidades neste compartimento. Cada voxel com um valor de cinza (intensidade do pixel) entre esses limiares mencionados foi definido como 1 na imagem binária resultante, enquanto os outros voxels foram definidos como zero. A imagem binária foi filtrada espacialmente, realizando uma convolução tridimensional com uma matriz de dimensões $5 \times 5 \times 5$, resultando em uma imagem da JBC, na qual os voxels de valores próximos à unidade aparecem brilhantes (Figura 21). Além disso, é possível que regiões cerebrais não corticais (gânglios basais, tronco encefálico e cerebelo) sejam mascaradas por um modelo predefinido, uma vez que podem ser destacadas, pois suas intensidades de sinal estão no intervalo entre a substância cinzenta e branca.

FIGURA 21: Fluxo de trabalho pelo programa de mapeamento estatístico paramétrico (SPM12) do chamado mapa de junção entre as substâncias branca e cinzenta. Normalização e segmentação são semelhantes ao VBM clássico. Em seguida cria-se uma imagem binária na fronteira da transição branco/cinzenta com base na distribuição de voxels com intensidade entre ambas as substâncias, e finalmente suavizada com uma operação de convolução.

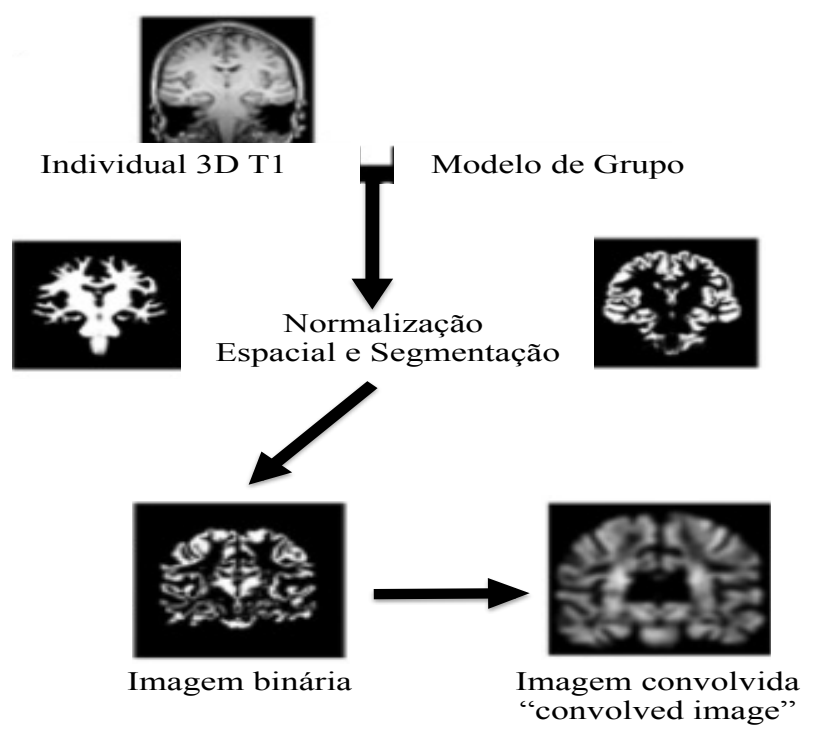

Martin $P$ et al. Quant Imaging Med Surg.

@2015 Quantitative Imaging in Medicine and Surgery

Fonte disponível em https://www.ncbi.nlm.nih.gov/pmc/articles/PMC4379317/ (Acesso em: 20/02/2017). 
Todos os pacientes e controles foram processados dessa mesma maneira. As imagens da convolução dos controles foram "corregistradas" e criou-se um cérebro normalizado dessa população com as médias e os desvios-padrões de cada região. Nesse ponto, é importante ressaltar a necessidade de checar se o alinhamento de todos os encéfalos foi satisfatório para que as regiões equivalentes sejam utilizadas para o cálculo (Figura 22). Para evitar problemas de zonas fronteiriças no cérebro - casos em que poucos sujeitos podem estar contribuindo para a base de dados e com isso gerando valores aberrantes -, as imagens convolvidas somadas foram previamente suavizadas, usando um núcleo fixo gaussiano de $6 \mathrm{~mm}$ de largura à meia altura (FWHM).

FIGURA 22: Imagens que exemplificam o fluxo de trabalho da formação das imagens de junção entre as substâncias branca e cinzenta (JBC). A) Imagem da convolução da JBC ("convolved image") de um único indivíduo após o processamento indicado na figura 21. B) Imagem JCB normalizada e suavizada de toda a população de controles saudáveis participante do estudo mostrando um excelente alinhamento e corregistro das estruturas.
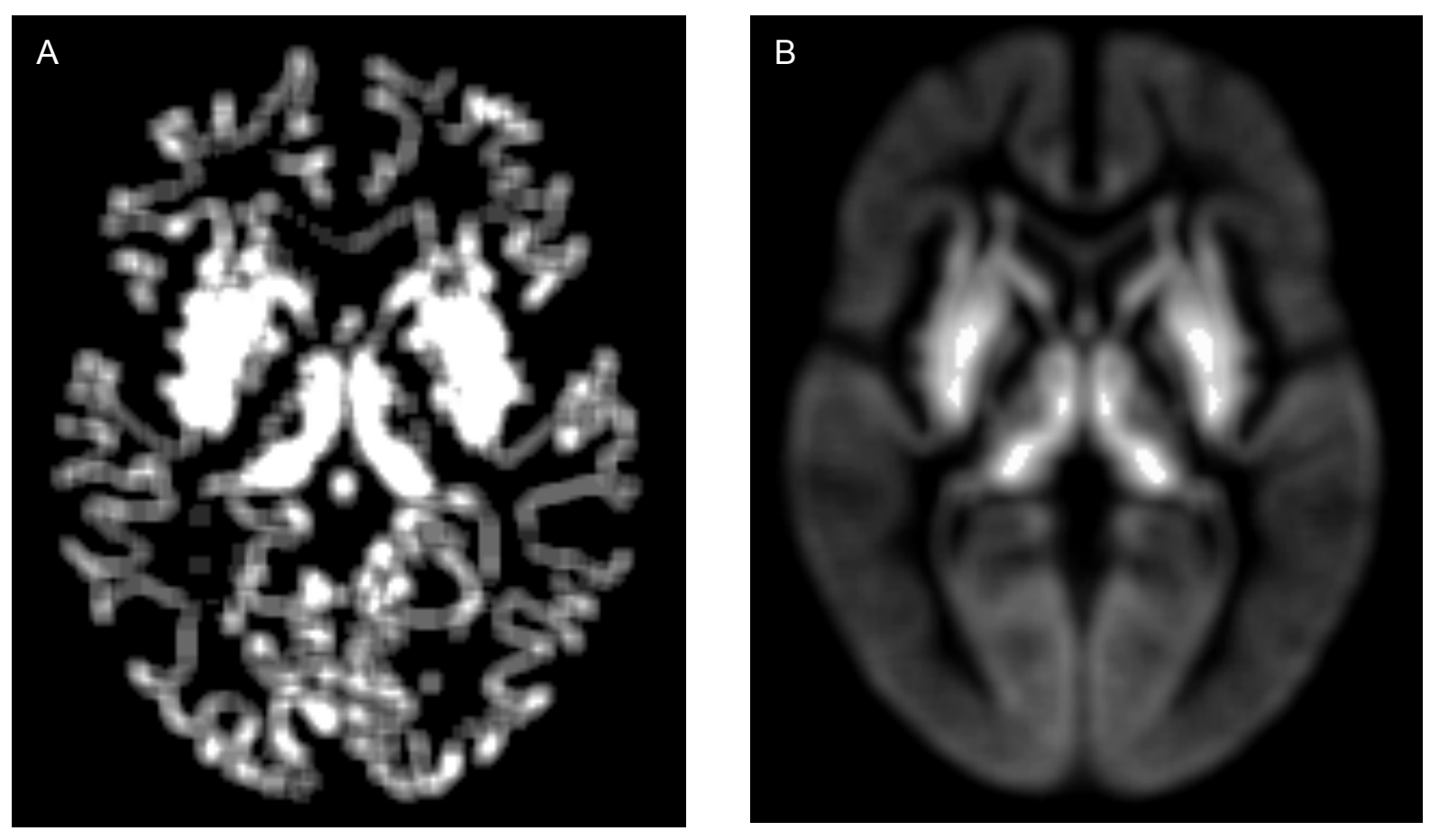

Fonte: Arquivo pessoal (Acesso em: 10/03/2017). 
Definimos a variável "contraste negativo" como a principal a ser identificada nas avaliações dos pós-processamentos individualizados da JBC pelo SPM12. Ela foi escolhida após avaliarmos um paciente com DCF visível na RM com o protocolo rotina para epilepsia e o programa apontar a região correspondente como alterada ao procedermos com esta variável (Figura 23). Utilizou-se um paciente com DCF, pois os achados que esperamos identificar nos pacientes da pesquisa são os mesmos encontrados nessa patologia, porém tão sutis que podem não ser identificados em uma inspeção visual.

FIGURA 23: Processo de validação do contraste negativo como a alteração a ser identificada nos mapas de junção entre as substâncias branca e cinzenta (JBC). Reconstrução axial 3D T1 (A), axial FLAIR (B) e coronal FLAIR (C), mostrando a displasia cortical focal caracterizada por uma alteração de sinal subcortical (setas brancas), bastante discreta na imagem ponderada em T1. D) Resultado do pósprocessamento dos mapas da JBC pelo programa de mapeamento estatístico paramétrico (SPM12) deste paciente versus um grupo-controle de indivíduos normais mostrando um agrupamento ("cluster") de voxels alterados no que definimos como variável contraste negativo, utilizando as variáveis valor-p não corrigido de 0,001 e agrupamento de 30 voxels (ponta de seta vermelha e foco amarelo avermelhado) na mesma região da DCF identificada nas imagens de RM estrutural (A, B e C).

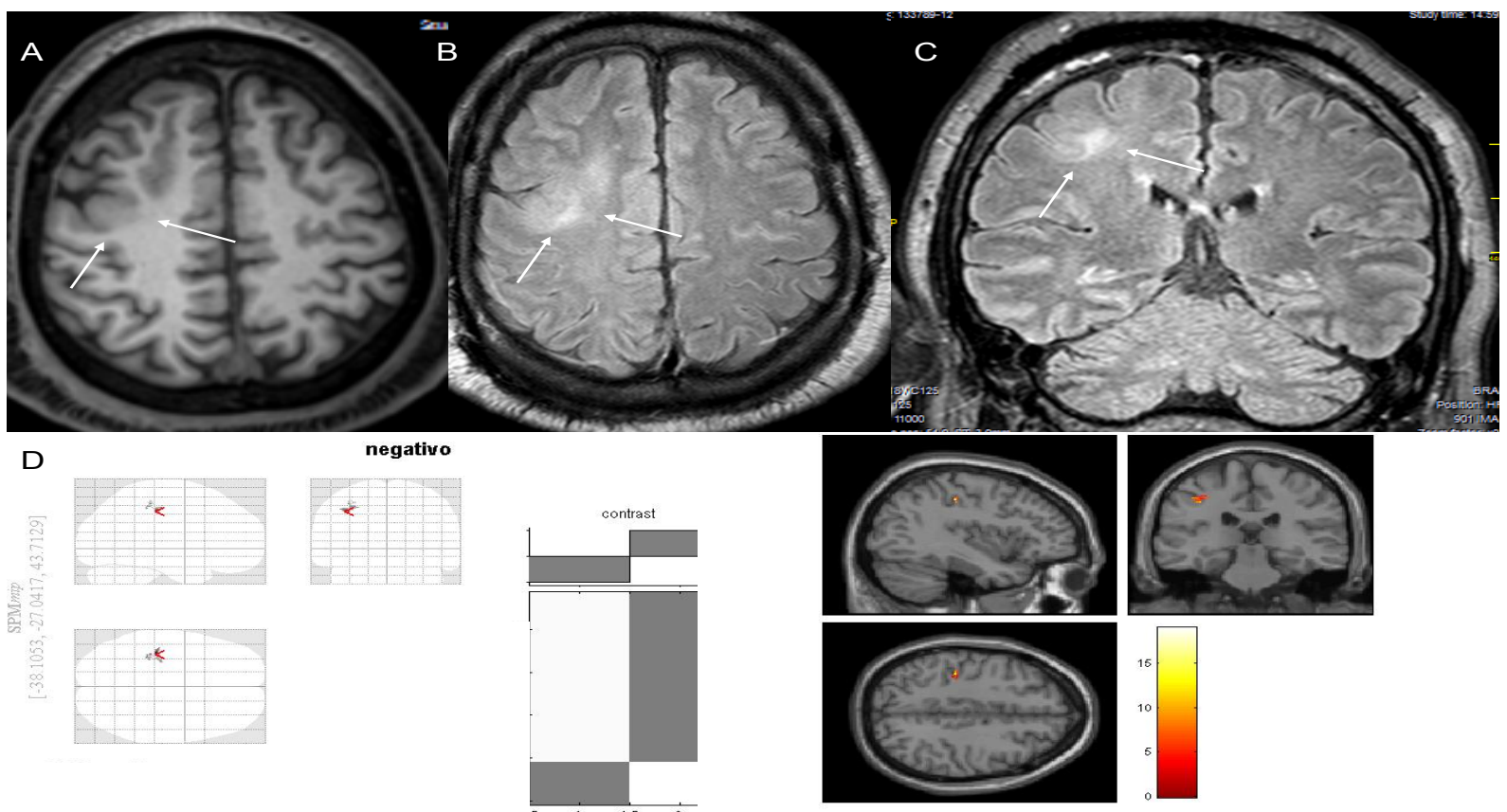

Fonte Arquivo pessoal (Acesso em: 10/03/2017). 
Prosseguimos com a avaliação de 20 indivíduos do grupo-controle (10 homens, 10 mulheres, idade média de 30,8 anos, desvio-padrão de 9,4 anos e faixa etária de 19 a 51 anos), no intuito de determinar o agrupamento de voxels e o valorp para esta medida quantitativa a serem utilizados na avaliação dos pacientes.

\subsubsection{Análises baseadas em voxel dos mapas da relaxometria T2 (VBA e RT2)}

Com as sequências de RT2, calculamos o tempo de relaxação (ms) por meio da geração de um mapa onde cada voxel apresenta esta informação. Neste cálculo a intensidade de sinal é ajustada em cinco valores de TE (20, 40, 60, 80 e $100 \mathrm{~ms})$ a uma exponencial decrescente. A escolha destes TEs objetivou assegurar uma boa reprodução do decaimento exponencial de T2 na faixa de 40 a 100 ms, na qual se encontram os valores de T2 esperados para as sustâncias branca e cinzenta em um campo magnético de 3-T. A teoria da medida de taxas de relaxação baseia-se nos aspectos físicos de relaxação de núcleos de hidrogênio que é produzida por variações na intensidade do campo magnético local, experimentado por cada molécula. No caso específico da relaxação transversal, o T2 será mais alto quanto maior for a mobilidade do hidrogênio, por exemplo os prótons da água livre possuem um elevado valor de T2. Dessa forma, o T2 quantificado no voxel correlaciona-se com o volume de água contido no tecido e é extraído com operações aritméticas entre as imagens, incluindo uma regressão por mínimos quadrados.

Foi definida a variável relacionada ao aumento do parâmetro avaliado do indivíduo em relação ao grupo de controles saudáveis, no caso da RT2, como "contraste negativo" no pós-processamento deste mapa pelo SPM12. Ela foi validada após avaliar um paciente com áreas de gliose visíveis na RM com o protocolo de rotina e, adicionalmente, o programa apontar a região correspondente como alterada ao proceder com esta variável (Figura 24). Optamos por um paciente com gliose, pois os achados que esperamos identificar nos pacientes da pesquisa são os mesmos encontrados nesta patologia (aumento do tempo de relaxação), porém tão sutis que podem não ser identificados em uma inspeção visual. Portanto, apesar de avaliarmos tanto aumento como diminuição deste parâmetro, assim como nas demais técnicas avançadas, focalizamos o aumento por ser o achado esperado. Ademais, isso nos deu segurança para esta técnica e nas restantes em relação a 
identificar qual contraste (positivo ou negativo) seria esperado: aumento ou diminuição de cada parâmetro.

FIGURA 24: Processo de validação do contraste negativo como a alteração a ser identificada nos mapas da relaxometria T2 (RT2). Coronal (A) e axial FLAIR (B), mostrando uma área de gliose caracterizada por alto sinal T2 na substância branca periventricular e subcortical ao lado esquerdo em um paciente com história de injúria hipóxico-isquêmica perinatal. Resultado do pós-processamento da RT2 pelo programa de mapeamento estatístico paramétrico (SPM12) deste paciente versus o grupo-controle de indivíduos normais utilizados na pesquisa, mostrando um agrupamento de voxels alterados $(\mathrm{C})$, em que se definiu como variável o contraste negativo, utilizando um valor-p corrigido pelo FWE (Family-wise error) de 0,05 e um agrupamento de 40 voxels (focos amarelos avermelhados) na mesma região da alteração de sinal das imagens de RM estrutural (A e B). FLAIR: Fluid attenuated inversion-recovery.
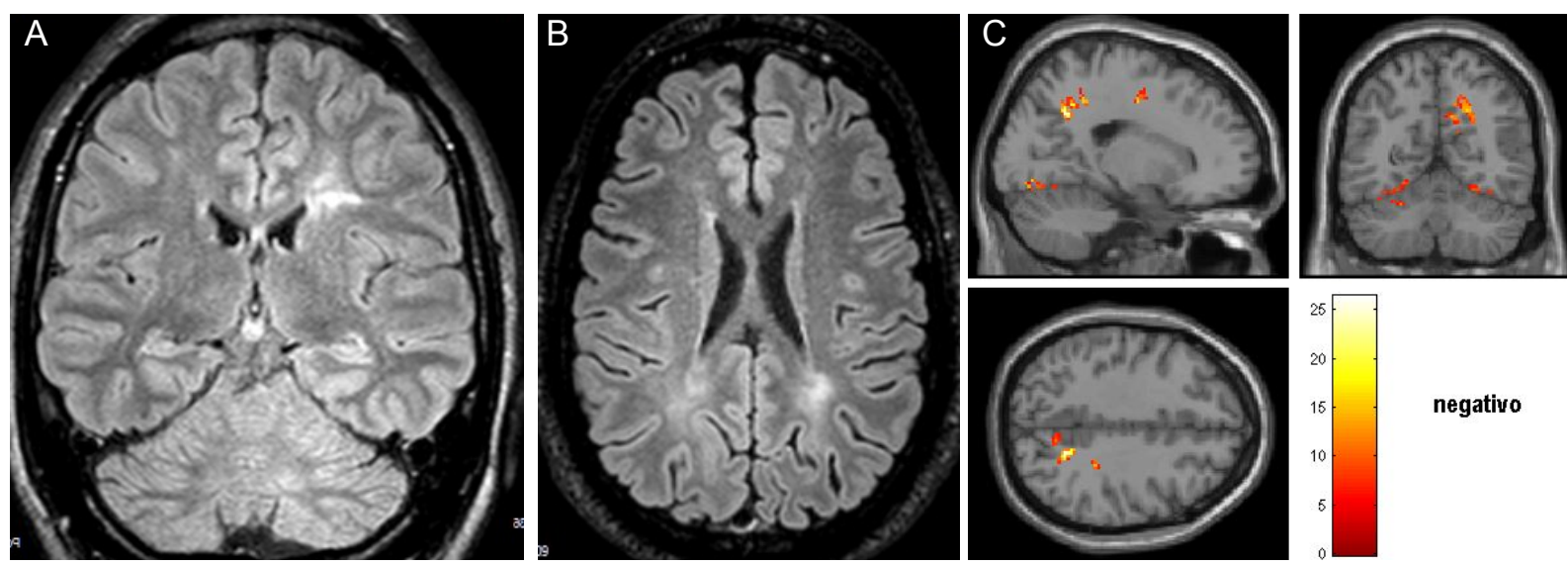

Fonte: Arquivo pessoal (Acesso em: 17/03/2017).

Para as comparações estatísticas voxel a voxel, as imagens foram espacialmente normalizadas para um modelo personalizado e posteriormente suavizadas com um filtro gaussiano (FWHM de $8 \mathrm{~mm}$ isotrópico). Esse modelo foi criado após diversas tentativas de normalizar as imagens, utilizando aquelas oriundas do primeiro TE dos indivíduos do grupo de controles saudáveis e pacientes. Assim, criamos um modelo-padrão com um grupo de controles que apresentou alinhamento o mais perfeito possível entre eles e, a partir dele, prosseguimos com os corregistros dos mapas de RT2 dos demais controles e pacientes (Figura 25). 
FIGURA 25: Fluxo de trabalho visando um alinhamento satisfatório dos mapas da relaxometria T2 (RT2). Imagens do primeiro tempo de eco da RT2 de um dos pacientes (A) e do modelo-padrão criado pelo grupo escolhido, normalizado e suavizado, mostrando um excelente alinhamento e corregistro das estruturas. $\mathrm{O}$ cursor (linhas azuis) mostra que realmente o objetivo do alinhamento próximo da perfeição foi alcançado.

A
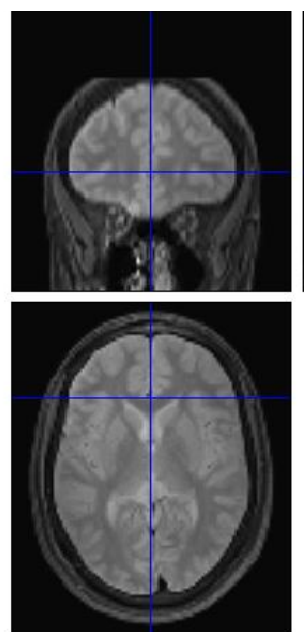

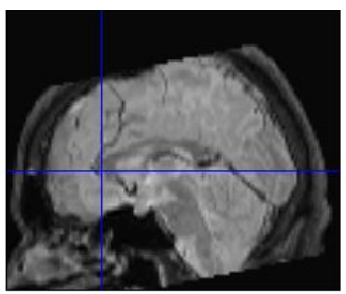

B
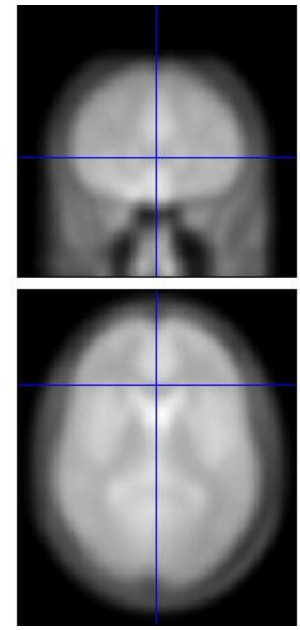

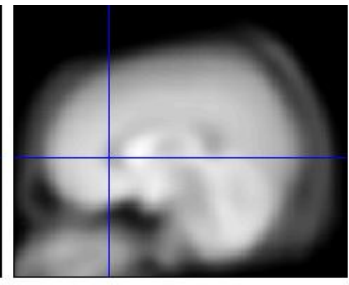

Fonte Arquivo pessoal (Acesso em: 17/03/2017).

Prosseguimos com a avaliação de 20 indivíduos do grupo-controle (10 homens, 10 mulheres, idade média de 30,9 anos, desvio-padrão de 8,8 anos e faixa etária de 19 a 50 anos) no intuito de determinar o agrupamento de voxels e o valor-p para esta medida quantitativa a serem utilizados na avaliação dos pacientes.

\subsubsection{Análises baseadas em voxel dos mapas de taxa de transferência de magnetização (VBA e TTM).}

Com base nas imagens geradas pela sequência de transferência de magnetização foi gerado um mapa de TTM, variável associada à existência de relaxação cruzada entre as populações de prótons livres e dos ligados às macromoléculas. Essa taxa é calculada em cada voxel pela diferença da intensidade do sinal entre as aquisições com e sem pulso de saturação, divididas pela condição sem o pulso, multiplicado por 100 [(Msem-Mcom)/Msem) x 100]. Com isso, foi gerado um mapa no qual cada voxel contém a informação da TTM. 
O contraste positivo foi definido como redução da TTM da região avaliada do indivíduo em relação ao grupo de controles saudáveis com base nos achados dos mapas de RT2 (Figura 24). Dessa forma, apesar de avaliarmos tanto o aumento como diminuição deste parâmetro, assim como das demais técnicas avançadas, nosso foco esteve na redução, por ser o achado esperado. Para as comparações estatísticas voxel a voxel as imagens foram espacialmente normalizadas e suavizadas com um filtro gaussiano (FWHM de $8 \mathrm{~mm}$ isotrópico) para um modelo personalizado. Esse modelo foi criado após várias tentativas de normalizar as imagens da sequência sem o pulso de magnetização dos indivíduos dos grupos de controles saudáveis e pacientes. Assim, decidimos criar um modelo-padrão com um grupo de controles que apresentaram alinhamento o mais perfeito possível entre eles e, a partir disto, prosseguir com os corregistros com os mapas de TTM após verificação cuidadosa do alinhamento das estruturas encefálicas (Figura 26).

FIGURA 26: Fluxo de trabalho visando um alinhamento satisfatório dos mapas de taxa de transferência de magnetização (TTM). A) Imagens da sequência de um dos pacientes sem o pulso de saturação. B) modelo-padrão criado com a mesma sequência do grupo de controles, normalizado e suavizado, mostrando um excelente alinhamento e corregistro das estruturas. O cursor (linhas azuis) mostra que realmente o objetivo do alinhamento próximo da perfeição foi alcançado.

A
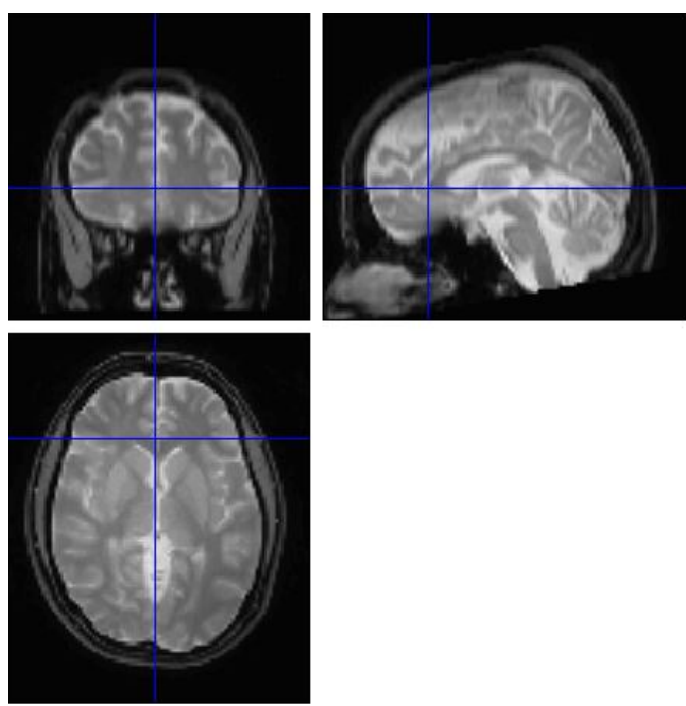

B
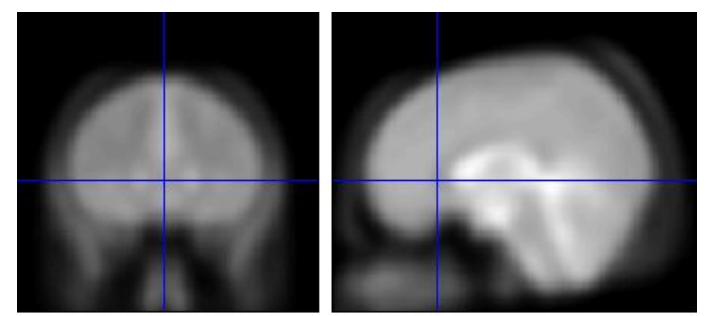

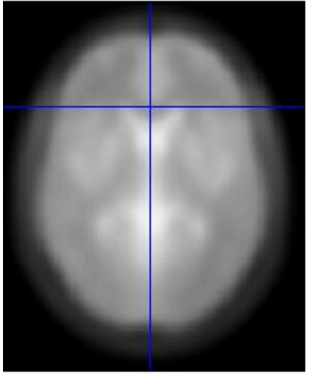

Fonte: Arquivo pessoal (Acesso em: 21/03/2017). 
A pesquisa prosseguiu com a avaliação de 20 indivíduos do grupo-controle (10 homens, 10 mulheres, idade média de 33,1 anos, desvio-padrão de 10,2 anos e faixa etária de 20 a 51 anos), no intuito de determinar o agrupamento de voxels e o valor-p para esta medida quantitativa a serem utilizados na avaliação dos pacientes.

\subsubsection{Análises baseadas em voxel dos mapas de difusibilidade média (VBA e DM).}

Seguindo os achados encontrados nos trabalhos de Thivard et al. (2005) e Chen et al. (2008), optamos pela DM como sendo o parâmetro presente nos mapas gerados a ser confrontado entre cada paciente e seu respectivo grupo de indivíduos saudáveis, uma vez que apresentou uma melhor correlação com as ZE em ambos os estudos citados.

Para as comparações estatísticas voxel a voxel as imagens foram espacialmente normalizadas e suavizadas com um filtro (FWHM) de $8 \mathrm{~mm}$ para um modelo personalizado. Esse modelo foi desenvolvido após várias tentativas, normalizando as imagens EPI (mapa de difusibilidade) dos indivíduos do grupo de controles saudáveis e pacientes. Desse modo, decidimos criar um modelo-padrão com um grupo de controles que apresentaram alinhamento o mais perfeito possível entre eles e, a partir disto, prosseguir com os corregistros com o próprio mapa de difusibilidade (Figura 27). 
FIGURA 27: Fluxo de trabalho visando um alinhamento satisfatório dos mapas de difusibilidade média (DM). Imagens do mapa de difusibilidade de um dos pacientes (A) e do modelo-padrão criado pelo grupo escolhido, normalizado e suavizado, mostrando um excelente alinhamento e corregistro das estruturas. DM: Difusibilidade média.
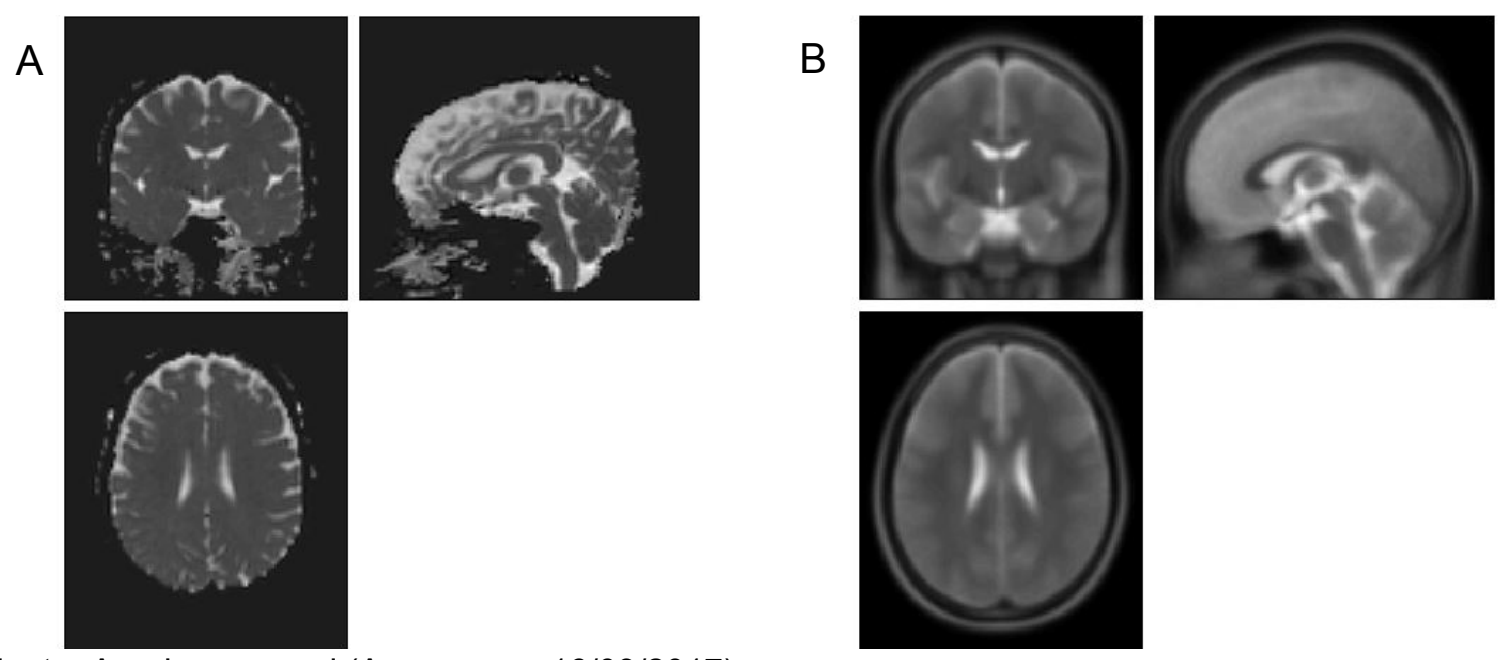

Fonte: Arquivo pessoal (Acesso em: 16/03/2017).

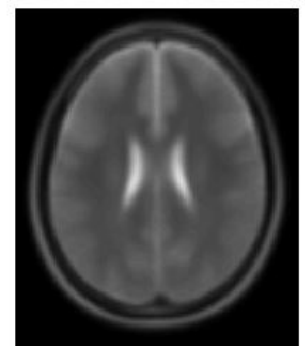

Prosseguimos com a avaliação de 20 indivíduos do grupo-controle (10 homens, 10 mulheres, idade média de 31,2 anos, desvio-padrão de 9,0 anos e faixa etária de 19 a 46 anos), no intuito de determinar o agrupamento de voxels e o valorp para esta medida quantitativa a serem utilizados na avaliação dos pacientes.

\subsection{Avaliação visual da RM com direcionamento localizatório pelos pós- processamentos}

Ao fim de todo o processo foi realizada uma nova inspeção, qualitativa e visual pela RM, agora direcionada para o local sugerido de ser a ZE, usando o conjunto das avaliações dos processamentos individualizados. Ou seja, essa nova inspeção foi voltada apenas para as regiões consideradas alteradas pelas medidas quantitativas.

Para esta etapa, todos os 46 pacientes foram avaliados, visto que, até o momento da realização da RM com o protocolo avançado, estavam sendo acompanhados como RM NLE e/ou com alterações sutis/inespecíficas.

Nesta fase, definimos um direcionamento mais específico na investigação da ZE pela RM estrutural. Além disso, nos eventuais casos de positividade para 
alterações morfológicas sugestivas de lesões epileptogênicas anteriormente não detectadas, buscamos identificar qual método quantitativo utilizado propiciou esta mudança de grupo do paciente (RM NLE versus RM LE) e se alguma sequência adicional favoreceu esse reconhecimento.

Os achados considerados positivos pelo pesquisador foram apresentados ao radiologista e docente responsável por esta área do Centro de Ciências da Imagem e Física Médica (CCIFM) do HCFMRP/USP e orientador do trabalho e a um dos neurologistas responsáveis do CIREP - HCFMRP/USP. A alteração foi considerada como suspeita se, dentre as hipóteses diagnósticas, estivessem incluídas aquelas pertencentes ao grupo das lesões conhecidamente epileptogênicas.

\section{8 Avaliação de mudança do estado localizatório dos pacientes na RM no decorrer do estudo}

Nesta etapa foi feita uma revisão do seguimento dos pacientes no que se refere a mudanças de classificação da RM durante a investigação, ou seja, se houve alteração do estado de RM NLE para RM LE. Procuramos também identificar, nos eventuais casos de alteração, o que a propiciou, ou seja, se algum direcionamento localizatório mais específico (por outro método não relacionado aos pósprocessamentos) para alguma determinada região e/ou alguma sequência adicional de RM (do nosso protocolo avançado ou não) pudessem ter favorecido eventuais mudanças. 


\section{RESULTADOS}

Os resultados gerais estão apresentados na tabela 7 na forma de taxa percentual de pacientes com achados alterados, identificados com cada técnica quantitativa em relação ao número total de dados disponíveis por técnica. Nessa tabela é possível ter uma visão geral da correspondência entre a localização desses achados e provável da zona epileptogênica definida pela avaliação da origem eletroclínica das crises.

TABELA 7: Taxa de pacientes com achados alterados, identificados com cada técnica quantitativa, seguindo critérios de concordância espacial com os achados da avaliação eletroclínica das crises. Na segunda e terceira linhas, a taxa considera somente os pacientes com foco localizatório suspeito.

\begin{tabular}{|c|c|c|c|c|c|c|}
\hline $\begin{array}{c}\text { Localização espacial do } \\
\text { achado/Técnica quantitativa } \\
\text { Número de doentes/todos os } \\
\text { doentes com dados } \\
\text { disponíveis (\%) }\end{array}$ & EC & JBC & TTM & RT2 & DM & Todas \\
\hline $\begin{array}{l}\text { Em qualquer lobo ou região } \\
\text { dos hemisférios cerebrais. }\end{array}$ & $\begin{array}{r}15 / 46 \\
32,6 \%\end{array}$ & $\begin{array}{r}17 / 46 \\
36,9 \%\end{array}$ & $\begin{array}{r}15 / 38 \\
39,5 \%\end{array}$ & $\begin{array}{l}20 / 41 \\
48,8 \%\end{array}$ & $\begin{array}{l}22 / 39 \\
56,4 \%\end{array}$ & $\begin{array}{l}39 / 46 \\
84,8 \%\end{array}$ \\
\hline $\begin{array}{l}\text { FLS: Com correspondência } \\
\text { com a região ou o lobo de } \\
\text { origem eletroclínica das } \\
\text { crises. }\end{array}$ & $\begin{array}{l}3 / 31 \\
9,7 \%\end{array}$ & $\begin{array}{l}3 / 31 \\
9,7 \%\end{array}$ & $\begin{array}{c}4 / 26 \\
15,4 \%\end{array}$ & $\begin{array}{c}7 / 28 \\
25,0 \%\end{array}$ & $\begin{array}{c}9 / 29 \\
31,0 \%\end{array}$ & $\begin{array}{r}16 / 31 \\
51,6 \%\end{array}$ \\
\hline $\begin{array}{l}\text { FLS: Sem correspondência } \\
\text { com a região ou o lobo de } \\
\text { origem eletroclínica das } \\
\text { crises. }\end{array}$ & $\begin{array}{c}8 / 31 \\
25,8 \%\end{array}$ & $\begin{array}{c}9 / 31 \\
29,0 \%\end{array}$ & $\begin{array}{c}9 / 26 \\
34,6 \%\end{array}$ & $\begin{array}{c}9 / 28 \\
32,1 \%\end{array}$ & $\begin{array}{r}15 / 29 \\
51,7 \%\end{array}$ & $\begin{array}{l}26 / 31 \\
83,9 \%\end{array}$ \\
\hline
\end{tabular}

EFRTM: Epilepsia parcial (focal) refratária ao tratamento medicamentoso. EC: Espessura cortical. JBC: Junção entre as substâncias branca e cinzenta. TTM: Taxa de transferência de magnetização. RT2: Relaxometria T2, DM: Difusibilidade média. FLS: Foco localizatório suspeito.

$\mathrm{Na}$ tabela 8 há uma visão mais detalhada de todos os pacientes individualmente em relação aos achados alterados encontrados em cada medida quantitativa, se houve correspondência ou não com a origem eletroclínica das crises nos casos pertinentes (naqueles considerados como FLS) e a localização dos achados (quando presentes) na avaliação visual após direcionamento localizatório, seja pelo VEEG, seja pelos métodos de pós-processamentos com os dados de RM. 
TABELA: Resultados, por paciente, da localização dos achados no videoencefalograma, nas análises das medidas quantitativas de ressonância magnética e na reavaliação visual com direcionamento localizatório, considerando todos os dados em conjunto.

\begin{tabular}{|c|c|c|c|c|c|c|c|}
\hline Paciente & EEG & EC & JBC & TTM & RT2 & DM & AVDL \\
\hline 1 & NLSR & - & - & - & - & + & NDN \\
\hline 2 & LTD & - & $+\mathrm{SC}$ & - & - & $+\mathrm{CC}(\mathrm{OR})$ & NDN \\
\hline 3 & NLSR & - & - & NA & - & - & NDN \\
\hline 4 & RFTE & - & - & - & NA & $+\mathrm{CC}(\mathrm{OR})$ & NDN \\
\hline 5 & RFTE & $+\mathrm{SC}$ & $+\mathrm{SC}$ & NA & - & $+\mathrm{CC}(\mathrm{OR})$ & NDN \\
\hline 6 & RRD & - & $+\mathrm{SC}$ & - & $+S C$ & - & NDN \\
\hline 7 & RFTE & $+\mathrm{CC}(\mathrm{OR})$ & $+\mathrm{CC}(\mathrm{OR})$ & $+\mathrm{CC}(\mathrm{OR})$ & $+\mathrm{CC}$ & $+\mathrm{CC}(\mathrm{OR})$ & NDN \\
\hline 8 & RFTD & - & - & $+\mathrm{CC}$ & - & $+\mathrm{CC}(\mathrm{OR})$ & NDN \\
\hline 9 & NLSR & - & - & - & - & NA & NDN \\
\hline 10 & LFD RR & - & - & - & - & NA & NDN \\
\hline 11 & LFD & - & $+\mathrm{SC}$ & $+\mathrm{SC}$ & - & - & NDN \\
\hline 12 & RRD & - & $+S C$ & $+\mathrm{CC}(\mathrm{OR})$ & - & NA & NDN \\
\hline 13 & LPD & $+\mathrm{SC}$ & - & $+\mathrm{SC}$ & NA & $+\mathrm{SC}$ & NDN \\
\hline 14 & LFD & $+\mathrm{SC}$ & $+\mathrm{SC}$ & - & - & $+S C$ & RIAE \\
\hline 15 & LTE & $+\mathrm{SC}$ & - & $+\mathrm{SC}$ & $+\mathrm{CC}$ & $+\mathrm{SC}$ & NDN \\
\hline 16 & HCD SR & + & + & NA & + & NA & NDN \\
\hline 17 & NLSR & + & - & - & + & + & RPOB \\
\hline 18 & LFE & - & $+\mathrm{SC}$ & - & NA & - & LFE \\
\hline 19 & NLSR & + & + & - & + & - & RTID \\
\hline 20 & RTPOE & - & $+\mathrm{Cc}$ & - & - & $+s c$ & LPE \\
\hline 21 & NLSR & - & - & NA & NA & NA & NDN \\
\hline 22 & LTE & - & $+\mathrm{CC}$ & $+\mathrm{SC}$ & $+\mathrm{SC}$ & $+\mathrm{CC}(\mathrm{OR})$ & NDN \\
\hline 23 & NLSR & - & + & + & + & NA & NDN \\
\hline 24 & RTPOE & $+\mathrm{CC}$ & - & - & - & - & RTOE \\
\hline 25 & LFE & - & - & NA & - & - & NDN \\
\hline 26 & NLSR & - & - & - & - & - & NDN \\
\hline 27 & RFTE & $+\mathrm{CC}$ & - & - & - & - & NDN \\
\hline 28 & NLSR & + & - & + & - & - & NDN \\
\hline 29 & RTO NL & - & - & - & $+\mathrm{CC}$ & $+\mathrm{CC}(\mathrm{OR})$ & NDN \\
\hline 30 & RRE & $+S C$ & - & - & - & - & NDN \\
\hline 31 & NLSR & - & - & + & - & + & NDN \\
\hline 32 & LPE & - & - & NA & $+S C$ & - & LPE \\
\hline 33 & RFTD & - & - & $+\mathrm{CC}(\mathrm{OR})$ & $+\mathrm{CC}(\mathrm{OR})$ & - & NDN \\
\hline
\end{tabular}




\begin{tabular}{cccccccc}
\hline Paciente & EEG & EC & JBC & TTM & RT2 & DM & AVDL \\
\hline 34 & NLSR & - & - & - & NA & - & NDN \\
35 & NLSR & - & - & NA & + & + & NDN \\
36 & NLSR & + & - & + & - & + & NDN \\
37 & NLSR & - & + & + & - & + & NDN \\
38 & LTE & - & - & - & + CC (OR) & + SC & NDN \\
39 & RRE & + SC & - & + SC & - & - & LPE \\
40 & LTD & - & - & - & + CC & + CC (OR) & NDN \\
41 & LFD & + SC & + SC & - & + CC & + CC (OR) & NDN \\
42 & RFTD & - & - & - & + SC & NA & NDN \\
43 & LTE & - & + SC & NA & + SC & + SC & NDN \\
44 & NLSR & - & + & - & + & + & NDN \\
45 & LTE & - & - & - & + SC & - & NDN \\
46 & LOE & - & - & + SC & + SC & - & NDN \\
\hline
\end{tabular}

EEG: Eletroencefalograma, EC: Espessura cortical. JBC: Junção entre as substâncias branca e cinzenta. TTM: Taxa de transferência de magnetização. RT2: Relaxometria T2, DM: Difusibilidade média. NLSR: Não lateralizatório e sem regionalização. LTD: Lobo temporal direito. RFTE: Região frontotemporal esquerda. RRD: Região rolândica direita. RFTD: Região frontotemporal direita. LFD RR: Lobo frontal direito na região rolândica. LPD: Lobo parietal direito. LFD: Lobo frontal direito. HCD SR: Hemisfério cerebral direito sem regionalização. LFE: Lobo frontal esquerdo. RTPOE: Região têmporo-occipital esquerda. LTE: Lobo temporal esquerdo. RTO NL: Região têmporo-occipital não lateralizatória. RRE: Região rolândica esquerda. LPE: Lobo parietal esquerdo. LOE: Lobo occipital esquerdo: sem achados positivos ou alterados (negativo), + SC: achado positivo (alterado) sem correspondência com a origem eletroclínica das crises. + CC (OR): achados positivos (alterados) com correspondência com a origem eletroclínica das crises e em outras regiões. NA: Não avaliado devido à falha no pós-processamento. + CC: achado positivo (alterado) apenas com correspondência com a origem eletroclínica das crises. +: achado positivo (alterado) em paciente sem definição da origem eletroclínica das crises. NDN: Nada digno de nota. AVDL: Avaliação visual com direcionamento localizatório. RIAE: Região da ínsula anterior esquerda. RPOB: Região parieto-occipital bilateral. RTID: Região têmporo-insular direita. RTOE: Região têmporo-occipital esquerda.

\subsection{Avaliação da espessura cortical (SBM da EC)}

$\mathrm{Na}$ análise de um indivíduo normal retirado do grupo dos controles saudáveis versus o restante do grupo foram encontradas alterações em três pacientes (um de afilamento e dois de espessamento), ou seja, em 10\% (3/30). Este grupo dos avaliados individualmente foi formado por 15 homens, 15 mulheres, idade média de 30,4 anos, desvio-padrão de 8,2 anos e faixa etária de 19 a 51 anos.

No grupo desses pacientes observamos algum tipo de alteração em 15 dos 46 investigados (15/46 ou 32,6\%), sendo seis com áreas de espessamento cortical, seis com áreas de afilamento e três apresentando tanto áreas de afilamento quanto de espessamento. Em sete pacientes os achados foram únicos (7/46 ou 15,2\%), e em oito múltiplos $(8 / 46$ ou $17,4 \%)$. 
Nos pacientes considerados como FLS, verificamos achados anormais nesta avaliação em dez pacientes (10/31 ou 32,2\%), sendo três com áreas de espessamento cortical, quatro com áreas de afilamento e três apresentando tanto áreas de afilamento quanto de espessamento. Três $(9,7 \%)$ dos 31 pacientes com FLS apresentaram aumento ou afilamento da EC no lobo ou na região de provável início das crises, sendo que o achado de espessamento foi encontrado apenas em um paciente, espessamento e afilamento em outro e exclusivamente afilamento em um único paciente (Figura 28). Destes, um (1/3 ou 33\%) também apresentou alterações em outros lobos ou regiões. Paralelamente, sete pacientes com FLS apresentaram alguma alteração apenas em outra região (7/31 ou 22,5\%). Em nenhum dos pacientes operados foi encontrada alteração na região ressecada.

FIGURA 28: Pós-processamentos individualizados da medida da espessura cortical (EC) de dois pacientes, utilizando-se da ferramenta QDEC para visualização das alterações no cérebro-padrão inflado. A) Exemplo do paciente 24, no qual é possível identificar regiões com medidas da EC consideradas reduzidas (vermelho) e aumentadas (azul). Pelo videoencefalograma (VEEG), a zona epileptogênica (ZE) foi considerada como localizada na região têmporo-parieto-occipital esquerda. B) Exemplo do paciente 27, em que é possível identificar regiões com medida da EC considerada reduzida (áreas em vermelho). Pelo VEEG, a ZE foi considerada como localizada na região frontotemporal esquerda. Nos dois pacientes, essas alterações foram consideradas significativas com as variáveis escolhidas (FDR: 0,05 e "smoothing" de $10 \mathrm{~mm}$ ). FDR: false discovery rate.

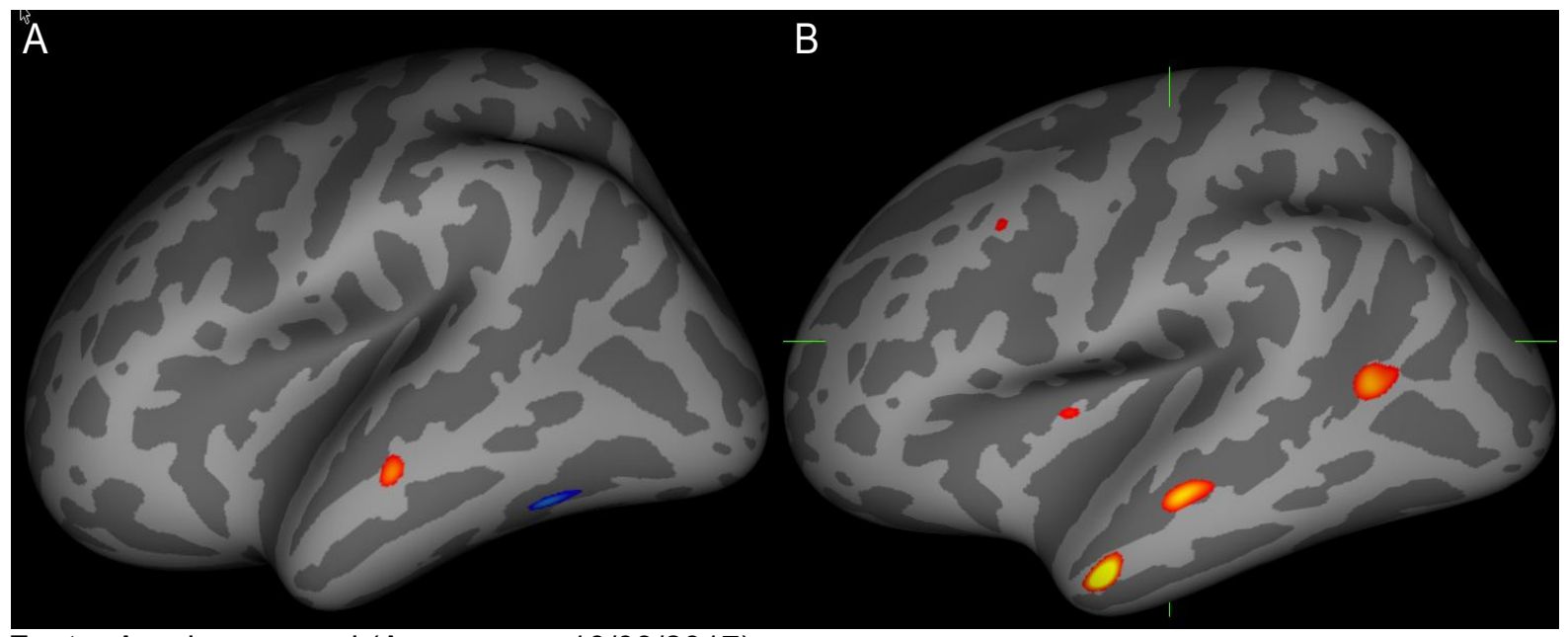

Fonte: Arquivo pessoal (Acesso em: 10/03/2017). 
Entre os pacientes considerados como FNL, verificamos achados anormais nesta avaliação em cinco (5/15 ou $33,3 \%)$, sendo três com áreas de espessamento cortical e dois com áreas de afilamento.

\subsection{Avaliação dos mapas de junção entre as substâncias branca e cinzenta (VBA da JBC)}

Testamos os parâmetros tanto para aumento quanto para redução do contraste da JBC.

$\mathrm{Na}$ avaliação individual dos 20 controles saudáveis testados, utilizamos um valor-p não corrigido de 0,001 que consideramos adequado. No gráfico 1 podemos verificar as taxas de falso-positivos de acordo com o agrupamento de voxels escolhido. Assim, utilizamos um agrupamento de 30 voxels com o valor-p não corrigido de 0,001 para a avaliação dos pacientes, pois nesse limiar a taxa de falsopositivos foi de $10 \%$, a mesma encontrada na técnica SBM para análise da EC.

GRÁFICO 1: Taxa de falso-positivos versus o agrupamento de voxels na análise individual dos pós-processamentos dos controles saudáveis, referente aos mapas de junção entre as substâncias branca e cinzenta (JBC) e com um valor-p não corrigido de 0,001 . Veja que com um agrupamento de 30 voxels a taxa de falso-positivos é de $10 \%$ (seta azul).

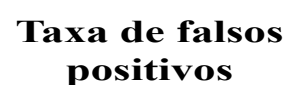
positivos

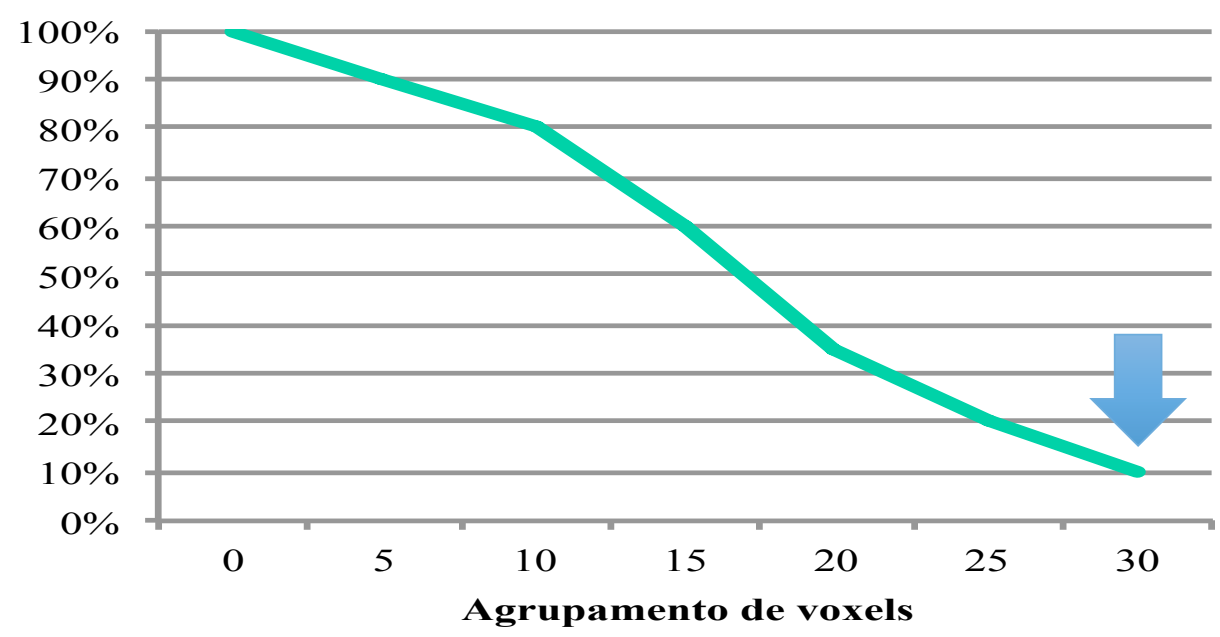


$\mathrm{Na}$ análise estatística dos resultados JBC pelo SPM12 foi detectada ao menos uma área de borramento na transição branco/cinzenta em 17 pacientes dos 46 investigados, ou seja, em 36,9\%\%. Quinze destes (15/46 ou 32,6\%) apresentaram achados múltiplos e dois (2/46 ou 4,3\%) achado único.

Dos 31 pacientes com FLS, 12 apresentaram alteração em alguma região, ou seja, $12 / 31$ ou $38,7 \%$. Três apresentaram esta alteração no lobo ou na região de provável início das crises (3/31 ou 9,7\%). Destes, um também teve alterações em outros lobos (1/3 ou 33\%). Paralelamente, oito pacientes com FLS apresentaram alguma alteração apenas em outra região (8/31 ou 25,8\%). Em um dos pacientes operados foi encontrada certa correspondência com a região ressecada, ou seja 1/5 ou $20 \%$ (Figura 29 ).

FIGURA 29: Exemplo do paciente 22, operado e com diagnóstico de displasia cortical tipo la. Axial FLAIR (A), sem evidência de alterações estruturais. Reconstrução axial de aquisição tomográfica 3D (B) mostrando o local da cirurgia com ressecção da região têmporo-occipital esquerda sem sinais de complicação. C) Resultado do pós-processamento dos mapas de junção entre as substâncias branca e cinzenta pelo programa de mapeamento estatístico paramétrico (SPM12) desse paciente versus o grupo-controle de indivíduos normais mostrando um agrupamento de voxels alterados (setas pretas) no que se define como variável contraste negativo (valor-p não corrigido de 0,001 e agrupamento de 30 voxels) na mesma região da ressecção cirúrgica. FLAIR: Fluid attenuated inversion-recovery.

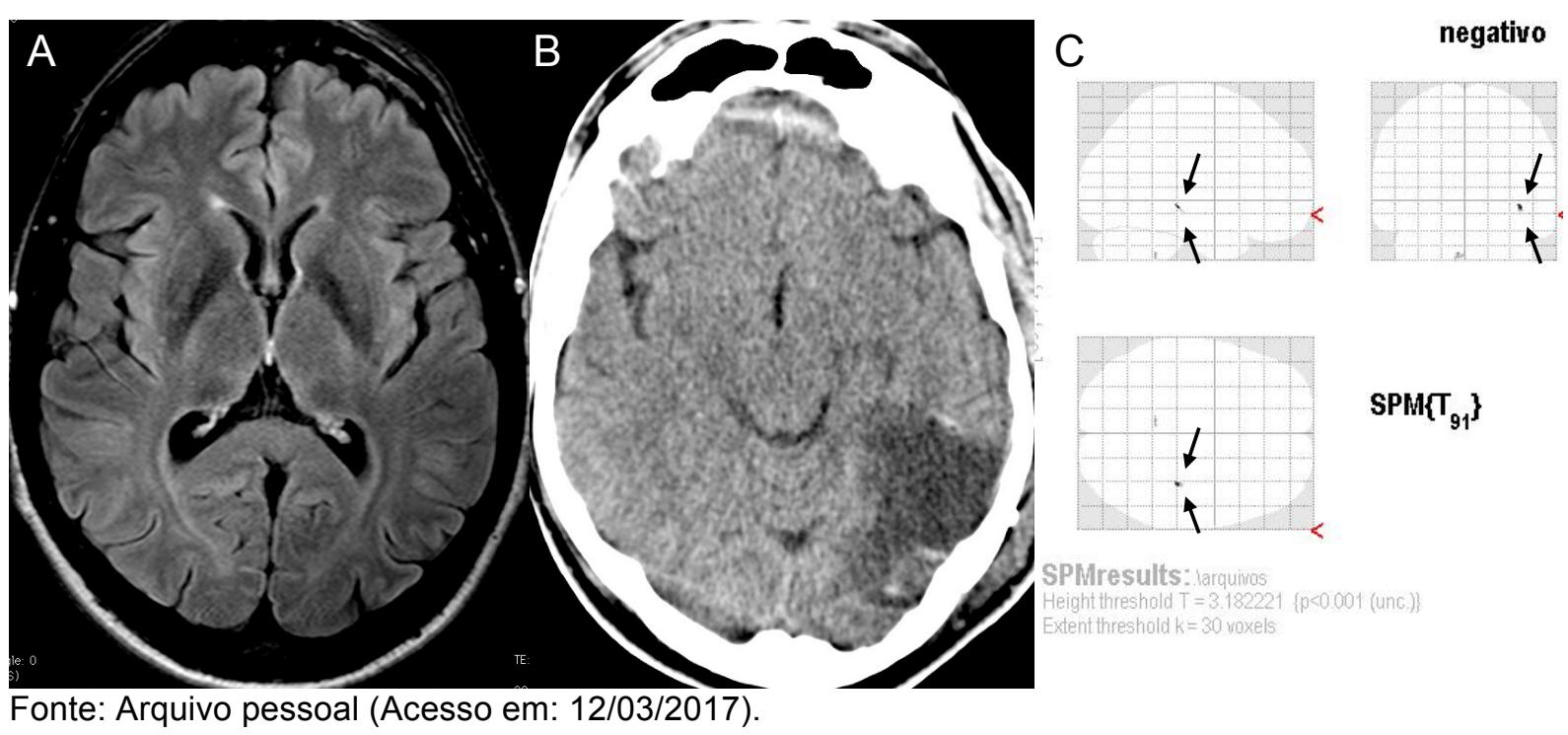


No grupo do estudo considerado como FNL este possível achado de borramento da JBC foi encontrado em cinco pacientes, ou seja, 5/15 ou 33,3\%. Em todos eles, o achado foi considerado único.

\subsection{Avaliação dos mapas da relaxometria T2 (VBA da RT2).}

Testamos os parâmetros tanto para aumento quanto para redução do tempo de relaxação T2.

$\mathrm{Na}$ avaliação individual dos 20 controles saudáveis testados utilizamos um valor-p corrigido pelo FWE de 0,05 , que se mostrou mais adequado após não conseguirmos obter taxas satisfatórias de falso-positivos nas tentativas com valor-p não corrigido de 0,001, mesmo com agrupamento de voxels elevados. No gráfico 2 podemos verificar as taxas de falso-positivos de acordo com o agrupamento de voxels escolhido. Assim, utilizamos um agrupamento de 55 voxels com o valor-p corrigido pelo FWE de 0,05 para a avaliação dos pacientes, pois nesse limiar a taxa de falso-positivos foi de $10 \%$.

GRÁFICO 2: Taxa de falso-positivos versus o agrupamento de voxels na análise individual dos pós-processamentos dos controles saudáveis, referente aos mapas da relaxometria T2 (RT2) e com um valor-p corrigido pelo de family-wise error (FWE) de 0,05 . Veja que com um agrupamento de 55 voxels a taxa de falso-positivos é de $10 \%$ (seta azul).

Taxa de falsos positivos

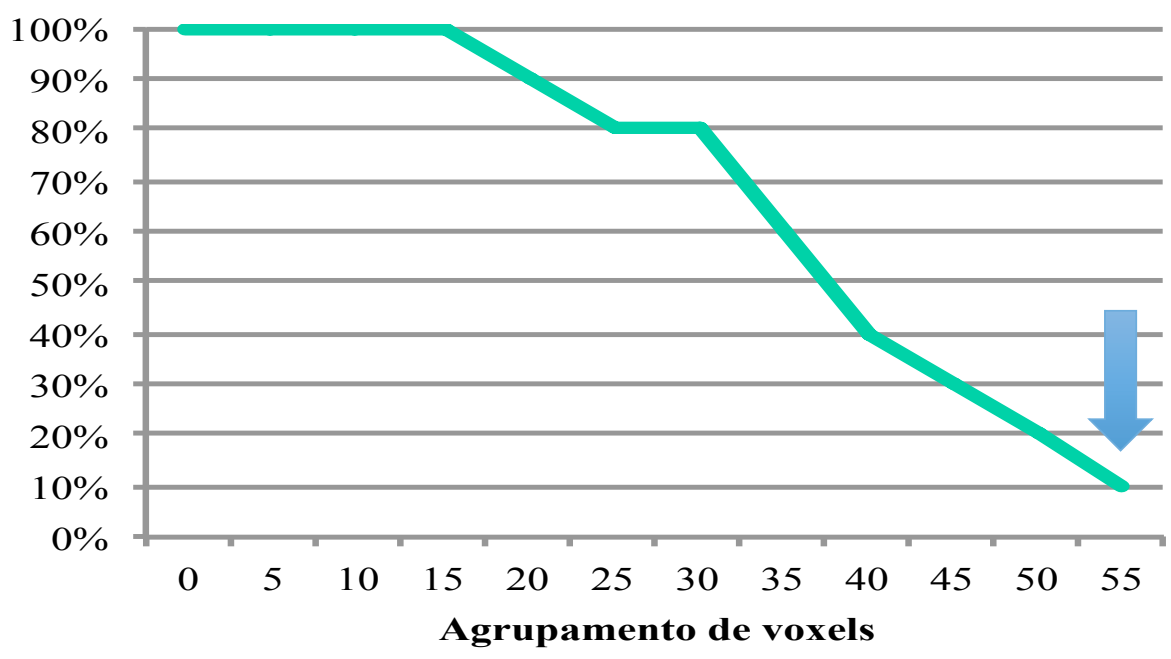


Na análise dos mapas de RT2 pelo programa SPM12 houve falhas no pósprocessamento em cinco pacientes (5/46 ou 10,9\%) por problemas nas aquisições das imagens e/ou corregistro, sendo três com FLS e dois considerados como FNL.

Dos 41 pacientes restantes, notamos áreas alteradas em 20, ou seja, 20/41 ou 48,8\%, sendo dez com achados múltiplos e dez com achado único (10/41 ou $24,4 \%$ ). Todos apresentaram aumento do tempo de relaxação T2, e em apenas dois foram evidenciadas regiões de diminuição desse parâmetro.

Dos 28 pacientes remanescentes com FLS, 14 apresentaram alteração em alguma região, ou seja, $14 / 28$ ou $50,0 \%$. Sete apresentaram essa alteração no lobo ou na região de provável início das crises, isto é $7 / 28$ ou 25,0\% (Figura 30). Destes, dois também tiveram alterações em outros lobos. Paralelamente, sete pacientes com FLS e possíveis de avaliação apresentaram alguma alteração apenas em outra região (7/28 ou $25,0 \%)$. Em nenhum dos pacientes operados foi encontrada alguma correspondência com a região operada.

FIGURA 30: Exemplos dos pós-processamentos dos mapas de relaxometria T2 (RT2) pelo programa de mapeamento estatístico paramétrico (SPM12) de dois pacientes. A) Paciente 7 apresentando agrupamentos de voxels alterados (focos vermelhos) na região frontal esquerda, a mesma considerada como a zona epileptogênica (ZE) pelo videoencefalograma (VEEG). B) Paciente 40 apresentando na região temporal direita, a mesma sugerida com sendo a ZE no VEEG, agrupamentos de voxels alterados (focos vermelhos). Em ambos os casos, essas alterações foram apenas nas regiões sugeridas pelo VEEG.

A
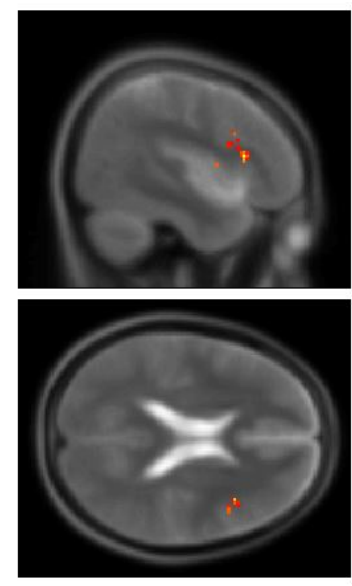
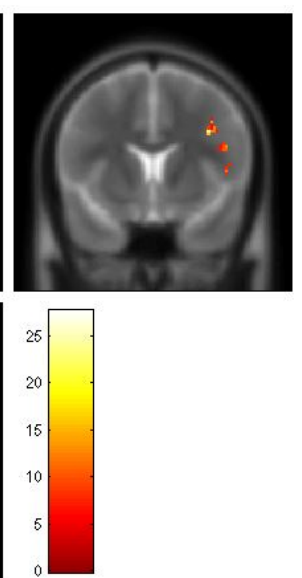

B
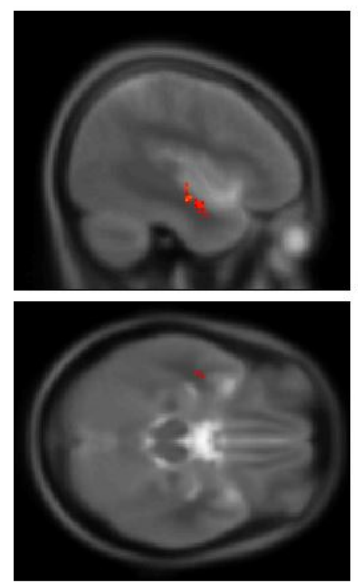
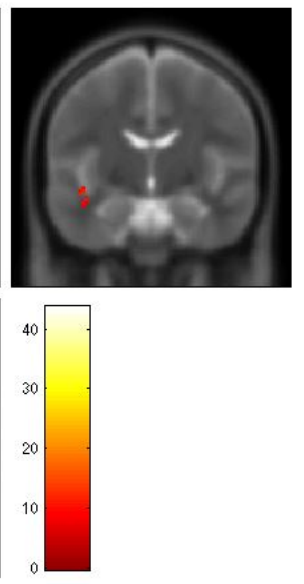

Arquivo pessoal (Acesso em: 17/03/2017). 
No grupo remanescente do estudo considerado como FNL foram encontradas alterações em cinco pacientes, ou seja, $6 / 13$ ou $46,1 \%$.

\subsection{Avaliação dos mapas de transferência de magnetização (VBA da TTM)}

Também foram testados os parâmetros tanto para aumento quanto para redução da TTM.

$\mathrm{Na}$ avaliação individual dos 20 controles saudáveis testados utilizamos um valor-p corrigido pelo FWE de 0,05 , que se mostrou mais adequado após não conseguirmos obter taxas satisfatórias de falso-positivos nas tentativas com valor-p não corrigido de 0,001 , mesmo com agrupamentos de voxels elevados. No gráfico 3 podemos verificar a taxa de falso-positivos de acordo com o agrupamento de voxels escolhido. Assim, utilizamos um agrupamento de 30 voxels com o valor-p corrigido pelo FWE de 0,05 para a avaliação dos pacientes, pois nesse limiar a taxa de falsopositivos foi de $10 \%$.

GRÁFICO 3: Taxa de falso-positivos versus o agrupamento de voxels na análise individual dos pós-processamentos dos controles saudáveis, referente aos mapas de transferência de magnetização (TTM) e com um valor-p corrigido pelo de family-wise error (FWE) de 0,05. Veja que com um agrupamento de 30 voxels a taxa de falsopositivos é de $10 \%$ (seta azul).

Taxa de falsos posiivos

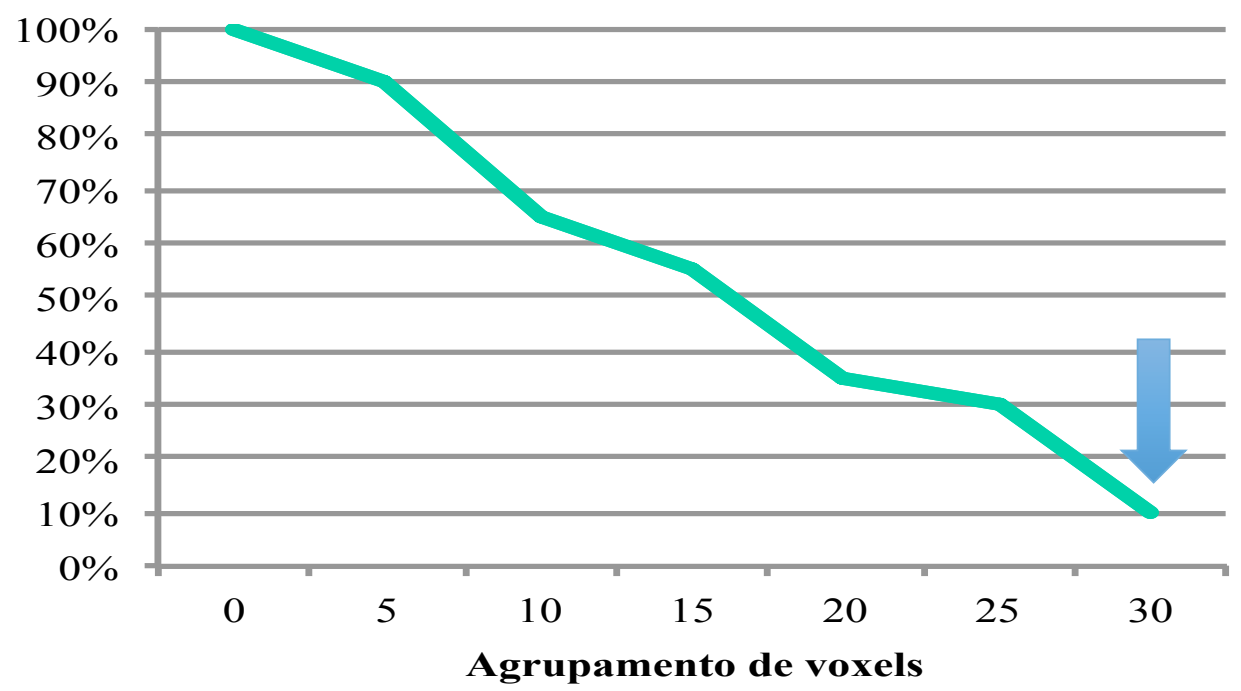


$\mathrm{Na}$ análise da sequência TM pelo programa SPM12 e analisando os mapas de TTM houve falhas no pós-processamento em oito pacientes ( $8 / 46$ ou $17,4 \%$ ) por problemas nas aquisições das imagens e/ou corregistro, sendo cinco destes com FLS e três considerados como FNL.

Dos 38 pacientes restantes foram constatadas áreas alteradas em 15, ou seja, $15 / 38$ ou $39,5 \%$. Cinco deles (5/38 ou $13,2 \%$ ) apresentaram achados múltiplos e dez (10/38 ou 26,2\%) em uma única região ou lobo. Todos apresentaram redução da TTM.

Dos 26 pacientes remanescentes com FLS, dez apresentaram alteração em alguma região, ou seja, $10 / 26$ ou $38,5 \%$. Quatro apresentaram esta alteração no lobo ou na região de provável início das crises, ou seja, 4/26 ou 15,4\% (Figura 31). Destes, três também tiveram alterações em outros lobos. Paralelamente, seis pacientes com FLS e possíveis de avaliação apresentaram alguma alteração apenas em outra região (6/26 ou $23,1 \%$ ). Em um dos pacientes operados (paciente 22) foi encontrada alguma correspondência com a região operada, ou seja $1 / 4$ ou $20 \%$. Em um dos pacientes operados houve falhas no pós-processamento.

FIGURA 31: Exemplo do pós-processamento dos mapas da taxa de transferência de magnetização (TTM) pelo programa de mapeamento estatístico paramétrico (SPM12) do paciente 7. Resultados apresentando agrupamentos de voxels alterados (focos vermelhos e amarelos) na região temporal esquerda (A e B). A zona epileptogênica foi considerada como de origem frontotemporal esquerda pelo videoencefalograma.
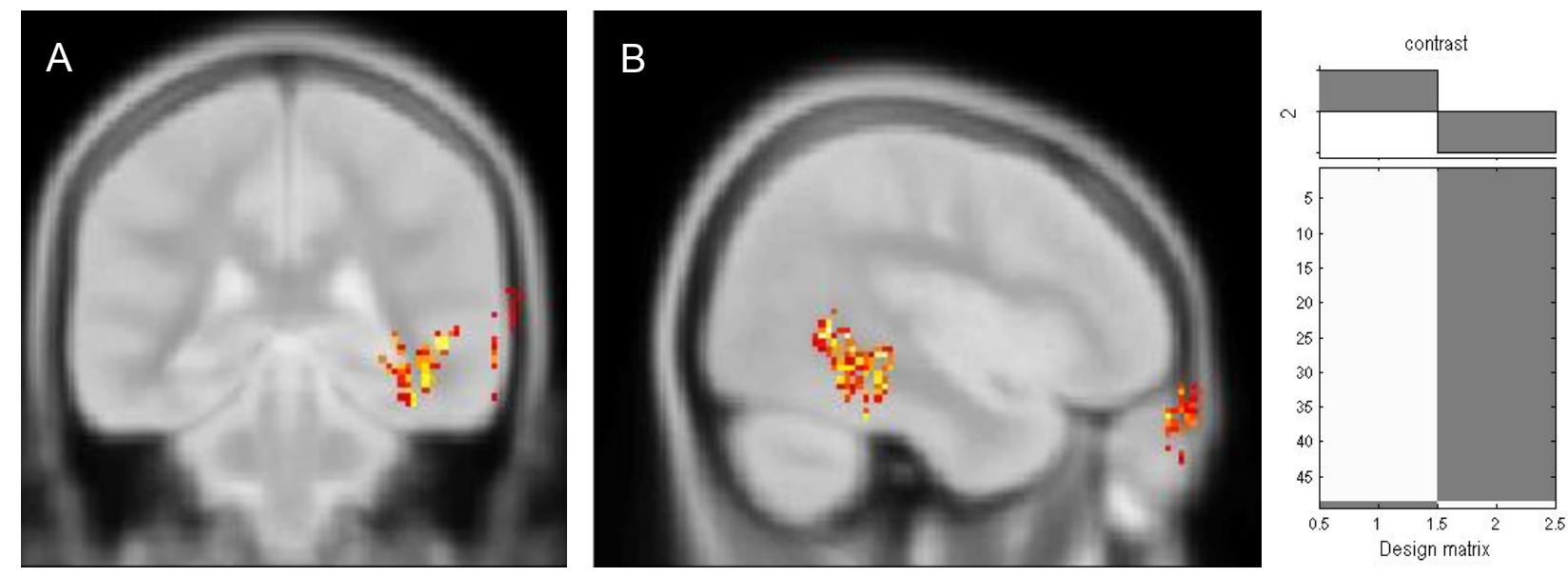

Fonte: Arquivo pessoal (Acesso em: 21/03/2017). 
No grupo remanescente do estudo considerado como FNL foram encontradas alterações em cinco pacientes, ou seja, $5 / 11$ ou $45,4 \%$.

\subsection{Avaliação dos mapas de difusibilidade média (VBA da DM).}

Os parâmetros foram testados tanto para aumento quanto para redução da DM.

$\mathrm{Na}$ avaliação individual dos 20 controles saudáveis testados utilizamos um valor-p corrigido pelo FWE de 0,05 , que se mostrou mais adequado após não conseguirmos obter taxas satisfatórias de falso-positivos nas tentativas com valor-p não corrigido de 0,001, mesmo com agrupamentos de voxels elevados. No gráfico 4 podemos verificar as taxas de falso-positivos de acordo com o agrupamento de voxels escolhido. Assim, utilizamos um agrupamento de 40 voxels com o valor-p corrigido pelo FWE de 0,05 para a avaliação dos pacientes, pois nesse limiar a taxa de falso- positivos foi de $10 \%$.

GRÁFICO 4: Taxa de falso-positivos versus o agrupamento de voxels na análise individual dos pós-processamentos dos controles saudáveis, referente aos mapas de difusibilidade média (DM) e com um valor-p corrigido pelo de family-wise error (FWE) de 0,05 . Veja que com um agrupamento de 40 voxels a taxa de falso-positivos é de $10 \%$ (seta azul).

Taxa de falsos positivos

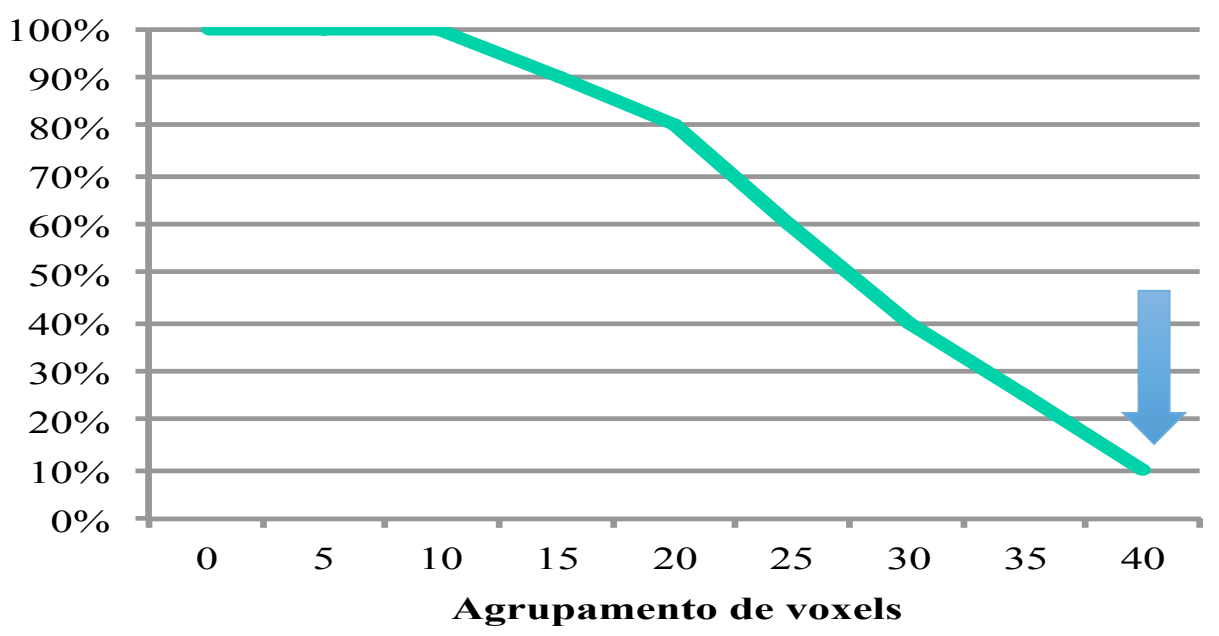


$\mathrm{Na}$ análise da sequência de DTI pelo programa SPM12 e analisando os mapas de DM tivemos falhas no pós-processamento em sete pacientes (7/46 ou $15,2 \%)$, por problemas nas aquisições das imagens e/ou corregistro, sendo dois destes com FLS e cinco considerados como FNL.

Dos 39 pacientes restantes, verificamos áreas alteradas em 22, ou seja, $22 / 39$ ou $56,4 \%$. Dez destes (10/39 ou 25,6\%) apresentaram achados múltiplos e 12 (12/39 ou $30,8 \%)$ achado único. Todos mostraram aumento da DM.

Dos 29 pacientes remanescentes com FLS, 15 apresentaram alteração em alguma região, ou seja, $15 / 29$ ou $51,7 \%$. Nove apresentaram esta alteração no lobo ou na região de provável início das crises $(9 / 29$ ou $31,0 \%)$. Destes, todos também tiveram alterações em outros lobos. Paralelamente, seis pacientes com FLS e possíveis de avaliação apresentaram alguma alteração apenas em outra região (6/29 ou $20,7 \%$ ). Em um dos pacientes operados (paciente 22) foi encontrada alguma correspondência com a região operada, ou seja $1 / 5$ ou $20 \%$ (Figura 32). 
FIGURA 32: Exemplos dos pós-processamentos dos mapas de difusibilidade média (DM) pelo mapeamento estatístico paramétrico (SPM12) de dois pacientes. A) Paciente 7 apresentando agrupamentos de voxels alterados (focos vermelhos e amarelos) na região frontotemporal esquerda, a mesma considerada como a zona epileptogênica pelo videoencefalograma. B). Paciente 22, que foi operado com ressecção têmporo-occipital esquerda e teve diagnóstico anátomo-histopatológico de displasia cortical focal tipo la, apresentando, na mesma região abordada cirurgicamente, agrupamentos de voxels alterados (focos vermelhos e amarelos). Nos dois casos é possível identificar outras regiões com alteração da difusibilidade média.

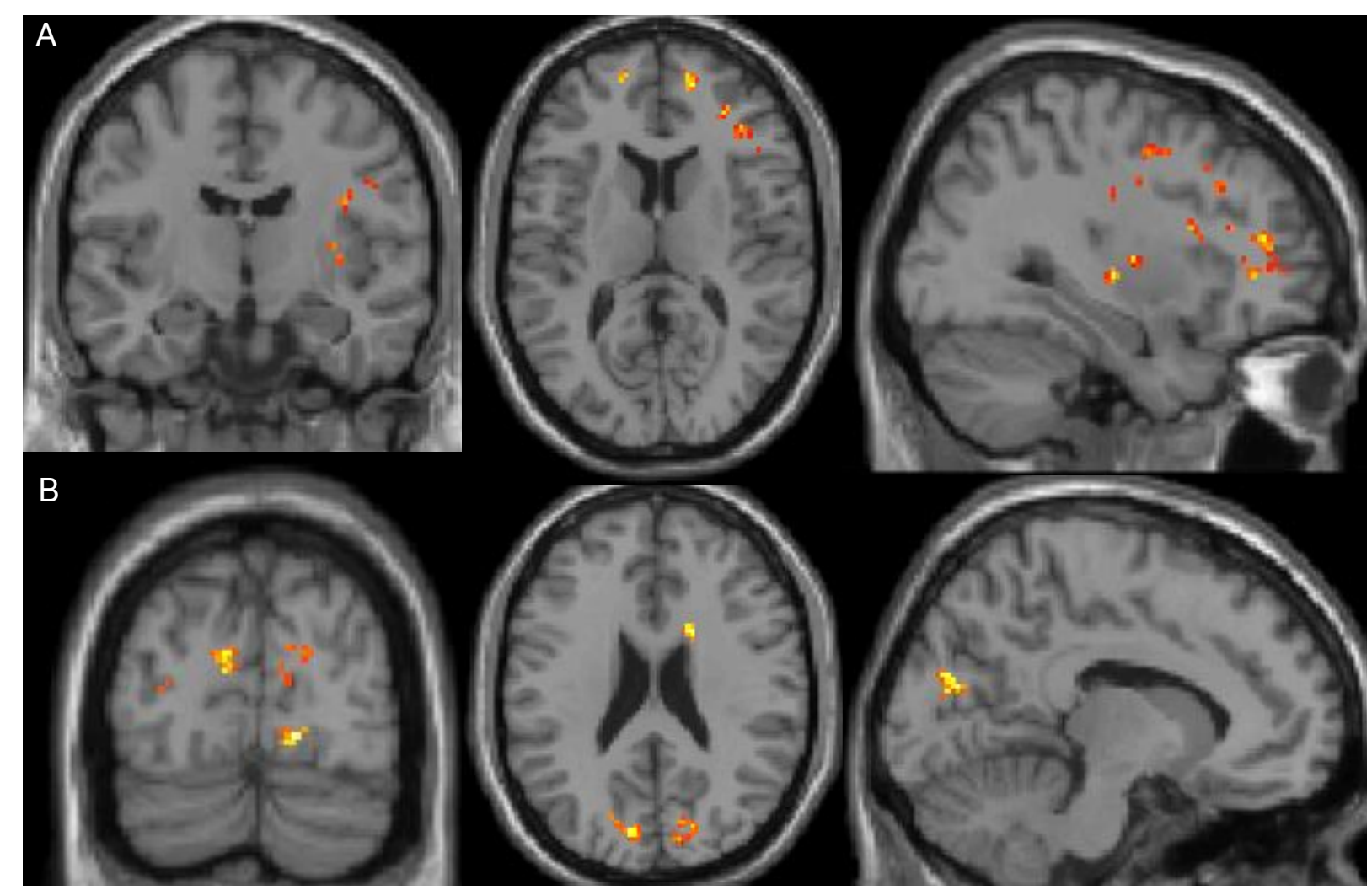

Arquivo pessoal (Acesso em: 16/03/2017).

No grupo remanescente do estudo considerado como FNL foram encontradas alterações em sete pacientes, ou seja, $7 / 10$ ou $70,0 \%$. 


\subsection{Avaliação conjunta das análises quantitativas}

Dezesseis pacientes apresentaram falhas nos pós-processamentos em pelo menos uma das técnicas por problemas nas aquisições das imagens e/ou corregistro (16/46 ou $34,8 \%)$. Um paciente teve falhas em duas, e outro em três técnicas.

Sete pacientes não apresentaram regiões consideradas alteradas mesmo considerando todas as avaliações quantitativas (7/46 ou 15,2\%). Dois destes foram considerados como FLS e cinco como FNL.

Quinze pacientes do grupo com FLS tiveram anormalidades de sinal em pelo menos uma das medidas quantitativas do SBM ou VBA no lobo ou na região considerada como a ZE (16/31 ou 51,6\%). Todos estes também apresentaram alteração em outras regiões em ao menos uma das medidas quantitativas. Foram detectadas alterações em pelo menos duas destas medidas que correspondiam à região sugerida pelo VEEG em sete destes pacientes, isto é, $7 / 31$ ou $22,6 \%$. Entretanto, uma localização mais próxima (mesmo lobo) dos achados (colocalização) foi identificada em cinco pacientes deste grupo (pacientes 7, 19, 22, 29 e 40) ou seja 5/31 ou 16,1\% (Figura 33). Paralelemente, 26 pacientes deste grupo apresentaram alteração fora da região de possível origem das crises em pelo menos uma das medidas (26/31 ou $83,9 \%$ ) e 14 em pelo menos duas (14/31 ou $45,2 \%)$. Em um dos pacientes operados houve alguma correspondência entre as medidas quantitativas, duas das cinco utilizadas no estudo, e a região operada (paciente 22). 
FIGURA 33: Exemplo do paciente 7, considerado com foco localizatório suspeito pela origem eletroclínica das crises e que apresentou colocalização de achados concordantes com a possível zona epileptogênica (ZE) localizada na região frontotemporal esquerda. Nas imagens é possível identificar três medidas quantitativas positivas para a mesma região. Resultados dos pós-processamentos pelo programa de mapeamento estatístico paramétrico (SPM12) da relaxometria (RT2) (A: plano coronal) e difusibilidade média (DM) (B: plano sagital), assim como da espessura cortical (EC) pelo QDEC do FreeSurfer, evidenciam alterações notadamente no lobo frontal esquerdo.

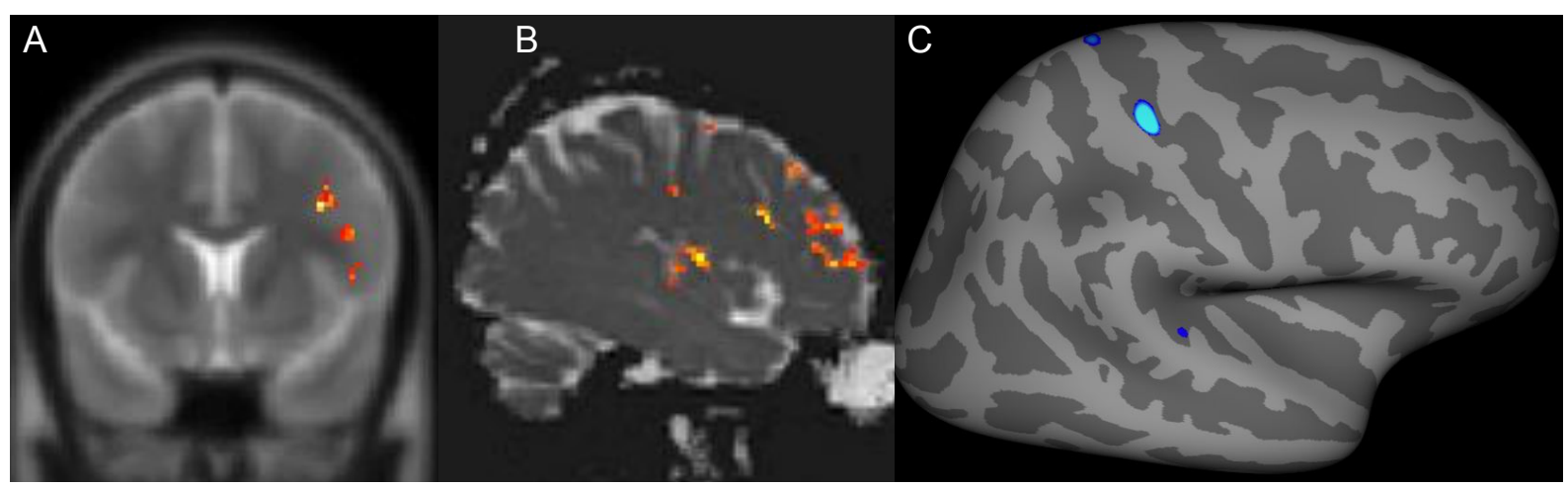

Fonte: Arquivo pessoal (Acesso em: 21/03/2017).

No grupo remanescente do estudo considerado como FNL foram encontradas alterações em 12 pacientes em pelo menos uma das avaliações quantitativas, ou seja, $12 / 14$ ou $85,7 \%$.

\subsection{Avaliação visual da RM com direcionamento localizatório pelos pós- processamentos}

Em cinco dos 46 pacientes (5/46 ou 10,9\%) incluídos no estudo inicialmente como RM NLE foi possível identificar alguma alteração estrutural após a avaliação visual com direcionamento localizatório pelo conjunto das medidas quantitativas do estudo através dos pós-processamentos (AVDLPP). Foram os pacientes 14, 17, 19, 20 e 24. Todas essas alterações identificadas foram apresentadas ao radiologista e docente responsável por esta área do CCIFM - HCFMRP/USP e a um dos neurologistas responsáveis pelo CIREP - HCFMRP/USP, ambos conhecedores da neuroimagem em epilepsia. As hipóteses diagnósticas para essas lesões pertenciam ao grupo das patologias possivelmente epileptogênicas, notadamente as DCFs. 
Três destes pacientes foram classificados como FLS pelo VEEG (3/5 ou $60 \%$ ), porém em um houve discordância da localização sugerida pela avaliação eletroclínica e a região do achado suspeito. Os outros dois foram classificados como FNL pelo VEEG (2/5 ou $40 \%$ ). Em quatro pacientes ( $4 / 46$ ou $8,7 \%$ ) utilizamos, principalmente, a avaliação SBM da EC e, no caso de um paciente (1/46 ou 2,2\%), a avaliação VBA da JBC. Em um deles houve colocalização entre os achados das avaliações SBM, da EC VBA da RT2 e da alteração estrutural na inspeção visual (paciente 19).

Em todos estes pacientes a sequência 3D T1 RAGE, a mesma utilizada para a análise SBM da EC e VBA da JBC, evidenciou as alterações. Em todos eles outras sequências rotineiramente utilizadas, como axial FLAIR não volumétrico, coronal FLAIR não volumétrico e coronal T2 STIR, influenciaram bastante na confirmação dos achados. Em dois deste grupo os axiais T2 STIR também foram bastante úteis. Por fim, em três deles foi realizada a sequência 3D FLAIR e, em pelo menos dois (pacientes 18 e 19), é possível afirmar, ainda que subjetivamente, que houve uma mais clara caracterização das lesões com esta técnica.

Nos quatro pacientes em que a medida da EC orientou a identificação de alterações estruturais, o achado característico foi exatamente o apontado no programa FreeSurfer, isto é, um espessamento cortical (Figura 34). Em todos eles, sequência 3D T1 possibilitou a caracterização do espessamento cortical. Em dois, foi realizada a sequência 3D FLAIR e, com ela, também identificamos a lesão. Em outros dois, os espessamentos corticais foram mais bem caracterizados nas sequências axiais T2 STIR, em um paciente o axial FLAIR não volumétrico foi bastante útil e, em outro, o plano coronal foi confirmatório da suspeita. Em um paciente a localização do achado foi discordante da ZE sugerida pelo VEEG (Figura 35). Além disso, dois haviam sido classificados com FNL pelo VEEG, sendo quem em um deles (paciente 19) ainda foi caracterizada uma colocalização das alterações vistas na EC e RT2 (Figura 36). 
FIGURA 34: Exemplo do paciente 24 que mudou para o estado de ressonância magnética positiva apenas após a avaliação visual com direcionamento localizatório guiada pelos pós-processamentos. Esse paciente foi considerado como foco localizatório suspeito com a zona epileptogênica determinada pela eletrofisiologia possivelmente localizada na transição têmporo-parieto-occipital esquerda. A) Resultado do pós-processamento da espessura cortical pelo FreeSurfer, evidenciando um espessamento cortical na transição têmporo-occipital esquerda inferiormente. Coronais FLAIR não volumétrico (B) e T2 STIR com janela invertida (C), evidenciando discreto espessamento cortical focal e borramento da transição branco-cinzenta (círculos brancos) na região do achado da análise quantitativa. Neste paciente não foi realizada a sequência 3D FLAIR. FLAIR: Fluid attenuated inversion-recovery.

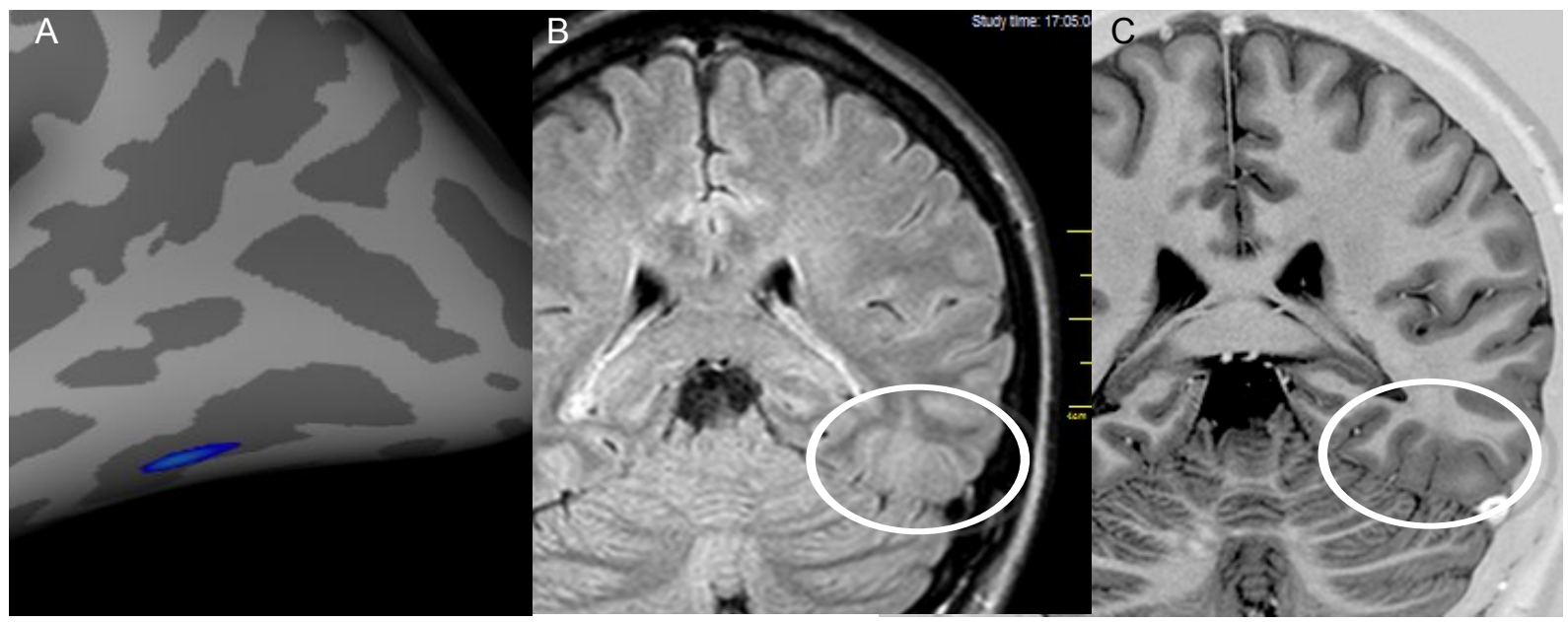

Fonte: Arquivo pessoal (Acesso em: 25/03/2017). 
FIGURA 35: Exemplo do paciente 14 que mudou para o estado de ressonância magnética positiva unicamente apenas após a avaliação visual com direcionamento localizatório guiada pelos pós-processamentos. Esse paciente foi considerado com foco localizatório suspeito no lobo frontal direito pelo videoencefalograma. A) Resultado do pós-processamento da espessura cortical pelo FreeSurfer, evidenciando um espessamento cortical da porção anterior da ínsula do lado esquerdo (imagem azul). Na avaliação retrospectiva desta região nos planos axiais FLAIR (B) e T2 STIR com janela invertida (C) é possível evidenciar o espessamento cortical frontoinsular esquerdo, ou seja, na localização correspondente ao achado da análise quantitativa. RM: Ressonância magnética.
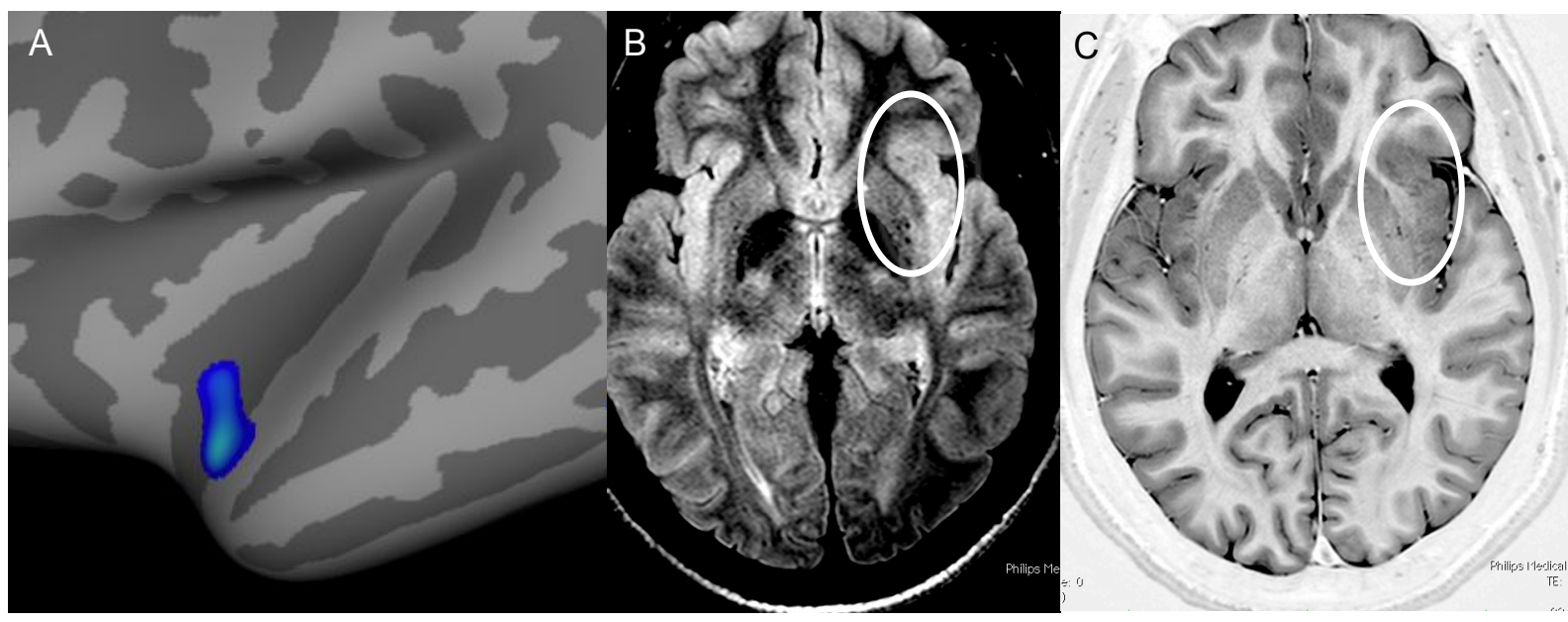

Fonte: Arquivo pessoal (Acesso em: 25/03/2017). 
FIGURA 36: Exemplo do paciente 19 que mudou para o estado de ressonância magnética positiva somente após a avaliação visual com direcionamento localizatório guiada pelos pós-processamentos. Esse paciente não apresentou regionalização para uma possível zona epileptogênica pelo videoencefalograma, porém, ele mostrou duas medidas quantitativas positivas para a mesma região. A) Resultado do pós-processamento da EC pelo FreeSurfer evidenciando um espessamento têmporo-insular do lado direito (imagem azul). B) $\mathrm{Na}$ avaliação dos mapas da relaxometria T2 pelo programa de m mapeamento estatístico paramétrico (SPM12) também foi possível identificar uma alteração na mesma localização (focos amarelos e vermelhos). C) Coronal T2 STIR com janela invertida evidenciando o espessamento cortical na região correspondente aos achados da análise quantitativa (setas pretas). FLAIR: Fluid attenuated inversion-recovery. STIR: Short time inversion.
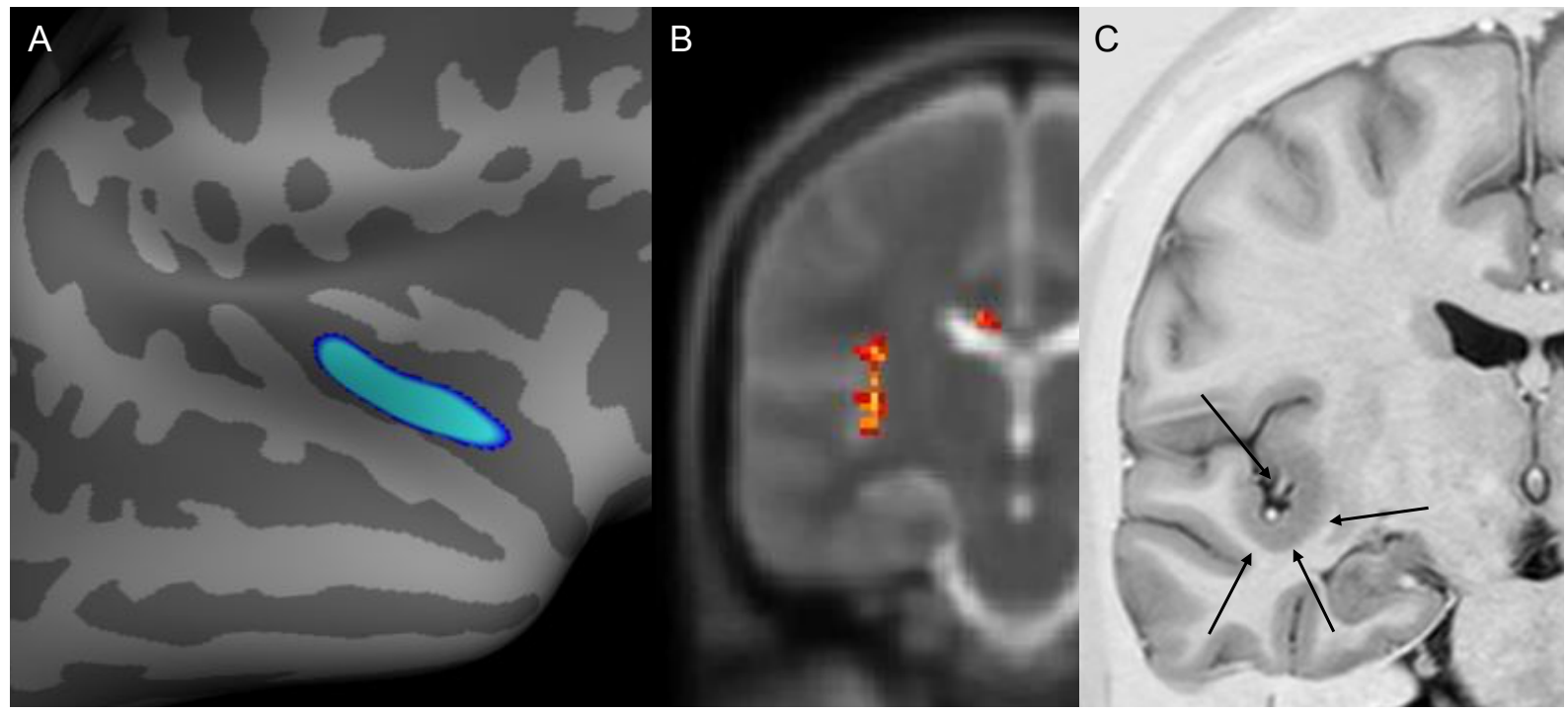

Fonte: Arquivo pessoal (Acesso em: 21/03/2017).

Vale ressaltar que a lesão do paciente 19 foi mais bem definida no plano coronal, o que foi considerado como sendo o principal fator para identificá-la. As principais sequências que identificaram a lesão foram: 3D FLAIR, coronal FLAIR, coronal STIR e 3D T1 RAGE. Ou seja, todas realizadas em coronal ou que possuíam a possibilidade de avaliação nesse plano. Apesar de não ter sido essencial a realização da sequência 3D FLAIR para identificação da provável DCF nesse paciente, ela viabilizou uma melhor definição da mesma pela possibilidade de 
reconstrução nos diversos planos ortogonais e pela sua maior resolução espacial (Figura 37).

FIGURA 37: Detalhamento da caraterização do espessamento cortical do paciente 19 na ressonância magnética estrutural. Veja que mesmo com relação às reconstruções axiais de sequências 3D FLAIR (A) e GM0 - DIR (B), há uma mais clara identificação desta alteração no plano coronal FLAIR não volumétrico (círculos brancos). Apesar disto, nas reconstruções nos planos axial (D), sagital (E) e coronal (F) da sequência 3D FLAIR, há uma nítida definição da lesão, inclusive caracterizando melhor a extensão da lesão e o borramento da transição entre as substâncias branca e cinzenta (setas brancas). FLAIR: Fluid attenuated inversionrecovery. GMO: Gray-matter only.

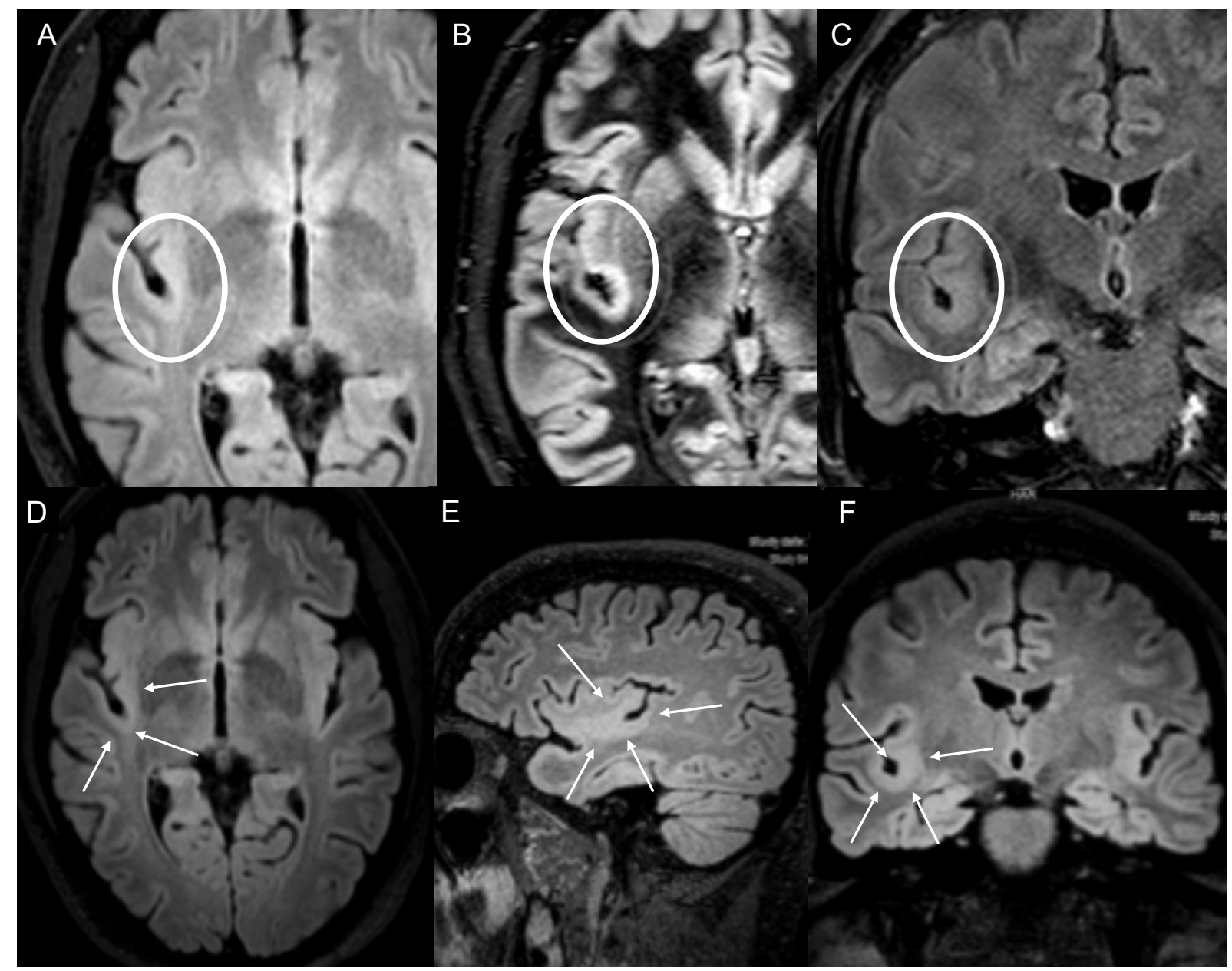

Fonte: Arquivo pessoal (Acesso em: 04/03/2017).

Em um paciente, a identificação da possível alteração estrutural foi guiada pela VBA (SPM12) da JBC. Nele, foi possível, na inspeção retrospectiva com o 
direcionamento localizatório, caracterizar um mínimo foco de hipersinal subcortical na sequência FLAIR não volumétrica no plano axial, além de um espessamento cortical focal na sequência 3D T1 (Figura 38).

FIGURA 38: Exemplo do paciente 20 que mudou para o estado de ressonância magnética positiva apenas após a avaliação visual com direcionamento localizatório guiada pelos pós-processamentos. Esse paciente foi considerado como foco localizatório suspeito com a zona epileptogênica determinada pela eletrofisiologia possivelmente localizada na região têmporo-parieto-occipital esquerda. A) Resultado do pós-processamento dos mapas de junção entre as substâncias branca e cinzenta pelo programa de mapeamento estatístico paramétrico (SPM12), evidenciando uma alteração na alta convexidade da região parietal esquerda (ponta de seta vermelha e foco amarelo). Reconstrução axial do 3D T1 (B) e axial FLAIR não volumétrico, evidenciando discreto espessamento cortical focal e pequeno foco de alto sinal respectivamente (círculos brancos) em região próxima ao achado da análise quantitativa. RM: Ressonância magnética. FLAIR: Fluid attenuated inversionrecovery.
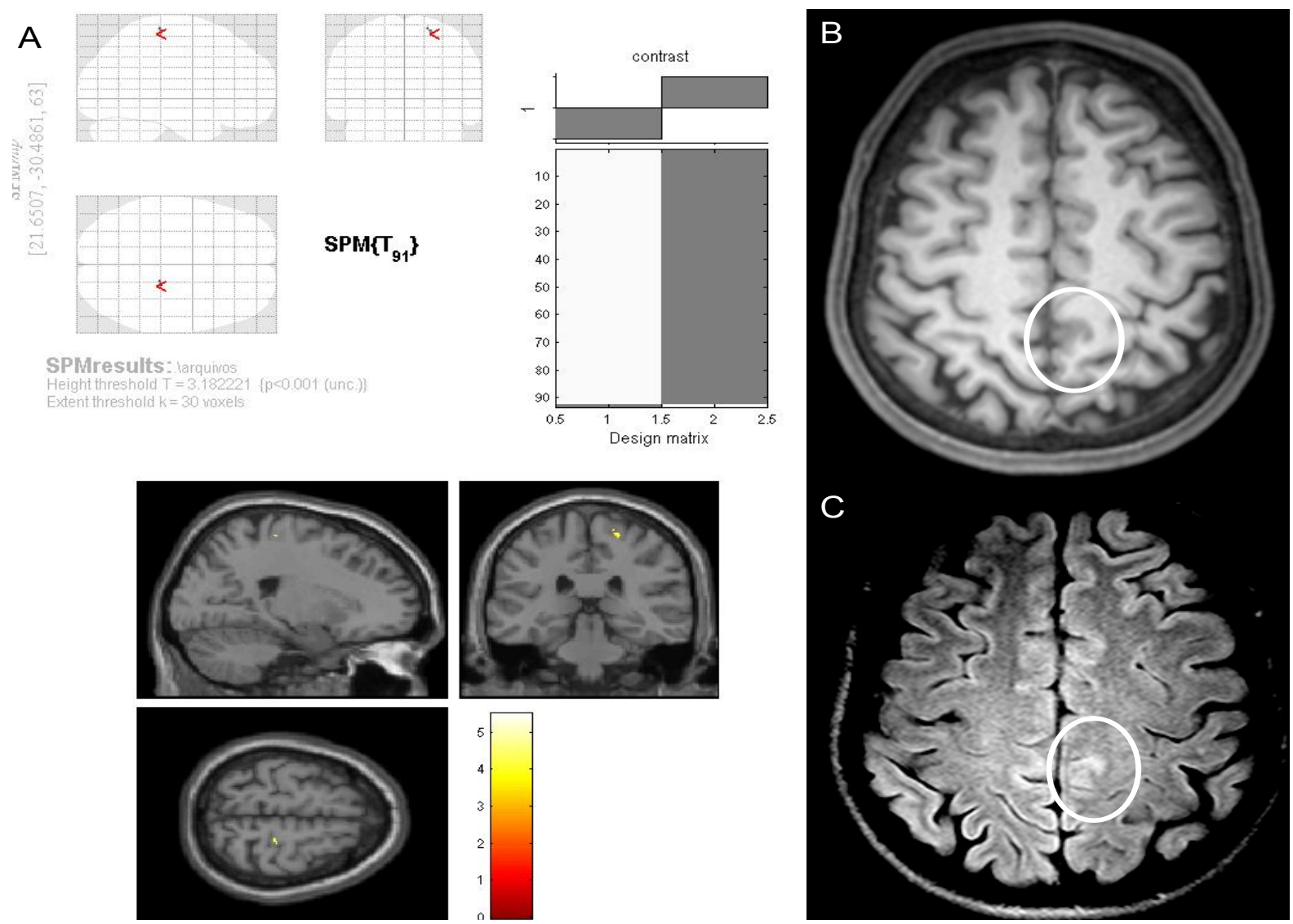

Fonte: Arquivo pessoal. (Acesso em: 25/03/2017). 


\subsection{Avaliação de mudança do estado localizatório dos pacientes na RM no decorrer do estudo}

Em três dos 46 pacientes (3/46 ou 6,5\%) incluídos no estudo inicialmente com RM NLE foi possível identificar alguma alteração estrutural após avaliação visual com direcionamento localizatório pelo EEG (AVDLEEG) e semiologia das crises. Todos foram operados, e o diagnóstico foi de DCF. Em nenhum deles foram detectadas alterações nas medidas quantitativas, ou seja, as avaliações SBM da EC e VBA da JBC, da RT2, da TTM e da DM não levantaram suspeitas para as respectivas regiões. Em dois desses pacientes (pacientes 18 e 39), a única sequência que propiciou a identificação dos achados foi a 3D FLAIR, isto é, 2/3 ou $66,7 \%$ (Figuras 39 e 40). No outro (paciente 32), ela foi a única que possibilitou evidenciar o acometimento cortical e delimitou melhor a alteração de sinal da JBC (Figura 41). Concluindo, nos três pacientes havia um discreto espessamento cortical e borramento da transição entre as substâncias branca e cinzenta no 3D FLAIR, sendo que visualmente na sequência 3D T1 RAGE não foi possível evidenciar o espessamento cortical. 
FIGURA 39: Exemplo do paciente 18 que mudou para o estado de ressonância magnética positiva apenas após associação de avaliação visual com direcionamento localizatório guiada pelo videoencefalograma e da sequência 3D FLAIR. No primeiro exame esse paciente foi considerado normal com o protocolo de RM rotina, exemplificado pelas sequências axial FLAIR não volumétrico $(A)$, reconstrução axial T1 3D (B) e coronal T2-STIR com janela invertida (C). Após indicação da localização pelo videoencefalograma e avaliando a sequência 3D FLAIR, foi possível identificar um espessamento cortical focal discreto e um borramento da transição entre as substâncias branca e cinzenta destacada no interior dos círculos brancos nas reconstruções axiais (D e E). O local da cirurgia corresponde ao dos achados na RM (F: interior do círculo branco). O resultado anátomo-histopatológico foi de displasia cortical focal tipo Ilb. Retrospectivamente, é possível identificar algum grau de alteração de sinal nas sequências do protocolo rotina para epilepsia (setas brancas) na região da displasia, porém permanecendo duvidosa. FLAIR: Fluid attenuated inversion-recovery. STIR: Short time inversion recovery.

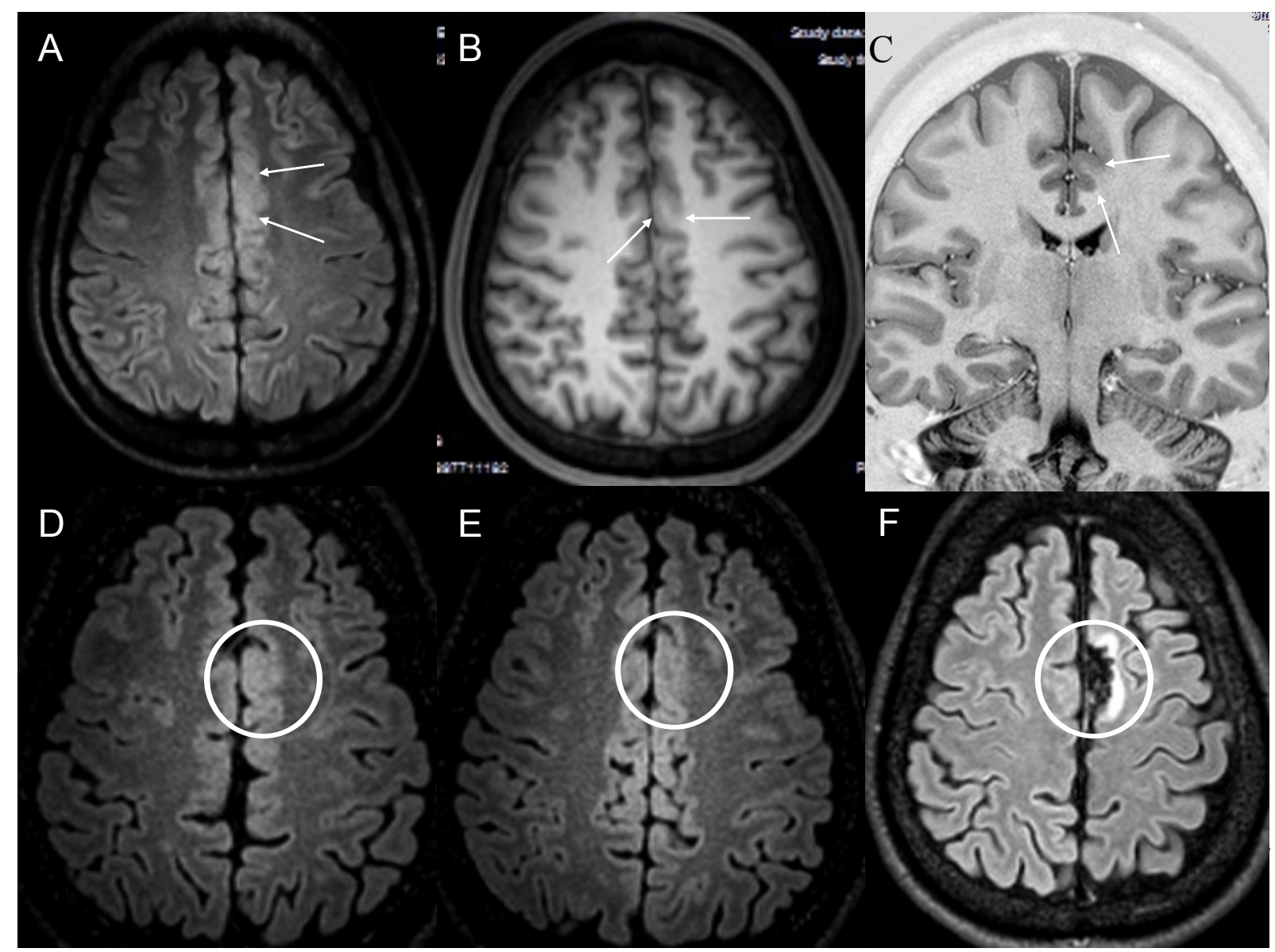

Fonte: Arquivo pessoal (Acesso em: 26/03/2017). 
Figura 40: Exemplo do paciente 39 que mudou para o estado de ressonância magnética positiva apenas após associação de avaliação visual com direcionamento localizatório guiada pelo videoencefalograma e da sequência 3D FLAIR. No primeiro exame este paciente foi considerado normal com o protocolo de RM rotina, exemplificado pelas sequências axial T2 (A), axial FLAIR não volumétrico (B) e reconstrução axial T1 3D $\quad$ (C). Após indicação da localização pelo videoeletroencefalograma e avaliando a sequência 3D FLAIR, foi possível identificar um espessamento cortical focal discreto e um borramento da transição entre as substâncias branca e cinzenta destacados no interior dos círculos brancos nas reconstruções axiais (D e E). Na sequência GMO (F), é possível identificar alguma alteração de sinal na região, porém de maneira bastante duvidosa. O paciente foi operado, e o resultado anátomo-histopatológico foi de displasia cortical focal tipo llb. Mesmo retrospectivamente, é difícil caracterizar alguma alteração estrutural nas sequências do protocolo rotina para epilepsia (setas brancas) na região da displasia. FLAIR: Fluid attenuated inversion-recovery. GMO: Gray-matter only.

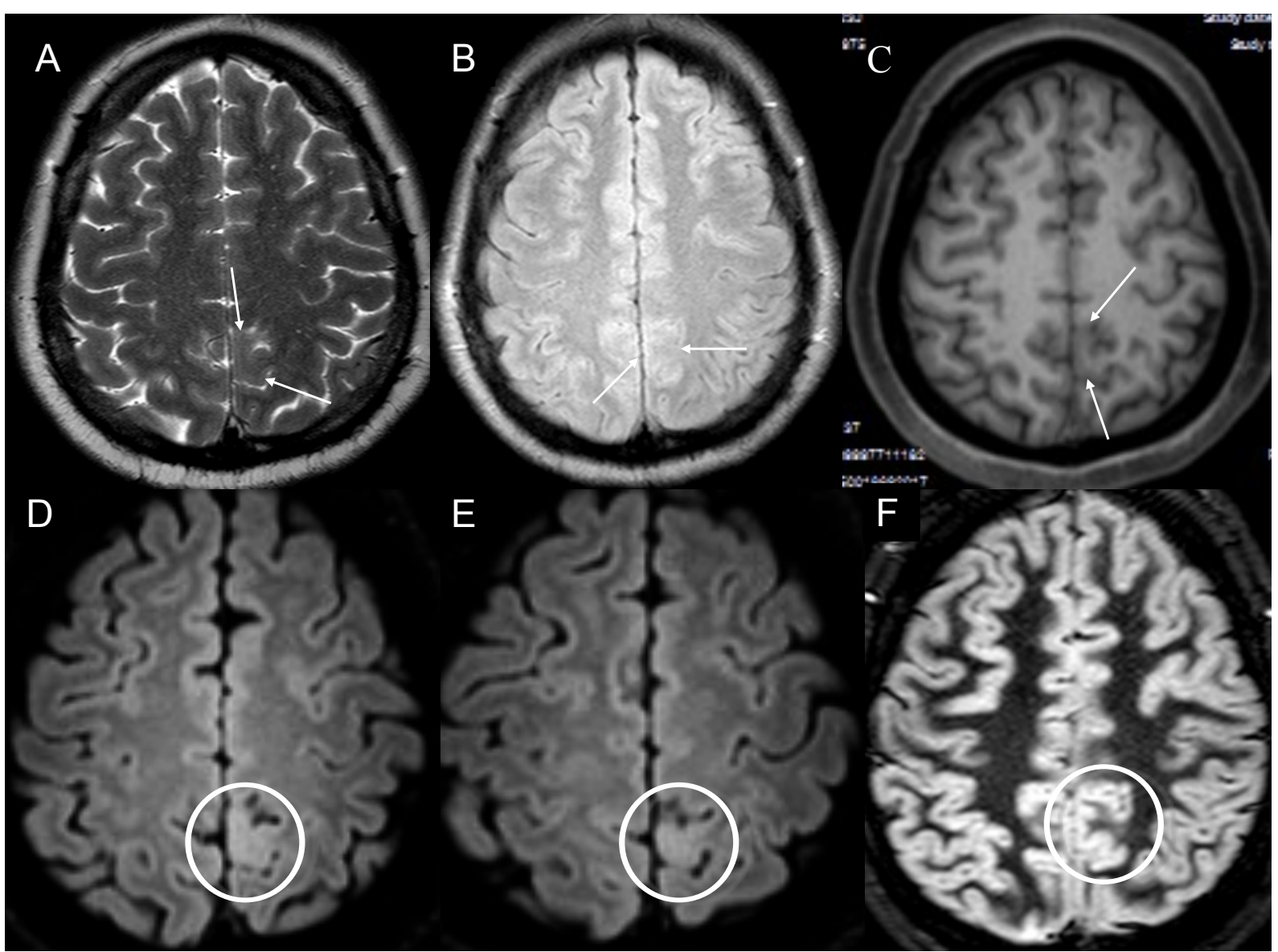

Fonte: arquivo pessoal (Acesso em: 06/03/2017). 
FIGURA 41: Exemplo do paciente 32, cujos achados na ressonância magnética foram inicialmente considerados duvidosos, porém confirmados após associação de avaliação visual com direcionamento localizatório guiada pelo videoencefalograma e da sequência 3D FLAIR. No primeiro exame com o protocolo de RM rotina é possível identificar uma alteração inespecífica, porém suspeita (duvidosa), na região do lóbulo parietal superior esquerdo exemplificado pelas sequências axial T2 (A), reconstrução axial T1 3D (B) e axiais FLAIR não volumétricos (C e D) e). Há discreta alteração de sinal subcortical (setas brancas) caracterizada na sequência FLAIR. Após indicação da localização pela eletrofisiologia e avaliando a sequência 3D FLAIR, foram caracterizados um espessamento cortical focal discreto e um borramento da transição entre as substâncias branca e cinzenta destacados no interior dos círculos brancos nas reconstruções axial (E) e coronal (F). O espessamento cortical está mais claro na reconstrução coronal orientada no maior eixo do giro acometido, o que mostra a importância da realização de uma sequência 3D. Na reconstrução axial da sequência 3D GMO (G), é possível identificar alguma alteração de sinal na região no interior do círculo branco, porém de maneira bastante duvidosa. O local da cirurgia corresponde ao dos achados na RM $(\mathrm{H}$ : interior do círculo branco). O resultado anátomo-histopatológico mostrou displasia cortical focal tipo Ila. FLAIR: Fluid attenuated inversion-recovery. GMO: Gray-matter only.

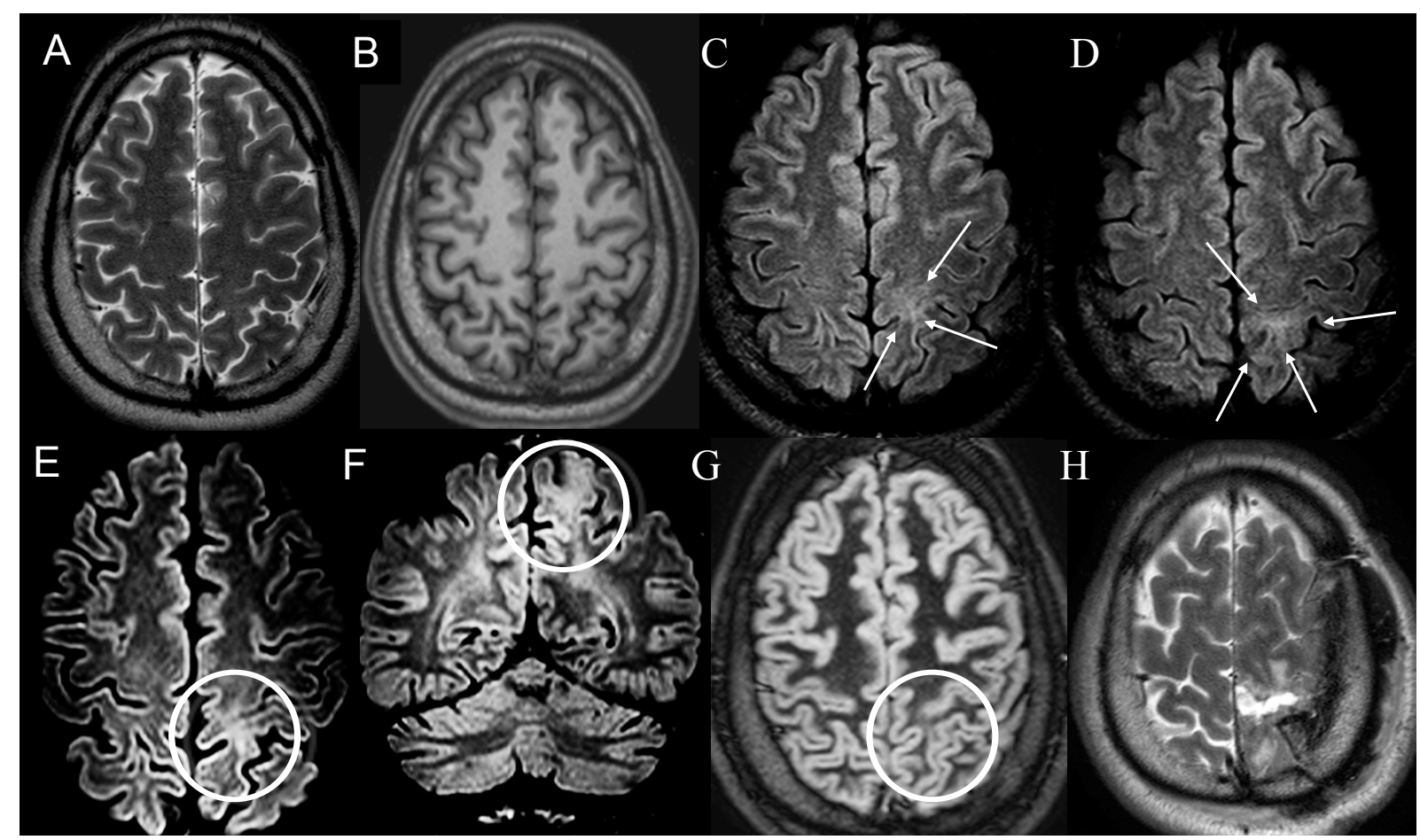

Fonte: arquivo pessoal (Acesso em: 06/03/2017). 


\subsection{Avaliação geral de mudança do estado localizatório na RM qualitativa}

Pode-se dizer que em oito dos 46 pacientes incluídos no estudo foi possível identificar alguma alteração estrutural potencialmente epileptogênica, inicialmente não caracterizada, após o direcionamento localizatório pelo conjunto das medidas quantitativas do estudo e/ou orientação pelo VEEG (8/46 ou 17,4\%). Nos três operados e com diagnóstico de DCF utilizamos, principalmente, do VEEG como método de orientação para uma nova avaliação dirigida para uma região, e nos outros cinco pacientes ainda em acompanhamento foi 0 uso dos pósprocessamentos individualizados que propiciou mudarem de estado (RM NLE para RM LE).

Dos seis pacientes em que foi realizada a sequência 3D FLAIR, cinco tiveram um benefício para análise (5/6 ou $83,3 \%$ ). Em três desses pacientes, essa sequência foi a única a caracterizar o acometimento cortical e, com isso, possibilitar a suspeição de uma DCF. Esses três sujeitos foram operados e confirmou-se a hipótese diagnóstica. Apenas em um sujeito essa sequência não acrescentou benefício algum para avaliação visual no que se refere à caracterização da morfologia e extensão da lesão. 


\section{DISCUSSÃO}

A pesquisa mostrou, por meio de um estudo prospectivo, a contribuição de técnicas avançadas de RM com pós-processamentos individualizados em uma mesma coorte de pacientes com epilepsia focal sintomática, de difícil controle, potencialmente candidatos cirúrgicos e em acompanhamento com RM negativa ou NLE. Visando o aprimoramento da localização da possível zona epileptogênica foram avaliadas cinco medidas quantitativas retiradas de quatro sequências de RM: EC, JBC, RT2, TTM e DM.

Utilizamos duas técnicas para os processamentos individualizados das imagens, SBM pelo software FreeSurfer para as medidas da EC, e VBA pelo software SPM12 para as demais medidas quantitativas (JBC, RT2, DM e TTM), abrangendo todo o cérebro e com intuito de identificar alterações cerebrais tão sutis que não pudessem ser caracterizadas nas inspeções visuais qualitativas habituais. Nosso objetivo foi avaliar o rendimento e a utilidade dessas análises quantitativas em um mesmo grupo consecutivo de pacientes, já que a literatura é bastante escassa em relação à utilização conjunta dessas técnicas de RM em uma mesma amostra de pacientes, além do que muitos, ou melhor, quase que a totalidade desses estudos, é retrospectiva (MARTIN; BENDER; FOCKE, 2015).

Ambas as técnicas de pós-processamento (SBM e VBA) utilizadas exigem que, em um primeiro momento, as imagens sejam normalizadas em um espaçopadrão para que regiões equivalentes possam ser comparadas (FISCHL; DALE, 2000; FRISTON, 2007). Os critérios utilizados para normalização, suavização e agrupamento de voxels, esse último no caso da VBA, foram escolhidos com base na literatura para o SBM e, principalmente, em testes iniciais para a VBA. Após encontrar uma taxa de falso-positivos de $10 \%$ nos sujeitos retirados do grupo de controles saudáveis durante a análise individualizada da EC pelo SBM com os parâmetros escolhidos para suavizamento $(10 \mathrm{~mm})$ baseado na literatura (THESEN et al., 2011) e valor-p corrigido pelo FDR padrão do programa $(0,05)$, decidimos expandir esse valor como aceitável para as demais medidas. No estudo de Thesen et al. (2011) conseguiu-se, com um suavizamento de $9 \mathrm{~mm}$ e definição do limiar de significância do Z-valor em 4, controlar de maneira bastante eficaz os falso-positivos, ou melhor, não se observaram clusters nos controles normais com esses 
parâmetros. Em todos os nossos casos falso-positivos, mesmo com Z-valores acima de 4,0, houve persistência dos achados (clusters). Tanto no presente estudo quanto neste outro prévio, foram utilizadas amostras de sujeitos saudáveis, com ampla distribuição etária e sem correções para idade ou sexo.

Com isso, para a VBA também foram testados sujeitos retirados do grupo de controles saudáveis, utilizando-se dos valores-p padrões do programa, não corrigidos de 0,001 e corrigidos pelo FWE de 0,05 , em associação com agrupamentos de voxel, até atingir pelo menos esse alvo. Para os mapas de JBC foi possível alcançar a taxa de $10 \%$ falso-positivos utilizando-se do valor-p não corrigido e um limiar de agrupamento de voxels. Porém, para as medidas extraídas das técnicas avançadas essa taxa não foi alcançada com o valor-p não corrigido, mesmo com valores bastante elevados de agrupamento de voxel. Porém, ao utilizarmos um critério mais restritivo para a definição da significância estatística, ou seja, o valor-p corrigido pelo FWE, foi possível atingir a meta. Essa combinação de valores-p, corrigidos ou não, e aglomerados de voxels, é utilizada em diversos trabalhos, porém de maneira relativamente heterogênea. Ou seja, não existe um limiar estatístico comum para todos os estudos que aplicam métodos de pósprocessamento automático e individualizado, possivelmente pelas diferenças populacionais dos pacientes e indivíduos normais, dos parâmetros de cada sequência, entre outros. Entretanto, uma prática rotineira nesses tipos de trabalho, em que as análises visam ao diagnóstico individual e os resultados falso-positivos precisam ser minimizados, é a confrontação de indivíduos saudáveis do próprio grupo de controle com o restante do grupo de controle. Por exemplo, no estudo de Kosior et al. (2012), os autores detectaram pelo menos uma anormalidade em 24 de seus 45 controles saudáveis (53\%) avaliando mapas de RT2 cobrindo todo o cérebro pelo programa SPM (VBA). Já no trabalho de Salmenpera et al. (2007), em que os autores avaliaram 4 medidas quantitativas pelo programa SPM, as taxas de achados positivos nos pós-processamentos dos indivíduos saudáveis dos grupos de controles foram de 3,5\% (VBM), 10,3\% (DIR), 10,0\% (RT2) e 7,7\% (MTR).

Acreditamos, dessa forma, que as medidas retiradas das sequências avançadas possam apresentar maior variabilidade interindividual, além de maior susceptibilidade a artefatos, por envolverem, geralmente, a aquisição de mais de uma imagem e pela sua menor resolução espacial. Essas dificuldades puderam ser parcialmente solucionadas mediante a escolha do valor-p corrigido pelo FWE 
(critério mais restritivo) em associação com o agrupamento de voxels. Inclusive essas características inerentes a essas sequências trouxeram uma redução do número de dados devido a algumas falhas de pós-processamento. É considerado falhas de pós-processamento problemas no corregistro e/ou alinhamento dos pacientes, artefatos de movimento e dificuldades na aquisição de dados de diferentes naturezas, como erros de aquisição, problemas técnicos com o aparelho de RM, etc. Em outras palavras, qualquer intercorrência que tenha impossibilitado o processamento adequado dos dados. A análise dos mapas T2 falhou em quatro pacientes devido a artefatos de movimento. A análise de imagens de DIR falhou em dois pacientes devido a problemas com a aquisição de dados. O processamento de dados falhou em 11 pacientes. A maior taxa de falha foi com a sequência de ITM (8/46 ou 17,4\%). Para as avaliações da EC e JBC, com dados baseados na sequência de maior resolução espacial do estudo e de aquisição única, a 3D T1 MPRAGE, não houve qualquer problema de pós-processamento.

As medidas quantitativas detectaram individualmente anormalidades em alguma região do cérebro de 32,6\% (15/46) a 56,4\% (22/39) dos pacientes, considerando os dois subgrupos de acordo com a presunção da ZE pelo VEEG e semiologia das crises (FLS e FNL). Se compararmos com a taxa de $10 \%$ de alterações encontradas nos testes dos controles saudáveis, seguindo os critérios aqui definidos, é perceptível a grande diferença entre os pacientes e sujeitoscontroles. Supõe-se que essa diferença decorra do distúrbio neurológico presente na amostra de pacientes, que é a principal variável discrepante do grupo de controles saudáveis. Considerando-se todas as medidas quantitativas, obtivemos alguma alteração nos pacientes, pelo menos uma delas, em $84,8 \%$ da amostra (39/46). Contudo, não foi possível fazer essa análise mais geral nos controles saudáveis em virtude da escolha aleatória dos indivíduos retirados dos respectivos grupos, além de não terem sido os mesmos para todos os pós-processamentos das medidas quantitativas.

No subgrupo dos pacientes classificados como FLS e com os dados disponíveis, as medidas quantitativas detectaram individualmente anormalidades na região ou no lobo presumido de ser a origem das crises de 9,7\% (3/31) a 31,0\% (9/29). Além disso, em 48,4\% (15/31) desses pacientes houve correspondência entre a alteração e a região sugerida pelo VEEG em pelo menos uma das medidas. Individualmente, essa correspondência (aumento do rendimento ou da eficiência no 
diagnóstico) foi mais alta com os mapas de DM (31,0\% ou 9/29), extraídos do DTI, e mapas de tempo de relaxação T2 $(25,0 \%$ ou $7 / 28)$ extraídos da RT2. Essa correspondência foi mais baixa com a EC e o JBC $(9,7 \%$ ou $3 / 31)$, extraídos da sequência 3D T1. Na ITM, o aumento de rendimento foi de $(15,4 \%$ ou $4 / 26)$. Paralelamente, esses achados foram aparentemente de baixa especificidade, pois alterações observadas fora da região ou do lobo presumido de ser a origem das crises foram sempre superiores do que nestas regiões, variando de $25,8 \%(8 / 31)$ a $51,7 \%$ (15/29), chegando, inclusive, a $83,9 \%$, quando consideramos as anormalidades encontradas em pelo menos uma das medidas. Todos esses resultados estão resumidos na tabela 7 .

A literatura tem mostrado trabalhos que também utilizam pósprocessamentos individualizados com boa concordância entre essas medidas quantitativas de avaliação e a análise visual convencional, assim como resultados promissores com o uso dessas ferramentas em pacientes sem achados na RM convencional, o que indica uma potencial capacidade de detectar lesões epileptogênicas não visíveis na inspeção convencional (MARTIN; BENDER; FOCKE, 2015). Paralelamente, outros estudos com algumas dessas técnicas obtiveram resultados menos animadores.

Com relação à avaliação da EC usando o FreeSurfer, Thesen et al. (2011) reportaram sensibilidade e especificidade bastante satisfatórias, $100 \%$ e $84 \%$, respectivamente. Nesse trabalho, eles utilizaram a técnica SBM e a sequência 3D T1 obtida em uma RM 3T para as avaliações, mas estudaram pacientes com lesões únicas visíveis na RM convencional. No entanto, não encontramos na literatura trabalhos que tenham utilizando mais especificamente o FreeSurfer, a medida da EC e o mesmo tipo de pós-processamento automático apresentado nesta tese, que investigassem pacientes com RM NLE e se guiassem pela avaliação eletroclínica para identificação das ZEs, sobretudo por meio de um estudo prospectivo. Assim, neste ponto, acredita-se que nosso estudo seja relevante por verificar a potencial utilidade dessa técnica em pacientes com EFRTM neocortical e RM negativa ainda em investigação da possível ZE.

Com a utilização da técnica VBA, sequência 3D T1 e gerando mapas de apresentação das alterações da JBC semelhantes aos utilizados no nosso estudo, destacamos dois trabalhos. Pail et al. (2012) reportaram que a análise VBM foi superior para a detecção de malformações estruturais temporopolares (DCF) em 
comparação com a inspeção visual. Além dessa superioridade, eles obtiveram aumento do rendimento diagnóstico de $38 \%$ ao detectarem alterações no polo temporal confirmadas como DCF na avaliação anátomo-histopatológica pósoperatória em três de oito pacientes com epilepsia do lobo temporal e inspeção visual de rotina negativa nessa região. Em contrapartida, Riney et al. (2012) não conseguiram detectar qualquer mudança de sinal em sua coorte de 14 crianças com RM NLE que correspondesse à origem eletroclínica das crises. Além disso, mesmo nos pacientes com lesão visível, foi possível detectar apenas $3 / 8(38 \%)$ dos casos. Os nossos resultados foram intermediários a estes dois estudos ao encontrarmos alteração no possível lobo ou na região de origem das crises em $9,7 \%$ dos pacientes (3/31). Entretanto, o estudo se assemelha mais ao de Riney et al. (2012), já que o de Pail et al. (2012) focaram basicamente em pacientes com esclerose temporal mesial associada ou não a DCF no polo temporal do mesmo lado. Com isso, podemos dizer que nossos resultados com relação a essa medida quantitativa, e utilizando-se do mesmo método de pós-processamento, foram aparentemente mais satisfatórios do que os disponíveis na literatura com relação às epilepsias extratemporais.

Avaliando os mapas da RT2 de todo o cérebro com a técnica VBA pelo programa SPM, Kosior et al. (2012) detectaram uma taxa bastante alta, de $70 \%$ (19/27), de mudança de sinal na mesma região de origem eletroclínica das crises. Esse trabalho sugere que esta ferramenta pode ser utilizada em casos de dúvidas em relação ao foco de origem das crises epilépticas, principalmente naqueles pacientes em que a análise estrutural por RM foi inconclusiva. A correspondência encontrada nesse estudo prévio ficou bem acima daqui reportada $(25,0 \%$ ou $7 / 28)$ para a mesma técnica. Uma diferença importante da casuística dos pacientes é que cerca de $45 \%$ deles, nesse artigo publicado em 2012, já apresentavam alguma alteração estrutural suspeita na RM convencional identificada anteriormente aos pós-processamentos. Nos dois trabalhos pareceu evidente que nem todas as alterações evidenciadas nos mapas de VBR puderam ser atribuídas diretamente às ZEs. Porém, o estudo de Kosior et al. (2012) não relatou exatamente qual foi essa taxa de achados fora da origem eletroclínica das crises no subgrupo de pacientes classificados como EEG localizatório e/ou lateralizatório. Assim, não podemos dizer se a maior eficiência diagnóstica desse trabalho foi à custa ou não de uma menor especificidade. 
Rugg-Gunn et al. (2003) já haviam reportado que a TTM, analisada voxel a voxel e utilizando-se do SPM, foi sensível na identificação de lesões cerebrais visíveis na RM em pacientes com epilepsia focal. Eles mostraram uma concordância de 35,7\% (15/42) entre as alterações dessa medida quantitativa e as alterações epileptiformes vistas no EEG e/ou a semiologia clínica em pacientes com RM NLE. Sugeriram, assim, que há alterações estruturais epileptogênicas ocultas que podem ser identificadas por essa técnica. Durante a realização do nosso estudo, encontramos uma porcentagem menor de pacientes com alteração da TTM nas supostas regiões candidatas à ZE pelo VEEG e com base na semiologia das crises (15,4\% ou 4/26). Em contrapartida, tivemos mais alterações fora das mesmas (34,6\% ou 9/26). Nesse trabalho de Rugg-Gunn et al. (2003), não foram encontradas referências claras sobre a presença de mudanças de sinal em regiões distantes da origem eletroclínica das crises. Novamente, não podemos dizer se a maior eficiência diagnóstica desse trabalho foi à custa ou não de uma menor especificidade.

O trabalho de Thivard et al. (2005) conseguiu uma alta especificidade a partir de dados de DTI com o parâmetro de DM e utilizando-se do SPM para o pósprocessamento no subgrupo das epilepsias extratemporais. Mais claramente, a especificidade foi de $83 \%$ para a epilepsia extratemporal, contra $20 \%$ para a do lobo temporal. Além disso, os autores encontraram sensibilidade de 63,6\% com o parâmetro de ADC, muito semelhante à DM. Esses achados foram mais animadores do que os encontrados no nosso estudo. Nós, embora tenhamos encontrado alteração na mesma região de origem eletroclínica das crises em 31,0\% (9/29), tivemos mais achados fora da possível ZE (51,7\% ou 15/29). Vale ressaltar que no estudo de Thivard et al. (2005) a avaliação eletrofisiológica foi com eletrodos intracranianos, o que permite uma definição mais localizada e precisa da zona de início das crises. Outro trabalho mais semelhante ao nosso é o de Chen et al (2008), pois também verificaram se o DTI poderia ajudar na localização da ZE em pacientes com EFRTM neocortical e RM negativa através da utilização da técnica VBA. Ao avaliarem 15 pacientes com a elaboração de mapas e realizar uma comparação individual (paciente versus um grupo-controle de 40 voluntários saudáveis), usando um valor-p <0,05 corrigido, verificaram regiões de aumento da DM em treze pacientes $(86,7 \%)$, sendo que em sete deles $(46,7 \%)$ houve concordância com a origem eletroclínica das crises. Embora essa concordância tenha sido um pouco superior a nossa fica claro que também não poderiam relacionar automaticamente 
as alterações identificadas com a ZE já que em $92,3 \%$ dos pacientes foram encontrados achados não correspondentes ao EEG.

Por fim, um estudo mais semelhante a nossa abordagem é o de Salmenpera et al. (2007), em termos de utilização de VEEG de superfície para presunção da ZE e de múltiplas modalidades avaliadas. Eles avaliaram as mudanças na intensidade de pixel com base nos dados de quatro medidas quantitativas e usando o VBA individualizado no software SPM em uma mesma coorte de 93 pacientes com RM negativa ou NLE e compararam com os resultados localizatórios pelos dados eletroclínicos. As medidas quantitativas avaliadas nesse trabalho foram RT2, VBM T1, VBM DIR e TTM. Os aumentos na eficiência de detecção (rendimento diagnóstico) foram de 13/82 para o VBM DIR (15,8\%), de 13/83 para a RT2 (15,6\%), de $7 / 75$ para o VBM T1 $(9,3 \%)$ e de $4 / 77$ (para a TTM $(5,2 \%)$. Ou seja, os pósprocessamentos detectaram individualmente mudança de sinal na região presumida de ser a origem das crises em 5,2 a 15,8\% dos pacientes. O rendimento foi maior com RT2 e VBM DIR e menor com VBM T1 e TTM. Essa taxa de rendimento foi, de maneira geral, um pouco menor do que a encontrada no nosso grupo de pacientes, chegando até $31,0 \%$. Porém, as sequências, os parâmetros e as medidas utilizados para as avaliações não foram os mesmos, o que inviabiliza comparações mais direitas. Eles também descreveram uma aparente baixa especificidade diante de mais alterações fora da região possivelmente responsável pela ZE. Foram observadas mudanças de sinal em outras regiões em até $42 \%$ dos pacientes.

A análise desses dados quantitativos extraídos das sequências de RM baseou-se, em grande parte, na indicação a respeito da região sugerida como suspeita de ser o local de início das crises utilizando-se do VEEG de superfície. A avaliação eletrofisiológica com essa técnica apresenta algumas limitações, porém foi o dado localizatório mais apropriado e disponível para todos esses pacientes no momento da realização das comparações. Além da dificuldade de regionalização e lateralização em uma significativa parcela dos pacientes, vivenciada em nosso estudo em um terço dos investigados, ainda há o problema da possibilidade de uma localização enganosa quanto à zona de início da atividade em até cerca de $20 \%$ desses estudos eletrofisiológicos (LEE et al., 2000). Isso significa que em alguns pacientes as anormalidades de sinal identificadas nos pós-processamentos fora das regiões presumidamente consideradas como a ZE podem, inclusive, refletir o foco da origem das crises epilépticas. Essa hipótese só poderia ser testada com o 
prosseguimento da investigação, consequentemente com colocação de eletrodos intracranianos e/ou placas subdurais, comprovação após avaliação anátomohistopatológica da região ressecada na cirurgia e, finalmente, validada mediante evolução clínica favorável no seguimento pós-operatório.

Neste momento é importante resgatar os conceitos das causas que podem influenciar as alterações identificadas nessas técnicas quantitativas, a fim de entender as hipóteses diagnósticas a serem consideradas. i: A medida da EC tem influência direita da carga neuronal cortical e/ou de algum processo infiltrativo nesta região, pois é exatamente o que ela quantifica (FISCHL; DALE, 2000). É lógico, então, supor que uma perda neuronal reduz o volume da substância cinzenta e, com isso, determina afilamento cortical, enquanto as lesões tumorais e a maiorias das MDC tendem a um espessamento cortical. Além disso, as crises recorrentes determinam atrofias em certas regiões que não a ZE, e isso pode ser, inclusive, um preditor do prognóstico pós-cirúrgico em pacientes com esclerose hipocampal (GARCIA et al. 2017). ii: Os mapas de JBC podem sofrer influência de qualquer patologia que altere o sinal da substância branca desta região. Gliose e alteração da distribuição da substância cinzenta, como encontrado nas MDC, podem, potencialmente, serem responsáveis por essas alterações (HUPPERTZ et al. 2005; BONILHA et al., 2006). iii: Os mapas da RT2 quantificam o sinal T2 dos tecidos e, no caso da presença de processos patológicos cerebrais, geralmente acompanhados de uma maior hidratação tecidual, podem identificar anormalidades, mesmo que sutis, deste parâmetro. Ou seja, MDC, lesões cerebrais adquiridas glióticas e alteração da mielinização cursam com aumento do sinal T2 e, consequentemente, determinam alterações dos mapas de RT2 (RUGG-GUNN et al., 2005). iv: A redução da TTM está intimamente relacionada à redução de macromoléculas, tipicamente encontrada nas doenças que alteram a mielinização axonal, como a MDC, lesões adquiridas glióticas e doenças desmielinizantes (VAN BUCHEM et al., 1998; RUGGGUNN et al., 2003). v: A DM pode sofrer influência (aumento) de alterações secundárias à degradação microestrutural do córtex cerebral e da substância branca subcortical adjacente, assim como da presença de neurônios heterotópicos, achados tipicamente encontrados nas DCFs / MDC, além de mielinização anormal, edema, lesão axonal, doenças desmielinizantes e gliose (SHULTZ et al., 2014). Em suma, tudo que afeta as propriedades de difusão da água determina alteração dos mapas de DM. 
Assim, pode-se dizer que diversas doenças, relacionadas ou não às crises recorrentes, alteram o córtex cerebral, assim como a substância branca subcortical, prolongam o tempo $\mathrm{T} 2$, reduzem a concentração de macromoléculas e alteram a difusibilidade. Esses são fatores responsáveis diretos pelas medidas da EC, JBC, RT2, TTM e DM, utilizadas no nosso estudo. Há na literatura diversos trabalhos destinados a encontrar anormalidades distantes da ZE, utilizando-se dessas medidas quantitativas, isto é, testando a hipótese de causa e efeito dessas alterações com o próprio quadro de epilepsia. Por exemplo, Diniz et al. (2011) procuraram avaliar a existência de anormalidades estruturais extratemporais não detectáveis nas inspeções visuais de rotina utilizando as técnicas VBA para volumetria da substância cinzenta e TTM em pacientes com esclerose hipocampal. Nesse estudo, os autores encontraram diferenças significativas entre os grupos de controle saudáveis e pacientes em algumas regiões, de modo que os resultados suportaram a hipótese de que há anormalidades disseminadas no cérebro consequentes às crises e não causadoras das mesmas, por exemplo, alteração da mielinização. Ou seja, somando-se à possibilidade de erro na localização da ZE pelo VEEG de superfície temos outros confundidores relacionados ou não à doença de base da amostra do estudo (dentre elas, trauma, infecções e, finalmente, as crises epilépticas recorrentes) que podem causar alterações evidenciadas com as técnicas quantitativas em outras regiões que não a ZE (SALMENPERA et al. 2007; CAMPOS et al., 2014).

Diante do exposto, apesar de bem descrita a relação entre a DCF, principal patologia determinante das crises nesse grupo de pacientes, e as alterações encontradas nas medidas quantitativas nas regiões de início das crises, ela não é a única. Isso quer dizer, mais claramente, que não seria correto relacionar automaticamente as alterações identificadas nos pós-processamentos aqui efetuados como sendo a ZE. No presente estudo identificamos muito mais mudanças nas medidas quantitativas fora das possíveis ZEs determinadas pelo VEEG do que nessas regiões; também muito acima das mudanças nos sujeitos controles, levantando também a hipótese de que essas alterações possam ser secundárias às mudanças microestruturais relacionadas às crises epilépticas recorrentes, além do foco de início das mesmas. Outra possibilidade pouco provável, mas que não pode ser descartada sem o prosseguimento das investigações, é a de 
que haja malformações sutis que podem passar despercebidas nas inspeções visuais de rotina.

Vale ressaltar que a influência no resultado pós-operatório de epilepsia não é clara quando há correspondência entre as alterações evidenciadas pelos métodos de pós-processamentos quantitativos, a origem eletroclínica das crises e a região ressecada na cirurgia, sem que haja alteração estrutural potencialmente epileptogênica visível na RM convencional. Ou seja, não se sabe o real fator prognóstico pós-cirúrgico dos pacientes se a única alteração identificada na RM na região apontada pelo EEG como sendo a ZE for por meio desses métodos quantitativos de pós-processamento. Considerando essa relação de prognóstico pós-operatório e os achados de medidas quantitativas pela técnica VBA, destacamos dois trabalhos. Wagner et al. (2011) mostraram maior taxa de eliminação das crises em pacientes com RM negativa se a área alterada detectada pelo SPM, avaliando a JBC no 3D T1, fosse completamente ressecada na cirurgia $(P=0,02)$. $O$ outro trabalho, publicado ainda mais recentemente (WANG et al., 2015), também avaliou o 3D T1 com a técnica VBM e mostrou resultados satisfatórios no prognóstico pós-operatório em um paciente (homem de 30 anos com epilepsia focal farmacorresistente e RM negativa) em que o grau de ressecção da lesão evidenciada no pós-processamento do SPM foi considerado completo. Entretanto, os dois trabalhos foram retrospectivos e avaliaram os pacientes após a comprovação anátomo-histopatológica de lesão epileptogênica, havendo, portanto, uma localização bem definida para estudo. Isto é, apesar de serem resultados bastante relevantes, não permitem uma extrapolação direita de sua utilidade na investigação pré-operatória de pacientes, principalmente naqueles em que não há um alvo claro a ser avaliado. Além disso, ambos os trabalhos fizeram uma abordagem diferente com relação aos pós-processamentos pelo SPM, chamada de análise morfométrica.

Por outro lado, conforme já amplamente debatido na introdução, podemos dizer que a literatura é bastante vasta sobre os significativos benefícios da identificação de lesões estruturais potencialmente epileptogênicas na avaliação préoperatória em pacientes candidatos à cirurgia. Dentre outros benefícios, destacamse encurtamento do tempo de investigação, maior chance de cirurgia, redução da necessidade de métodos invasivos no período pré-cirúrgico e, sobretudo, resultados mais satisfatórios no pós-operatório em relação à redução da frequência ou 
completa eliminação das crises. Na meta-análise de Tellez-Zenteno et al. (2010), no geral, as probabilidades de serem livres de crises após a cirurgia foram 2,5 vezes maiores em pacientes com lesões na RM ou no exame anátomo-histopatológico (OR 2,5, IC 95\% 2,1, 3,0, p <0,001), e sem diferenças estatísticas significativas quando separadas entre esses dois métodos utilizados para definir a epilepsia NLE e LE. Nesse estudo publicado em 2010 conclui-se que, em pacientes com cirurgia de epilepsia extratemporal/neocortical, as chances parecem ser ainda maiores, tendo sido observada uma taxa de sucesso 2,9 vezes maior naqueles com lesões (OR 2,9, IC 95\% 1,6, 5,1, p <0,001). Ou seja, esse benefício é ainda maior nos casos com lesões não relacionadas à esclerose temporal mesial, o que favorece sobremaneira o paciente em questão. Resumindo, as chances do paciente se tornar livre da crise após a cirurgia são duas a três vezes maiores na presença de uma lesão estrutural tanto na anátomo-histopatologia quanto na RM convencional (TELLEZ-ZENTENO et al., 2010).

Assim, quando utilizamos a localização das alterações nos pósprocessamentos para guiar a inspeção visual foi possível reduzir o número de pacientes considerados como RM NLE. Houve, com isso, um incremento do rendimento na detecção de alterações estruturais potencialmente epileptogênicas em 10,9\% (5/46). Em dois deles, as alterações coincidiram também com a região de origem eletroclínica das crises, o que, nesses casos, permite o benefício mais rápido desta identificação. Em outros dois, os pacientes tinham sido considerados como FNL pelo VEEG, porém agora poderão ser investigados com um direcionamento mais preciso para uma possível ZE. Por fim, tivemos um paciente em que achado foi discordante da origem eletroclínica das crises, o que não nos leva a descartá-lo, pois é sabido que o VEEG de superfície apresenta algumas limitações. Todavia, isso impõe a necessidade de maior cautela no prosseguimento da investigação do mesmo. O caso do paciente 19 exemplifica bem a importância da caracterização de uma lesão cortical em pacientes com avaliação neuroeletrofisiológica não localizatória e não lateralizatória. Este problema de localização quanto à da zona da atividade elétrica é, neste caso, explicada pelo fato da anormalidade estrutural estar localizada em uma região profunda em relação ao couro cabeludo onde são colocados os eletrodos. Consequentemente, a propagação da atividade elétrica ao longo das vias fisiológicas até chegar a superfície e ser detectada por esses eletrodos dificulta a localização por este método (SMITH, 2005). A ausência de uma 
localização possivelmente relacionada à origem das crises por esse método aumenta ainda mais a importância da identificação desta alteração estrutural compatível com uma MDC.

A medida que mais influenciou esse aumento diagnóstico na avaliação retrospectiva foi a $E C$, principalmente quando o achado foi um espessamento cortical. Isso não nos surpreende, uma vez que reflete uma alteração morfológica mais direta, um espessamento ou afilamento do córtex cerebral, enquanto as demais medidas refletem mudanças de sinal. As mudanças sutis de sinal na região com alteração são parcialmente detectadas por processamentos matemáticos específicos e muitas vezes não serão visíveis nos protocolos convencionais, mesmo com inspeções direcionadas. Na prática, isso significa que, caso esses pacientes, agora considerados como RM LE, venham a ser operados, passarão a se beneficiar dos significativos impactos positivos desta identificação, notadamente com relação ao prognóstico pós-cirúrgico. Ademais, se incluirmos aqueles que mudaram de grupo após novas inspeções com direcionamento localizatório pelo VEEG e semiologia das crises (3/46 ou $6,5 \%)$, é possível dizer que o incremento na eficiência de detecção de lesões estruturais corticais pelo método de RM aumenta consideravelmente diante de uma avaliação direcionada para uma determinada região considerada suspeita, seja pelos pós-processamentos e/ou seja pelo VEEG. Ao todo, aumentouse essa identificação para 17,4\% (8/46). Por isso, esses pacientes com RM NLE e candidatos a procedimentos invasivos e/ou cirúrgicos devem sempre ser avaliados pelo neurorradiologista com conhecimento clínico e eletrofisiológico das crises, pois essa conduta potencialmente aumenta a taxa de identificação de lesões epileptogênicas sutis. Essa sistematização para análise das imagens já é rotineiramente utilizada na instituição onde este trabalho transcorreu e discutiremos mais abaixo que a introdução de uma nova sequencia 3D ainda não habitualmente utilizada foi a responsável por esse incremento

$\mathrm{O}$ aparente baixo rendimento entre as alterações encontradas nas medidas quantitativas e as possíveis lesões estruturais potencialmente epileptogênicas nas análises retrospectivas com direcionamento localizatório pelos pós-processamentos que pudessem ter passadas despercebidas nas avaliações anteriores pode ser explicado por alguns fatores intrínsecos e relacionados ao alto padrão reconhecido do serviço neste campo da cirurgia de epilepsia. Esses fatores já foram amplamente descritos como fundamentais na literatura e, especificamente na parte da imagem, 
podemos destacar a utilização de RM de alto campo $(3,0 \mathrm{~T})$, protocolo específico que possibilita a detecção das potenciais patologias relacionadas a esse distúrbio neurológico, e a presença de neurorradiologistas/neurologistas com grande experiência em epilepsia. Importante também ressaltar e destacar que esses indivíduos fazem parte de um grupo extremamente desafiador de pacientes que apresentam alguma lesão estrutural determinando as crises epilépticas, porém ainda não identificada nos exames de imagem mesmo após diversas avaliações, inclusive já direcionadas pelos métodos eletrofisiológicos (VEEG) e funcionais (medicina nuclear) rotineiramente realizados no serviço onde o trabalho se desenvolveu.

Os dados do trabalho de Von Oertezen et al. (2002), pormenorizados na discussão, deixam claro que a sensibilidade e a especificidade melhoraram quando os exames passaram a ser analisados por um especialista em imagem das epilepsias, notadamente quando este dispunha de um protocolo dedicado para as principais patologias desse grupo de pacientes. Paralelamente, estudos têm sustentando a tese da superioridade da utilização de RM com o maior campo possível nesses pacientes, notadamente 3,0 T, para caracterização de lesões corticais, algumas vezes não identificáveis adequadamente nos exames iniciais realizados em RM de 1,5-T (PHAL et al., 2008; KNAKE et al., 2005; MELLERIO et al., 2014; ZIJLMANS et al., 2009). Ou seja, todos esses fatores presentes no processo investigatório da instituição onde o estudo foi realizado, entre outros, com certeza reduzem muito o número de lesões sutis que potencialmente podem não ser reconhecidas nas inspeções visuais das imagens da RM com o protocolo rotina para epilepsia.

Paralelamente, tivemos uma influência positiva da introdução da sequência 3D FLAIR, quando realizada, na inspeção visual em quase todos os pacientes inicialmente classificados como RM NLE e que posteriormente mudaram para o grupo da RM LE (5/6 ou 83,3\%). Este benefício foi observado principalmente naqueles três pacientes em que o VEEG foi utilizado para direcionar a localização, sendo que todos foram operados e tiveram diagnóstico de DCF. Podemos, inclusive, dizer que em todos os pacientes deste pequeno grupo essa sequência foi a que possibilitou tanto caracterizar o borramento da JBC quanto identificar um espessamento cortical. Embora não tenha sido este o foco da tese, é importante relatar que essa constatação vai ao encontro do trabalho de Saini et al., 2010, o qual concluiu que essa sequência 3D FLAIR de alta resolução deve ser incluída sempre 
que houver uma alta suspeita de DCF, principalmente quando a RM é considerada NLE com a utilização do protocolo rotina para epilepsia e o paciente candidato a cirurgia ou, ainda, diante da necessidade de definir mais precisamente a extensão de alguma lesão. Apesar desse estudo apresentar limitações, em especial número relativamente pequeno de pacientes (nove) e falta de correlação anátomohistopatológica, conseguiu-se, em todos os casos, melhorar a avaliação anatômica das alterações com essa técnica e, em alguns, esta foi única forma de identificar as lesões.

Ou seja, esses apontamentos foram exatamente os mesmos observados pelo nosso grupo com relação ao 3D FLAIR. No entanto, mostramos também uma potencialização na identificação de lesões corticais na inspeção visual por esta sequencia quando de alguma forma há um direcionamento para essas análises com relação a localização da provável ZE. Assim, fica claro que nesse grupo de pacientes com EFRTM e RM NLE avaliações sucessivas são necessárias, principalmente de maneira multimodal/multidisciplinar e associadas a novas técnicas de imagem com maior resolução espacial.

Por isso, atualmente na instituição onde este trabalho foi realizado o protocolo rotina de RM de todos os pacientes com epilepsia já inclui as sequências 3D FLAIR e GMO. Além dos benefícios dessas sequências na avaliação morfológica pela maior resolução espacial e possibilidade de reconstruções multiplanares, trabalhos recentes têm demonstrado maior taxa de detecção nas análises VBM utilizando essas sequências em relação ao 3D T1 (RINEY et al., 2012; SALMENPERA et al. 2007). Ambas as técnicas são praticamente as únicas não incluídas no nosso estudo, porém apresentaram resultados promissores na literatura e, com certeza, serão investigadas em trabalhos futuros. Acreditamos muito no potencial de sequências 3D com melhor resolução, notadamente quando o intuito for direcionar novas inspeções visuais e, com isso, proporcionar benefícios mais concretos aos pacientes.

As diferentes medidas quantitativas utilizadas na RM são potencialmente sensíveis a diversas patologias, relacionadas ou não com a epilepsia, de modo que não nos surpreende que as alterações que possam captar não sejam altamente específicas. Correlações entre as alterações encontradas nos pós-processamentos e as análises neuropatológicas da mesma região poderão ajudar a entender melhor as relações de causa e efeito. Com isso, será possível determinar de forma mais 
exata a sensibilidade e especificidade dessas técnicas, para fins de validá-las ou não para uma aplicação mais prática, além de podermos melhor compreender os benefícios dessas correlações no prognóstico pós-operatório desses pacientes. De fato, o que já pode beneficiar rotineiramente os pacientes é este aumento na taxa de detecção de lesões estruturais potencialmente epileptogênicas identificadas visualmente após uma nova inspeção direcionada. Nesse ponto, a literatura já é bastante concordante no que se refere aos benefícios desse grupo de pacientes caso a cirurgia seja o procedimento escolhido para reduzir ou eliminar o número de crises. 


\section{CONCLUSÃO}

As medidas quantitativas de RM avaliadas por meio de pós-processamentos individualizados em softwares específicos parecem sugerir alterações estruturais ocultas em pacientes seguidos com RM convencional negativa para lesões epileptogênicas. No entanto, é preciso termos cautela ao analisar as anormalidades identificadas nessas avaliações devido à aparente baixa especificidade dos achados para determinação única e exclusivamente do foco de origem das crises. Nesse grupo de pacientes com EFRTM neocortical, essas anormalidades devem refletir não só as ZEs, mas as alterações microestruturais secundárias às crises epilépticas recorrentes. Embora menos provável, não é possível afastar totalmente a existência de malformações cerebrais mais extensas, porém não visíveis nos protocolos de rotina, que determinam essas alterações detectadas nos pós-processamentos quantitativos. Uma potencial utilidade na prática clínica desses métodos na investigação pré-operatória é a de auxiliar na colocação de eletrodos intracranianos e/ou placas subdurais com intuito de definir mais precisamente os locais de início das crises em alguns pacientes selecionados.

O nosso estudo mostrou, sobretudo, uma possibilidade de aumento da eficiência na detecção de lesões potencialmente epileptogênicas, que passaram despercebidas na análise visual convencional dos protocolos de rotina da RM após reavaliações dirigidas pelos pós-processamentos, notadamente pela medida da EC. Enquanto a influência no resultado pós-operatório com a predição da lesão apenas pelos métodos de pós-processamentos das medidas quantitativas não está clara, a identificação de alteração estrutural visível nas sequências convencionais dos protocolos rotinas pode ser considerada o melhor fator prognóstico para eliminação das crises nesse grupo de pacientes candidatos a cirurgia de lesionectomia. Isto sugere que os métodos devem ser usados ou como uma ferramenta de triagem para evitar que qualquer lesão visível seja ignorada ou guiar uma nova inspeção visual dirigida para uma região suspeita. Neste âmbito do direcionamento localizatório, o VEEG também mostrou a sua utilidade em transformar pacientes seguidos com RM NLE para RM LE. Esse aumento do rendimento foi potencializado principalmente com a associação da sequência 3D FLAIR, ainda não realizada rotineiramente na maioria dos protocolos e que também apresenta grande potencial para novos 
estudos pelas técnicas VBM e SBM devido à sua melhor sensibilidade na detecção de alterações de sinal subcorticais em relação ao 3D T1.

Por fim, apenas com o prosseguimento das investigações será possível testar todas as hipóteses relacionadas com as alterações identificadas nos pósprocessamentos. Além disso, com a evolução tecnológica, o aprimoramento dos aparelhos de RM, surgimento de novas técnicas de pós-processamentos e sequências com maior resolução espacial, novos estudos deverão ser realizados com o intuito de avaliar a utilidade e o rendimento das mesmas na identificação de lesões estruturais epileptogênicas ocultas. 


\section{REFERÊNCIA BIBLIOGRÁFICA}

ABUD, L. G. et al. Partial epilepsy: A pictorial review of 3 TESLA magnetic resonance imaging features, Clinics, São Paulo, v. 70, n. 9, p. 654-661, sept. 2015. ISSN 1980-5322 (Electronic) 1807-5932 (Linking).

Disponível em <https://www.ncbi.nlm.nih.gov/pubmed/26375569 >.

AKHONDI-ASL, A. et al. Hippocampal volumetry for lateralization of temporal lobe epilepsy: automated versus manual methods, Neuroimage, v. 54, n. 1, p. 218-226, jan 2011. ISSN 1095-9572 (Electronic) 1053-8119 (Linking).

Disponível em <https://www.ncbi.nlm.nih.gov/pubmed/20353827>.

ARROYO, S. Evaluation of drug-resistant epilepsy. Rev. Neurol, v. 30, n. 9, p. 881-886, may. 1-15 2000. ISSN 0210-0010 (Print) 0210-0010 (Linking).

Disponível em <https://www.ncbi.nlm.nih.gov/pubmed/10870204 >.

ASHBURNER, J. SPM: a history. Neuroimage, v. 62, n. 2, p. 791-800, aug.2012. ISSN 1095-9572 (Electronic) 1053-8119 (Linking).

Disponível em <https://www.ncbi.nlm.nih.gov/pubmed/22023741>.

ASHBURNER, J.; FRISTON, K. J. Voxel-based morphometry--the methods. Neuroimage, v. 11, p. 805-821, june.2000. ISSN 1053-8119 (Print) 1053-8119 (Linking).

Disponível em <https://www.ncbi.nlm.nih.gov/pubmed/10860804>.

BANERJEE, P. N.; FILIPPI, D.; ALLEN HAUSER, W. The descriptive epidemiology of epilepsy-a review. Epilepsy Res, v. 85, n. 1, p. 31-45, july. 2009. ISSN 18726844 (Electronic) 0920-1211 (Linking).

Disponível em <https://www.ncbi.nlm.nih.gov/pubmed/19369037>.

BARKOVICH, A. J. et al. A developmental and genetic classification for malformations of cortical development: update 2012. Brain, v. 135, n. 5, p. 13481369, may 2012. ISSN 1460-2156 (Electronic) 0006-8950 (Linking).

Disponível em <https://www.ncbi.nlm.nih.gov/pubmed/22427329>.

BERG, A. T. et al. Neuroimaging in children with newly diagnosed epilepsy: A community-based study. Pediatrics, v. 106, n. 3, p. 527-532, sep 2000. ISSN 1098-4275 (Electronic) 0031-4005 (Linking).

Disponível em <https://www.ncbi.nlm.nih.gov/pubmed/10969098>. 
BLACKMON, K. et al. Cortical Gray-White Matter Blurring and Cognitive

Morbidity in Focal Cortical Dysplasia. Cereb Cortex, v. 25, n. 9, p. 2854-2862, sept 2015. ISSN 1460-2199 (Electronic) 1047-3211 (Linking).

Disponível em<https://www.ncbi.nlm.nih.gov/pubmed/24770710>.

BLUMCKE, I. et al. The clinicopathologic spectrum of focal cortical dysplasias: a consensus classification proposed by an ad hoc Task Force of the ILAE Diagnostic Methods Commission. Epilepsia, v. 52, n. 1, p. 158-174, jan 2011. ISSN 1528-1167 (Electronic) 0013-9580 (Linking).

Disponível em <https://www.ncbi.nlm.nih.gov/pubmed/21219302>.

BONILHA, L. et al. Voxel-based morphometry reveals excess gray matter concentration in patients with focal cortical dysplasia. Epilepsia, v. 47, n. 5, p. 908-915, may 2006. ISSN 0013-9580 (Print) 0013-9580 (Linking).

Disponível em <https://www.ncbi.nlm.nih.gov/pubmed/16686656 >.

BORGES, M. A. et al. Urban prevalence of epilepsy: populational study in Sao Jose do Rio Preto, a medium-sized city in Brazil. Arq Neuropsiquiatr, v. 62, n. 2A, p. 199-204, june 2004. ISSN 0004-282X (Print) 0004-282X (Linking).

Disponível em < https://www.ncbi.nlm.nih.gov/pubmed/15235717 >.

BRIELLMANN, R. S. et al. Structural abnormalities remote from the seizure focus: a study using T2 relaxometry at 3 T. Neurology, v. 63, n. 12, p. 2303-2308, dec 2004. ISSN 1526-632X (Electronic) 0028-3878 (Linking).

Disponível em <https://www.ncbi.nlm.nih.gov/pubmed/15623691>.

BRONEN, R. A. et al. A systematic approach for interpreting MR images of the seizure patient. AJR Am J Roentgenol, v. 169, n. 1, p. 241-247, july 1997. ISSN 0361-803X (Print) 0361-803X (Linking).

Disponivel em < https://www.ncbi.nlm.nih.gov/pubmed/9207533>.

BRONEN, R. A. et al. Refractory epilepsy: comparison of MR imaging, CT, and histopathologic findings in 117 patients. Radiology, v. 201, n. 1, p. 97-105, oct 1996. ISSN 0033-8419 (Print) 0033-8419 (Linking).

Disponível em <https://www.ncbi.nlm.nih.gov/pubmed/8816528>.

BROOKS, B. S. et al. MR imaging in patients with intractable complex partial epileptic seizures. AJR Am J Roentgenol, v. 154, n. 3, p. 577-583, mar 1990. ISSN 0361-803X (Print) 0361-803X (Linking).

Disponível em <https://www.ncbi.nlm.nih.gov/pubmed/2106225>. 
CARDINALE, F. et al. Validation of FreeSurfer-estimated brain cortical thickness: comparison with histologic measurements. Neuroinformatics, v. 12, n. 4, p. 535-542, oct 2014. ISSN 1559-0089 (Electronic) 1539-2791 (Linking).

Disponível em <https://www.ncbi.nlm.nih.gov/pubmed/24789776>.

$\mathrm{CHEN}, \mathrm{H}$. et al. Application of T2 relaxometry in lateralization and localization of mesial temporal lobe epilepsy and corresponding comparison with MR volumetry. Acta Radiol, v. 57, n. 9, p. 1107-1113, sept 2016. ISSN 1600-0455 (Electronic) 0284-1851 (Linking).

Disponível em <https://www.ncbi.nlm.nih.gov/pubmed/26622058>.

CHEN, Q. et al. MRI-negative refractory partial epilepsy: role for diffusion tensor imaging in high field MRI. Epilepsy Res, v. 80, n. 1, p. 83-89, july 2008. ISSN 0920-1211 (Print) 0920-1211 (Linking).

Disponível em: < https://www.ncbi.nlm.nih.gov/pubmed/18440782 >.

CHEN, W. et al. Multicontrast single-slab 3D MRI to detect cerebral metastasis. AJR Am J Roentgenol, v. 198, n. 1, p. 27-32, jan. 2012. ISSN 1546-3141 (Electronic) 0361-803X (Linking).

Disponível em: <https://www.ncbi.nlm.nih.gov/pubmed/22194476>.

COAN, A. C. et al. 3T MRI quantification of hippocampal volume and signal in mesial temporal lobe epilepsy improves detection of hippocampal sclerosis. AJNR Am J Neuroradiol, v. 35, n. 1, p. 77-83, jan 2014. ISSN 1936-959X (Electronic) 0195-6108 (Linking).

Disponível em: <https://www.ncbi.nlm.nih.gov/pubmed/23868151>.

COLOMBO, N. et al. Imaging of malformations of cortical development.

Epileptic Disord, v. 11, n. 3, p. 194-205, sept 2009. ISSN 1294-9361 (Print) 12949361 (Linking).

Disponível em: <https://www.ncbi.nlm.nih.gov/pubmed/19720583>.

Commission on Neuroimaging of the International League Against Epilepsy. Guidelines for neuroimaging evaluation of patients with uncontrolled epilepsy considered for surgery. Epilepsia, v. 39, n. 12, p. 1375-13746, dec 1998. ISSN 0013-9580 (Print) 0013-9580 (Linking).

Disponível em <https://www.ncbi.nlm.nih.gov/pubmed/9860078>.

COSSU, M. et al. Stereoelectroencephalography in the presurgical evaluation of focal epilepsy: a retrospective analysis of $\mathbf{2 1 5}$ procedures. Neurosurgery, v. 57 , n. 4, p. 706-718; oct 2005. ISSN 1524-4040 (Electronic) 0148-396X (Linking).

Disponível em < https://www.ncbi.nlm.nih.gov/pubmed/16239883 >. 
COTTON, F.; RAMBAUD, L.; HERMIER, M. Dual inversion recovery MRI helps identifying cortical tubers in tuberous sclerosis. Epilepsia, v. 47, n. 6, p. 10721073, june 2006. ISSN 0013-9580 (Print) 0013-9580 (Linking).

Disponível em <https://www.ncbi.nlm.nih.gov/pubmed/16822256>.

DALE, A. M.; FISCHL, B.; SERENO, M. I. Cortical surface-based analysis. I. Segmentation and surface reconstruction. Neuroimage, v. 9, n. 2, p. 179-194, feb 1999. ISSN 1053-8119 (Print) 1053-8119 (Linking).

Disponível em <https://www.ncbi.nlm.nih.gov/pubmed/9931268>.

DESPOTOVIC, I. et al. Automatic 3D graph cuts for brain cortex segmentation in patients with focal cortical dysplasia. Conf Proc IEEE Eng Med Biol Soc, p.

7981-7984, 2011. ISSN 1557-170X (Print) 1557-170X (Linking).

Disponível em <https://www.ncbi.nlm.nih.gov/pubmed/22256192>.

DINIZ, P. R. et al. Extratemporal damage in temporal lobe epilepsy:

magnetization transfer adds information to volumetric MR imaging. AJNR Am J Neuroradiol, v. 32, n. 10, p. 1857-1861, nov/dec 2011. ISSN 1936-959X (Electronic) 0195-6108 (Linking).

Disponível em <https://www.ncbi.nlm.nih.gov/pubmed/21885719>.

DUNCAN, J. S. Imaging and epilepsy. Brain, v. 120 ( Pt 2), p. 339-377, feb 1997. ISSN 0006-8950 (Print) 0006-8950 (Linking).

Disponível em: < https://www.ncbi.nlm.nih.gov/pubmed/9117380 >.

ENGEL, J., JR. et al. Practice parameter: temporal lobe and localized neocortical resections for epilepsy: report of the Quality Standards Subcommittee of the American Academy of Neurology, in association with the American Epilepsy Society and the American Association of Neurological Surgeons. Neurology, v. 60, n. 4, p. 538-547, feb 2003. ISSN 1526-632X (Electronic) 0028-3878 (Linking).

Disponível em <https://www.ncbi.nlm.nih.gov/pubmed/12601090>.

ENGEL, J., JR.; INTERNATIONAL LEAGUE AGAINST, E. A proposed diagnostic scheme for people with epileptic seizures and with epilepsy: report of the ILAE Task Force on Classification and Terminology. Epilepsia, v. 42, n. 6, p. 796-803, jun 2001. ISSN 0013-9580 (Print) 0013-9580 (Linking).

Disponível em <https://www.ncbi.nlm.nih.gov/pubmed/11422340>.

FISCHL, B. et al. High-resolution intersubject averaging and a coordinate system for the cortical surface. Hum Brain Mapp, v. 8, n. 4, p. 272-284,1999. ISSN 1065-9471 (Print) 1065-9471 (Linking).

Disponível em <https://www.ncbi.nlm.nih.gov/pubmed/10619420>. 
FISCHL, B.; DALE, A. M. Measuring the thickness of the human cerebral cortex from magnetic resonance images. Proc Natl Acad Sci U S A, v. 97, n. 20, p. 11050-11055, sept 2000. ISSN 0027-8424 (Print) 0027-8424 (Linking).

Disponível em <https://www.ncbi.nlm.nih.gov/pubmed/10984517>.

FISCHL, B.; SERENO, M. I.; DALE, A. M. Cortical surface-based analysis. II: Inflation, flattening, and a surface-based coordinate system. Neuroimage, v. 9, n. 2, p. 195-207, feb 1999. ISSN 1053-8119 (Print) 1053-8119 (Linking).

Disponível em <https://www.ncbi.nlm.nih.gov/pubmed/9931269>.

FISHER, R. S. et al. Epileptic seizures and epilepsy: definitions proposed by the International League Against Epilepsy (ILAE) and the International Bureau for Epilepsy (IBE). Epilepsia, v. 46, n. 4, p. 470-472, apr 2005. ISSN 0013-9580 (Print) 0013-9580 (Linking).

Disponível em <https://www.ncbi.nlm.nih.gov/pubmed/15816939>.

FRISTON K.J. Statistical parametric mapping, In Statistical Parametric Mapping, Academic Press, London, 2007, p. 10-31, ISBN 9780123725608. (Linking).

Disponível em < http://doi.org/10.1016/B978-012372560-8/50002-4 >

GARCIA, M. T. et al. Morphometric MRI features are associated with surgical outcome in mesial temporal lobe epilepsy with hippocampal sclerosis.

Epilepsy Res, v. 132, p. 78-83, mar 2017. ISSN 1872-6844 (Electronic) 0920-1211 (Linking).

Disponível em <https://www.ncbi.nlm.nih.gov/pubmed/28324681>.

GEURTS, J. J. et al. Intracortical lesions in multiple sclerosis: improved detection with 3D double inversion-recovery MR imaging. Radiology, v. 236, n. 1, p. 254-260, july 2005. ISSN 0033-8419 (Print) 0033-8419 (Linking).

Disponível em <https://www.ncbi.nlm.nih.gov/pubmed/15987979 >.

GRAHAM, J. M. et al. Diffusion tensor imaging for the assessment of upper motor neuron integrity in ALS. Neurology, v. 63, n. 11, p. 2111-2119, dec 2004. ISSN 1526-632X (Electronic) 0028-3878 (Linking).

Disponível em <https://www.ncbi.nlm.nih.gov/pubmed/15596758>.

HENKELMAN, R. M.; STANISZ, G. J.; GRAHAM, S. J. Magnetization transfer in MRI: a review. NMR Biomed, v. 14, n. 2, p. 57-64, apr 2001. ISSN 0952-3480 (Print) 0952-3480 (Linking).

Disponível em <https://www.ncbi.nlm.nih.gov/pubmed/11320533>. 
HONG, S. J. et al. Automated detection of cortical dysplasia type II in MRInegative epilepsy. Neurology, v. 83, n. 1, p. 48-55, july 01 2014. ISSN 1526-632X (Electronic) 0028-3878 (Linking).

Disponível em <https://www.ncbi.nlm.nih.gov/pubmed/24898923>.

HOUSE, P. M. et al. Comparison of morphometric analysis based on T1- and T2weighted MRI data for visualization of focal cortical dysplasia. Epilepsy Res, v. 106, n. 3, p. 403-409, oct 2013. ISSN 1872-6844 (Electronic) 0920-1211 (Linking). Disponível em <https://www.ncbi.nlm.nih.gov/pubmed/23891304>.

HUPPERTZ, H. J. et al. Enhanced visualization of blurred gray-white matter junctions in focal cortical dysplasia by voxel-based 3D MRI analysis. Epilepsy Res, v. 67, n. 1-2, p. 35-50, oct/nov 2005. ISSN 0920-1211 (Print) 0920-1211 (Linking).

Disponível em <https://www.ncbi.nlm.nih.gov/pubmed/16171974>.

JACK, C. R., JR. Hippocampal T2 relaxometry in epilepsy: past, present, and future. AJNR Am J Neuroradiol, v. 17, n. 10, p. 1811-1814, nov/dec 1996. ISSN 0195-6108 (Print) 0195-6108 (Linking).

Disponível em <https://www.ncbi.nlm.nih.gov/pubmed/8933862>.

JELLISON, B. J. et al. Diffusion tensor imaging of cerebral white matter: a pictorial review of physics, fiber tract anatomy, and tumor imaging patterns. AJNR Am J Neuroradiol, v. 25, n. 3, p. 356-369, mar 2004. ISSN 0195-6108 (Print) 0195-6108 (Linking).

Disponível em <https://www.ncbi.nlm.nih.gov/pubmed/15037456>.

JONES, R. M. et al. Adherence to treatment in patients with epilepsy: associations with seizure control and illness beliefs. Seizure, v. 15, n. 7, p. 504508, oct 2006. ISSN 1059-1311 (Print) 1059-1311 (Linking).

Disponível em <https://www.ncbi.nlm.nih.gov/pubmed/16861012>.

KING, M. A. et al. Epileptology of the first-seizure presentation: a clinical, electroencephalographic, and magnetic resonance imaging study of $\mathbf{3 0 0}$ consecutive patients. Lancet, v. 352, n. 9133, p. 1007-1111, sep 1998. ISSN 01406736 (Print) 0140-6736 (Linking).

Disponível em <https://www.ncbi.nlm.nih.gov/pubmed/9759742>.

KINI, L. G.; GEE, J. C.; LITT, B. Computational analysis in epilepsy neuroimaging: A survey of features and methods. Neuroimage Clin, (local da publicação) v. 11, p. 515-529, (mês) 2016. ISSN 2213-1582 (Electronic) 2213-1582 (Linking).

Disponível em <https://www.ncbi.nlm.nih.gov/pubmed/27114900>. 
KOSIOR, R. K. et al. Voxel-based relaxometry for cases of an unresolved epilepsy diagnosis. Epilepsy Res,v. 99, n. 1-2, p. 46-54, mar 2012. ISSN 18726844 (Electronic) 0920-1211 (Linking).

Disponível em <https://www.ncbi.nlm.nih.gov/pubmed/22342566>.

LEE, S. K. et al. Diffusion tensor MRI visualizes decreased subcortical fiber connectivity in focal cortical dysplasia. Neuroimage, v. 22, n. 4, p. 1826-1829, aug 2004. ISSN 1053-8119 (Print) 1053-8119 (Linking).

Disponível em <https://www.ncbi.nlm.nih.gov/pubmed/15275939>.

LEE, S. K. et al. The clinical usefulness of ictal surface EEG in neocortical epilepsy. Epilepsia, v. 41, n. 11, p. 1450-1455, nov 2000. ISSN 0013-9580 (Print) 0013-9580 (Linking).

Disponível em <https://www.ncbi.nlm.nih.gov/pubmed/11077459>.

LEITE, C. C. et al. Multivoxel proton MR spectroscopy in malformations of cortical development. AJNR Am J Neuroradiol, v. 28, n. 6, p. 1071-1075; jun/july 2007. ISSN 0195-6108 (Print) 0195-6108 (Linking).

Disponível em <https://www.ncbi.nlm.nih.gov/pubmed/17569960>.

LIM, C. C. et al. Malformations of cortical development: high-resolution MR and diffusion tensor imaging of fiber tracts at 3T. AJNR Am J Neuroradiolv. 26, n. 1, p. 61-64, jan 2005. ISSN 0195-6108 (Print) 0195-6108 (Linking).

Disponível em <https://www.ncbi.nlm.nih.gov/pubmed/15661702 >.

LITTLE, D. M.; HOLLOWAY, R. G. Diffusion tensor imaging: scientific advance, clinical tool, or just a pretty picture? Neurology, v. 68, n. 1, p. 9-10, jan 2007. ISSN 1526-632X (Electronic) 0028-3878 (Linking).

Disponível em <https://www.ncbi.nlm.nih.gov/pubmed/17200483>.

MADAN, N.; GRANT, P.E. New directions in clinical imaging of cortical dysplasias. Epilepsia, v. 50. Suppl 9, p. 9-18, Oct 2009. ISSN 1528-1167 (Electronic) 0013-9580 (Linking).

Disponível em <https://www.ncbi.nlm.nih.gov/pubmed/19761449>.

MARTIN, P.; BENDER, B.; FOCKE, N. K. Post-processing of structural MRI for individualized diagnostics. Quant Imaging Med Surg, v. 5, n. 2, p. 188-203, apr 2015. ISSN 2223-4292 (Print) 2223-4306 (Linking).

Disponível em < https://www.ncbi.nlm.nih.gov/pubmed/25853079 >. 
MARTINS, C. et al. Automated volumetry for unilateral hippocampal sclerosis detection in patients with temporal lobe epilepsy. Conf Proc IEEE Eng Med Biol Soc, v. 2016, p. 6339-6342, aug 2016. ISSN 1557-170X (Print) 1557-170X (Linking). Disponível em <https://www.ncbi.nlm.nih.gov/pubmed/28269699>.

MELLERIO, C. et al. 3T MRI improves the detection of transmantle sign in type 2 focal cortical dysplasia. Epilepsia, v. 55, n. 1, p. 117-122, jan 2014. ISSN 15281167 (Electronic) 0013-9580 (Linking).

Disponível em <https://www.ncbi.nlm.nih.gov/pubmed/24237393>.

NORONHA, A. L. et al. Prevalence and pattern of epilepsy treatment in different socioeconomic classes in Brazil. Epilepsia, v. 48, n. 5, p. 880-885, may 2007. ISSN 0013-9580 (Print) 0013-9580 (Linking).

Disponível em <https://www.ncbi.nlm.nih.gov/pubmed/17326788 >.

PAIL, M. et al. The role of voxel-based morphometry in the detection of cortical dysplasia within the temporal pole in patients with intractable mesial temporal Iobe epilepsy. Epilepsia, v. 53, n. 6, p. 1004-1112, jun 2012. ISSN 1528-1167 (Electronic) 0013-9580 (Linking).

Disponível em <https://www.ncbi.nlm.nih.gov/pubmed/22510082>.

PELL, G. S. et al. Voxel-based relaxometry: a new approach for analysis of T2 relaxometry changes in epilepsy. Neuroimage, v. 21, n. 2, p. 707-713, feb 2004. ISSN 1053-8119 (Print) 1053-8119 (Linking).

Disponível em <https://www.ncbi.nlm.nih.gov/pubmed/14980573>.

PHAL, P. M. et al. Qualitative comparison of 3-T and 1.5-T MRI in the evaluation of epilepsy. AJR Am J Roentgenol, v. 191, n. 3, p. 890-895, sep 2008. ISSN 15463141 (Electronic) 0361-803X (Linking).

Disponível em <https://www.ncbi.nlm.nih.gov/pubmed/18716125>.

RINEY, C. J. et al. Voxel based morphometry of FLAIR MRI in children with intractable focal epilepsy: implications for surgical intervention. Eur J Radiol, v. 81, n. 6, p. 1299-1305, jun 2012. ISSN 1872-7727 (Electronic) 0720-048X (Linking).

Disponível em <https://www.ncbi.nlm.nih.gov/pubmed/21242042>.

ROSENOW, F.; LUDERS, H. Presurgical evaluation of epilepsy. Brain, v. 124, n. 9, p. 1683-1700, sep 2001. ISSN 0006-8950 (Print) 0006-8950 (Linking).

Disponível em <https://www.ncbi.nlm.nih.gov/pubmed/11522572>. 
RUGG-GUNN, F. J. et al. Imaging the neocortex in epilepsy with double inversion recovery imaging. Neuroimage,v. 31, n. 1, p. 39-50, may 2006. ISSN 1053-8119 (Print) 1053-8119 (Linking).

Disponível em <https://www.ncbi.nlm.nih.gov/pubmed/16460962>.

RUGG-GUNN, F. J. et al. Magnetization transfer imaging in focal epilepsy. Neurology, v. 60, n. 10, p. 1638-1645, may 27 2003. ISSN 1526-632X (Electronic) 0028-3878 (Linking).

Disponível em <https://www.ncbi.nlm.nih.gov/pubmed/12771255>.

RUGG-GUNN, F. J. et al. Whole-brain T2 mapping demonstrates occult abnormalities in focal epilepsy. Neurology, v. 64, n. 2, p. 318-325, jan 2005. ISSN 1526-632X (Electronic) 0028-3878 (Linking).

Disponível em <https://www.ncbi.nlm.nih.gov/pubmed/15668431>.

SAINI, J. et al. Role of three-dimensional fluid-attenuated inversion recovery (3D FLAIR) and proton density magnetic resonance imaging for the detection and evaluation of lesion extent of focal cortical dysplasia in patients with refractory epilepsy. Acta Radiol, v. 51, n. 2, p. 218-225, mar 2010. ISSN 1600-0455

(Electronic) 0284-1851 (Linking).

Disponível em <https://www.ncbi.nlm.nih.gov/pubmed/20144146>.

SALMENPERA, T. M. et al. Evaluation of quantitative magnetic resonance imaging contrasts in MRI-negative refractory focal epilepsy. Epilepsia, v. 48, n. 2, p. 229-237, feb 2007. ISSN 0013-9580 (Print) 0013-9580 (Linking).

Disponível em <https://www.ncbi.nlm.nih.gov/pubmed/17295615>.

SASAKI, K. et al. Cerebral cortical dysplasia: assessment by MRI and SPECT. Pediatr Neurol, v. 23, n. 5, p. 410-415, nov 2000. ISSN 0887-8994 (Print) 08878994 (Linking).

Disponível em < https://www.ncbi.nlm.nih.gov/pubmed/11118796 >.

SATO, S. et al. T2 relaxometry improves detection of non-sclerotic epileptogenic hippocampus. Epilepsy Res, v. 126, n.----, p. 1-9, oct 2016. ISSN 1872-6844 (Electronic) 0920-1211 (Linking).

Disponível em <https://www.ncbi.nlm.nih.gov/pubmed/27400070>.

SCHMIDT, M. H.; POHLMANN-EDEN, B. Neuroimaging in epilepsy: the state of the art. Epilepsia, v. 52, Suppl 4, p. 49-51, july 2011. ISSN 1528-1167 (Electronic) 0013-9580 (Linking).

Disponível em <https://www.ncbi.nlm.nih.gov/pubmed/21732944>. 
SCOTT, C. A. et al. Presurgical evaluation of patients with epilepsy and normal MRI: role of scalp video-EEG telemetry. J Neurol Neurosurg Psychiatry, v. 66, n. 1, p. 69-71, jan 1999. ISSN 0022-3050 (Print) 0022-3050 (Linking).

Disponível em <https://www.ncbi.nlm.nih.gov/pubmed/9886455>.

SHULTZ, S. R. et al. Neuroimaging the epileptogenic process.

Neurotherapeutics, v. 11, n. 2, p. 347-357, apr 2014. ISSN 1878-7479 (Electronic) 1878-7479 (Linking).

Disponível em <https://www.ncbi.nlm.nih.gov/pubmed/24488707>.

SMITH, S. J. EEG in the diagnosis, classification, and management of patients with epilepsy. J Neurol Neurosurg Psychiatry, v. 76, Suppl 2, p. 2-7, jun 2005. ISSN 0022-3050 (Print) 0022-3050 (Linking).

Disponível em <https://www.ncbi.nlm.nih.gov/pubmed/15961864>.

SPENCER, D. Classifying the epilepsies by substrate: Clin Neurosci, v.2, p. 104109, 1994.

SPENCER, S. S.; GUIMARAES, P.; SHEWMON, A. Intracranial electrodes. New York: Lippincott-Raven, p. 1719-1748,1998.

SPERLING, M. R. et al. Magnetic resonance imaging in intractable partial epilepsy: correlative studies. Ann Neurol, v. 20, n. 1, p. 57-62, jul 1986. ISSN 0364-5134 (Print) 0364-5134 (Linking).

Disponível em <https://www.ncbi.nlm.nih.gov/pubmed/3488709>.

SUNDGREN, P. C. et al. Diffusion tensor imaging of the brain: review of clinical applications. Neuroradiology, v. 46, n. 5, p. 339-350, may 2004. ISSN 0028-3940 (Print) 0028-3940 (Linking).

Disponível em <https://www.ncbi.nlm.nih.gov/pubmed/15103435>.

TAYLOR, J. et al. Self-reported and parent-reported quality of life of children and adolescents with new-onset epilepsy. Epilepsia, v. 52, n. 8, p. 1489-1498, aug 2011. ISSN 1528-1167 (Electronic) 0013-9580 (Linking).

Disponível em <https://www.ncbi.nlm.nih.gov/pubmed/21569020>. 
TELLEZ-ZENTENO, J. F. et al. Surgical outcomes in lesional and non-lesional epilepsy: a systematic review and meta-analysis. Epilepsy Res, v. 89, n. 2-3, p. 310-318, may 2010. ISSN 1872-6844 (Electronic) 0920-1211 (Linking).

Disponível em <https://www.ncbi.nlm.nih.gov/pubmed/20227852>.

THESEN, T. et al. Detection of epileptogenic cortical malformations with surface-based MRI morphometry. PLoS One, v. 6, n. 2, p. 16430, feb 042011. ISSN 1932-6203 (Electronic) 1932-6203 (Linking).

Disponível em <https://www.ncbi.nlm.nih.gov/pubmed/21326599>.

THIVARD, L. et al. Interictal diffusion MRI in partial epilepsies explored with intracerebral electrodes. Brain, v. 129, Pt 2, p. 375-385, feb 2006. ISSN 14602156 (Electronic) 0006-8950 (Linking).

Disponível em <https://www.ncbi.nlm.nih.gov/pubmed/16339794>.

TSIPTSIOS, D. I.; HOWARD, R. S.; KOUTROUMANIDIS, M. A. Electroencephalographic assessment of patients with epileptic seizures. Expert Rev Neurother, v. 10, n. 12, p. 1869-1886, dec 2010. ISSN 1744-8360 (Electronic) 1473-7175 (Linking).

Disponível em <https://www.ncbi.nlm.nih.gov/pubmed/21091317>.

VAN BUCHEM, M. A. et al. Correlation of volumetric magnetization transfer imaging with clinical data in MS. Neurology, v. 50, n. 6, p. 1609-1617, jun 1998. ISSN 0028-3878 (Print) 0028-3878 (Linking).

Disponível em <https://www.ncbi.nlm.nih.gov/pubmed/9633701>.

VELASCO, T. R. et al. Foramen ovale electrodes can identify a focal seizure onset when surface EEG fails in mesial temporal lobe epilepsy. Epilepsia, v. 47, n. 8, p. 1300-1307, aug 2006. ISSN 0013-9580 (Print) 0013-9580 (Linking).

Disponível em <https://www.ncbi.nlm.nih.gov/pubmed/16922874>.

VEZINA, L. G. MRI-negative epilepsy: protocols to optimize lesion detection. Epilepsia, v. 52, Suppl 4, p. 25-27, july 2011. ISSN 1528-1167 (Electronic) 00139580 (Linking).

Disponível em <https://www.ncbi.nlm.nih.gov/pubmed/21732937>.

VON OERTZEN, J. et al. Standard magnetic resonance imaging is inadequate for patients with refractory focal epilepsy. J Neurol Neurosurg Psychiatry, v. 73, n. 6, p. 643-647, dec 2002. ISSN 0022-3050 (Print) 0022-3050 (Linking).

Disponível em <https://www.ncbi.nlm.nih.gov/pubmed/12438463>. 
WAGNER, J. et al. Morphometric MRI analysis improves detection of focal cortical dysplasia type II. Brain, v. 134, n. Pt 10, p. 2844-2854, oct 2011. ISSN 1460-2156 (Electronic) 0006-8950 (Linking).

Disponível em <https://www.ncbi.nlm.nih.gov/pubmed/21893591>.

WANG, Z. I. et al. Voxel-based morphometric MRI post-processing in MRInegative focal cortical dysplasia followed by simultaneously recorded MEG and stereo-EEG. Epilepsy Res, v. 100, n. 1-2, p. 188-193, jun 2012. ISSN 18726844 (Electronic) 0920-1211 (Linking).

Disponível em <https://www.ncbi.nlm.nih.gov/pubmed/22391138>.

WHITWELL, J. L. Voxel-based morphometry: an automated technique for assessing structural changes in the brain. J Neurosci, v. 29, n. 31, p. 9661-9664, aug 05 2009. ISSN 1529-2401 (Electronic) 0270-6474 (Linking).

Disponível em <https://www.ncbi.nlm.nih.gov/pubmed/19657018>.

WIDDESS-WALSH, P.; DIEHL, B.; NAJM, I. Neuroimaging of focal cortical dysplasia. J Neuroimaging, v. 16, n. 3, p. 185-196, july 2006. ISSN 1051-2284 (Print) 1051-2284 (Linking).

Disponível em <https://www.ncbi.nlm.nih.gov/pubmed/16808819>.

YOGARAJAH, M. et al. Long term monitoring in refractory epilepsy: the Gowers Unit experience. J Neurol Neurosurg Psychiatry, v. 80, n. 3, p. 305-310, mar 2009. ISSN 1468-330X (Electronic) 0022-3050 (Linking).

Disponível em <https://www.ncbi.nlm.nih.gov/pubmed/18931008>.

ZIJLMANS, M. et al. 3T versus 1.5T phased-array MRI in the presurgical work-up of patients with partial epilepsy of uncertain focus. J Magn Reson Imaging, $\mathrm{v}$. 30, n. 2, p. 256-262, aug 2009. ISSN 1053-1807 (Print) 1053-1807 (Linking).

Disponivel em <https://www.ncbi.nlm.nih.gov/pubmed/19629993>. 


\section{ANEXOS}

ANEXO A - Termo de aprovação do Comitê de Ética em Pesquisa.

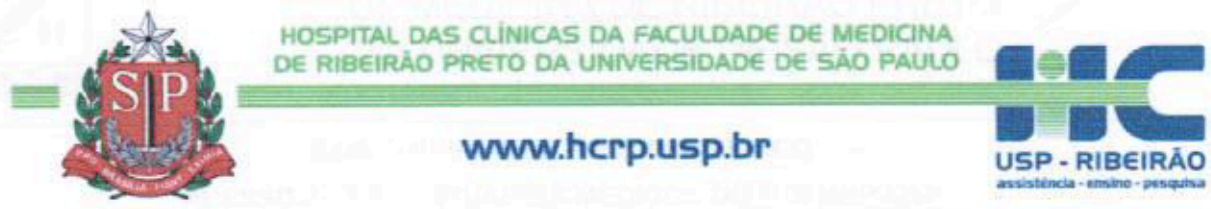

Ribeirão Preto, 30 de março de 2011

Oficio $n^{\circ} 1088 / 2011$

CEP/MGV

Prezados Senhores,

O trabalho intitulado "ANÁLISE MULTIMODAL QUANTITATIVA POR RESSONÂNCIA MAGNÉTICA DA EPILEPSIA PARCIAL SINTOMÁTICA DE DIFÍCIL CONTROLE COM IMAGEM QUALITATIVA NORMAL" foi analisado pelo Comitê de Ética em Pesquisa, em sua $320^{a}$ Reuniāo Ordinária realizada em 28/03/2011 e enquadrado na categoria: APROVADO, bem como o Termo de Consentimento Livre e Esclarecido, de acordo com o Processo HCRP n 13803/2010.

Este Comitê segue integralmente a Conferência Internacional de Harmonizaçāo de Boas Práticas Clínicas (IGH-GCP), bem como a Resoluçāo no 196/96 CNS/MS. Lembramos que devem ser apresentados a este CEP, o Relatório Parcial e o Relatório Final da pesquisa. Atenciosamente.

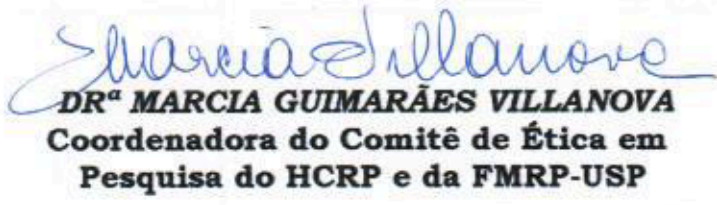

Ilustrissimos Senhores

LUCAS GIANSANT ABUD

PROF. DR. ANTÔNIO CARLOS DOS SANTOS (Orientador)

Depto. de Neurociências e Ciências do Comportamento

\footnotetext{
Comitê de Ética em Pesquisa HCRP e FMRP-USP - Campus Universitário FWA - 0000 2733; IRB - 00002186 e Registro SISNEP/CONEP $n^{\circ} 4$

Fone (16) 3602-2228 - E-mail : cep $\widehat{a}$ hcrp.usp.br
}

Monte Alegre 14048-900 Ribeirăo Preto SP 
ANEXO B - Termo de consentimento livre e esclarecido

\section{TERMO DE CONSENTIMENTO LIVRE E ESCLARECIDO}

Você está sendo convidado a participar de uma pesquisa científica, denominada "Analise Multimodal Quantitativa por Ressonância Magnética da Epilepsia Parcial Sintomática de Difícil Controle com Imagem Qualitativa Normal".

Nesta pesquisa serão aplicadas técnicas avançadas de Ressonância Magnética com a finalidade de buscar meios que ajudem a detecção de alterações cerebrais que possam causar epilepsia. Para isto realizaremos em você um exame de Ressonância Magnética, parecido com os que você já fez, com duração aproximada de 40 minutos. A diferença é que este exame vai utilizar novas sequências, mas o barulho e a necessidade de manterse imóvel durante o exame serão os mesmos. Este exame não acarretará nenhum risco à sua saúde. Além disso, o exame poderá ser interrompido em qualquer momento.

Sua identidade não será revelada em nenhuma circunstância. Sua participação é voluntária e você pode se retirar do estudo quando quiser, sem qualquer comprometimento do seu atendimento no HCRP.

Estarei disponível no telefone abaixo indicado para esclarecer a você ou sua família sobre qualquer dúvida que surja, relacionada ao projeto.

$\mathrm{Eu}$, R.G. $N^{\circ}$

declaro haver recebido e compreendido as informações acima escritas. Estou ciente de meus direitos e concordo em participar desta pesquisa. Declaro também que a minha concordância é feita de livre e espontânea vontade.

Data: Assinatura

Pesquisador Responsável: Lucas Giansante Abud CRM-SP: 117442 Telefones: 99703-9147

Data: Assinatura 


\title{
ANEXO C - Artigo publicado na linha de pesquisa da tese
}

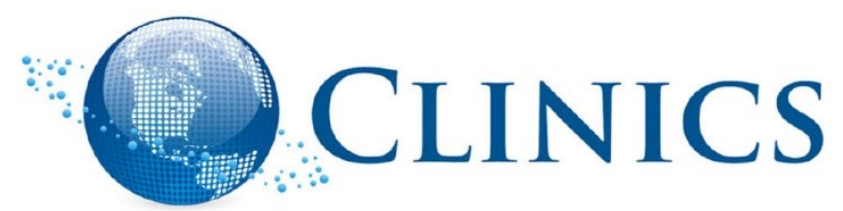

\section{Partial epilepsy: A pictorial review of 3 TESLA magnetic resonance imaging features}

\author{
Lucas Giansante Abud,,"* Lionel Thivard," Thiago Giansante Abud,"' Guilherme Seizem Nakiri,' \\ Antonio Carlos dos Santos,' Didier Dormont"
}

'Hospital das Clínicas da Faculdade de Medicina de Ribeirão Preto da Universidade de São Paulo, Neuroradiology, Ribeirão Preto/SP, Brazil. "Hôpital de la Pitié-Salpêtrière, Neurology/Neuroradiology, Paris, France. "' Universidade Federal de São Paulo, Neuroradiology, São Paulo/SP, Brazil.

\begin{abstract}
Epilepsy is a disease with serious consequences for patients and society. In many cases seizures are sufficiently disabling to justify surgical evaluation. In this context, Magnetic Resonance Imaging (MRI) is one of the most valuable tools for the preoperative localization of epileptogenic foci. Because these lesions show a large variety of presentations (including subtle imaging characteristics), their analysis requires careful and systematic interpretation of MRI data. Several studies have shown that 3 Tesla (T) MRI provides a better image quality than 1.5 T MRI regarding the detection and characterization of structural lesions, indicating that high-field-strength imaging should be considered for patients with intractable epilepsy who might benefit from surgery. Likewise, advanced MRI postprocessing and quantitative analysis techniques such as thickness and volume measurements of cortical gray matter have emerged and in the near future, these techniques will routinely enable more precise evaluations of such patients. Finally, the familiarity with radiologic findings of the potential epileptogenic substrates in association with combined use of higher field strengths ( $3 \mathrm{~T}, 7 \mathrm{~T}$, and greater) and new quantitative analytical post-processing techniques will lead to improvements regarding the clinical imaging of these patients. We present a pictorial review of the major pathologies related to partial epilepsy, highlighting the key findings of 3 T MRI.

KEYWORDS: Magnetic Resonance Imaging; 3 T; Partial Epilepsy.

Abud LG, Thivard L, Abud TG, Nakiri GS, Santos AC, Dormont D. Partial epilepsy: A pictorial review of 3 TESLA magnetic resonance imaging features. Clinics. 2015;70(9):654-661

Received for publication on May 06, 2015; First review completed on June 01, 2015; Accepted for publication on June 01, 2015

E-mail: abud.lucas@gmail.com

*Corresponding author
\end{abstract}

\section{INTRODUCTION}

Epilepsy is a public health problem that afflicts more than 50 million people worldwide (1). This common chronic neurological disorder is characterized by recurrent, unprovoked seizures that occur because of acute systemic or neurological insult (2). Epilepsy syndromes are categorized as either idiopathic generalized epilepsy involving a diffuse origin or partial epilepsy including symptomatic and cryptogenic types. When possible, magnetic resonance imagining (MRI) is performed to diagnose focal epilepsy. Epilepsy typically requires long-term pharmacotherapy; however, medical management remains unsatisfactory for approximately one third of patients with partial epilepsy. Neurosurgical intervention might be an effective therapy for selected cases $(3,4)$. MRI has emerged as the most valuable tool for the preoperative localization of the epileptogenic

Copyright (c) 2015 CLINICS - This is an Open Access article distributed under the terms of the Creative Commons License (http://creativecommons.org/licenses/by/ 4.0/) which permits unrestricted use, distribution, and reproduction in any medium or format, provided the original work is properly cited.

No potential conflict of interest was reported.

DOI: $10.6061 /$ clinics/2015(09)10 lesion because of its excellent soft-tissue contrast. Moreover, its sensitivity at $1.5 \mathrm{~T}$ for patients with medically refractory partial epilepsy is between $82 \%$ and $86 \%(5,6)$. The detection of a lesion that might correspond with the epileptogenic zone enables an etiological diagnosis of symptomatic versus cryptogenic epilepsy. In certain patients, newly diagnosed epileptic seizures lead to the discovery of an evolving lesion (e.g., a neoplasm, infectious disease or immune encephalitis), which might require a specific surgical or medical treatment independent of epilepsy management.

Furthermore, in the case of patients with refractory epilepsy and a clearly delineated lesion (e.g., those with mesial temporal lobe epilepsy or hippocampal sclerosis), a preoperative evaluation via scalp video-EEG is often sufficient to identify the epileptogenic zone, thereby resulting in a positive postoperative prognosis. On the other hand, patients who suffer from refractory partial epilepsies without lesions detected using structural MRI (the so-called "cryptogenic" epilepsies) are not ideal candidates for surgery because their pre-surgical evaluation is often complicated (7) and requires expensive and time-consuming procedures involving intracranial EEG recording; furthermore, their post-surgical outcomes are frequently unsatisfactory.

Recent studies have shown that 3 T MRI has great potential for improving the detection and characterization of structural 
lesions compared with $1.5 \mathrm{~T}$ because of its greater signal-tonoise ratio. This ratio translates into higher image resolution that facilitates the detection of subtle epileptogenic lesions (8-14). Faced with this evidence, we assume that 3 T MRI is preferable when patients with refractory epilepsy have a negative or equivocal $1.5 \mathrm{~T}$ scan (especially when a focal cortical dysplasia is suspected). Furthermore, we recommend that $3 \mathrm{~T}$ systems be used routinely in clinical investigations of epileptogenic substrates.

In addition, advanced MRI techniques with quantitative evaluations such as diffusion tensor imaging, proton spectroscopy, magnetization transfer imaging, T2 relaxometry, double inversion recovery imaging and thickness and volume measurements of cortical gray matter have been applied to this group of patients to improve the detection of epileptogenic substrates. These new techniques and image processing methods are being applied to improve the detection of epileptogenic substrates, especially for cases when conventional MRI does not clearly depict a lesion (15-19).

All patients underwent a 3 T MRI examination with an HDX 3 T MRI (General Electric Healthcare, Milwaukee, Wisconsin, USA) at Pitié-Salpêtrière Hospital, Paris, France or with an Achieva Duo 3 T (Philips Medical Systems, Best, Netherlands) at the Faculty of Medicine of Ribeirão Preto, University of São Paulo, Ribeirão Preto, SP, Brazil according to the most appropriate protocol. A systematic approach was applied to MRI interpretation. Routine MRI in patients with epilepsy at these institutions includes an axial turbo spin-echo T2-weighted sequence; a coronal turbo spin-echo T2-weighted sequence perpendicular to the long axis of the hippocampus; a coronal fluid-attenuated inversion recovery (FLAIR) image perpendicular to the long axis of the hippocampus; an axial $\mathrm{T} 2^{*}$-weighted gradient-echo sequence or susceptibility-weighted imaging (SWI); and a T1-weighted volume fast spoiled gradient recalled (FSPGR-IR) sequence. Contrast administration was performed depending on the clinical situation, particularly for neoplasm evaluation in addition to more advanced techniques in select cases.

This article retrospectively reviews the 3 T MRI features of various pathologic entities in a sample of patients with partial epilepsy, with an emphasis on the importance of this imaging method regarding the detection of epileptogenic lesions.

\section{MESIAL TEMPORAL SCLEROSIS}

Hippocampal sclerosis, which is characterized by gliosis and neuronal loss, is the most common cause of medically refractory epilepsy. MRI is a useful tool for depicting hippocampal abnormalities (20-23). Patients with this condition often have a history of childhood febrile seizures followed by a seizure-free interval of several years before the onset of often medically intractable recurrent seizures.

Coronal sequences perpendicular to the long axis of the hippocampus are the best approach to visualize mesial temporal sclerosis. These sequences demonstrate a hyperintense signal on T2-weighted images and hippocampal atrophy (Figure 1). Another diagnostic criterion used to establish the MRI diagnosis of hippocampal sclerosis is the complete loss of digitations in the hippocampal head, with a sensitivity of $92 \%$ and a specificity of $100 \%$ (21). Associated findings include increased T2 signal in the anterior temporal lobe white matter, atrophy of the fornix and mammillary bodies and atrophy of the parahippocampal gyrus.

Bilateral hippocampal sclerosis occurs in approximately 10 to $20 \%$ of cases and can be difficult to identify using MRI. In these cases, quantitative methods and the identification of the complete loss of digitations in the hippocampal head are useful for diagnosis (Figure 2A).

The so-called "dual pathology" occurs when mesial temporal sclerosis is associated with another epileptogenic abnormality, and it is observed in $8-22 \%$ of patients with surgical epilepsy. Thus, an exhaustive search for additional epileptogenic lesions must be performed, even after the detection of a possible epileptogenic substrate using MRI (24) (Figure 2).

Temporal lobe epilepsy is potentially curable with surgery; however, this cure depends on the accurate identification of hippocampal sclerosis on MRI scans. Recent studies have found that improved imaging of the internal structures of the hippocampus using 3 T MRI have acceptable histopathological correlations, which suggests that this scanning technique can be used to detect mesial temporal sclerosis and predict postoperative seizure outcomes in this group of patients $(12,13)$. Moreover, 3 T MRI scans assessed using the quantification of hippocampal volume and signal can improve the detection of epileptogenic substrates, even among experienced radiologists (14).
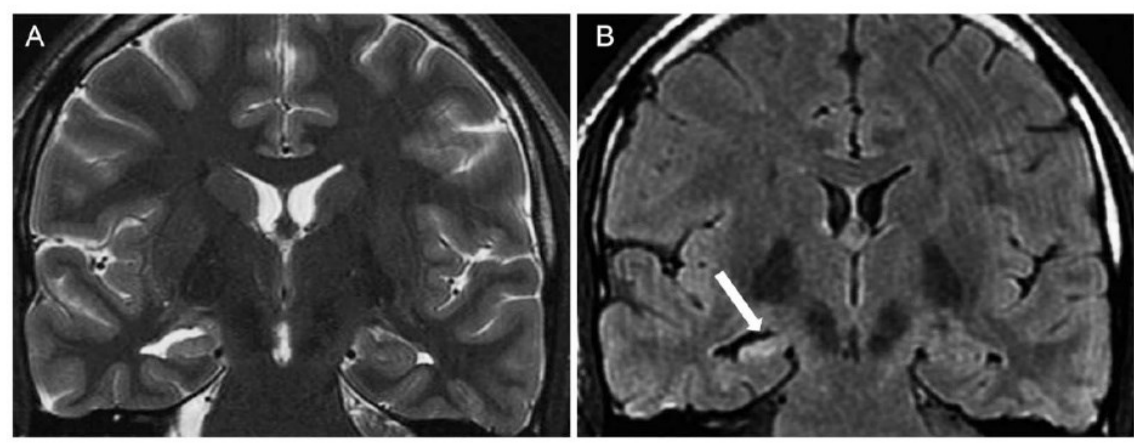

Figure 1 - Hippocampal sclerosis in a 31-year-old man with refractory right mesial temporal sclerosis. A) coronal T2-weighted image and B) coronal FLAIR images, both perpendicular to the long axis of the hippocampus. These images show a hyperintense signal, the loss of digitations and atrophy in the right hippocampal head (white arrow). 

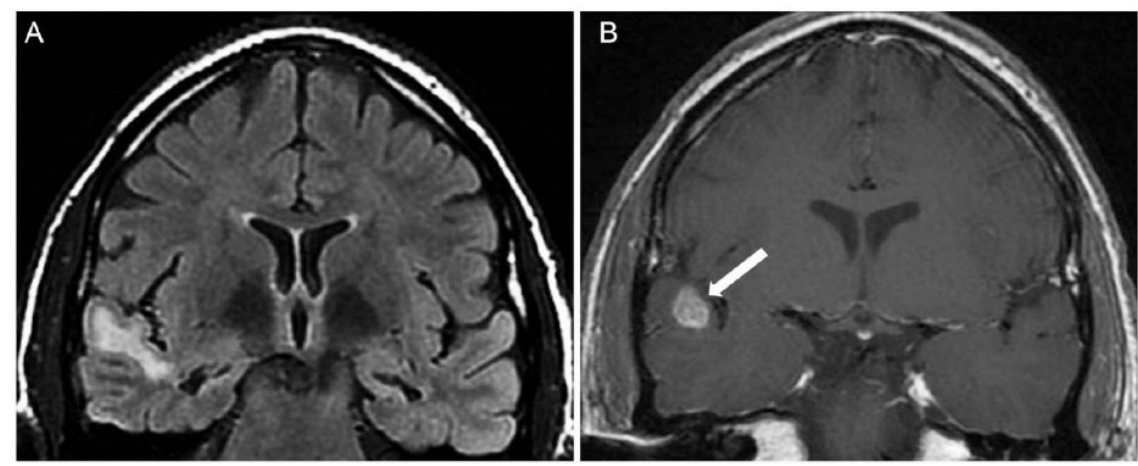

Figure 2 - Bilateral hippocampal sclerosis and "dual pathology" in a 34-year-old woman. A) Coronal FLAIR image showing bilateral hippocampal atrophy and hyperintensity as well as a hyperintense lesion in the right superior temporal gyrus. B) Coronal T1-weighted image after a contrast administration revealed a nodular mass enhancement situated at the gray-matter-white-matter junction (white arrows); this mass might correspond to a developmental neoplasm. This lesion appeared stable on consecutive MRI scans.

\section{CORTICAL DEVELOPMENT MALFORMATIONS}

Cortical development malformations account for $10-50 \%$ of all pediatric epilepsy cases and $4-25 \%$ of all adult cases. These malformations can be classified into four categories: malformations caused by abnormal neuronal and glial proliferation or apoptosis; those caused by abnormal neuronal migration; those caused by abnormal neuronal organization; and malformations of cortical development not otherwise classified (25-27). However, the most common cortical development malformations encountered in these patients is focal cortical dysplasia.

The advent of MRI has revolutionized our understanding and recognition of the malformations caused during cortical development. Because many of these defects are subtle, the use of high-resolution $3 \mathrm{~T}$ imaging (which enables excellent visualization of the corticomedullary junction) might be necessary (8-11). The term "focal cortical dysplasia" denotes a spectrum of laminar structure cortical abnormalities variably associated with giant neurons, dysmorphic neurons and balloon cells (28-30). MRI findings best evaluated at $3 \mathrm{~T}$ include local cortical thickening, morphological surface alterations, the blurring of the grey-matter to white-matter junction, the T2 and FLAIR hyperintensities of gray and white matter and the bands of abnormal signal intensity from the cortex to the lateral ventricle. Increased signal in the underlying white matter that sometimes appears as a wedge-shaped tail extending radially to the ventricle is also known as "transmantle dysplasia" (Figure 3). Other cortical development malformations include the agyria-pachygyria spectrum, gray matter heterotopia, polymicrogyria and schizencephaly (31-33).

A recent study analyzed Type 2 focal cortical dysplasia imaging using five criteria: cortical thickening, blurring, cortical signal changes, subcortical signal changes, and "transmantle" signature. This study showed that $3 \mathrm{~T}$ MRI improves the detection and characterization of these lesions compared with 1.5 T MRI, which corroborates other studies in the literature (8-11). In addition, the use of advanced techniques such as
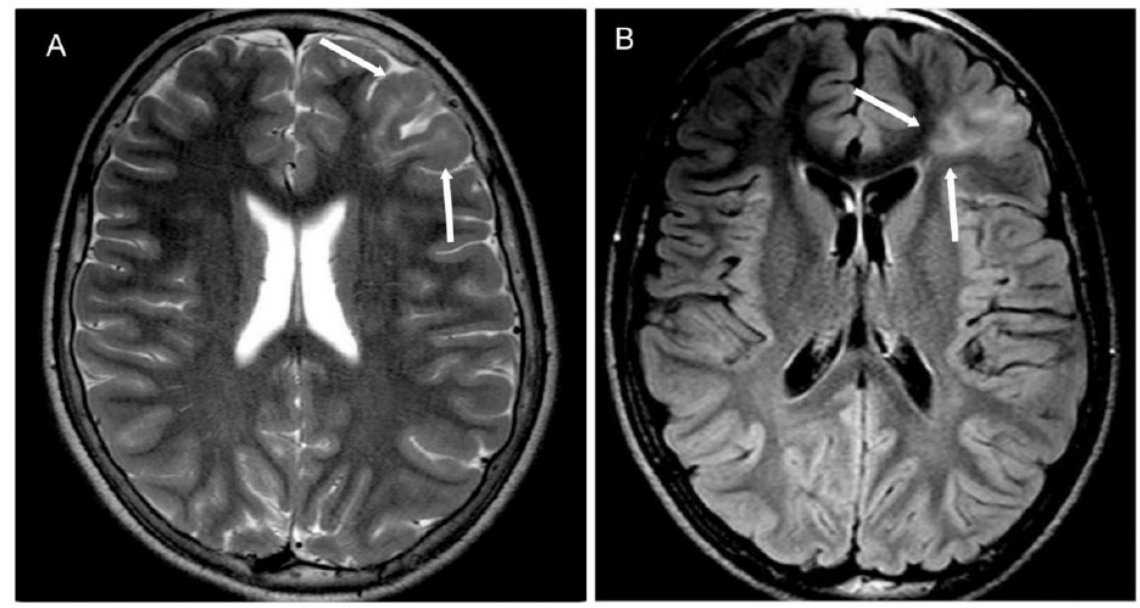

Figure 3 - A typical MRI of focal transmantle cortical dysplasia in a 34-year-old woman. A) A coronal T2-weighted image demonstrating focal hyperintensity and the thickening of the right frontal cortex with a loss of demarcation between the gray and white matter (white arrow). B) A coronal T2 FLAIR showing a band of abnormal signal intensity extending from the cortex to the lateral ventricle (white arrows). 


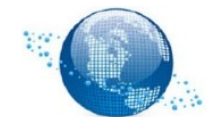

Partial epilepsy and 3 Tesla MR Abud LG et al.
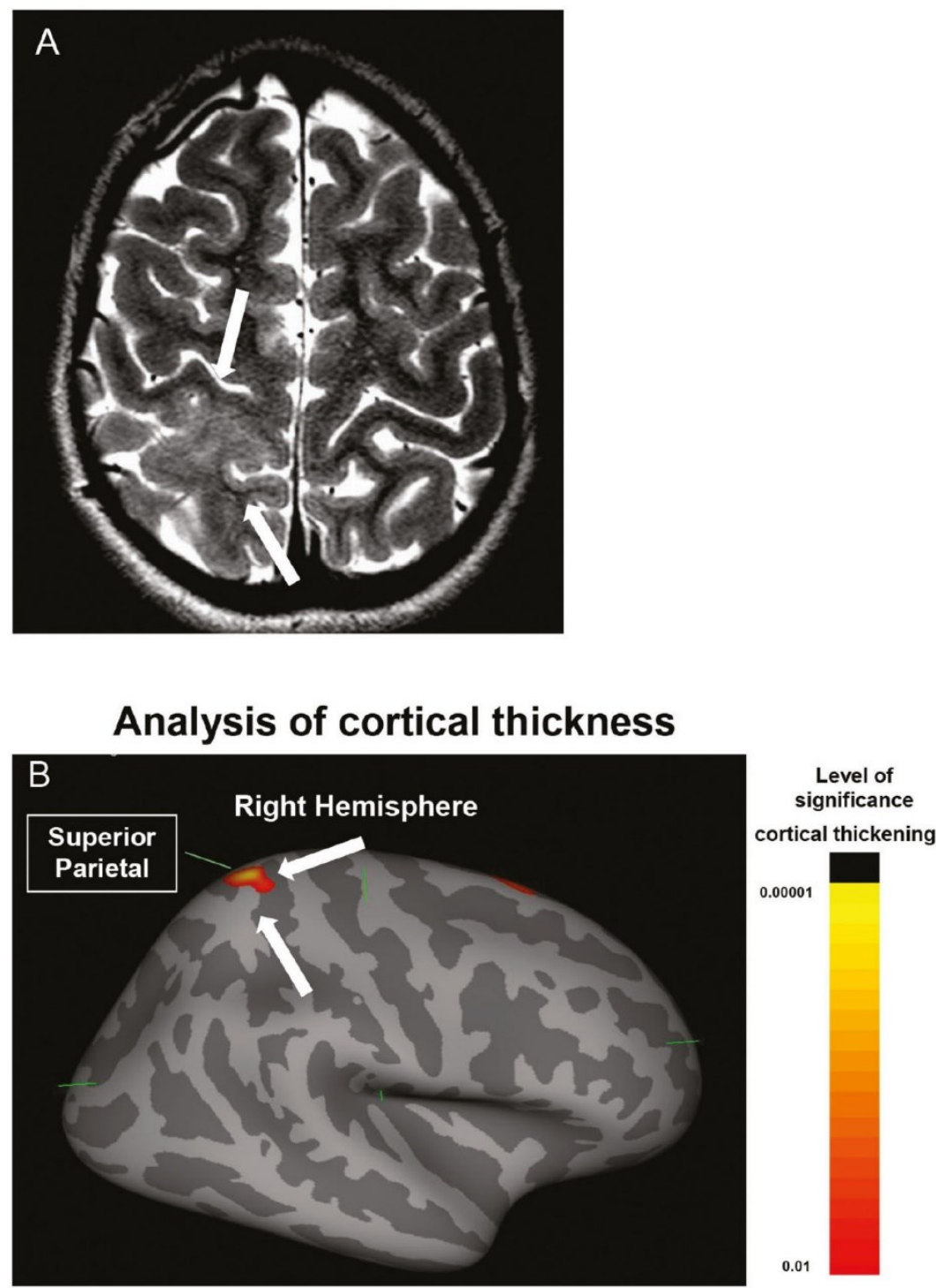

Figure 4 - Focal cortical dysplasia type IIB of Palmini in a 10-year-old girl. A) An axial T2-weighted image demonstrating a focal thickening of the right parietal cortex (white arrows). B) An automated analysis of cortical thickness generated by Freesurfer using a volumetric T1-weighted image. These measurements clearly show a significant focal area of cortical thickening in the right superior parietal region that corresponds to the lesion observed in the T2-weighted sequence.

cortical thickness measurements and diffusion tensor imaging can assist in the detection of areas of focal cortical dysplasia in some cases (15-19). We can automatically calculate cortical thickness from high-resolution 3D T1-weighted gradient-echo images using FreeSurfer software (Athinoula A. Martinos Center for Biomedical Imaging at Massachusetts General Hospital, Massachusetts, USA; Figure 4).

\section{- TUBEROUS SCLEROSIS}

Tuberous sclerosis is an autosomal dominant disorder that results in multiorgan hamartome. Classically, this disease is presented as a triad of clinical features (i.e., the Vogt triad): mental retardation, epilepsy, and adenoma sebaceum. The central nervous system involvement of tuberous sclerosis is characterized by cortical tubers, subependymal nodules and subependymal giant cell astrocytomas. Cortical tubers are developmental abnormalities of the cerebral cortex that are characterized by loss of the normal six-layer structure of the cortex and the presence of dysmorphic neurons and large astrocytes. Cortical tubers are histologically and radiologically identical to focal cortical dysplasia with balloon cells, also known as "forme-frusta tuberous sclerosis" (34) (Figure 5).

\section{NEOPLASMS}

Neoplasms associated with partial epilepsy constitute a distinct group of tumors that are often revealed by seizures 

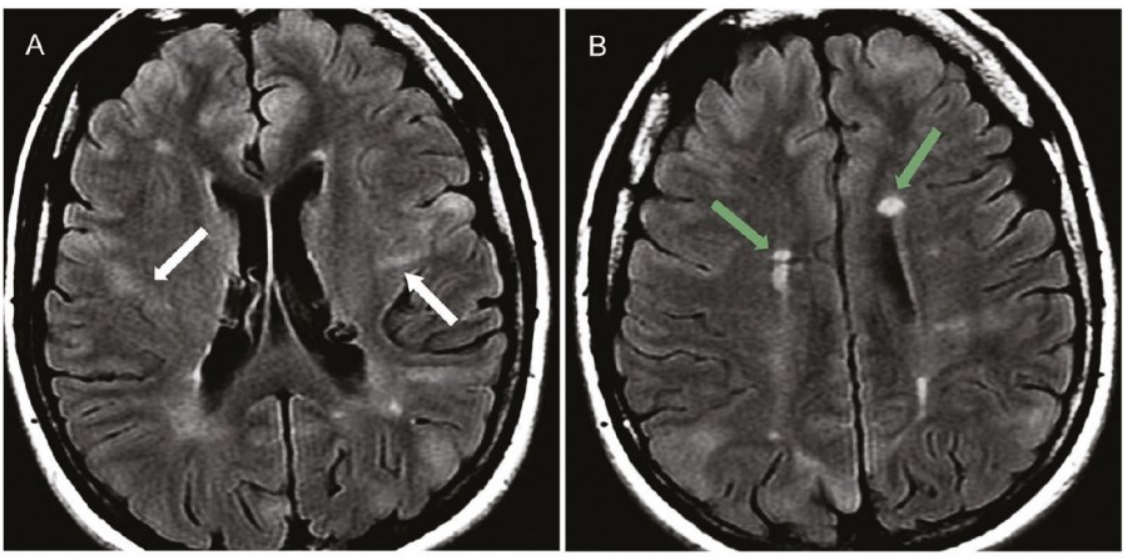

Figure 5 - Tuberous sclerosis in a 21-year-old female with drug-resistant partial epilepsy. A) Axial FLAIR images show hyperintense cortical tubers with a band of abnormal signal intensity from the cortex to the lateral ventricle (white arrows) and B) multiple subependymal hamartome (green arrows) with a hyperintense signal.
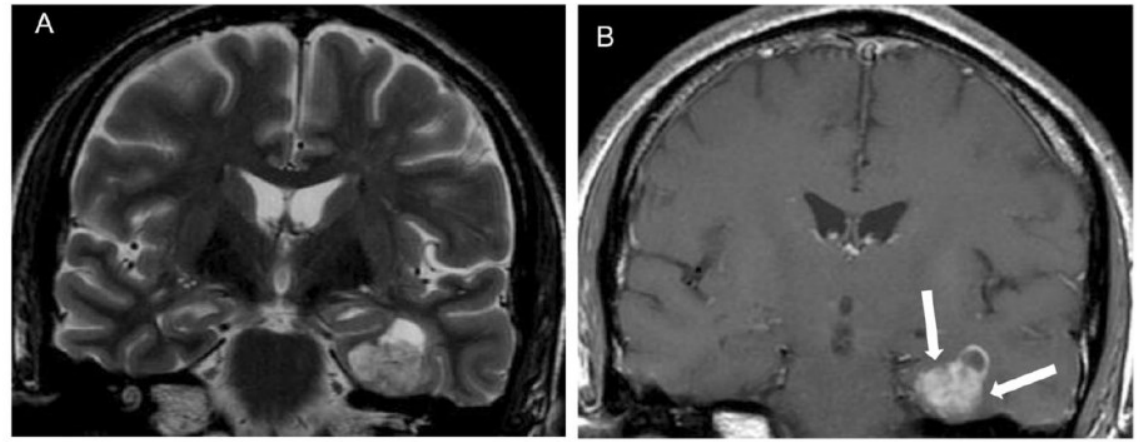

Figure 6 - A MRI of a ganglioglioma in a 45-year-old man with refractory left partial mesial temporal lobe epilepsy. A) A coronal T2-weighted image and B) a contrast-enhanced coronal T1-weighted image showing a solid-cystic lesion in the mesial left temporal lobe with intense enhancement of the soft tissue component (white arrows).
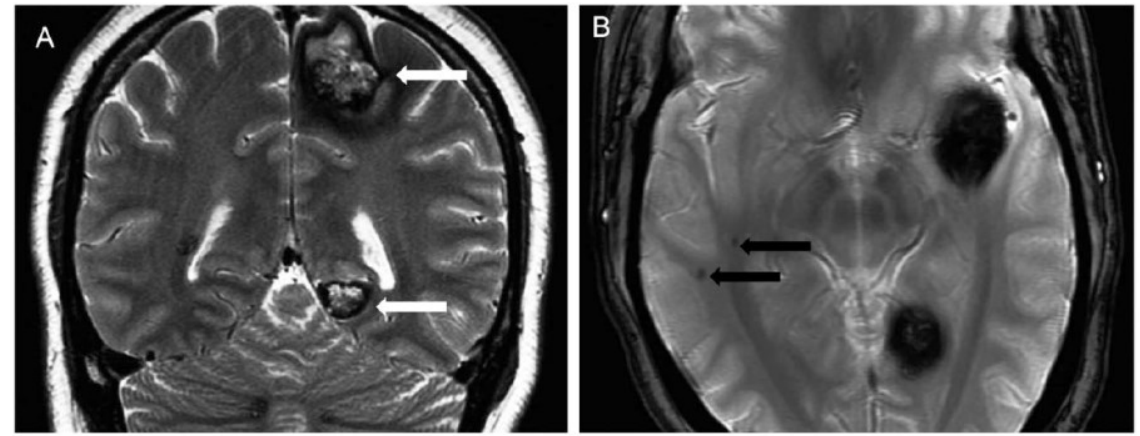

Figure 7 - Familial cerebral cavernous malformations caused by a KRIT1 gene mutation in a 36-year-old woman with multiple epileptic foci (video-EEG) and chronic partial epilepsy. A) Coronal T2-weighted images show the typical appearance of a type 2 cavernoma (white arrows) characterized by mixed signal intensity with a hemosiderin ring. B) An axial T2*-weighted gradient-echo sequence revealing two type 4 cavernomas (black arrows) in the right temporal lobe, only observed using this sequence. 

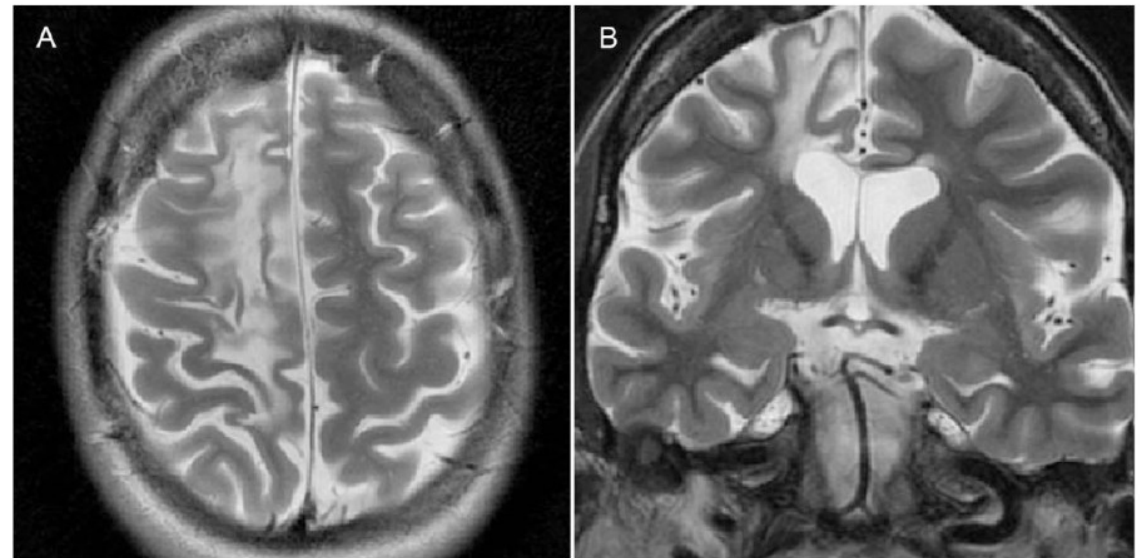

Figure 8 - Rasmussen encephalitis confirmed via biopsy in a 37-year-old woman with refractory partial motor epilepsy. A) An axial T2-weighted image and B) a coronal T2-weighted image showing atrophy and gliosis of the right frontal lobe.

in young patients. These neoplasms are located in the cortex (typically in the temporal lobe) and can be difficult to differentiate from cortical dysplasias $(35,36)$. Gangliocytoma, dysembryoplastic neuroepithelial tumors and ganglioglioma are currently considered as cortical development malformations secondary to abnormal stem cell proliferation (17). These developmental neoplasms appear as focal lesions on MRI, often with a cystic component, and are generally cortical (Figure 6). Glial neoplasms can also be responsible for intractable epilepsy.

\section{vascular maLFormations}

Cavernous malformations are often associated with intractable focal epilepsy, and surgical resection is appropriate in the case of a unique lesion (37). Cavernomas usually occur sporadically; however, they can be hereditary and occur after radiation therapy. Cavernomas are best detected using MRI. Four distinct appearances have been described.
Type 1 lesions correspond to subacute hemorrhage and appear hyperintense using T1 sequences but hyper- or hypointense using T2 sequences. Type 2 lesions have a well-delineated complex reticulated core of mixed signal intensities representing multiple hemorrhages of varying age, and a complete hypointense rim of hemosiderin has been noted on T2 images. Type 3 lesions are iso- hypointense according to $\mathrm{T} 1$ sequences but hypointense on $\mathrm{T} 2$ sequences. Lastly, type 4 lesions are only observed using gradient echo or SWI sequences as punctuate hypointense areas (38) (Figure 7).

\section{MISCELLANEOUS PATHOLOGIES WITH GLIOSIS}

a) Rasmussen encephalitis is a chronic childhood disease, possibly of autoimmune origin, characterized by progressive inflammation of the brain, seizures and psychomotor
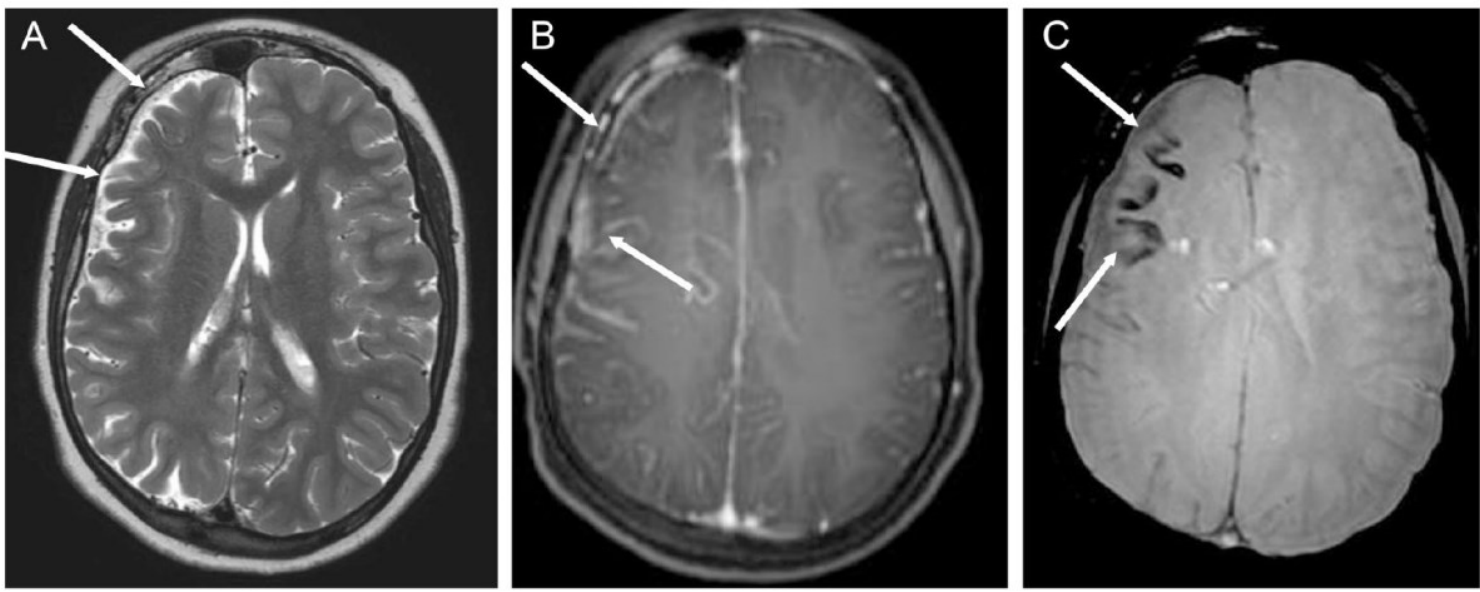

Figure 9 - Sturge-Weber syndrome in a 14-year-old boy with multiple epileptic foci in the right cerebral hemisphere (video-EEG) and chronic partial epilepsy. A) An axial T2-weighted image showing right cerebral hemiatrophy (white arrows). B) An axial T1-weighted sequence after gadolinium injection, demonstrating leptomeningeal enhancement of the fronto-parietal region (white arrows). C) Axial SWI revealing cortical calcification in the frontal lobe, appearing as signal voids (white arrows). 

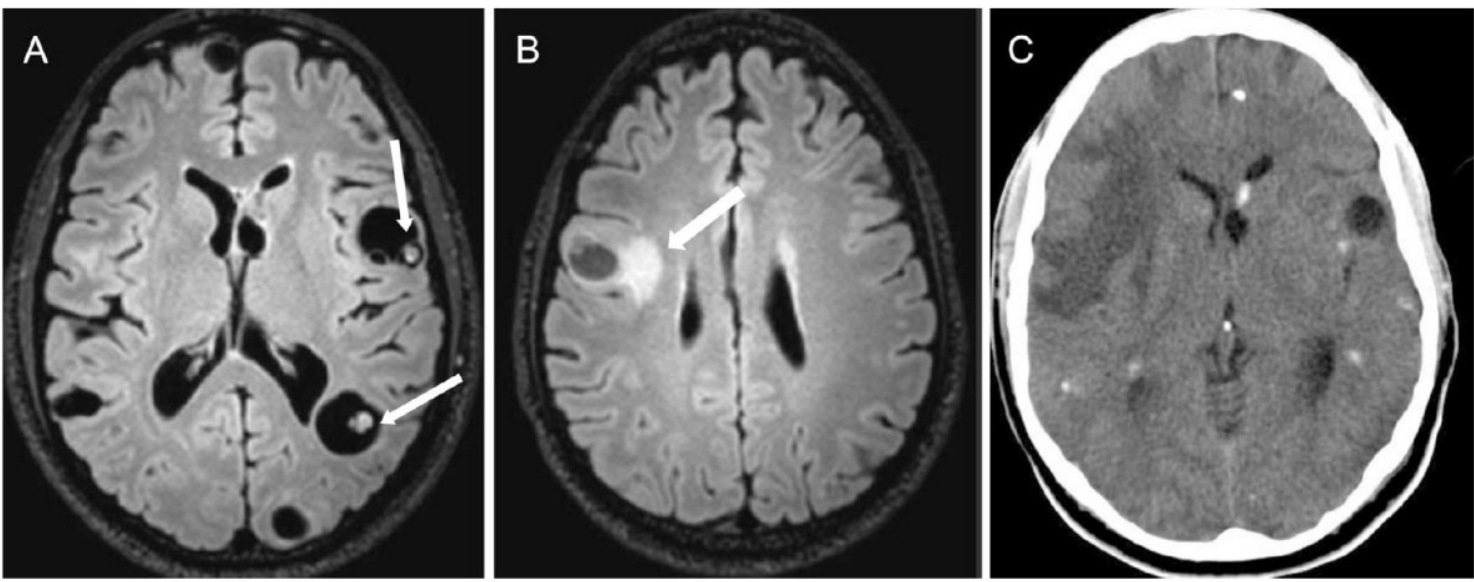

Figure 10 - Disseminated parenchymal neurocysticercosis in a 23-year-old man with intractable epilepsy and multiple epileptic foci (video-EEG). A) An axial T2 FLAIR sequence showing multiple vesicular cysts, some with scolex inside (white arrows). B) An axial T2 FLAIR image revealing perilesional edema in the right frontal lobe (white arrow). C) An axial TC shows multiple calcified lesions. These findings characterize the different phases of neurocysticercosis, which are pathognomonic of this disease.

deterioration (39). Initial imaging can be normal; over time, however, T2 prolongation appears in the cerebral cortex and subcortical white matter on MRI. Atrophy can develop during the chronic phase (40) (Figure 8).

b) Sturge-Weber syndrome consists of a facial port wine nevus in the trigeminal nerve distribution, leptomeningeal angiomatosis, epilepsy and mental retardation. Characteristic tram-track gyriform calcification is observed on CT scans, and this condition appears as a linear low signal on MRI associated with atrophy of the involved hemisphere (41) (Figure 9).

c) Posttraumatic seizures are the result of brain damage caused by physical trauma and might be a risk factor for posttraumatic epilepsy. This physiopathology includes cortical gliosis and the deposition of hemosiderin (a potent epileptogenic agent) (42). Subsequent studies have shown that cerebrovascular disease is the most common cause of seizures in the elderly, and the pathologic mechanism of chronic epilepsy after stroke is similar to that of posttraumatic epileptogenesis (43).

d) Central nervous system infections can cause chronic epilepsy due to gliotic scarring. Neurocysticercosis is a potential cause of chronic epilepsy in developing countries, and this condition is usually associated with calcified lesions. However, this cause of intractable epilepsy is uncommon even in endemic regions and might represent a comorbid pathology in most patients (44) (Figure 10).

\section{CONCLUSION}

MRI is one of the most valuable tools for preoperative localization of epileptogenic lesions. Due to their large variety of presentation, including subtle imaging characteristics, their analysis requires careful and systematic MRI interpretation. The precise characterization of these images is crucial for the correct diagnosis and management of these patients. We presente a pictorial review of the main pathologies related to partial epilepsy, highlighting their key findings at 3 T MRI imaging.

Furthermore, several studies showed that MRI at $3 \mathrm{~T}$ performed better than 1.5-T in image quality, detection and characterization of structural lesions, indicating that highfield-strength imaging should be considered for patients with intractable epilepsy and normal or equivocal findings on 1.5 T MRI, who could benefit from surgery. In parallel, advanced MRI techniques with post-processing and quantitative analysis, such as thickness and volume measurements of cortical gray matter, have emerged as a near future possibility to be used routinely and allow more precise evaluation in this group of patients. Finally, we can assume that the combined use of higher field strengths $(3 \mathrm{~T}, 7 \mathrm{~T}$, and greater) and new sequences, associated or not with quantitative analytical post-processing, means the new directions in clinical imaging of epileptogenic substrates.

\section{AUTHOR CONTRIBUTIONS}

Abud LG conceived of and designed the research and acquired, analyzed and interpreted the data. Thivard L and Abdu TG acquired, analyzed and interpreted the data. Nakiri GS analyzed and interpreted the data and reviewed the manuscript. Santos AC analyzed and interpreted the data Dormont D conceived of and designed the research and analyzed and interpreted the data.

\section{REFERENCES}

1. Wiebe S, Blume WT, Girvin JP, Eliasziw M. A randomized, controlled trial of surgery for temporal lobe epilepsy. N Engl J Med. 2001;345(5):311-8, of surgery for temporal lobe epilepsy. N Engl J Med.

2. Blume W, Lüders H, Mizrahi E, Tassinari C, van Emde Boas W, Engel J. Glossary of descriptive terminology for ictal semiology: report of the ILAE task force on classification and terminology. Epilepsia. 2001;42(9): 1212-8, http://dx.doi.org/10.1046/j.1528-1157.2001.22001.x.

3. Arroyo S. Evaluation of drug-resistant epilepsy. Rev Neurol. 2000;30(9): 881-9.

4. Kwan P, Brodie M. Early identification of refractory epilepsy. N Engl J Med 2000;342(5):314-9, http://dx.doi.org/10.1056/NEJM200002033420503.

5. Bronen RA, Fulbright RK, Spencer DD, Spencer SS, Kim JH, Lange RC, et al. Refractory epilepsy: comparison of MR imaging, CT, and histopathologic findings in 117 patients. Radiology. 1996;201(1):97-105, http://dx.doi.org/10.1148/radiology.201.1.8816528.

6. Scott CA, Fish DR, Smith SJ, Free SL, Stevens JM, Thompson PJ, et al. Presurgical evaluation of patients with epilepsy and normal MRI: role of scalp video-EEG telemetry. J Neurol Neurosurg Psychiatry. 1999;66(1): 69-71, http://dx.doi.org/10.1136/jnnp.66.1.69. 
7. Lee SK, Lee SY, Kim KK, Hong KS, Lee DS, Chung CK. Surgical outcome and prognostic factors of cryptogenic neocortical epilepsy. Ann Neurol. 2005;58(4):525-32, http://dx.doi.org/10.1002/(ISSN)1531-8249.

8. Phal PM1, Usmanov A, Nesbit GM, Anderson JC, Spencer D, Wang P, et al. Qualitative Comparison of 3-T and 1.5-T MRI in the Evaluation of Epilepsy. AJR 2008;191(3):890-5, http://dx.doi.org/10.2214/AJR.07.3933.

9. Knake S, Triantafyllou C, Wald LL, Wiggins G, Kirk GP, Larsson PG, et al. 3T phased array MRI improves the presurgical evaluation in focal epilepsies: a prospective study. Neurology. 2005;65(7):1026-31, http://dx.doi. lepsies: a prospective study. Neurology. 2005

10. Mellerio C1, Labeyrie MA, Chassoux F, Roca P, Alami O, Plat M, et al, 3T MRI improves the detection of transmantle sign in type 2 focal cortical dysplasia. Epilepsia. 2014;55(1):117-22, http://dx.doi.org/10.1111/epi. 12464.

11. Zijlmans M1, de Kort GA, Witkamp TD, Huiskamp GM, Seppenwoolde JH, van Huffelen AC, Leiiten FS. 3T versus 1.5T phased-array MRI in the presurgical work-up of patients with partial epilepsy of uncertain focus. J Magn Reson Imaging. 2009;30(2):256-62, http://dx.doi.org/10.1002/jmri.v30:2.

12. Mitsueda-Ono T, Ikeda A, Sawamoto N, Aso T, Hanakawa T, Kinoshita M, Matsumoto R, Mikuni N, Amano S, Fukuyama H, Takahashi R. Internal structural changes in the hippocampus observed on 3-tesla MRI in patients with mesial temporal lobe epilepsy. Intern Med. 2013;52(8): in patients with mesial temporal lobe epilepsy. Intern Med.

13. Howe KL, Dimitri D, Heyn C, Kiehl TR, Mikulis D, Valiante T. Histologically confirmed hippocampal structural features revealed by $3 \mathrm{~T}$ MR imaging: potential to increase diagnostic specificity of mesial temporal sclerosis. AJNR Am J Neuroradiol. 2010;31(9):1682-9, http://dx.doi.org/ 10.3174/ajnr.A2154

14. Coan AC, Kubota B, Bergo FP, Campos BM, Cendes F. 3T MRI quantification of hippocampal volume and signal in mesial temporal lobe epilepsy
improves detection of hippocampal sclerosis. AJNR Am J Neuroradiol. 2014;35(1):77-83, http://dx.doi.org/10.3174/ajnr.A3640

15. Madan N, Grant PE. New directions in clinical imaging of cortical dysplasias. Epilepsia, 2009:50(9):9-18, http://dx.doi.org/10.1111/epi.2009.50.issue-s9.

16. Vézina LG. MRI negative epilepsy: protocols to optimize lesion detection. Epilepsia. 2011;52 Suppl 4:25-7.

17. Colombo N, Salamon N, Raybaud C, Ozkara C, Barkovich AJ. Imaging of malformations of cortical development. Epileptic Disord, 2009;11(3): 194-205.

18. Bernasconi A, Bernasconi N, Bernhardt BC, Schrader D. Advances in MRI for 'cryptogenic' epilepsies. Nat Ver Neurol. 2011;7(2):99-108, http://dx doi.org/10.1038/nrneurol.2010.199.

19. Kosior RK1, Sharkey R, Frayne R, Federico P. Voxel-based relaxometry for cases of an unresolved epilepsy diagnosis. Epilepsy Res. 2012;99(1-2) 46-54, http://dx.doi.org/10.1016/j.eplepsyres.2011.10.015.

20. Falconer MA. Mesial temporal (Ammon's horn) sclerosis as a common cause of epilepsy: etiology, treatment, and prevention. Lancet. 1974; 2(7883):767-70, http://dx.doi.org/10.1016/S0140-6736(74)90956-8.

21. Oppenheim C, Dormont D, Biondi A, Lehéricy S, Hasboun D, Clémenceau S, et al. Loss of Digitations of the Hippocampal Head on High-Resolution Fast Spin-Echo MR: A Sign of Mesial Temporal Sclerosis. AJNR Am J Neuroradiol. 1998;19(3):457-63.

22. Andrade-Valença LP, Valença MM, Ribeiro LT, Matos AL, Sales LV, Velasco TR, et al. Clinical and neuroimaging features of good and poor seizure control patients with mesial temporal lobe epilepsy and hippocampal atrophy. Epilepsia. 2003;44(6):807-14, http://dx.doi.org/10.1046/ j.1528-1157.2003.58002

23. Lehéricy $S$, Semah F, Hasboun D, Dormont D, Clémenceau S, Granat $O$ et al. Temporal lobe epilepsy with varying severity: MRI study of 222 patients. Neuroradiology. 1997;39(11):788-96, http://dx.doi.org/10.1007/ s002340050507.

24. Cendes F, Cook MJ, Watson C, Andermann F, Fish DR, Shorvon SD, et al. Frequency and characteristics of dual pathology in patients with lesional epilepsy. Neurology. 1995;45(11):2058-64, http://dx.doi.org/10.1212/ WNL.45.11.2058.
25. Sisodiya SM. Malformations of cortical development: burdens and insights from important causes of human epilepsy. Lancet Neurol. 2004 3(1):29-38, http://dx.doi.org/10.1016/S1474-4422(03)00620-3.

26. Barkovich AJ, Kuzniecky RI, Jackson GD, Guerrini R, Dobyns WB A developmental and genetic classification for malformations of cortical development. Neurology. 2005;65(12):1873-87, http://dx.doi.org/10.1212/01. wnl.0000183747.05269.2d.

27. Guerrini R, Dobyns BW, Barkovich JA. Abnormal development of the human cerebral cortex: genetics, functional consequences and treatment options. Trends in Neurosciences. 2008;31(3):154-62, http://dx.doi.org/ options. Trends in Neuroscis.

28. Palmini A. Revising the classification of focal cortical dysplasias. Epilepsia. 2011;52(1):188-90, http://dx.doi.org/10.1111/epi.2011.52.issue-1.

29. Tassi L, Colombo N, Garbelli R, Francione S, Lo Russo G, Mai R, et al. Focal cortical dysplasia: neuropathological subtypes, EEG, neuroimaging and surgical outcome. Brain. 2002;125(8):1719-32, http://dx.doi.org/ 10.1093/brain/awf175

30. Colombo N, Tassi L, Galli C, Citterio A, Lo Russo G, Scialfa G, et al. Focal Cortical Dysplasias: MR Imaging, Histopathologic, and Clinical Correlations in Surgically Treated Patients with Epilepsy. AJNR Am J Neuroradiol. 2003;24(4):724-33.

31. Barkovich AJ, Kjos BO. Gray matter hereotopias: MR characteristics and correlation with developmental and neurological manifestations. Radiology. 1992;182(2):493-9, http://dx.doi.org/10.1148/radiology.182.2.1732969.

32. Barkovich AJ, Gressens P, Evrard P. Formation, maturation, and disorders of brain cortex. AJNR Am J Neuroradiol. 1992;13(2):423-46.

33. Abdel Razek AAK, Kandell AY, Elsorogy LG, Elmongy A, Basett AA. Disorders of Cortical Formation: MR Imaging Features. AJNR Am J Neuroradiol. 2009;30(1):4-11, http://dx.doi.org/10.3174/ajnr.A1223.

34. Mackay MT, Becker LE, Chuang SH, Otsubo H, Chuang NA, Rutka J, BenZeev B, et al. Malformations of cortical development with balloon cells. Clinical and radiologic correlates. Neurology. 2003;60(4):580-7, http://dx. doi.org/10.1212/01.WNL.0000044053.09023.91.

35. Zentner I, Hufnagel A, Wolf HK, Ostertun B, Behrens E, Campos MG, et al. Surgical treatment of neoplasms associated with medically intractable epilepsy. Neurosurgery. 1997;41(2):378-86; discussion 386-7.

36. Le Blanc FE, Rasmussen T. Cerebral Seizures and Brain Tumors Amsterdam, Netherlands: North Holland Publishing, 1974;295-301.

37. Iakovlev G, Devaux B, Ghossoub M, Beuvon F, Brami F, Roux F-X. Cerebral cavernomas, epilepsy and seizures. Natural history and therapeutic strategy. Neurochirurgie. 2005;51(1):3-14, http://dx.doi.org/10.1016/ S0028-3770(05)83414-9.

38. Zabramski JM, Wascher TM, Spetzler RF, Johnson B, Golfinos J, Draye BP, et al. The natural history of familial cavernous malformations: results of an ongoing study. J Neurosurg. 1994;80(3):422-32, http://dx.doi.org/ of an ongoing study. J Ne

39. Rogers SW, Andrews PI, Gahring LC, Whisenand T, Cauley K, Crain B, et al. Autoantibodies to glutamate receptor GluR3 in Rasmussen's encephalitis. Science. 1994;265(5172):648-51, http://dx.doi.org/10.1126/science. 8036512 .

40. Cendes F, Andermann F, Silver K, Arnold DL. Imaging of axonal damage in vivo in Rasmussen's syndrome. Brain. 1995;118(3):753-8, http://dx.doi. org $/ 10.1093 /$ brain/118.3.753

41. Kotagal P, Rothner AD. Epilepsy in the setting of neurocutaneous syndromes. Epilepsia. 1993;34(3):71-8, http://dx.doi.org/10.1111/epi.1993.34 issue-S3.

42. Lee ST, Lui TN, Wong CW, Yeh YS, Tzaan WC. Early seizures after moderate closed head injury. Acta Neurochir (Wien). 1995;137(3-4):151-4.

43. Bromfield EB. Seizure Disorders in the Elderly. In SC Schachter D Schomer (eds), The Comprehensive Evaluation and Treatment of Epilepsy: a Practical Guide. San Diego: Academic. 1997;233-54.

44. Velasco TR, Zanello PA, Dalmagro CL, Araújo D Jr, Santos AC, Bianchin MM, et al. Calcified cysticercotic lesions and intractable epilepsy: a cros sectional study of 512 patients. J Neurol Neurosurg Psychiatry. 2006; 77(4):485-8, http://dx.doi.org/10.1136/jnnp.2005.078675. 